\title{
O ENSINO E A APRENDIZAGEM NA ERA DIGTALL UM PROCESSO MEDIADO PELAS TECNOLOGIAS
}

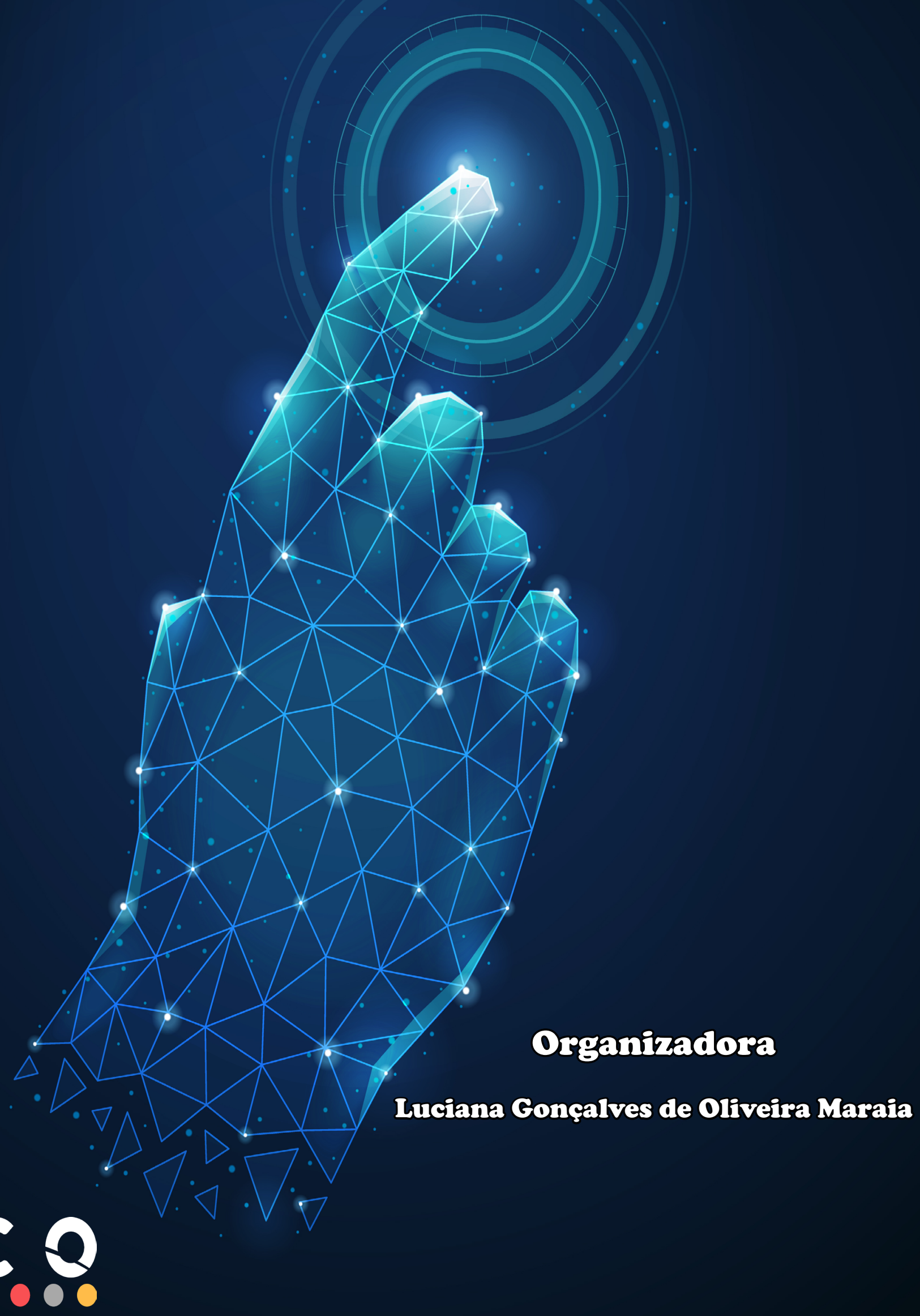




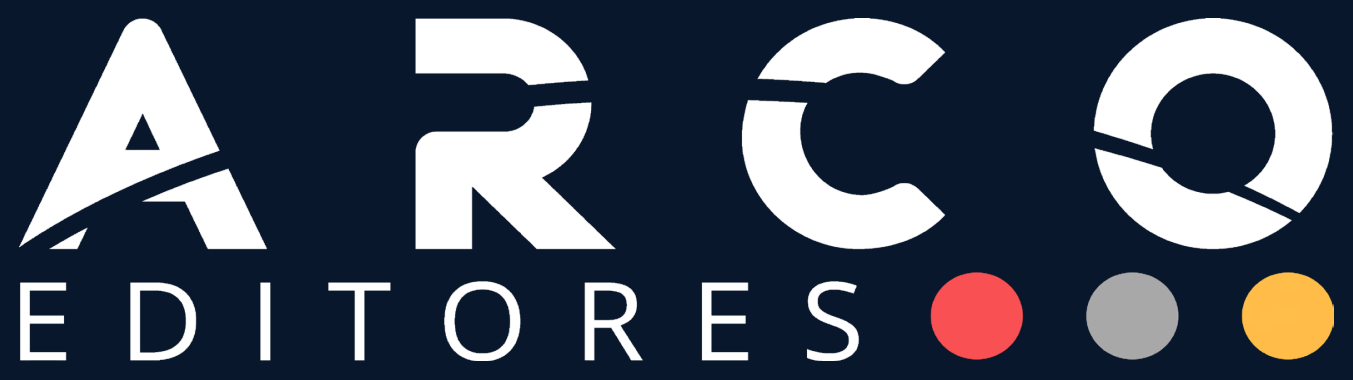

\section{O ENSINO E A APRENDIZAGEM NA ERA DIGITAL UM PROCESSO MEDIADO PELAS TECNOLOGIAS}

Luciana Gonçalves de Oliveira Maraia [Organizadora] 


\section{FICHA CATALOGRÁFICA}

Dados Internacionais de Catalogação na Publicação (CIP) (Câmara Brasileira do Livro, SP, Brasil)

- Ensino e a aprendizagem na era digital um processo mediado pelas tecnologias [livro eletrônico] / Luciana Gonçalves de Oliveira Maraia (organizadora). -- 1 . ed. -Santa Maria, RS : Arco Editores, 2021. PDF

\section{Bibliografia}

ISBN $978-65-994306-2-6$

1. Aprendizagem - Metodologia 2. Educação 3. Educação - Finalidades e objetivos 4. Tecnologia educacional I. Maraia, Luciana Gonçalves de Oliveira. $\mathrm{CDD}-371.102$ Índices para catálogo sistemático:

1. Ensino e aprendizagem : Educaçăo 371.102 Maria Alice Ferreira - Bibliotecária - CRB-8/7964

\section{$10.48209 / 978-65-994306-2-6$}

1. ${ }^{a}$ Edição - Copyright@ 2021 dos/as autores/as. 


\section{CAPA}

Arco Editores.

\section{DIAGRAMAÇÃO E PROJETO GRÁFICO}

Gabriel Machado.

\section{REVISÃO}

Dos/as Autores/as.

\section{CONSELHO EDITORIAL}

Prof. Dr. Adilson Tadeu Basquerot e Silva - UNIDAVI/SC

http://lattes.cnpq.br/8318350738705473

Profa. Msc. Jesica Wendy Beltrán -UFCE- Colômbia

http://lattes.cnpq.br/0048679279914457

Profa. Dra Fabiane dos Santos Ramos UFSM- Santa Maria/RS

http://lattes.cnpq.br/0003382878348789

Dr. João Riél Manuel Nunes Vieira de Oliveira Brito -

UAL - Lisboa- Portugal.

http://lattes.cnpq.br/1347367542944960

Profa. Dra. Alessandra Regina Müller Germani -

UFFS- Passo Fundo/RS

http://lattes.cnpq.br/7956662371295912

Prof. Dr. Everton Bandeira Martins UFFS - Chapecó/SC

http://lattes.cnpq.br/9818548065077031

Prof. Dr. Erick Kader Callegaro Corrêa UFN- Santa Maria/RS

http://lattes.cnpq.br/2363988112549627

Prof. Dr. Pedro Henrique Witchs - UFES - Vitória/ES

http://lattes.cnpq.br/3913436849859138

Prof. Dr.Thiago Ribeiro Rafagnin UFOB

http://lattes.cnpq.br/3377502960363268
Prof. Dr. Mateus Henrique Köhler UFSM- Santa Maria/RS http://lattes.cnpq.br/5754140057757003

Profa. Dra. Liziany Müller Medeiros UFSM- Santa Maria/RS

http://lattes.cnpq.br/1486004582806497

Prof. Dr. Camilo Darsie de Souza UNISC- Santa Cruz do Sul/RS

http://lattes.cnpq.br/4407126331414

Prof. Dr. Dioni Paulo Pastorio - UFRGS Porto Alegre/RS

http://lattes.cnpq.br/7823646075456872

Prof. Dr. Leonardo Bigolin Jantsch -

UFSM- Palmeira das Missões/RS http://lattes.cnpq.br/0639803965762459

Prof. Dr. Leandro Antônio dos Santos -UFU- Uberlândia/MG http://lattes.cnpq.br/4649031713685124

Dr. Rafael Nogueira Furtado UFJF- Juiz de Fora/MG http://lattes.cnpq.br/9761786872182217

Profa. Dra. Angelita Zimmermann UFSM- Santa Maria/RS

http://lattes.cnpq.br/7548796037921237

Profa. Dra. Francielle Benini Agne Tybusch UFN- Santa Maria/RS http://lattes.cnpq.br/4400702817251869 


\section{PREFÁCIO}

As pesquisas e o debate sobre o processo de ensino e aprendizagem, principalmente no cerne das demandas atuais mediadas pelas tecnologias digitais, têm ocupado lugar central no cenário educacional contemporâneo. Neste sentido, trazer ao conhecimento experiências e reflexões que unem teoria e prática pode contribuir para a construção de ações disruptivas que ultrapassam os limites impostos pela concepção tradicional de ensino.

Desta forma, a obra O Ensino e a Aprendizagem na Era Digital: Um Processo Mediado pelas Tecnologias, tende a favorecer a disseminação dos conhecimentos e das práticas pedagógicas pautadas na dialogicidade que constitui o contexto educacional composto por múltiplas linguagens e múltiplos saberes que se inter-relacionam e se complementam.

Para tanto, foram selecionados trabalhos que discutem experiências e olhares acerca da adoção das tecnologias digitais situadas na concepção de aluno como protagonista de sua aprendizagem, compreendendo vivências tecnológicas educacionais desde a Educação Infantil até o Ensino Superior, com ênfase na relação construtiva entre o ensinar e o aprender.

Esta relação tem por base as variadas formas de comunicação e disseminação de informações influenciadas pelo avanço tecnológico digital, de maneira a potencializar o hibridismo desta e a consequente transformação dos comportamentos das pessoas. Este cenário evidencia as novas demandas que se apresentam nas instituições de ensino e que exigem dos profissionais um novo posicionamento a partir de ações didáticas mais eficazes e que se aproximem dos estudantes em seus diversos níveis de aprendizagem.

Por esta razão, o referido E-book torna-se um meio de enriquecimento no campo dos conhecimentos acadêmicos e profissionais propondo um redimensionamento didático-pedagógico, contemplando saberes docentes nascidos da experiência e de pesquisas com foco no ensino e no aprendizado mediado e influenciado pela evolução das tecnologias como recursos potencializadores da comunicação e do desenvolvimento cognitivo e social. 


\section{SUMÁRIO}

O FUTURO DA APRENDIZAGEM EM UM MUNDO PÓS-PANDEMIA: A RECRIAÇÃo dAs INSTITUIÇÕES E dOS PROCEDIMENTOS ESCOLARES MEDIADO PELAS TECNOLOGIAS DIGITAIS................9

Leonardo Freire Marino

A CRITICAL ESSAY ABOUT DISTANCE EDUCATION IN UNDERGRADUATE COURSES OF PSYCHOLOGY IN BRAZIL. .25

Adriano Boettcher Brandes

A CRIAÇÃo de COMUNIDAde de APRENDIZAGEM COMO FORMAÇÃO CONTINUAdA PARA O USO DAS TICS COMO FERRAMENTAS PEDAGÓGICAS. 41

Francisco Gerbson de Oliveira

A PRÁXIS DOCENTE ON-LINE NAS ESCOLAS PÚBLICAS: PERSPECTIVAS dE EDUCAÇÃo A DISTÂNCIA MEDIANTE AO CENÁRIO dE PANDEMIA DE CORONAVÍRUS...............................................55

Marina Cabreira Rocha de Moraes

Mari Regina Rocha Janke

O HIPERTEXTO E AS NOVAS POSSIBILIDADES DE LEITURA.............68

Luciana Oliveira Atanásio

O PROJETO “LITERATURA NA REDE EM TEMPOS DE COVID-19” DA SECRETARIA MUNICIPAL DE EDUCAÇÃO DE FRANCA-SP, O ENSINO REMOTO NA EDUCAÇÃO. .80

Ana Clara Paris Kemp Angélica Vieira de Souza-Lopes 


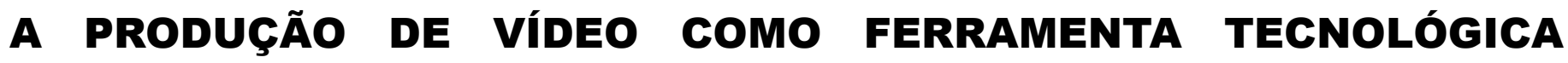
AVAlIATIVA DA DISCIPLINA DE PATOLOGIA DO CURSO DE FISIOTERAPIA DE UMA IES PRIVADA EM SÃO LUÍS: RELATO DE EXPERIÊNCIA .94

Saint-Clair Asafe Araujo Neves

O USO DA TECNOLOGIA EM TEMPO DE PANDEMIA: A COMUNICAÇÃo dos alunos de InClusão COM OS PROFESSORES DE ATENDIMENTO EDUCACIONAL ESPECIALIZADO.......................106

Vanessa Aparecida Palermo Campos

O ENSINO REMOTO MEDIATIZADO POR TECNOLOGIAS: INTERAÇÃO LITERATURA INFANTIL, O BRINCAR E A CRIANÇA PRÉ-ESCOLAR 120

Marlei Mitura

Nájela Tavares Ujiie

o processo de inclusão digital em uma escola pública estadual de são JoÃo da SERRA - PI.

Letícia Maria da Silva

O UNIVERSO EDUCACIONAL E O DIREITO AUTORAL NO BRASIL CONTEMPORÂNEO. 150

Vanessa Andriani Maria

TECNOLOGIAS DA INFORMAÇÃO E COMUNICAÇÃO (TICS): ESTRÁtEgIAS PARA A FORMAÇÃo DE PROFESSORES NO ENSINO A DISTÂNCIA..........................................................

Roberto da Silva Poliana dos Santos Silva Ana Paula dos Santos Silva 
TECNOLOGIAS DIGITAIS NA EDUCAÇÃO: O USO DA INTERNET NA PRÁTICA PEDAGÓGICA DO PROFESSOR.........................................175

Richard Fernandes

O CELULAR COMO FERRAMENTA NO ENSINO DE LEITURA..............186

Aline Aparecida Teodoro

Eliane dos Santos Macedo Oliveira

CINEMA EM SALA DE AULA E OS POTENCIAIS DE APRENDIZAGEM. 200

Nice Rejane da Silva Oliveira

Rodrigo José Rodrigues Maciel

SOBRE A ORGANIZADORA 


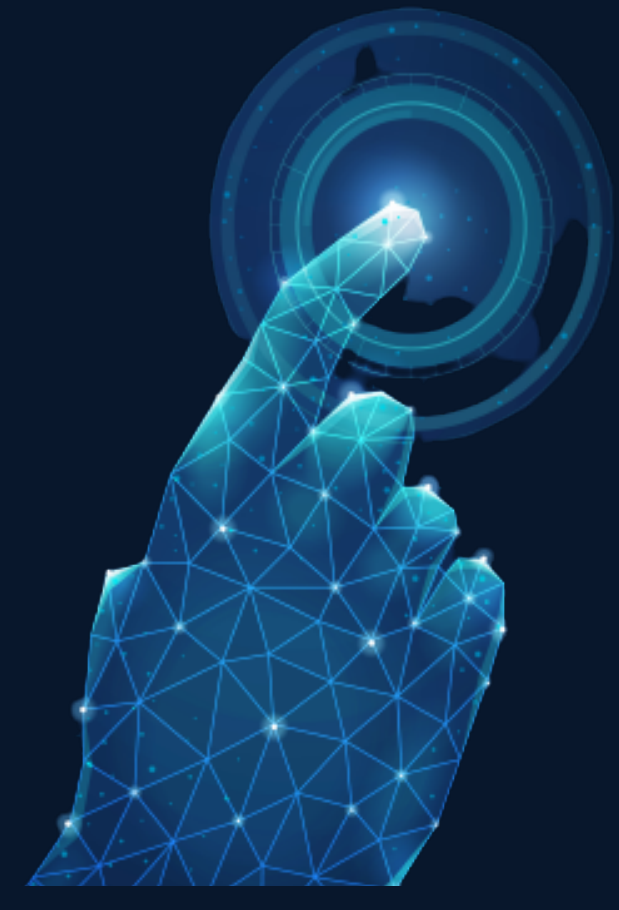

\section{O FUTURO DA APRENDIZAGEM EM UM MUNDO PÓS-PANDEMIA: A RECRIAÇÃO DAS INSTITUIÇÕES E DOS PROCEDIMENTOS ESCOLARES MEDIADO PELAS TECNOLOGIAS DIGITAIS}

Leonardo Freire Marino ${ }^{1}$

1 Professor Adjunto da Universidade do Estado do Rio de Janeiro (UERJ). Doutor em Geografia pela Universidade Federal Fluminense, membro do Corpo Docente do Programa de Pós-graduação de Ensino em Educação Básica (PPGEB) e líder do Grupo de Pesquisa Ensino e Pesquisa em Educação Geográfica (GEPEG). 


\section{INTRODUÇÃO}

"Esta não é uma história da pandemia da covid-19 e da crise do coronavírus. Haverá tempo suficiente no futuro para escrever essa história. Agora não é o momento de escrevê-la, mas de fazê-la".

HARARI, Y. Notas sobre a pandemia. Edição do Kindle, p. 35.

Vivemos um momento singular em nossa história, um momento caracterizado por grandes transformações sociais e espaciais. No entanto, engana-se quem pensa que essas transformações resultam das inquietações humanas, mesmo que estas componham, igualmente, suas razões. O cenário atual é fruto da disseminação do vírus Sars-CoV-2 no Globo Terrestre. A busca por controlar a propagação do vírus, determinou um experimento global. Neste momento, passamos a compartilhar experiências, medos, interesses e informações. As elevadas taxas de transmissão, associadas aos longos e penosos períodos de internação e o expressivo número de óbitos, tem levado os gestores públicos a adotarem diversas medidas de enfrentamento da pandemia, entre elas a imposição das medidas de distanciamento físico e de redução das atividades econômicas. O estabelecimento de períodos de fechamento de bares, restaurantes, cinemas e espaços de lazer foram medidas adotadas em diversos países. Da mesma forma, a suspensão das atividades letivas presenciais, foi uma medida adotada por diferentes governos.

Neste curto ensaio, buscarei discutir de que forma as medidas estabelecidas para controlar a disseminação do Sars-CoV-2 tem impacto nos processos formativos, com especial atenção, para as consequências percebidas no ambiente escolar. Michel Foucault (2019), aponta que a produção de discursos a respeito da realidade, especialmente quando os discursos são construídos com base em uma reconhecida racionalidade, constitui um exercício de poder. Para ele, o poder é exercido de diversas maneiras, entre as quais podemos destacar a construção de narrativas a respeito da realidade em que estamos inseridos. A construção de narrativas, de formas de descrever o mundo, constitui uma forma de intervenção no presente, e seus desdobramentos, tendem a afetar nossas relações humanas no futuro. Ao construirmos narrativas a respeito do presente, estamos interferindo em processos que ainda não se consolidaram. 
O futuro é uma construção em aberto. No entanto, o futuro não se constrói por acaso, mas com base em procedimentos e artefatos estabelecidos no presente. Desta forma, para pensarmos os impactos da pandemia nos processos formativos, é preciso analisar as estruturas que existem em nossos dias. Acreditamos que alguns aspectos da conjuntura atual apontam para mudanças sociais, para a construção de novas formas de ser e estar no mundo e que, por esta condição, precisam ser objetos de análises. Por esta característica, não pretendemos apresentar considerações definitivas, mas elencar possibilidades e apresentar campos que se encontram abertos, que devem ser disputados pelos atores sociais.

Desta forma, o presente ensaio está dividido em duas partes. A primeira, intitulada 'A pandemia e as transformações socioespaciais', apresentará como foco os impactos da pandemia no tecido social e no espaço das grandes cidades. Nesta parte do ensaio buscaremos relacionar alguns aspectos que consideramos fundamentais para o entendimento dos hábitos e costumes que estão emergindo e que, acreditamos, se consolidarão em breve. A segunda parte, intitulada 'A necessária reinvenção da educação escolar', focalizará na realidade vivenciada nas instituições escolares e nos impactos que a pandemia tem determinado nos processos formativos.

\section{A PANDEMIA E AS TRANSFORMAÇÕES SOCIOESPACIAIS}

No dia 11 de março de 2020, a Organização Mundial da Saúde, classificou a disseminação do Sars-CoV-2 como uma Pandemia ${ }^{1}$. Neste momento, aproximadamente um terço da população mundial iniciou um gradativo e sazonal processo de quarentema e de isolamento físico. Acreditamos que a orientação mundial para a adoção de medidas de distanciamento acelerou diversos processos que se encontravam em gestação e determinou o início de um processo de grandes transformações socioespaciais. No entanto, ainda estamos vivenciando a pandemia e as transformações ainda estão em curso, são mudanças que não se consolidaram e que podem nos levar para caminhos diversos. Por esta condição, podemos afirmar que vivemos um momento de incertezas, especialmente, por se tratar de um período marcado

1 Segundo a Organização Mundial de Saúde (OMS), o termo pandemia é utilizado para os processos de disseminação mundial de uma nova doença. O termo é empregado quando uma epidemia, surto que afeta uma região se espalha por diferentes continentes com transmissão sustentada de pessoa para pessoa. 
pela existência de estruturas e hábitos pré-pandêmicos, pela adoção de soluções incipientes para conter a disseminação do vírus e pela formulação e construção de novas estruturas e hábitos sociais que se consolidarão em um mundo pós-pandemia.

A ocorrência de pandemias não constitui uma novidade na história humana1. São incontáveis os casos de doenças que se espalharam por diversos continentes e que provocaram um incontável número de mortes. A história humana demonstra que os períodos marcados por pandemias são determinantes para a consolidação de mudanças socioespaciais. Nestes períodos, muitas medidas emergenciais passam a compor parte de nossas vidas. Esta é uma das consequências dos períodos de emergência, eles apresentam a capacidade de acelerar processos históricos. Nestes momentos, decisões que em tempos comuns demandariam anos de deliberação são aprovadas em questão de dias. Tecnologias incipientes, não consolidadas, e que podem representar perigo para a vida humana, são ativadas imediatamente, uma vez que o risco de não fazer nada ultrapassa as incertezas associadas ao seu uso. Assim, populações inteiras assumem o papel de cobaias em experimentos globais ${ }^{2}$. Sem dúvida este é o caso das inúmeras vacinas e medicamentos que estão sendo colocados de maneira emergencial em diversos países para conter a pandemia e os óbitos provocados pelo Sars-CoV-2.

O mundo pós-pandemia será diferentes do que o antecedeu. São incontáveis as medidas adotadas para o enfrentamento dos efeitos da pandemia e que culminarão com mudanças em nossa sociedade e nos diversos territórios urbanos. Mesmo que tais medidas ainda não tenham se consolidado, podemos apontar a existência de possíveis caminhos. Cada um deles apresentando aspectos positivos e negativos. São arenas de disputa social, campos que podem levar a construção de sociedades mais equilibradas, equânimes e justas ou acarretar o aprofundamento de diversos problemas sociais que afligem o mundo atual.

Com base nesta conjuntura, um dos aspectos mais impactados pelas medidas de controle da pandemia abarca nossas relações de trabalho. As mudanças nas dinâmicas laborais e a consolidação de novos espaços de trabalho tendem a sofrer pro-

1 "Epidemias desempenharam um papel central na história humana desde a Revolução Agrícola e frequentemente deflagaram crises políticas e econômicas. Como em pandemias anteriores, também em relação à covid-19 a coisa mais importante a lembrar é que os vírus não moldam a história. Os humanos, sim. Somos muito mais poderosos do que os vírus, e cabe a nós decidir como responderemos ao desafio". HARARI, Y. 2000, p. 43.

2 HARARI, Y. 2020, p. 182. 
fundas transformações. O cenário que vivenciamos aponta para a ampla utilização das redes informacionais nos processos produtivos e do chamado home office como prática consolidada. Provavelmente as tecnologias digitais, as redes informacionais, amplamente utilizadas para atenuar os efeitos da pandemia, não serão abandonadas com a diminuição dos casos de contágio. Pelo contrário, as atividades remotas e os espaços destinados para a sua realização deverão pautar as relações de trabalho na pós-pandemia. Esta condição poderá apontar para condições de trabalho mais adequadas e flexíveis, ou para a intensificação das atividades precarizadas, insalubres e que poderão determinar o agravamento de diversos problemas sociais. Essa resposta não se encontra encerrada e, acreditamos, que ela dependerá da forma como consolidaremos o emprego das tecnologias digitais nos ambientes laborais.

As atividades remotas poderão acirrar as desigualdades de gênero e salarias, aprofundando o sobretrabalho e acentuando a desvalorização da mão-de-obra feminina e menos qualificada. O distanciamento físico poderá desencorajar os movimentos reivindicatórios e as manifestações políticas em espaços públicos e, consequentemente, reduzir as possibilidades de construções de pautas unificadas. Os velhos movimentos sindicais tendem a sair enfraquecidos deste processo e precisarão estabelecer inovações em suas práticas de mobilização social para permanecerem relevantes. Por outro lado, a realização das atividades laborais de maneira remota, a incorporação das novas tecnologias informacionais e a virtualidade, poderão, igualmente, gerar mudanças positivas, sobretudo, por possibilitarem uma melhora na qualidade de vida dos trabalhadores. Fato que deverá atingir, principalmente, os estratos populacionais que são obrigados a realizar diariamente longos e exaustivos deslocamentos entre seus locais de moradia e trabalho' ${ }^{1}$. A diminuição do tempo gasto poderá ser revertida em maiores períodos livres, permitindo a ampliação dos momentos de lazer, de convivência familiar e comunitária.

O pensador estadunidense Richard Sennett (2020), em um ensaio publicado no Jornal El Pais, destacou que o mundo pós-pandemia será caracterizado por grandes desafios em relação ao planejamento dos centros urbanos. Pare ele as regiões centrais, tradicionalmente, marcadas pela existência de maiores adensamentos populacionais, sofrerão mudanças no perfil de suas moradias. Para Sennett, a concen-

1 Outro aspecto que merece ser destacado em relação a ampliação das atividades remotas refere-se à redução dos congestionamentos, reduzindo o tempo de deslocamento nos grandes centros urbanos e garantindo uma significativa diminuição na emissão de gases poluentes. 
tração populacional apesar de representar um bom princípio ecológico e social, uma vez que reduz os gastos para a construção de infraestruturas e garante a possibilidade de um maior contato social entre seus moradores, tende a ser questionada. Sennett acredita que os planejadores urbanos buscarão um equilíbrio entre as concentrações de residências, a disponibilidade de equipamentos urbanos e de atividades econômicas. Para ele a preocupação com o estabelecimento de uma arquitetura que não possibilite a propagação de doenças ocupará um lugar central no planejamento das cidades, na arquitetura dos prédios e na construção de moradias.

O medo de ser contaminado permanecerá por muitos anos e continuaremos norteando parte de nossos hábitos com base neste sentimento. Para o sociólogo Dacher Keltner (2003), a sensação de pertencimento a uma comunidade e as relações de cooperação entre os indivíduos é resultado do contato físico. Para ele, a redução do contato físico entre os diferentes indivíduos, provocado pelo medo de ser contaminado, poderá acarretar alterações no senso de confiança e no estabelecimento de conexões entre os membros de uma comunidade. A consolidação do distanciamento como um hábito consolidado tenderá a acirrar de forma considerável as tensões, provocando uma maior fragmentação dos tecidos sociais. Não compartilhamos integralmente dessa consideração. Certamente, corremos o risco de que as sociedades aprofundem o distanciamento entre os estratos sociais, ampliando medidas restritivas de circulação e de contato físico entre indivíduos. No entanto, acreditamos que outros processos de socialização têm sido construídos, novas dinâmicas de construção e reconhecimento de identidades estão sendo estabelecidas e processos de pertencimento a grupo sociais diferenciados têm sido constituídos diariamente.

Mesmo que os processos de socialização passem a apresentar novas dinâmicas, tal fato, não representa que retornaremos as condições anteriores. Não podemos desprezar a longa história das epidemias e seus impactos sociais. O risco de construirmos uma sociedade que aprofunde o individualismo e o desprezo a vida dos diferentes e, consequentemente, uma ampliação do número de segmentos sociais classificados como indesejados e considerados como descartáveis é uma possibilidade real e objetiva. Mas, igualmente, podemos caminhar para a construção de uma sociedade assentada na empatia, no reconhecimento das diferenças e na consolidação de mecanismos universais de assistência social e integração dos grupos minoritários ou historicamente discriminados. 
Em diversos países, o receio pelo contágio e, especialmente, pela circulação do vírus por meio de pessoas contaminadas têm levado a ampliação dos mecanismos de controle social. Tais mecanismos objetivam evitar o surgimento e a disseminação de novas variantes virais e, consequentemente, a ampliação do número de óbitos. Neste cenário, em nome de um bem maior, corremos o risco de que ocorram severas violações da privacidade dos indivíduos. A obrigatoriedade de apresentação de exames de saúde, a aferição constante da temperatura e da pressão sanguínea estão sendo empregadas como medidas obrigatórias para o acesso a determinados estabelecimentos e serviços. Entretanto, os mecanismos de vigilância e controle, a cada dia, estão se tornando mais complexos e sofisticados. Em alguns países da Ásia, com destaque para a China, as pessoas estão sendo monitoradas de maneira inadvertida por governos, empresas privadas e pesquisadores da área de saúde. Como consequência das novas medidas de controle, os cidadãos, sem consentirem ou serem informados, tem seus passos e contatos diários georreferenciados por sofisticados sistemas de monitoramento'.

O aprofundamento dos mecanismos de vigilância e de controle populacional de maneira inadvertida representa um risco aos sistemas democráticos. Corremos o risco de que quando a pandemia atual estiver superada, alguns governos obcecados por dados e mecanismos de controle, não descartarão esses mecanismos. Certamente, os sistemas de monitoramento permanecerão e sua utilidade poderá envolver os interesses de governos pouco democráticos e tolerantes com dissidentes e críticos políticos. O filósofo Byung-Chul Han (2020), alerta para o risco da implementação de um regime de vigilância tecnológica permanente. Para Han, a colheita de dados de maneira indiscriminada, o chamado Big-Data, estará cada vez mais presente em nossos dias, constituindo o principal mecanismo de controle das populações e de manutenção de regimes totalitários. Han acredita que a colheita indiscriminada de dados determinará o soerguimento de uma 'Psicopolítica', de um regime político que controlará não apenas a circulação dos indivíduos, mas buscará influenciar o pensamento e as emoções dos cidadãos ${ }^{2}$.

1 HARARI, Y. 2020, p. 233.

2 "A liberdade e a comunicação ilimitadas se transformaram em monitoramento e controle total. Cada vez mais as mídias sociais se assemelham a panópticos digitais que observam e exploram impiedosamente o social. Mal nos livramos do panóptico disciplinar e já nos encontramos em um novo e ainda mais eficiente. Os internos do panóptico digital, comunicam-se intensivamente e expõem-se por vontade própria. Participam assim ativamente da construção do panóptico digital. $\mathrm{O}$ grande irmão digital repassa, por assim dizer, seu trabalho aos internos. A entrega dos dados não 
Há algum tempo estamos travando uma batalha pela nossa privacidade, a crise atual pode ser um marco dessa disputa, sobretudo, porque quando se apresenta as pessoas uma escolha entre privacidade e saúde, elas tendem a optar pela saúde, renunciando a sua privacidade.

O mundo pós-pandêmico certamente será diferente do que foi antes da pandemia. Corremos o risco de que os mecanismos que procuram atenuar os efeitos da pandemia, consolidem uma ordem social ainda mais desigual, marcando um mundo pautado pelo exclusivismo e pela fragmentação social. Naomi Klein (2008), em seu livro 'Doutrina do Choque', reforça a ideia de que os momentos de crise favorecem o estabelecimento de novas formas de exercício do poder. Contudo, passado o choque, o medo inicial, as soluções pensadas e estabelecidas ganham concretude e assumem uma disposição permanente.

Estamos inseridos na primeira fase, imersos no medo inicial e, por esta condição, ainda estamos em choque. Porém, as soluções estão sendo pensadas e estabelecidas. Este é o caso dos processos que envolvem a educação escolar e os processos formativos. As soluções pensadas para atenuar os efeitos da pandemia estão sendo estabelecidos, aprimoradas e aprofundadas. Parte do que está sendo realizado para manter os processos formativos não será abandonado. Cabe a cada um de nós estabelecer uma análise ampla das potencialidades e limites dos mecanismos empregados, precisamos elencar os aspectos positivos e negativos de cada um deles e, caso seja necessário, construir alternativas, processos de correção ou de ajustes no que consideramos como necessário.

\section{A NECESSÁRIA REINVENÇÃO dA EDUCAÇÃo ESCOLAR}

Entre as medidas adotadas para a contenção da disseminação do vírus, uma das mais polêmicas, envolve a suspensão das atividades letivas presenciais. Para alguns gestores públicos, esses espaços deveriam permanecer abertos, recebendo discentes, docentes e demais membros das comunidades escolares. Para os defensores da (re)abertura das escolas, os impactos nos processos formativos da suspensão das atividades presenciais tem sido incomensurável e será sentido nos próximos 
anos e décadas. Para outros, a suspensão das atividades presenciais nas instituições de ensino constitui um procedimento inevitável, uma medida fundamental para a redução da disseminação do vírus e, consequentemente, para evitar um número incontável de óbitos. Esse cenário tem levado a momentos de abertura e fechamento dos espaços formativos em diversos países e cidades e determinado um cenário de incertezas e imprevisibilidade para docentes e discentes. Não escolhemos viver a pandemia, nenhum ser humano fez essa escolha, por isso não existia um planejamento prévio e consolidado de como deveríamos responder a essa questão. O mesmo ocorre com as escolas, não existia um receituário de como deveríamos enfrentar a pandemia. Neste cenário, todos os argumentos devem ser levados em consideração e não existe um lado certo e um errado.

Em um primeiro momento, ficamos desorientados, assustados com as condições impostas por esta realidade e aceitamos com receio o chamado ensino remoto. Muitos olharam a utilização das redes informacionais como um aspecto negativo, a imposição de uma virtualidade para questões que deveriam ser presenciais. Contudo, o transcorrer dos dias, semanas e meses, demonstrou que existiam recursos que poderiam atenuar os efeitos da pandemia nos processos formativos e, gradativamente, a utilização das conexões informacionais passou a ser ampliada e largamente utilizada. As escolas não ficaram fechadas, docentes e discentes não estão isolados. Não existe isolamento social, apenas distanciamento físico. Não estamos isolados. Pelo contrário, as redes informacionais serviram para aproximar os membros das comunidades escolares, evitando que o distanciamento físico se transformasse em isolamento social, aspecto que, em um primeiro momento, parecia inevitável.

No Brasil, nos momentos que antecederam a pandemia, diversas escolas se orgulhavam de apresentarem rigorosas regras para impedir a utilização de equipamentos eletrônicos em salas de aula. O descumprimento das normas acarretava severas punições, com a imposição da disciplinarização em detrimento da educação e da construção de autonomias. Este é o caso do uso dos smartphones nos espaços escolares. Os smartphones eram vistos como mecanismos de escapismo, como inimigos dos processos de aprendizagem e, por isso, objetos quase que amaldiçoados pelos docentes em uma sala de aula. Contraditoriamente, muitas instituições que 
defenestravam a utilização dos smartphones em sala de aula, alardeavam em propagandas a utilização de inúmeros recursos tecnológicos em seus espaços formativos. No entanto, em muitos casos, a tecnologia não passava de uma nova roupagem para antigos procedimentos disciplinares e para práticas de ensino congeladas no tempo. A conjuntura produzida pela pandemia alterou significativamente essa realidade. O cenário que está emergindo da pandemia aponta para mudanças substanciais na utilização das redes informacionais nos processos formativos. Neste novo contexto, docentes, discentes e demais integrantes das comunidades escolares, foram obrigados a incorporar as redes informacionais em suas práticas. Mas, será que esse processo tem sido exitoso? Será que que os docentes e os discentes têm sido atendidos em suas demandas? As respostas para essas questões são múltiplas e variadas. Não existe uma única forma de analisar o que estamos vivenciando. Contudo, uma ressalva deve ser feita, em muitos momentos reduzimos a aprendizagem aos processos disciplinares que ocorrem no interior de escolas e superdimensionamos 0 papel dessas instituições nos processos educativos. No entanto, a educação e, consequentemente, os processos de aprendizagem, não são exclusividades das escolas, não estando delimitados a ocorrerem apenas entre seus muros. Os processos de aprendizagem são inerentes as relações humanas e ultrapassam as barreiras físicas ou virtuais. E é inegável que o momento atual se encontra marcado por inúmeros processos de aprendizagem e educativos em espaços afastados dos muros escolares.

Mesmo antes da pandemia, estávamos submetidos a um processo de transição de modelos escolares. A escola vivia uma crise sem precedentes. Portanto, os questionamentos ao funcionamento das instituições de ensino antecedem a pandemia. Porém, como mencionado, os momentos de crise aceleraram as mudanças que estavam em curso. Em momentos de transição é comum avanços e retrocessos, a adoção de medidas exitosas e a ocorrência de retumbantes fracassos. Esses aspectos compõem o itinerário das transformações sociais e fazem parte do processo de criação do novo. Estamos criando um modelo escolar diferente daquele que existia, já vivenciávamos esse processo, mas, a pandemia, antecipou uma série de mudanças que estavam em curso. As escolas não voltarão a ser como eram e nossas práticas de ensino-aprendizagem deverão se adaptar aos novos tempos. Não devemos 
resistir ao novo ou temer as mudanças que estão ocorrendo. Mas, devemos encarar as possibilidades que existem, avaliarmos os caminhos possíveis e estabelecermos as correções necessárias.

Alguns aspectos deste novo cenário indicam questões preocupantes. Contudo, muitas das nossas preocupações não constituem uma novidade e, seguramente, os recursos empregados para atenuar os efeitos da pandemia não serão capazes de estabelecer soluções para eles. Este é o caso das desigualdades nos processos formativos, o abandono dos alunos que apresentam maiores dificuldades e as limitações no atendimento dos alunos que apresentam necessidades especiais, fatores marcantes do sistema de ensino pré-pandêmico e que podem ser aprofundados com a utilização das tecnologias informacionais ${ }^{1}$. Precisamos estar atentos para não ampliarmos esses problemas. Porém, igualmente, devemos estar atentos para enxergar as possibilidades que estão emergindo da aproximação entre os processos formativos e as tecnológicas informacionais.

A busca por novas formas de ensinar não constitui uma novidade, a inquietação pela construção de metodologias de ensino inovadoras sempre esteve presente. Contudo, o sucesso, quando alcançado, era descolado de movimentos amplos, ficando restrito a questões individuais. Esta não tem sido a característica predominante no cenário atual. Não vivemos uma revolução dos costumes, o individualismo continua sendo uma marca de nosso tempo, porém a multiplicação de debates virtuais, de vídeos tutoriais, de e-books gratuitos, de plataformas de aprendizagens, de reuniões e aulas on-line tem indicado para uma mudança significativa neste cenário. Acreditamos que esses procedimentos estão contribuindo para democratizar o conhecimento e os saberes que antes estavam restritos aos momentos presenciais e, consequentemente, a um grupo restrito de indivíduos. Ao ampliarmos o alcance de circulação das informações, estamos contribuindo para consolidar um amplo processo de democratização do conhecimento.

Ao passo que entramos em contato com essas novas conexões, estamos reaprendendo a ensinar e, concomitantemente, reaprendendo a aprender. Ao emprega1 De acordo com a pesquisa TIC Kids Online 2019, 39\% dos estudantes de escolas públicas urbanas não têm acesso a computadores e tablets em casa, $21 \%$ só acessam a internet por meio de smartphones. No entanto, na rede privada de ensino, estas taxas são, respectivamente, $9 \% \mathrm{e}$ $3 \%$. 
mos as novas tecnologias, validamos sua eficácia e referendamos o potencial que elas possuem para ampliar nossos métodos de ensino. O contato com os novos recursos faz com que eles passem a fazer parte dos arsenais metodológicos dos docentes, compondo caixas de ferramentas, materializando aquilo que pode ser empregado de forma sistemática. Estamos ensinando e aprendendo de uma forma diferente e este processo não envolve apenas o ensino formal, mas as diversas práticas educativas que se tornaram acessíveis a um número maior de indivíduos por meio das redes informacionais. São incontáveis os recursos formativos que passaram a ser disponibilizados na rede mundial de computadores. O isolamento físico não determinou um imobilismo, pelo contrário, mesmo que fisicamente distantes, passamos a integrar de forma mais efetiva um movimento global de produção de saberes e são incontáveis os produtos formativos que se tornaram acessíveis a um número cada vez maior de indivíduos 1 .

Mesmo que ainda não pareça uma realidade concreta, acreditamos que as soluções pensadas para atenuar os efeitos da pandemia têm contribuído, mesmo que de forma incipiente, para humanizarmos o sistema de ensino. Ampliamos nossa preocupação com os outros, entendemos que as necessidades pessoais de discentes e docentes precisam ser acolhidas, compreendidas e que estas condições são determinantes para a correção de rumos e construção de ambientes formativos mais saudáveis ${ }^{2}$. Estamos reconhecendo que é preciso que sejam estabelecidos procedimentos escolares abertos e flexíveis. De um dia para o outro, percebemos que os jovens são capazes de planejar suas rotinas de aprendizagem, de definir seus horá-

$1 \quad$ Neste cenário, a pesquisa intitulada 'Juventudes e a Pandemia do Coronavírus', cerca de $80 \%$ dos mais de 33 mil jovens que foram entrevistados apontaram que realizaram algum tipo de atividade de ensino remoto no período, porém encontraram grandes dificuldades em relação a infraestrutura tecnológica e as condições pessoais para realizar suas atividades. Contudo, a pesquisa apontou a grande disponibilidade dos jovens para integrar redes de ajuda: $70 \%$ dos jovens utilizaram as redes sociais para conscientizar os demais a respeito da pandemia, $40 \%$ apoiaram alguém vulnerável para garantir seu bem-estar e $29 \%$ realizam algum tipo de ação direta, tais como a doação.

2 "Nestes meses, escolas e famílias aproximaram-se de modos diversos. No caso das crianças pequenas, os responsáveis foram envolvidos na mediação das relações entre professores e crianças. Entre os mais velhos, o intenso compartilhamento do espaço domiciliar aproximou os familiares do universo escolar. Aconteceu ainda o reconhecimento, por parte das equipes escolares, da situação de vida das famílias de seus estudantes, obrigando os professores a desenvolver estratégias diversificadas para manter o contato com seus estudantes. Toda esta experiência deve direcionar a reinvenção de uma escola muito mais próxima das famílias, que as inclua em seu projeto pedagógico, currículo e gestão". SINGER, H. 2020, s/p. 
rios estudo e de que forma os conhecimentos serão acessados. Alguns estudantes preferem atividades assíncronas, outros entendem que o melhor são encontros síncronos, existem também aqueles que preferem atividades individuais e tantos outros que entendem que as atividades cooperativas são as mais efetivas.

A aceitação das redes informacionais não significa o abandono das escolas, a pandemia evidenciou que as escolas apresentam uma importância central em nossos dias. Constituindo espaços fundamentais para a formação humana e a assistência dos grupos sociais mais vulneráveis. Alguns discentes não possuem os recursos tecnológicos essenciais, outros não tem acesso a um lugar tranquilo para estudar ou não contam com recursos materiais necessários para auxiliar seus processos formativos. As escolas, mesmo que por algumas horas, garantem que essas questões sejam superadas, assim como outras, e que crianças e jovens possam destinar parte de seu tempo para a aquisição de conhecimentos historicamente consolidados. As escolas continuam sendo fundamentais, assim como o papel desempenhado pelos docentes. No entanto, o reconhecimento de sua importância não pressupõe que ao fim da pandemia retornaremos os velhos processos disciplinares. Pelo contrário, as escolas não voltarão a ser o que eram, o novo está sendo construído e devemos abraçar as mudanças, contribuindo para que as correções necessárias sejam realizadas.

\section{CONSIDERAÇÕES FINAIS}

"O novo coronavírus está gerando muita dor, muita solidão, muita insegurança, muito luto. Mas é hora de fazer da crise um propósito. Quem sabe construiremos um cotidiano com mais tempo e qualidade? Quem sabe não aprenderemos a dar tempo ao tempo?"

SCHWARCZ, L. Quando acaba o século XX. 2020, p. 13.

A pandemia nos impôs um desafio, a necessidade de governarmos as tecnologias. As tecnologias informacionais estavam presentes antes da pandemia, assim como, as desigualdades nos sistemas de ensino. No entanto, o momento atual impõe uma profunda reflexão a respeito dessas condições. As desigualdades são multidimensionais e, inúmeras vezes, observamos, analisamos e propomos soluções para uma de suas dimensões. O desafio que devemos enfrentar é perceber as desigualda- 
des em sua multidimensionalidade. Precisamos democratizar o acesso aos recursos tecnológicos, as redes informacionais, mas, igualmente, é preciso democratizarmos o conhecimento, a cultura e transformarmos os ambientes formativos em espaços de fomento a autonomias e abertos a um número cada vez maior de indivíduos.

Acredito que este processo está em curso. Existem diversos movimentos sociais, iniciativas de gestores públicos e individuais que procuram enfrentar as multidimensionalidades das desigualdades. No entanto, precisamos estar atentos para que as medidas adotadas para atenuar os efeitos da pandemia não aprofundem os problemas sociais. É preciso repensar de maneira radical os processos que podem apontar a ampliação das desigualdades sociais e este processo não envolve uma negativa ao uso das novas tecnologias, mas, fundamentalmente, uma avaliação de como elas devem ser empregadas nos processos formativos.

Hoje, uma parte da humanidade incorporou de maneira efetiva o distanciamento físico, porém outra parte seguiu vivendo em um mundo pré-pandêmico. $O$ isolamento, a realização da quarentena não tem sido uma condição democratizada, pelo contrário, representa um privilégio dos grupos sociais mais abastados que podem realizar o isolamento em suas residências e continuarem sendo atendidos pelos indivíduos mais empobrecidos em serviços de delivery. O distanciamento físico tem representado um marcador de status social, um identificador das desigualdades manifestadas em nosso cotidiano. O mesmo ocorre com o Ensino Remoto, os estratos sociais mais abastados continuaram sendo atendidos por docentes e profissionais da educação escolar, enquanto os mais empobrecidos foram completamente abandonados pelas instituições escolares.

Ampliamos a utilização das redes informacionais nos sistemas de ensino e a tendência é que estes recursos continuem a ser amplamente utilizados em um mundo pós-pandemia. Mas, devemos garantir que o acesso a estes recursos seja ampliado. Não podemos aceitar o abandono dos alunos que apresentem necessidades especiais, dificuldades de aprendizagens e/ou limitações de acesso as novas tecnologias digitais. A consolidação de um cenário mais aberto ao uso das tecnologias informacionais nos processos formativos pressupõe a ampliação dos estratos que serão atendidos e a garantia de que as camadas mais empobrecidas terão os recursos necessários para a sua realização.

\section{2}


Acreditamos que nossos maiores desafios não envolvem apenas o enfrentamento do vírus, mas as condições inerentes ao modo de vida prevalecente. Podemos reagir à crise atual propagando o ódio, reforçando os processos de criminalização, o preconceito e o desprezo pela vida dos diferentes. Da mesma forma, podemos reagir a pandemia estimulando a ganância, favorecendo o lucro de grupos empresariais. Mas, igualmente, podemos reagir à crise com a construção de medidas que contribuam para a construção de relações sociais equânimes, ambientalmente sustentáveis e equilibradas. Podemos construir novas relações humanas e acredito que estamos nesse caminho. O percurso não será curto, estamos apenas no início dele, mas, estamos caminhando e confio que chegaremos ao final do processo melhor do que iniciamos. As decisões que os indivíduos e os governos tomarem moldarão o mundo no futuro. Moldarão não apenas nossos sistemas de saúde, mas também a economia, a política, a cultura e a educação. Precisamos agir com racionalidade, mas, igualmente, com a preocupação em apontar alternativas para os problemas que se apresentam e se apresentarão ao longo do percurso.

No mundo pós-pandêmico poderemos nos deparar com um mundo mais desigual, marcado pelo exclusivismo, pela privatização da vida cotidiana e pela redução dos contatos sociais. Mas, igualmente poderemos nos deparar com um mundo mais socialmente justo, ambientalmente equilibrado e marcado pelo compartilhamento de informações e democratização do conhecimento. São possibilidades distantes, mas reais e o caminho que percorreremos para chegar a este ponto dependerá das escoIhas que realizamos em nossos dias. Se os discursos não apenas retratam fragmentos da realidade, mas também projetam uma realidade futura, é urgente que outras narrativas sejam criadas e que as medidas que buscam atenuar os efeitos da pandemia sejam avaliadas e, quando necessário, corrigidas para evitar o aprofundamento de diversos problemas sociais.

\section{REFERÊNCIAS}

FOUCAULT, M. A Ordem do Discurso: aula inaugural do Collège de France. São Paulo: Edições Loyola, 2019.

HAN, B. La révolution virale n'aura pas lieu. Journal Libération. Disponível em: $\underline{h t t p s: / /}$ www.liberation.fr/debats/2020/04/05/la-revolution-virale-n-aura-pas-lieu 1784260. Acessado em 20/10/2020. 
HAN, B. Psicopolítica: o neoliberalismo e as novas técnicas de poder. Belo Horizonte: Editora Âyiné, 2018.

HARARI, Y. Notas sobre a pandemia e breves lições para o mundo pós-coronavírus. São Paulo: Companhia das letras, 2020 - Versão do Kindle.

KELTNER, D., GRUENFELD, D. H., ANDERSON, C. Power, Approach, and Inhibition. Psychological Review, 2003, 110 (2), pp. 265-284.

KLEIN, N. A Doutrina do Choque: a ascensão do capitalismo de desastre. Rio de Janeiro, Nova Fronteira, 2008.

MARINO, L. Reaprendendo a Ensinar e Aprender. Revista Biblioo Cultura Informacional. Disponível em: https://bityli.com/Ek38L. Acesso em 25/10/2020.

- A falência do modelo escolar tradicional e a necessária construção de uma educação integral e comunitária. Revista Giramundo, Rio de Janeiro, V.5., n ${ }^{\circ}$ 10, 2018, jul/dez.

SINGER, $H$. Não voltar, recriar a escola. Disponível em: https://educacaointegral. org.brl. Acessado em 10/12/2020.

SCHWARCZ, L. Quando acaba o século XX. São Paulo: Companhia das Letras, 2020 - Versão do Kindle.

SENNETT, R. El futuro después del coronavirus. Jornal El País. Disponível em: https://elpais.com/especiales/2020/coronavirus-covid-19/predicciones/hacia-ciudades-de-15-minutos/. Acessado em 20/10/2020.

TIC KIDS ONLINE BRASIL 2019. Disponível em: https://cetic.br/pesquisa/kids-onlinel. Acessado em 10/12/2020. 


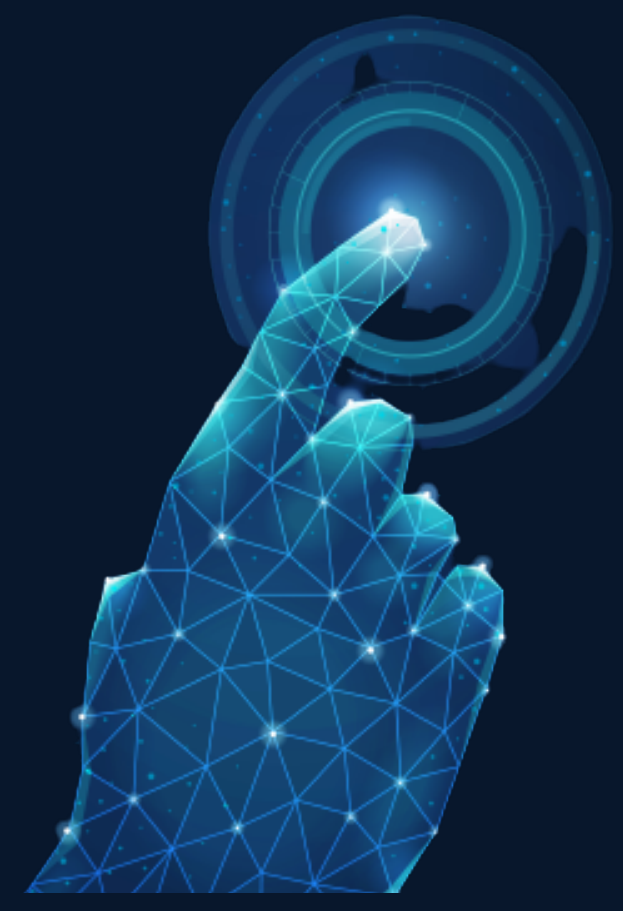

\section{A CRITICAL ESSAY ABOUT DISTANCE EDUCATION IN UNDERGRADUATE COURSES OF PSYCHOLOGY IN BRAZIL}

Adriano Boettcher Brandes ${ }^{1}$ psychology and master's in philosophy at the post graduate program of the University of Vale do Rio dos Sinos (UNISINOS). Professional contact: adriano.brandes@hotmail.com 


\section{INTRODUCTION}

As preliminary considerations of this writing, I need to make three comments: the first is that some fragments of this text were reused ${ }^{1}$ from a text I wrote in 2018 , at the invitation of the editor of a professional ads magazine. The second is that this work probably will be published also in portuguese at some point and the third is that I have to inform the reader that the argument that runs through this essay is that of prudence; perhaps it can even be considered conservative. There are multiple factors that must be evaluated for an achievable implementation of undergraduate psychology using the distance education method. This problematic topic, even outside the pandemic framework, is a pressing issue and one that should continue to be discussed. My considerations, possibly, will be in opposition to most of my coleagues; but it is through debate, and even through disagreement, that knowledge is built.

The history of the process of formalizing psychology in Brazil is relatively recent in historical terms; goes back to the 1970s. Soares (2010, p. 08), mentions that in 1975 he was asked to make a historical record of the profession in the country - despite the fact that the first Federal Council of Psychology ${ }^{2}$ was, according to the author , "[...] in full development of its activities". Having made this brief digression, I do not intend to make a reproduction or a detailed chronological line regarding the profession of psychologist in Brazil (something already methodically executed by several competent authors who are dedicated to this type of historical record). Yes, I intend to make incisive reflections, as I said before, about the implementation of undergraduate psychology using the distance education method in Brazil. Accustomed to writing in an essayistic tone, I choose to use the first person in an attempt to not only clarify my ideas, but to get closer to the readers.

Since before the COVID-19 pandemic, which strongly affected Brazil from midMarch 2020, dramatic changes have been observed in all sectors of civil society and there would be no reason why it should be different in the academic universe. Home office is one of the several anglicisms of the time. But, specifically, the issue of distance learning in several university courses, was already an issue that was already 
under debate long before the outbreak of the pandemic. The role of COVID-19 was to push students and teachers forcefully and urgently into virtual teaching environments. Such an emergency situation like this is an exception and, given the access we have to various technological instruments, it is a very useful and convenient possibility; especially because at the present moment of the writing date of this essay, there are still no sanitary conditions for safely returning to classes (or work). It is necessary to consider that distance learning as we conceive today is something completely new, because the new technologies that allow this type of model are also new; this when we refer to computers, internet, smartphones and all the highly technological resources that we currently have. In more analogous decades, before the 1900s and the digital revolution, there was also a type of distance learning: the learning by correspondence (by mail). Perhaps some readers will remember different courses that were offered through this modality, which was particularly interesting for people who lived far from urban centers and far from the transmission of knowledge centers (schools, technical centers, universities, etc.) and still wished to enter a certain area to be educated or professionalized. In general, distance learning is not something entirelly new, the resources for it and the historical moment in which we live in, are new - and that changes everything.

For this discussion, it seems impossible to analyze the issue of distance learning, if we do not examine, in parallel, the political and social instability that we have experienced as a nation, since the begining of the 2016 coup d'état, which opened the door to pandemonium. political-aesthetic-cultural-social of false news, dismantling of education, mismanagement, misinformation and proliferation of hate/resentment speech that we find ourselves sunk to the neck in the present moment in Brazil. I see it as impossible to analyze the issue of education, without addressing the political issue, as they are closely linked and in a codependent relationship. I will explore the facts that support this statement below. After the dismissal of the president in 2016, the Vice President Michel Temer took office, who tried to lay all the foundations for the events to come, which would culminate in the election of Jair Bolsonaro; a time when a certin agenda was already underway - the neoliberal agenda. It is important to pay attention to this word: agenda and neoliberal. From this moment on, I give myself per- 
mission for a brief tour to illustrate why I say that the political issues and the distance learning problem are inseparable — in addition to why I mention the word agenda and neoliberalism in the midst of it all.

\section{THE COUP AND ITS CONSEQUENCES}

Balbúrdia is a feminine noun in portuguese language. It is a word not so used today, even in colloquial language, as its synonym, racket. Some people prefer to use the words scandal, uproar, tumult, noise or simply disorder. Being a man born in the eighties, I perfectly remember having heard the word babble many times, at the time, when the ladies who took care of the schoolyard wanted to refer to the children of the first years of elementary school who ran mad, screaming at the time of playground. From this perspective, that word even sounds funny; before she was relegated to that - a childish memory.

Moved by the "pearls" of the presidential family through microblogs on the internet, by the nominations of people disqualified for certain positions and by the philosophies of an astrologer without any higher education, who despises the intellectual community and scientific production of the country, the agenda of dismantling and dilapidation of state assets, perpetrated by the mismanagement that assumed the presidency of the Republic of Brazil at the beginning of 2019. Continuing the coup that overthrew the first female head of state in the history of Brazil, legitimately re-elected for her second term, Dilma Rousseff, which ended on August 31, 2016 ${ }^{1}$, one of the subjects appointed as Minister of Education, Abraham Weintraub, in April of that year, said that the $\mathrm{MEC}^{2}$ would reduce federal investments in disciplines such as philosophy and sociology ${ }^{3}$. According to the wise minister, "[...] ideological issues, very controversial, as in the past, will not happen this year [...]" [sic] $]^{4}$ - referred to ENEM ${ }^{5}$ (at the time). He is also known for saying that "[...] universities in the Northeast stay there 1 Available in: https://www.historiadomundo.com.br/idade-contemporanea/impeachment-dilma-rousseff.htm Accessed in: 27.06.19.

2 Ministério da Educação (MEC), in portuguese.

3 Available in: https://www.gazetadopovo.com.br/educacao/ministro-promete-enem-sem-questoes-ideologicas-e-muito-polemicas/ Accessed in: 24.06.19.

4 Available in: https://oglobo.globo.com/sociedade/ministro-da-dica-para-enem-questoes-ideologicas-muito-polemicas-nao-devem-acontecer-esse-ano-23623156 Accessed in: 24.06.19.

5 Exame Nacional do Ensino Médio (EMEM), gate to the university for the most os the brazilian students. 
doing sociology, doing philosophy in the wild" [...] [sic] ${ }^{1}$. Nevertheless, the current President announced, in a microblog on the internet, that the Minister [...] [was] studying to decentralize investment in faculties of philosophy and sociology [humanities]. Students already enrolled will not be affected. "The objective is to focus on areas that generate immediate return to the taxpayer, such as: veterinary, engineering and medicine" $[\mathrm{sic}]^{2}$. A few weeks later he announced cuts of $30 \%$ in the bureau ${ }^{3}$, affecting funds from 60 federal universities and 40 federal institutes ${ }^{4}$. In an interview, Weintraub stated that "[...] the university must have enough money to make a mess and ridiculous events ... universities that, instead of seeking to improve academic performance, are making balbúrdia [mess, fuss, etc.], will have reduced funds. [...] "[sic] .

Evidently, the Minister ignores the fact that a university environment is naturally transgressive and could not be otherwise. He also ignores the merit of our country's intellectual production, which is respected internationally. Such declarations must be added to the cuts and contingencies of the Coordination for the Improvement of Higher Education Personnel (CAPES) ${ }^{6}$, an autarchy linked to the Ministry of Education (MEC), master's and doctoral scholarships, affecting dozens of graduate programs throughout the country ${ }^{7}$. Let us also not forget, the cuts in the scholarships reserved for "sandwich graduation" of the Science Without Borders (CsF) ${ }^{89}$ program, which had been agonizing for some time and had its coup de grâce with the possession of the interim president in $2017^{10}$, giving continuity to the coup d'etat, orchestrated by a

1 Available in: https://www.conversaafiada.com.br/brasil/nordestino-nao-precisa-de-filosofia-nem-de-sociologia Accessed in: 24.06.19.

2 Available in: https://twitter.com/jairbolsonaro/status/1121713534402990081 Accessed in:

24.06.19.

3 Available in: https://g1.globo.com/educacao/noticia/2019/05/03/universidades-afirmam-que-corte-de-30percent-do-mec-pode-comprometer-ensino.ghtml Accessed in: 24.06.19.

4 Available in: https://g1.globo.com/educacao/noticia/2019/05/07/nao-ha-corte-ha-contingenciamento-diz-ministro-da-educacao-sobre-orcamento-das-universidades-federais.ghtml Accessed in: 24.06.19.

5 Available in: https://www.correiodopovo.com.br/not\%C3\%ADcias/ensino/mec-cortar\%C3\%A1-verba-de-universidade-por-balb\%C3\%BArdia-1.335988 Accessed in: 24.06.19.

6 Coordenação de Aperfeiçoamento de Pessoal de Nível Superior (CAPES), in portuguese.

7 Available in: https://exame.abril.com.br/brasil/capes-bloqueia-mais-27-mil-bolsas-de-mestrado-e-doutorado-no-brasil/ Accessed in: 24.06.19.

8 Ciências sem fronteiras ( $\mathrm{CsF})$, in portuguese.

9 Available in: https://exame.abril.com.br/brasil/o-corte-do-ciencia-sem-fronteiras-em-numeros/ Accessed in: 24.06.19.

10 Available in: https://ptnosenado.org.br/17-de-abril-um-ano-depois-temer-assume-que-impeachment-foi-golpe/ Accessed in: 24.06.19. 
defeated and eternally bitter opposition in $2016^{1}$ elections. It should not be left out that in 2017 the same coup government changed the structure of high school, making it no longer mandatory, subjects as: arts, physical education, philosophy, and sociology (LIMA; MACIEL, 2018).

These facts elucidate how there is a very well-defined agenda and it has a particular interest in weakening the processes of transmission and acquisition of knowledge. This does not leave universities exempt from serious consequences and longterm collateral damage. The agenda I refer to aims to cripple not only critical thinking itself, but the quality of professional training that is obtained in graduation or in undergraduation - either with a well-paid and qualified directory board, or by providing very rich academic experiences, such as curricular internships and paid internships with partner agencies or even with the possibility for students from less favored classes, to take part of the academic course at a university abroad. By weakening the quality of teaching, not only the university students and universities suffer, but the knowledge itself; in addition, professional specialties are weakened. Beyond that, crippling intellectuality and the environments where intellectuals are produced, a gap is created that can take years, if not decades, to be reestablished. There is another dangerous discourse in the move and is related to that agenda: the neoliberal discourse. In this logic, which encompasses concepts such as entrepreneurship and meritocracy, only certain goods or services are accessed for whom has the monetary conditions to do so; this includes health, housing and education. In this same diapason, we see the complicated issue of outsourcing, the disentanglement of social security and the dismantling of labor laws - the result of decades of historic union struggles. All of this is directly related to the interest in keeping the population of an entire nation not only alienated, but ignorant; the old Roman tactic of dividing to conquer and, worse, offering bread and circus so that we do not cast glances on the poignant social misfortunes. 


\section{DISCUSSION}

Regarding the issue that entails this writing, the psychologist is a professional graduated from an academic course at a higher level, usually a bachelor (and may also be licensed). Its academic training course is recognized and regulated by the Ministry of Education (MEC), the highest authority in the respective field and which endorses educational entities. With approximately 4,085 class $/$ hours $^{1}$ , with a minimum of five years duration, ten semesters, for each threeyear cycle, the colleges that offer the psychology course have their trainee students evaluated by the National Student Performance Exam (ENADE) ${ }^{2}$ - and undergo thru this avaliation is a condition a sine que non for graduation. Psychology courses at universities undergo periodic curricular reforms, aiming at updates and optimizations; the students themselves evaluate the courses at the end of each semester. Psychology training follows strict, legal, regulated rules, dictated by a council and aimed at the quality and origin of the psychological services provided, as well as the training of future psychologists. In addition, training in psychology is "endless", requiring constant update, research and practice. Also due to the fact that there is a Federal Council of Psychology (CFP), which has its regional autarchy, we know the ethics that rules and supervise the practice of these professionals. Brazilian psychological science is recognized, respected worldwide and psychologists can work with theoretical lines of their choice and that guide their work. These can be: psychoanalysis, cognitive, humanism, gestalt, behaviorism, family systemic and others. All of these are based on research and evidence, have the prestige of years of safe clinical practice and have renowned world theorists, past and present, as exponents. Small theoretical quarrels among students are normal during graduation and very recurrent among trained and active professionals. In order to use the word "psychologist" (in Brazil), a psychology undergraduate must necessarily be registered with the Federal Psychological Council, and receive a professional registration number. During the course of psychology, future psychologists carry out group and individual work, read

1 I took the psychology course at Pontifical Catholic University of Rio Grande do Sul (PUCRS), as an example.

2 Exame Nacional do Ensino Médio (ENEM), in portuguese. 
technical texts, learn to apply psychological tests (private tools of the psychologist), participate in specialized seminars, are supervised and, perhaps most important of all, carry out internships in areas of interest. Later, if she/he decides to pursue an academic career, the undergraduate may choose to specialize in an area of interest, becoming a specialist, master, doctor and postdoctoral fellow.

Once graduated in the academic course, the graduate can act in several areas where psychology is inserted and, however, to be a psychotherapist, one does not necessarily need to be registered with the Class Council - in this case, one cannot present oneself socially as "psychologist". This is possible just because psychotherapy is not a tool protected by law and exclusive to the psychologist; what I understand to be a huge legal loophole that is extremely problematic, exploited by charlatans, and that puts lay society in danger. Psychiatrists can also be qualified to perform psychotherapy if they wish; and they have all the conditions and preparation to do so. Their performance is different from the psychologist one, but in certain cases, the two professionals can work together, optimizing the therapeutic gain of patients/ clients. In particular, I understand that psychotherapy should be regulated in Brazil and that it should be private to professional psychologists and psychiatrists ${ }^{1}$. This is a debate that should be addressed more emphatically by colleagues, the Federal Council of Psychology and even by society, as we have witnessed a series of theoretical chimeras and delusional professions that are, in fact, disguised as psychotherapies that wear fashionable clothes. These chimeras usually use appropriations of psychological, psychiatric, psychoanalytic, neuroscientific concepts and mix them with mysticism and esotericism, creating a patchwork that not only does not support itself theoretically, but has the potential to cause damage to the mental health of the unwary, people outside the "psy" disciplines and normally beings in a state of suffering, who do not know where they are going. On the internet, it is easy to find reports of

1 I will not go into the merit of psychoanalysis, although I myself am a psychoanalyst, because it is not a psychotherapy due to several factors. The most important of these is that psychoanalytic listening is directed at unconscious processes, which is contrary to most psychotherapies that seek some type of social / functional adequacy and direct their listening to conscious processes. With 121 years of existence (if we take the publication of "Interpretation of dreams" - 1900) as the starting point of psychoanalytic research and hundreds of articles published in journals, scientific or not (including studies on effectiveness), psychoanalysis is well established within the mental health professions. 
patients abused by alleged psychotherapists without any preparation or that attended a weekend course and surrounded themselves by invented titles.

The fact that psychotherapy is not an exclusive tool for psychologists and psychiatrists, is a shameful omission, nationally and internationally, and a public demonstration of the lack of strength of the brazilian Federal Council of Psychology.

Distance learning is a possible and practicable tool in several professional fields. However, we need to look at proposals for hybridization or totalization of this modality with healthy skepticism - especially when it comes to psychology. In particular I cannot think of a single class in an undergraduate psychology course that could be done remotely without any kind of damage. This damage occurs because there are very peculiar qualities arising from the encounter between subjects, that cannot be emulated through virtualities. I dare to affirm, from a place of active clinical psychologist, that the quality of the encounter between patient and psychotherapist is of such a unique nature that it finds no analogy in any other profession ${ }^{1}$; this can also be extended to the transmission of psychological science in university centers. The curriculum of a psychology course, usually seeks to be generalist, exposing students to several theoretical lines, so that, in a postgraduate course, the individual studies more deeply the approach that one identifies and that wants to use as a work tool. The presence is essential for the transmission process to occur; through it, identification mechanisms occur with supervisors, teachers and colleagues that would never occur in a virtual environment and that are fundamental to the constitution of the student's professional identity - the future professional. Similarly, we see this also in clinical situations; therapeutic bonds that start exclusively in presence (migrating or not to technologies, later) are significantly different from bonds that start exclusively at a distance. Psychology training demands the meeting and, preferably, the face-to-face meeting. Several classes in psychology courses require direct observation of human behavior and its consequences (which may include observation of clinical care and application of psychological tests through mirror rooms, application and participation of group dynamics, simulation of patient screenings and several other typical psy1 This observation is especially interesting in the case of psychoanalysis, which works with the concept of transference and, although other theoretical lines do not conceive of handling and identifying this phenomenon, it occurs nonetheless and is responsible for the quality and maintenance of the therapeutic link. 
chology situations). In this same argumentation, the very experience on a university campus, in the socialization among peers, has a fundamental weight for the formation of the professional psychologist. Socialization would be the word. Very respectfully, to all who disagree with my position, I must say that it is incoherent to take a profession that works $100 \%$ with human contact, and all its nuances, and propose to fit it in environments that not only distance people from people, but also deprive them of their own academic experience per se. In this debate, we must also take into consideration another issue that is directly associated with the face-to-face meeting with the other: the distance that the internet places between people, that are located in bubbles of content.

Another factor to be addressed, and perhaps this is especially delicate, is the student's maturity, discipline and commitment to distance learning material. When we talk about it, we talk about cultural issues in our country and that comes from elementary school. It is not new for any elementary school teacher or higher education teacher to have heard phrases such as: "why I need to know this?", or "this is of no use". We seem to tend to a type of thinking that, in philosophy, we call utilitarianism. The study routine is a problem even for cases of presencial studies, and we see this in the most varied arrangements: from students who skip classes, being careful just about the maximum number of absences they can have in order not to fail, even more serious cases, such as taking the presence and leaving the classroom right after. Another point that crosses this discussion, is that perhaps more than hybridizing the training of the psychologist, it might be pertinent to rethink the didactics of teachers and professors - from understandable vocabularies, to being able to communicate with young people and then introduce them into technical vocabularies, even the resourceful use of technological tools in the classroom.

We must also not forget that universities are companies; a business. I understand that this may sound pejorative when spoken in that way, but it is not; it is a business relationship like any other. You pay for a service and receive that service; so much that in case of lack of payment, the negotiation procedures are practically the same as for any vehicle or home appliance store. Distance learning proposals, henceforth DL, further improve the profits of a university, while wiping out the teaching 
staff - harming teachers who, literally, have studied their whole lives to be discarded when they are elderly and replaced by technologies. We are witnessing, in real time, several cases of highly qualified post-doctoral professors, who are being dismissed, as they are no longer essential for teaching classes. This is because there are several forms of DL: from recorded classes, in which the student can attend according to their availability, to classes taught live at scheduled times. There are also, curiously, companies that hire "content teachers" to develop class materials (slides, video lessons, exercises, etc.) and sell these materials as "packages" to be taught in classes. It is precisely here that I make the connection between the words agenda, neoliberalism and outsourcing - the latter, a direct slogan of the second. All this crossed by the overwhelming machine of capitalism and profit optimization, even at the cost of lives. At the same time, we see series of small universities in Brazil, which are part of large conglomerates, true empires, and which are making a fortune by offering DL courses in various areas - both undergraduate and postgraduate - flooding the market with professionals with deficient training. They are institutions that, shamelessly, advertise based on cheap monthly fees as a decoy; another reflection of the consumption issue. Oliveira et al (2017, p. 04), point out that in 2017:

[The] Brazil today has more than 304 thousand psychologists, more than seven hundred undergraduate courses in Psychology. Since the regulation of the profession in Brazil in 1962, training in Psychology has been the subject of reflection and debates involving the category and its entities, the Ministry of Education and the Ministry of Health. In 2004, the National Curricular Guidelines (DCN) were approved for undergraduate courses in Psychology, which in 2011 underwent reformulation in order to regulate the degree in Psychology.

Psychology, as an essentially questioning discipline, needs to take a stand and face up to this market trend that is not necessarily good - despite being new. This, precisely because not everything that is new is good! Homogenized formations, in which there is no space for personal and relational teacher-student development, affect the quality of learning and, as a consequence, the quality of the professional. There are indications that have pointed out high levels of functional illiteracy among brazilian university students, who find herculean difficulties in writing and interpreting a simple text - something that cannot be acceptable to someone from the culture of an academic campus. Even I can observe professional colleagues who make several 
theoretical confusions with content learned at the university; mixing theories that not only have antagonistic assumptions, for example, mixing psychology with all kinds of esotericism and religiosity; which evidences, irrefutably, very clearly, that even in presencial classroom teaching there are "noises" and gaps that are not being treated with proper attention. Before biting more than we can chew, perhaps brazilian psychology needs to rethink structural issues about the teaching process itself in the presencial modality. It is necessary for psychology to make a serious self-criticism before forcing or proposing implementations that are the result of precipitated social demands, but, above all, market trends mediated by neoliberal fashions and consume modalities. In this debate, it is interesting to mention a very important fact to avoid any kind of precipitation: that the country lacks in studies of this type of proposal; specially in psychology.

The survey of publications on the subject of distance education inserted in educational contexts, especially at the higher education level, which deal with learning and program evaluation, shows that the area of knowledge production on the quality and effectiveness of online courses line lacks more systematic research, with more robust statistical cuts, especially in the national context, with a large theoretical-methodological gap in the area of EAD program evaluation, specifically those offered on the internet [here the authors speak of postgraduate courses]. Despite the aforementioned findings, the search in databases that bring together works produced in the fields of Sciences and Humanities, indicates evident gaps in research on learning and evaluation of distance courses in these areas. The prominent scarcity of scientific research shows the gap with the growing offer of educational programs in distance education in the world. This indicates that the dynamics of publications follow the current situation of the topic with slow steps and how much it is imperative to dedicate studies that add knowledge and returns to society in relation to education (MARTINS; ZERBINI, 2012, p. 278-279).

More than feeding corporate interests to optimize profits from university empires, separating people through distance and technologies, perhaps we should be thinking of approaches to not only bring people together but to deal with the problems that we already have. There is nothing wrong with face-to-face presencial teaching; what may exist is something wrong with the curriculum of most universities, which do not prepare students for the real job market at all (and psychology departments usually shy away from this responsibility, claiming that this is a subject for post graduate, etc.). Also, as I mentioned, there may be something wrong with the didactics of the teachers, who in the best intentions, still follow methods of presenting the classes in 
an archaic and uninteresting way, not using visual resources that would call the students interest and attention. In view of what is said about the responsibility, on the students side, whether presencial or DL, we seem to be lacking a few more decades of maturity and didactics, not only to teach content in a more interesting way (in person), but also teach the people about why it is important to master such content, under penalty falling into utilitarian logic, making difficult, or even impossible, the critical thinking to articulate knowledge and reflexive criticism.

Nor it is my intention to demonize the possibility of DL in psychology in the future; now, however, I do not conceive it as possible in Brazil, because there are problems, not only in the institutions themselves, but in the curricular structures and in the social structure (of society), that does not seem to respond well to the autonomy and need for routine and discipline to self-manage its studies. Philosophically, it would be absurd to completely condemn DL because there are no things that are good or bad in themselves: good or bad are the use we make of the resources we have. As a nation, we seem to lack an education (from the elementary one), which teaches the value of knowledge and the way it is articulated to the higher one. Several recent events, including political ones, seem to prove this.

\section{CONCLUSION}

We are going through a difficult time for knowledge and for university centers and this is only the beginning of a process that will have a long-term impact. Scientists who were previously cloning animals, going to the moon, eradicating diseases with exemplary vaccination systems (including in Brazil) and perfecting drugs to combat various diseases (such as the huge advances in research on antiretrovirals for HIVI AIDS), now they must go public to deny fallacies about their own work. Scientists need to explain that the land is not flat, that vaccines do not make people go crazy and that there is no microchip in them. Psychologists are being forced to come to public alerting people about psychotherapies disguised, propagated by digital influencers, and several professional fields are being invaded by concept-binding chimeras. The internet, while it came with the proposal to strengthen ties, ends up creating bubbles and niches, separating us and making the people less and less tolerant, focused on 
themselves and their narcissistic activities. We are in an age (post-enlightenment, post-industrial revolution and in the midst of a digital revolution) where the obvious needs to be explained and the post-truth not only finds a voice, but becomes the dominant discourse. Much of this has a direct relationship with poor education (since basic education) that seeks to pass on knowledge, without explaining to the child that not only is knowledge what liberates, but that it is knowledge that will instrumentalize it for the life! We note that there seems to be a "tacit" project in Brazil (but maybe globally) to weaken fields of knowledge (specifically those of critical thinking) and more than that, there are market interests at stake. Unscrupulous university companies sell distance learning courses, which are completed in a very short period of time and with loose requirements, in the end, providing a certificate effectively valid by MEC and which makes its bearer enjoy all the benefits of a presencial course; a diploma empty of content and meaning.

There are professions that are impossible to be transmitted without personal contact, as personal contact and personality are intrinsic to them. I will ask a provocative question for you, my reader: Would you operate yourself with an educated DL surgeon? I think your answer is no; mine certainly is the same. Why should this be any different in psychology? What would be the criteria for stipulating which discipline in the psychology training course could be DL? It seems to me evident that the most theoretical disciplines would be harmed - because common sense understands that if something is written, to understand it is enough to read - something that could not be further from any truth. Acquiring knowledge is not exactly this way; theories need to be discussed, questioned, refuted and revisited many times to be understood. Some of them, even, can only be understood, if lived. Paradoxically, how could the theory be treated so secondarily as it is the most fundamental substrate for any type of active strategy in psychological approaches? Or are the disciplines of neuroanatomy that would be carried out in this DL modality, depriving the psychology student of knowing live and in color, the human brain in a real corpse, object of his own study? Would it be possible to teach inferential statistics, chi-square test and factor analysis (something extremely difficult for those not used to numbers) and quantitative and qualitative analyzes through a screen? And the descriptive psychopathology, full of intricacies and specificities of differential diagnoses in the DSM's, could be in distance? Even the 
orientation of a course conclusion work ${ }^{1}$, something that generates extreme anxiety in students, could not be conducted without being present. Or worse, will the disciplines taught at a distance, be those that precisely foster critical thinking, such as philosophy applied to psychology or the class of professional ethics? To understand something, effectively, is enough to read what is written in the books?

I will not go into the question of virtual learning environments themselves, which offer discussion forums that, at some point, no one else understands each other. Nothing replaces a student's question, answered publicly and live - which may be the question of several others.

What the COVID-19 pandemic seems to be showing is that there is a possibility of implementing investigative studies on DL modalities in psychology, at the undergraduate level. Long-term studies (quantitative and qualitative) are necessary for this and these studies could be being conducted precisely in this particular moment in which we live. What seems certain is that, with all the problems that the courses themselves present, it seems hasty to approve any legal device that allows distance education undergraduate courses in psychology, even semi-presential in Brazil, at the moment. Presence cannot be replaced by mechanisms that only make it look like something is being done. There are cultural factors in the country, which make self-management of the distance learning study impossible, especially in a profession as serious as psychology. We need more research on distance learning studies in psychology, more criticism of the course structures and, mainly, more time so that there is awareness that DL in psychology, as well as present studies, should be taken more than seriously.

In addition, in my final conclusion, I also affirm that, definitely, we need a class Council that comes out of its dogmatic sleep and defends issues such as the salary level for the category and the problematic issue of psychotherapy as an exclusive tool of the psychiatrists and the psychologists. We have structural problems in the exercise of our profession and it would seem unreasonable to precipitate into another one (in the training of future professionals).

Should psychology surrender to market demands or do just the opposite, denounce them for what they are?

1 Trabalho de conclusão de curso (TCC), in portuguese. 


\section{REFERENCES}

LIMA, Marcelo; MACIEL, Samanta Lopes. A reforma do Ensino Médio do governo Temer: corrosão do direito à educação no contexto de crise do capital no Brasil. Rev. Bras. Educ., Rio de Janeiro, v. 23, e230058, 2018. Disponível em <http://www.scielo.br/scielo.php?script=sci_arttext\&pid=S1413-24782018000100245\&lng=pt\&nrm=iso>. acessos em 16 fev. 2021. Epub 08-Out-2018. https://doi.org/10.1590/s1413$\underline{24782018230058 .}$.

MARTINS, Lara Barros; ZERBINI, Thaís. Educação a distância em instituições de ensino superior: uma revisão de pesquisas. Rev. Psicol., Organ. Trab., Florianópolis , v. 14, n. 3, p. 271-282, set. 2014 . Disponível em <http://pepsic.bvsalud.org/scielo.php?script=sci_arttext\&pid=S1984-66572014000300003\&lng=pt\&nrm=iso>. acessos em 15 fev. 2021.

OLIVEIRA, Irani Tomiatto de et al . Formação em Psicologia no Brasil: Aspectos Históricos e Desafios Contemporâneos. Psicol. Ensino \& Form., São Paulo, v. 8, n. 1, p. 3-15, jun. 2017 . Disponível em <http://pepsic.bvsalud.org/scielo.php?script=sci_arttext\&pid=S2177-20612017000100002\&lng=pt\&nrm=iso>. acessos em 15 fev. 2021. http://dx.doi.org/10.21826/2179-5800201781315.

SOARES, Antonio Rodrigues. A Psicologia no Brasil. Psicol. cienc. prof., Brasília , v. 30, n. spe, p. 8-41, Dec. 2010 . Available from <http://www.scielo.br/scielo. php?script=sci_arttext\&pid=S1414-98932010000500002\&lng=en\&nrm=iso $>$. access on 15 Feb. 2021. https://doi.org/10.1590/S1414-98932010000500002. 


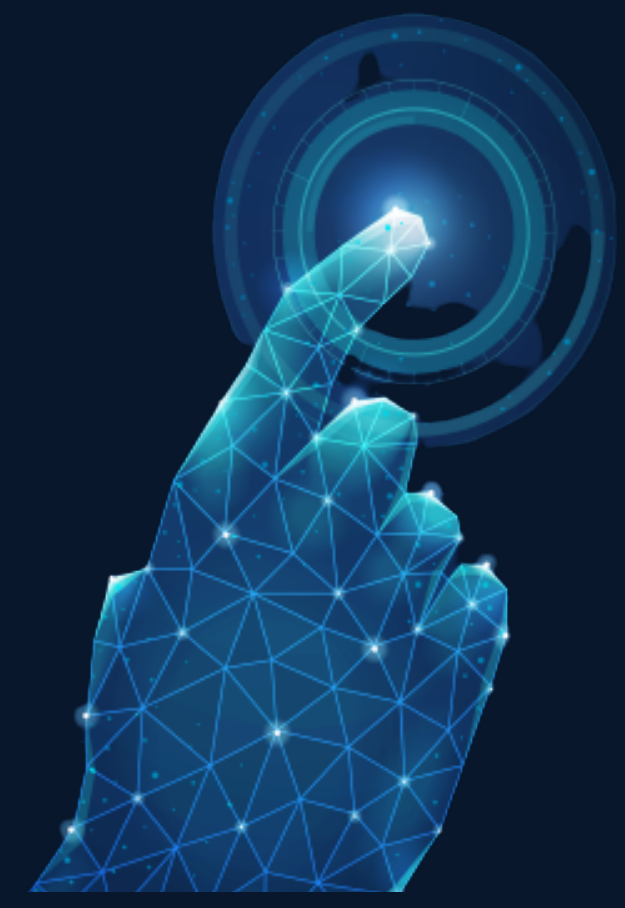
A CRIAÇÃO DE COMUNIDADE DE APRENDIZAGEM COMO FORMAÇÃO CONTINUADA PARA O USO DAS TICS COMO FERRAMENTAS PEDAGÓGICAS ${ }^{1}$

Francisco Gerbson de Oliveira ${ }^{2}$

1 Artigo criado a partir da dissertação do autor, intitulada O Uso Das Tics Na Escola De Ensino Médio Professora Lídia Carneiro De Barros, No Estado Do Ceará: Potencialidades e Desafios, defendida no curso de Mestrado Profissional em Gestão e Avaliação da Educação Pública da Universidade Federal de Juiz de Fora (UJFJ)

2 Mestre em Gestão e Avaliação da Educação Pública, pela Universidade Federal de Juiz de Fora. Especialista no Ensino de Língua Espanhola. Licenciado em Letras - Espanhol. Professor efetivo da rede estadual cearense de ensino. 


\section{INTRODUÇÃO}

Por volta da década de 1980, as Tecnologias da Informação e Comunicação (TICs) começaram a evoluir em velocidade nunca antes vista, e o ser humano passou a ser mais dependente delas. A partir desse cenário, percebeu-se a necessidade de usar tais tecnologias como ferramenta em vários setores da sociedade. A escola, instituição importante na transformação de uma sociedade, modificou-se significativamente com a evolução das tecnologias devido ao seu papel de instância formadora de cidadãos para o mercado de trabalho, cada vez mais ligada às novas tecnologias.

A instituição escolar, portanto, viu-se na necessidade de introduzir as TICs em seus processos administrativos e pedagógicos. Isso deveria ocorrer a partir da reestruturação física dos ambientes educacionais, da aquisição de equipamentos e da necessidade de formação inicial e continuada dos profissionais que iriam utilizar e mediar o uso dessas tecnologias. Porém, isso não ocorreu em todas as instituições de ensino, e, por essa razão, o não cumprimento desses requisitos dificulta o uso desses recursos nos espaços educacionais, pois falta estrutura tecnológica, pessoal preparado para o uso e manutenção dos equipamentos, a falta ou a má qualidade da internet nas escolas, leis que impedem o uso de celulares ou outros equipamentos em espaços educacionais, além da resistência de alguns profissionais em atualizarem-se e trabalharem com essas ferramentas tecnológicas no processo de ensino e de aprendizagem.

O uso das Tecnologias da Informação e Comunicação como ferramenta pedagógica na educação tem sido alvo de pesquisa de vários autores cujos estudos buscam entender as dificuldades em se introduzir tais recursos no cenário educacional brasileiro e as potencialidades que estes dispõem para incentivar os estudantes a buscarem o conhecimento.

Em relação às tecnologias ligadas à educação, também definidas como tecnologia educacional, Ramos (2012, p. 6) afirma: "Entende-se por tecnologia educacional, o conjunto de técnicas, processos e métodos que utilizam meios digitais e demais recursos como ferramentas de apoio aplicadas ao ensino, com a possibilidade de atuar de forma metódica entre quem ensina e quem aprende". A definição do autor afirma que as tecnologias têm como uma de suas características a possibilidade de 
proporcionar uma interação entre educadores e educandos, demonstrando assim um olhar do professor como mediador do conhecimento. Por esta razão, a escola deve ter como uma de suas funções a busca pela interação entre o conhecimento, o professor e o aluno, tendo como um dos principais meios o uso das TICs.

Destaca-se o fato de que a escola deve estar cada vez mais conectada ao cotidiano do aluno, e a educação deve usar o que o discente utiliza fora da escola como meio de produzir conhecimento, o que pode ser constatado na afirmação de Couto (2014):

As novas tecnologias estão cada vez mais acessíveis aos jovens e têm sido inclusive, objeto de medidas políticas que procuram tornar acessível um saber que se considera necessário para a participação cidadã e para a educação, já que os equipamentos e os saberes sobre as novas tecnologias estão desigualmente distribuídos, ou seja, não só o acesso, mas a própria qualidade de utilização varia em função da região e do grupo social a que se pertence (COUTO, 2014, p. 260).

Couto (2014) identifica a igualdade de acesso, conhecimento sobre as novas tecnologias e a busca por qualidade na utilização das tecnologias como algo a ser pensado como política pública, pois é fator necessário para a participação do cidadão no atual cenário social. Deve-se dar os meios de forma igualitária para que todos tenham as mesmas condições de conhecer, debater e participar da vida política e social, tendo como um dos meios a utilização de novas tecnologias. Ao mencionar o fato de que se deve haver uma preocupação com os saberes sobre as novas tecnologias e com a qualidade na utilização destas, a escola surge como mediadora do processo de mudança deste cenário, já que a mesma é um ambiente em que se deve buscar diminuir as desigualdades de conhecimento existentes na sociedade e produzir novos.

\section{ESTUDO TEÓRICO SOBRE AS DIFICULDADES DO USO DAS TICS NO AMBIENTE ESCOLAR}

Para explanar sobre as principais dificuldades de uso das tecnologias no ambiente escolar, se utilizará os estudos de Moreira et al. (2005), nos quais os autores classificam os obstáculos que dificultam o uso destas em três níveis, são eles: Macro (Sistema educativo), Meso (Institucional) e Pessoal (Professores e Alunos), que poderia ser denominado também de nível micro, já que se trata da menor instância 
dentro da análise do autor, como pode ser observado na Figura 1.

Figura SEQ Figura ${ }^{*} A R A B I C$ 1- Níveis e categorias de obstáculos à integração das TICs no processo de ensino e aprendizagem

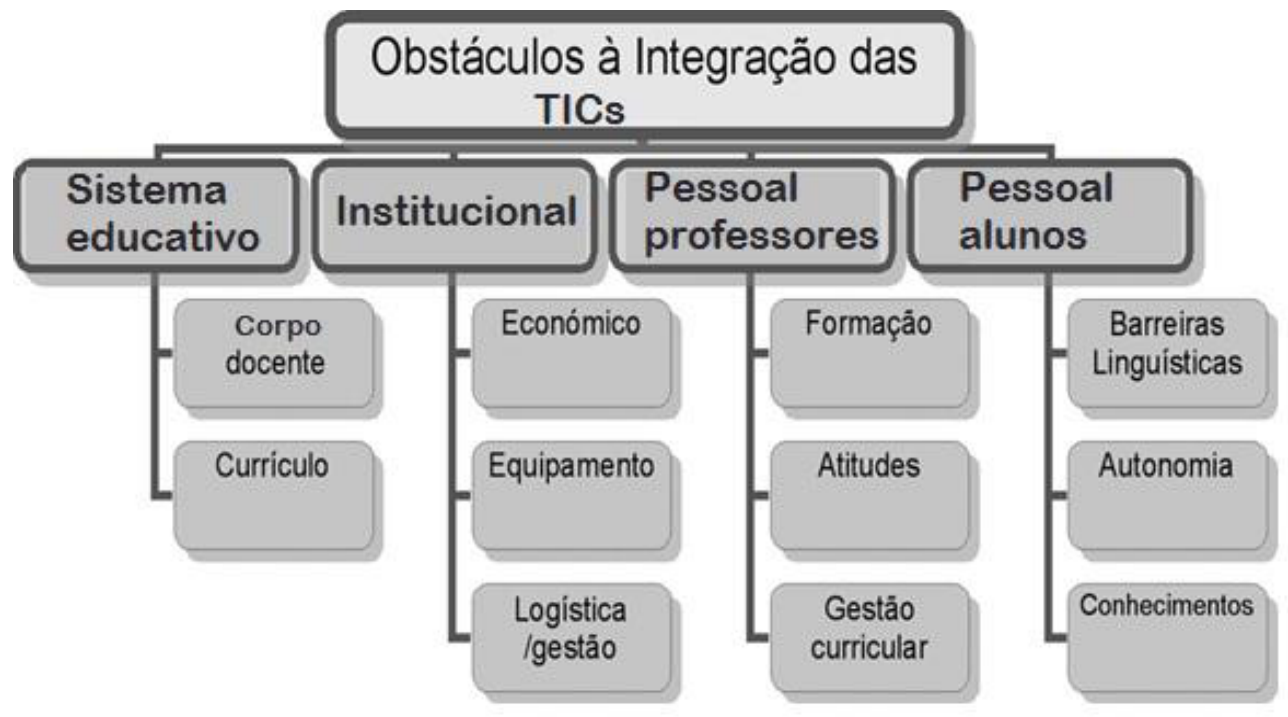

Fonte: Moreira et al. (2005).

No nível Macro, no qual se analisa o sistema educativo, o corpo docente e o currículo, são consideradas duas categorias que podem ser obstáculos à integração das TICs. Sobre esses obstáculos, Moreira et al. (2005, p. 2) afirmam: "Ao nível do Sistema Educativo, foram consideradas duas categorias de obstáculos: Corpo Docente (por exemplo, falta de estabilidade do corpo docente) e Currículo (extensão e conteúdos inadequados ou dificuldades sentidas na integração curricular das TIC)". A partir do exposto pelo autor, é possível afirmar que é necessário ter uma preocupação em relação à escolha de conteúdos, visto que alguns podem ser inadequados e, por esse motivo, dificultam a integração das TICs nas escolas.

Em relação ao corpo docente, a falta de estabilidade pode fazer com que treinamentos e investimentos em formação continuada não tenham o efeito esperado, pois a constante mudança do corpo docente nas escolas, a cada ano letivo, faz com que alguns projetos não tenham continuidade. Sobre o currículo, Couto (2014, p. 258) afirma: "Superar uma perspectiva de centralidade do Estado e defendo as micropolíticas produzidas nas escolas na significação de políticas curriculares". Segundo o autor, o currículo é muito centralizado no estado, e isso pode significar a não sensibilidade da real necessidade curricular dos alunos de determinada escola, acontecendo, por essa razão, a não introdução das TICs no currículo e no cotidiano 
de muitas escolas.

No nível Meso, está a instituição, na qual os obstáculos estão relacionados à estrutura física e/ou à gestão escolar, sobre os obstáculos deste nível Moreira et al. (2005, p. 2) afirmam:

A nível Institucional foram definidas três categorias de obstáculos: Econômicos (gastos com aquisição e manutenção de equipamento, custos de energia e comunicações), Equipamento (insuficiência e falta de infraestruturas), e Logística-Gestão (organização dos espaços, das turmas e dos horários, facilidade de acesso aos equipamentos, organização de grupos dinamizadores e de apoio às atividades relacionadas com as TIC, assim como de suporte aos professores).

Os obstáculos desse nível podem ser observados no exposto por Couto (2014) como o principal fator para a criação de políticas públicas relacionadas à introdução das TICs no ambiente escolar. Couto (2014) afirma que as políticas públicas que envolvem a introdução das TICs nas escolas apresentam, em suas justificativas, o déficit que as mesmas apresentam, tanto em quantidade como em qualidade.

Conforme Moreira et al. (2005), no nível Pessoal, no qual se encontram alunos e professores, é o que mais apresenta obstáculos, como pode ser observado na figura 1, pois este nível apresenta 6 categorias de problemas em relação ao uso das TICs na educação. Em relação aos alunos, a autonomia deve ser um fator a ser trabalhado, visto que o aluno deve desenvolvê-la para conseguir ser o protagonista de seu percurso estudantil e assim construir seus conhecimentos e não continuar a apenas ser um mero expectador no processo de ensino e aprendizagem. Em relação à importância de uma educação que incentiva a autonomia dos alunos, Lucena (2016, p. 288) afirma:

Trabalhar com as culturas digitais e com as tecnologias móveis na escola não é apenas usar uma nova metodologia de aprendizagem para transmitir conteúdos enfadonhos, mas é pensar nesse novo sujeito, praticante cultural que pensa, produz saberes e compartilha opiniões, conteúdos e informações nas redes.

O autor enfatiza que ao se trabalhar com as tecnologias, as escolas devem não apenas modificar ou criar metodologias, mas também dar ao aluno mais autonomia, pois com o uso das tecnologias os alunos devem passar de meros expectadores da exposição de conteúdos, para produtores e propagadores de conhecimento. A escola, portanto, deve entender o papel das tecnologias no processo de construção de 
conhecimento para conseguir desenvolver no aluno a ideia do mesmo como sendo protagonista deste processo. Sobre o papel da tecnologia na sala de aula Prensky (2010, p. 202) afirma:

O papel da tecnologia - e seu único papel - deveria ser o de apoiar os alunos no processo de ensinarem a si mesmos (obviamente com a orientação de seus professores). A tecnologia não apoia - nem pode apoiar - a velha pedagogia do professor que fala/palestra, exceto em formas mínimas, tais como através da utilização de imagens ou vídeos. Na verdade, quando os professores usam o velho paradigma de exposição, ao adicionarem e ela a tecnologia, ela com muito mais frequência do que o desejado se torna um empecilho.

O autor coloca que as tecnologias na sala de aula devem ter como papel o apoio no processo de ensino e aprendizagem dos alunos, onde estes ensinam a si mesmos com a orientação do professor. O autor afirma que as tecnologias não devem apoiar às aulas exclusivamente expositivas, mas podem auxiliá-las em formas mínimas, como a ilustração a partir da exposição de vídeos e imagens. Segundo o autor, as tecnologias, se usadas em excesso, podem tornar-se um empecilho para a melhoria dos processos pedagógicos escolares. Sobre a afirmação do autor, é possível exemplificar as aulas onde os conteúdos são expostos aos alunos com o auxílio de um projetor, porém com a mesma metodologia de exposição na lousa, neste caso, o projetor deixa de ser uma possível ferramenta de mudança e criação de novas metodologias pedagógicas e torna-se mais um recurso para a exposição de conteúdos.

Ainda no nível Pessoal, a mais frequente dificuldade encontrada nos artigos estudados é a relacionada aos professores. O autor divide em três categorias de obstáculos relacionadas aos professores, a saber: Formação, Atitudes e Gestão do currículo. Sobre a categoria Formação, Moreira et al. (2005, p. 2) afirmam que:

A categoria Formação, integra fatores relacionados com a falta de conhecimentos e competências dos professores para integrar as TIC no currículo, por exemplo, a nível de conhecimentos sobre como selecionar e explorar as TIC em contexto educativo, nomeadamente disciplinar, ou fracas possibilidades de formação e atualização em ações de formação de real interesse prático.

Entre os possíveis fatores que podem contribuir para a falta de competência para integrar as TICs no currículo, está a não preparação para o uso destas em sala de aula na formação inicial dos docentes. Esse é um dos fatores mais presentes nos estudos sobre o assunto, como se pode observar no exposto por Alonso (2008, p. 759): 
As discussões sobre a formação de professores e sobre a relevância que estes assumem no contexto educativo têm posto em destaque a compreensão da natureza do trabalho do docente. Tenta-se, dessa maneira, estabelecer os requisitos mínimos do estatuto profissional da profissão do docente e, como consequência, os requisitos mínimos para a formação desses profissionais.

Além da formação inicial, a formação continuada deve ser discutida, pois as mesmas são oferecidas como uma forma de sanar possíveis lacunas na formação inicial dos professores e por esta razão tornam-se essenciais para que se consiga uma formação mais sólida e mais próxima à realidade de sala de aula. Sobre a formação continuada é importante destacar a afirmação de Lucena (2016, p. 285):

Um dos principais problemas apresentados como fator da não utilização das TICs na escola é a formação de professores. Isso porque, em geral, os programas governamentais resumem a formação continuada de professores em pequenos cursos ou oficinas com carga horária de 40 a 80 horas, insuficientes para a reflexão crítica sobre o uso das TIC.

A autora expõe que dentre os problemas que se apresentam para o não uso das TICs como ferramentas pedagógicas estão os cursos de formação continuada oferecidos aos professores através de programas governamentais, pois estes se demonstram insuficientes para que se consiga uma reflexão plausível acerca do uso das TICs nas escolas. Portanto, é possível afirmar que para se conseguir introduzir as TICs nas práticas pedagógicas de maneira mais recorrente e que as mesmas consigam desempenhar o papel de mediadoras do processo de ensino-aprendizagem há a necessidade de se investir na formação inicial e continuada de professores, fazer com que o que se aprende na academia ou em cursos de aperfeiçoamento seja algo prático no cotidiano de sala de aula.

Sobre a categoria de obstáculos Atitudes, Moreira et al. (2005, p. 2) afirmam: "A categoria Atitudes engloba fatores que traduzem o sentimento dos professores relativamente à necessidade de inovação das práticas pedagógicas, ou à falta de evidência suficiente do valor educacional da utilização das TIC na aprendizagem dos alunos". Nessa categoria, a formação não é o principal empecilho à integração das TICs, mas o próprio professor cria uma barreira a partir de questionamentos relacionados à necessidade de atualizar suas práticas pedagógicas, além de questionar o valor educacional do uso destas como ferramentas pedagógicas. Ainda em relação à categoria de obstáculos Atitudes é importante a afirmação de Prensky (2010, p. 204): 
Portanto, antes de introduzirmos a tecnologia de forma bem sucedida em nossas escolas, precisamos dar um passo inicial. Precisamos trabalhar com nossos professores e convencê-los - por mais difícil que isso possa ser em alguns casos - a pararem de palestrar e a começarem a permitir que seus alunos aprendam por si mesmos.

O autor é claro ao colocar que antes de se conseguir a introdução bem sucedida das TICs no ambiente escolar faz-se necessário um trabalho de conscientização com os professores sobre a importância da inovação nas práticas pedagógicas, para que assim o aluno torne-se protagonista no processo de ensino-aprendizagem e desta maneira consigam aprender por si mesmos. Neste processo, o professor torna-se um mediador no processo de ensino-aprendizagem e pode ter as TICs como umas das ferramentas facilitadoras na execução de novas metodologias.

Sobre a importância do professor no processo de introdução das TICs no ambiente escolar com ferramentas facilitadoras na atualização de práticas pedagógicas e na criação de novas metodologias de ensino, Koch (2013, p. 17) afirma: "Para atualizar e qualificar os processos educativos, é necessário capacitar os professores buscando conhecer e discutir formas de utilização de tecnologias no campo educacional". Colocar o professor no centro dos debates referentes às diversas formas e maneiras de utilização das TICs deve ser uma das medidas para o fortalecimento do uso das mesmas no ambiente escolar, saber os anseios dos professores e contar com sua ajuda na criação de ferramentas TICs deve ser algo a ser incentivado.

Outro ponto referente aos professores que pode estar relacionado à dificuldade em integrar as TICs à educação é o chamado obstáculo didático, que diz respeito a não levar em consideração o que o aluno traz de conhecimento sobre o uso das novas tecnologias em seu cotidiano, conforme o que está exposto no que é relatado por Schuhmacher, Alves Filho e Schuhmacher (2017, p. 566):

O professor estabelece um obstáculo didático ao tomar decisões didáticas, ignorando que os jovens chegam às escolas com conhecimentos pré-estabelecidos sobre computadores, internet, celulares que lhe foram apresentados de uma forma atraente e duradoura pela onda de consumo tecnológico. $\mathrm{O}$ aluno traz consigo o conhecimento em TIC, adquirido em seu dia a dia.

Em relação às potencialidades do uso das TICs na educação, percebe-se a necessidade de mudança de postura da escola diante da era das tecnologias digitais, 
que é incontestável, pois, com um público cada vez mais dependente das tecnologias, a escola necessita criar estratégias que coloquem as tecnologias usadas por seus alunos fora do ambiente escolar como aliadas ao processo de ensino e aprendizagem, conforme afirma Alonso (2008, p. 749): "Pretende-se que a incorporação das TIC pelas escolas seja elemento catalisador de mudanças significativas na aprendizagem dos alunos".

Entre as ferramentas TICs que podem contribuir para mudanças significativas na aprendizagem dos alunos está a internet, pois a mesma torna-se cada vez mais presente no cotidiano da escola, e por esta razão faz-se necessário o uso dessa para conduzir uma educação colaborativa, em que o conhecimento seja construído a partir da interação entre alunos e professores, mesmo que à distância, o que é afirmado por Moran, Masetto e Behrens (2003 apud MORAN 2014, p. 2): “[...] na educação presencial a chegada da Internet está trazendo novos desafios para a sala de aula, tanto tecnológicos como pedagógicos. As tecnologias sozinhas não mudam a escola, mas trazem mil possibilidades de apoio ao professor e de interação com e entre os alunos"

Entre os muitos meios para se usar as TICs como ferramentas pedagógicas, o celular torna-se um instrumento com potencial indiscutível, porque está cada dia mais presente no cotidiano de alunos e professores, e isso deveria ser usado como aliado, e não como uma barreira, conforme Prenky (2010, p. 185): "Se forem espertos, os educadores descobrirão como oferecer seu produto de uma maneira adaptada à vida digital - e aos celulares - de seus alunos". A escola, portanto, perde ao não usar o potencial que os alunos possuem ao dominarem as tecnologias móveis, como é o caso do celular, pois, além de fácil manipulação, os celulares podem ser usados fora e dentro do ambiente escolar, o que facilita pesquisas de campo ou trabalhos para realização fora do ambiente escolar.

\section{RESULTADOS E DISCUSSÃO}

A partir do estudo dos teóricos apresentados fica evidente a necessidade de uma formação continuada, porém uma formação que atenda às necessidades dos docentes e também de toda a comunidade escolar, tendo como principal objetivo a melhoria dos índices de qualidade da educação. Por este motivo se apresenta como 
metodologia para a busca de solucionar as dificuldades de formação continuada dos docentes a criação de uma comunidade de aprendizagem que vise a troca de experiência entre docentes de escolas diferentes para que haja uma rede de ideias que auxiliem as escolas a introduzirem de forma mais eficiente as TICs no ambiente escolar.

As comunidades de aprendizagem têm em sua proposta o debate sobre temas a partir das experiências teóricas e práticas de interesse dos atores que a compõem. Estas são introduzidas em ambientes em que se pretende a mudança do contexto educativo em que está inserida a instituição de ensino. Entre os motivos para a escolha desta metodologia, está a presença de alunos e familiares na base do debate e na busca por soluções das problemáticas, pois o presente estudo julga que estes atores devem estar em lugar de destaque nas discussões sobre o uso das TICs como ferramentas pedagógicas, já que este deve ser um tema de debate em que toda a comunidade escolar deve participar, visto que o principal interesse desta temática é dar meios para que o uso das TICs possa tornar-se uma ferramenta que pode potencializar o processo de ensino e aprendizagem das escolas brasileiras. Sobre as comunidades de aprendizagem, Marigo et al. (2010) explica:

As Comunidades de Aprendizagem são uma proposta baseada na transformação do contexto educativo, realizada pelos(as) agentes educacionais da instituição escolar em conjunto com familiares e estudantes, visando a melhoria e a aceleração das aprendizagens de todos os conhecimentos escolares, com ênfase na leitura e na escrita, por parte de todas as pessoas envolvidas no processo educativo (MARIGO et al., 2010, p.74).

O autor afirma que as comunidades de aprendizagem têm por objetivo a melhoria e aceleração das aprendizagens e dos conhecimentos escolares, principalmente a leitura e a escrita, habilidades necessárias para que os alunos possam participar da vida social de forma digna e participativa. Nesta perspectiva de metodologia, as TICs podem ser utilizadas como ferramentas que facilitem a aquisição das habilidades pretendidas, já que a atual geração de alunos lê e escreve principalmente através de ferramentas tecnológicas.

As comunidades de aprendizagem serão organizadas de forma mensal, cada reunião terá um grupo de professores responsáveis pela condução dos debates, con- 
vites e organização do ambiente e do tempo. As comunidades de aprendizagem serão realizadas com a participação de instituições de ensino convidadas. Os temas abordados serão escolhidos nas reuniões mensais pelos próprios componentes da comunidade, e haverá a apresentação prática de experiências relacionadas ao uso das TICs como ferramentas pedagógicas, além do estudo de alguns temas a serem debatidos pela comunidade, pois a visão destes atores pode ajudar a validar e/ou adaptar algumas das metodologias estudadas ao contexto da instituição de ensino.

O principal objetivo da comunidade de aprendizagem será a aquisição de conhecimento a partir da troca de experiências exitosas em outros contextos escolares e/ou no próprio ambiente da escola estudada e, consequentemente, se coloque as TICs como ferramentas pedagógicas habituais no processo de ensino e aprendizagem da instituição.

Os assuntos e atividades escolhidos para o estudo nas reuniões da comunidade de aprendizagem terão como foco o conhecimento de ferramentas para se utilizar no processo de ensino, tais como sites, programas de computador e aplicativos mobiles.

Na condução das reuniões haverá a confecção de um portfólio com as atividades propostas nos debates e registros das reuniões para que posteriormente sirva como ferramenta de pesquisa e consulta para a própria comunidade escolar e para outras instituições. As atividades da ação relacionada às comunidades de aprendizagem estão expostas no Quadro 1.

Com o objetivo de tornar mais fácil a visualização e o entendimento das ação proposta, será utilizado o quadro $5 \mathrm{~W} 2 \mathrm{H}$. Este modelo é uma ferramenta administrativa que visa registrar de maneira organizada e planejada as ações de um plano. Seu nome se origina de iniciais de palavras (em inglês) que são as diretrizes para se elaborar e executar as ações pretendidas. What? (O quê?), Why? (Por quê?), Who? (Quem?), Where? (Onde?), When? (Quando?), How? (Como?) e How much? (Quanto?).

Portanto, com base no modelo $5 \mathrm{~W} 2 \mathrm{H}$, a ação foi organizada a partir das seguintes diretrizes: O que se fará: apresenta os objetivos a serem alcançados na ação. Por que se fará: expõe os motivos pelos quais se justifica a ação proposta. Quem 
fará: relata os responsáveis pela execução da ação. Onde se fará: mostra o local de execução da ação. Quando se fará: indica o tempo que será preciso para a execução da ação. Como se fará: apresenta a metodologia de execução da ação. Quanto custará: faz-se uma projeção do custo da execução da ação.

\section{Quadro 1 - Criação de comunidade de aprendizagem voltada para a utilização das TICs como ferramentas pedagógicas}

\begin{tabular}{|c|c|}
\hline O que se fará & $\begin{array}{l}\text { Criação de uma comunidade de aprendizagem composta por docentes, } \\
\text { gestores, alunos e parceiros externos com o objetivo de se compartilhar } \\
\text { dúvidas, ideias e experiências exitosas relacionadas às TICs como } \\
\text { ferramentas pedagógicas. }\end{array}$ \\
\hline $\begin{array}{l}\text { Por que } \\
\text { se fará }\end{array}$ & $\begin{array}{l}\text { Para que o compartilhamento de conhecimentos e experiências relacio- } \\
\text { nados ao uso das TICs em sala de aula possa auxiliar à escola na } \\
\text { utilização de suas ferramentas tecnológicas em prol do processo de } \\
\text { ensino e aprendizagem. }\end{array}$ \\
\hline Quem fará & Gestores; Professores; Alunos; Familiares; Parceiros externos \\
\hline $\begin{array}{l}\text { Onde } \\
\text { se fará }\end{array}$ & $\mathrm{Na}$ Escola \\
\hline $\begin{array}{l}\text { Quando } \\
\text { se fará }\end{array}$ & Ao longo de cada ano letivo \\
\hline Como se fará & $\begin{array}{l}\text { Uma vez por mês de forma intercalada com as aulas do curso } \\
\text { institucional para que os conhecimentos adquiridos sejam executados e } \\
\text { posteriormente discutido o que se pode melhorar ou ser adaptado na } \\
\text { metodologia. }\end{array}$ \\
\hline $\begin{array}{l}\text { Quanto } \\
\text { custará }\end{array}$ & Sem custos financeiros \\
\hline
\end{tabular}

Fonte: Elaboração própria (2019)

Esta ação é vista como fundamental para condução do trabalho de colocar o uso das TICs como possível ferramenta que pode potencializar o processo de ensino e aprendizagem das instituições de ensino. A comunidade de aprendizagem além de possuir os benefícios já elencados é colocada como uma forma de avaliação contínua das ações escolares, pois, em suas reuniões, todos os segmentos da comunidade escolar poderão dar opiniões que servirão de subsídios práticos para se entender o que se deve manter, adaptar ou ser cancelado no planejamento escolar. 


\section{CONCLUSÃO}

O presente estudo teve como objetivo geral identificar os fatores que levam ao baixo número de práticas pedagógicas que utilizam as TICs no ambiente escolar e propor ações para a inserção das tecnologias no cotidiano escolar. Para cumprir este objetivo, buscou-se uma fundamentação teórica que conseguisse expor de maneira clara e objetiva os principais fatores ligados à temática estudada. $O$ estudo analisou o fenômeno a partir do estudo de teóricos que em seus trabalhos detectaram os possíveis empecilhos para se utilizar as ferramentas TICs de forma mais habitual no ambiente escolar. A partir do estudo teórico, pode-se entender que as barreiras podem ser diversas e que cada uma delas pode indicar uma razão pela qual acontece e qual metodologia a se utilizar para a busca por sanar tal dificuldade em se inserir as TICs no ambiente escolar.

O estudo corrobora para a ideia de que a gestão escolar tem papel de suma importância na inserção das TICs no ambiente escolar, pois toda a ação que envolva a inserção das ferramentas tecnológicas requer um planejamento de ações bem definidas e analisadas de forma a oferecer a mínima probabilidade de erro. Por este motivo há a crescente necessidade de formação continuada também para gestores escolares, já que estes têm lugar chave na execução de qualquer plano que a escola venha desenvolver.

O estudo expõe o cuidado que se deve ter com os docentes, desde sua formação inicial, formação continuada, apoio da gestão escolar e dos governantes, pois para que qualquer ação escolar planejada venha a ser executada, faz-se necessário o engajamento dos professores da instituição. Diversas são as formas de se valorizar estes profissionais, contudo, colocar o docente dentro dos processos de debates e constantes mudanças que a educação venha a passar, deve ser uma ação ligada à essência da educação.

\section{REFERÊNCIAS}

ALONSO, Katia Morosov. Tecnologias da informação e comunicação e formação de professores: sobre rede e escolas. Educação \& Sociedade, Campinas, v. 29, n. 104, p.747-768, out. 2008.

COUTO, Heloisa Helena Oliveira de Magalhães. Jovens professores no contexto da 
prática e as tecnologias de informação e comunicação (TIC). Educação \& sociedade, Campinas, v. 35, n. 126, p.257-272, mar. 2014.

$\mathrm{KOCH}$, Marlene Zimmermann. As tecnologias no cotidiano escolar: uma ferramenta facilitadora no processo ensino-aprendizagem. Monografia de especialização. 2013. Universidade Federal de Santa Catarina, [s. I.], 2013.

LUCENA, Simone. Culturas digitais e tecnologias móveis na educação. Educar em Revista, Curitiba, v. 1, n. 59, pp.277-290, mar. 2016.

MARIGO, Adriana Fernandes Coimbra et al. Comunidades de aprendizagem: compartilhando experiências em algumas escolas brasileiras. Políticas Educativas, Porto Alegre, v. 3, n. 2, pp.74-89, 2010.

MORAN, José Manuel os novos espaços de atuação do professor com as tecnologias. Diálogo Educacional, Curitiba, v. 4, n. 12, p.13-21, mai/ago. 2004.

MOREIRA, A. P. LOUREIRO, Ma JOÃO; MARQUES, L. Percepções de professores e gestores de escolas Relativas aos obstáculos à integração das tic no ensino das ciências. Enseñanza de las Ciências, Aveiro, n. VII, pp. 1-5. 2005.

PRENSKY, Marc. O papel da tecnologia no ensino e na sala de aula. Conjectura, Caxias do Sul, v. 15, n. 2, pp. 201-204, jul. 2010.

PRENSKY, Marc. Não me atrapalhe, mãe - eu estou aprendendo!; como os videogames estão preparando nossos filhos para o sucesso no século XXI - e como você pode ajudar! Tradução de Lívia Bergo. São Paulo: Phorte, 2010.

RAMOS, Márcio Roberto Vieira. O uso de tecnologias em sala de aula. Ensino de Sociologia em Debate, Londrina, v. 1, n. 2, pp.1-15, jul. 2012.

SCHUHMACHER, Vera Rejane Niedersberg; ALVES FILHO, José de Pinho; SCHUHMACHER, Elcio. As barreiras da prática docente no uso das tecnologias de informação e comunicação. Ciência \& Educação (bauru), Bauru, v. 23, n. 3, pp.563576, jul. 2017. 


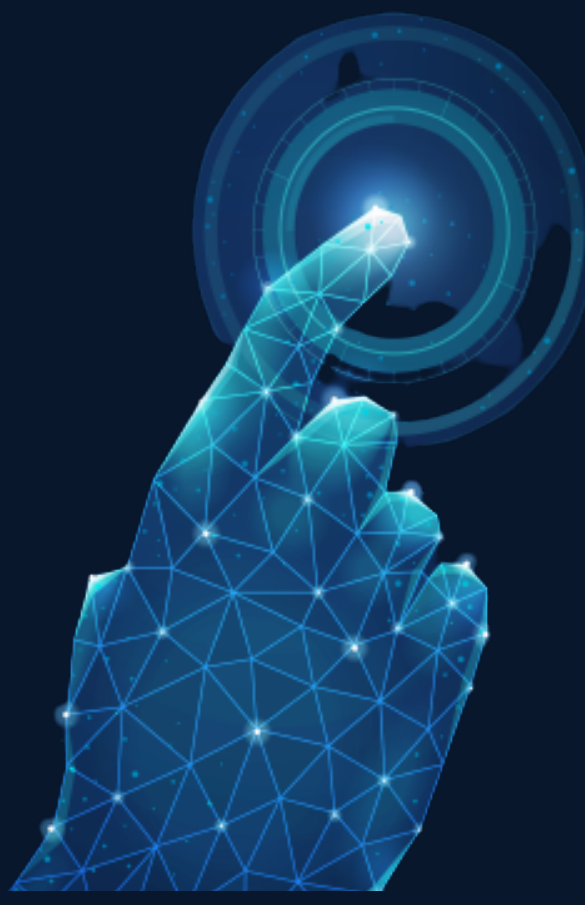

\title{
A PRÁXIS DOCENTE ON-LINE NAS ESCOLAS PÚBLICAS: PERSPECTIVAS DE EDUCAÇÃO A DISTÂNCIA MEDIANTE AO CENÁRIO DE PANDEMIA DE CORONAVÍRUS
}

\author{
Marina Cabreira Rocha de Moraes ${ }^{1}$ \\ Mari Regina Rocha Janke ${ }^{2}$
}

1 Possui graduação em Licenciatura Letras habilitação em Língua Portuguesa e Respectivas Literaturas em Língua Portuguesa pela Universidade Federal de Pelotas (UFPEL) e Especialização em Linguística Aplicada pela mesma instituição de ensino.

E-mail: ninabelmoraes@yahoo.com.br

2 Possui a primeira graduação em Possui graduação em Pedagogia pela Universidade Católica de Pelotas (UCPEL), Especialização em Psicopedagogia Institucional pela Universidade da Campanha (URCAMP) e Mestre em Ensino pelo Instituto Federal Sul Rio-Grandense (IFSUL) Campus Visconde da Graça.

E- mail: maric.rocha@yahoo.com.br 
Resumo: O presente artigo tem o intuito de refletir sobre as contribuições da Educação a Distância no contexto escolar das escolas públicas do estado do Rio Grande do Sul, diante do cenário caótico de pandemia referente ao coronavírus no Brasil. Assim, tal artigo promoverá uma discussão acerca da trajetória histórica e de implementação da Educação a Distância no Brasil e adesão a esta modalidade de ensino nas escolas públicas perante o contexto de pandemia do coronavírus vivenciado pela sociedade brasileira. Nesta perspectiva, pretende-se analisar as vantagens e desvantagens do processo do ensino-aprendizagem desta implementação de ensino a distância sobre a efetivação desta proposta nas escolas estaduais através de entrevista com professores. Diante de um contexto atípico vivenciado por professores e pelos estudantes brasileiros, a modalidade de Educação a Distância tem oportunizado a reflexão dos educadores sobre a forma de ensinar e quanto aos alunos tem exigido maior dedicação e empenho relacionado ao processo de construção de conhecimentos.

Palavras Chaves: ensino a distância; coronavírus; ensino-aprendizagem

\section{INTRODUÇÃo}

No século XXI, as Tecnologias de Informação e Comunicação (TICs) conquistam notoriedade e espaço no cenário da educação brasileira, suscitando maior divulgação de informações e de compartilhamento de conhecimentos científicos, principalmente, na modalidade de Ensino a Distância.

Por conseguinte, com a interação da sociedade brasileira à internet, o Ensino a Distância conseguiu promover a acessibilidade à educação a pessoas que vivem em áreas isoladas e precárias onde não há instituições acadêmicas a fim de prosseguir os estudos após concluir o ensino médio. Assim, a Educação a Distância (EAD) oportunizou a democratização de ensino, principalmente, a estudantes de classe social menos privilegiada devido ao fato de dispor de baixos custos com relação aos cursos e também de permitir a autonomia do aluno ao gerenciar o tempo quanto ao estudo.

Com a disseminação do coronavírus (covid-19) pelo mundo, exigiram-se medidas drásticas a serem tomadas por parte dos governantes do Brasil visando à prevenção e contenção desta doença, principalmente, a de isolamento social da população brasileira, coibindo as aglomerações em locais de circulação comum para evitar 
a transmissão do vírus. Tendo em vista, esta medida de prevenção, o Ministério da Educação, conjuntamente com as secretarias estaduais e municipais de educação, resolveram suspender as aulas presenciais nas redes públicas e privadas de ensino pelo período de março a maio de 2020 , podendo ser prorrogado como medida de segurança de proteção à saúde dos estudantes e do corpo docente.

A partir deste contexto social emergente, o Ministério da Educação decidiu dar continuidade ao processo de ensino dos estudantes através da iniciativa de adesão a modalidade de Educação a Distância. Nesse sentido, os professores estão enviando as atividades pedagógicas aos alunos através de plataformas digitais ou por grupos sociais via WhatsApp.

Partindo desse viés, este artigo tem como objetivos: analisar como o ensino a distância vem contribuindo para aprendizagem de alunos da rede estadual do município de Piratini e refletir sobre o desenvolvimento da práxis docente de duas professoras da rede estadual do município de Piratini frente ao contexto da pandemia de coronavírus.

Nesse sentido, este trabalho promoverá no primeiro tópico uma abordagem teórica sobre a trajetória histórica da Educação a Distância e do surgimento do coronavírus no Brasil. Já no segundo tópico, será apresentada a pesquisa desenvolvida acerca das contribuições do ensino a distância em uma escola estadual do ensino regular do município de Piratini. Por fim, as considerações finais sobre a relevância do ensino a distância frente ao cenário caótico de pandemia.

\section{A TRAJETÓRIA hISTÓRICA, POLÍTICA E SOCIAL DA EDUCAÇÃo A DISTÂNCIA NO BRASIL}

No século XX, a primeira experiência remota de registro de implementação da Educação a Distância no Brasil surgiu através do anúncio de curso de datilografia ofertado por correspondência nos classificados do Jornal Brasil em 1904, segundo Junge (2019).

Já em 1923, no Rio de Janeiro, de acordo com Junge (2019), iniciativas privadas de Educação a Distância foram sendo desenvolvidas por via Rádio através de programas instrutivos com aulas de Português, Literatura Francesa, Silvicultura, Esperanto, Radiotelegrafia e Telefonia. 
Posteriormente, com surgimento de cursos profissionalizantes por correspondência por intermédio dos Correios, institucionaliza a Educação a Distância como ensino formal, assim, o aluno recebia o material impresso através dos Correios, como destaca Almeida (2010, p. 1):

Nas últimas décadas do século XIX, a educação a distância tomou um novo
impulso com o uso das tecnologias tradicionais de comunicação como o rádio
e a televisão associados aos materiais impressos enviados pelo correio, o
que favoreceu a disseminação e a democratização do acesso à educação em
diferentes níveis, permitindo atender a grande massa de alunos. Nessa abor-
dagem, os centros de ensino e produção emitem as informações de maneira
uniforme para todos os alunos, os quais recebem as produções dos emisso-
res, estudam os conceitos recebidos, realizam os exercícios propostos e os
remetem aos órgãos responsáveis pelo curso para avaliação e emissão de
novos módulos de conteúdo.

Dessa forma, o aluno realizava atividades propostas e mandava-as para serem avaliadas. Este ensino formal oportunizou maior acessibilidade às pessoas que viviam em regiões afastadas dos grandes centros urbanos, formando diferentes profissionais como mecânico, eletricista, costureira, padeiro, cabelereiro, entre outros.

Em 1974, com o surgimento do Instituto Padre Réus oportunizou um novo avanço ao Ensino a Distância, ofertando cursos de formação continuada das antigas $5^{\circ} \mathrm{e}$ $8^{\circ}$ séries (atualmente $6^{\circ}$ e $9^{\circ}$ anos), na televisão do Ceará. Segundo Junge (2019), este instituto utilizava videoaulas, dispunha de material impresso e monitores para auxiliar os estudantes. Esta iniciativa pioneira contribuiu para o surgimento do Telecurso 2000, no qual desenvolveu atividades pedagógicas modernas com videoaulas na Televisão e também com recursos de material impresso, não só formando diferentes profissionais como oportunizando a continuidade dos estudos na modalidade da Educação Básica.

Outro marco importante da década de 1970 foi a instucionalização da Universidade de Brasília (UNB), atuando como entidade de ensino superior em Educação a Distância, ofertando cursos à distância através de jornais e revistas.

Ao percorrer esta trajetória de muitas lutas e conquistas, a Educação a Distância (EAD) foi regulamentada como modalidade de ensino por meio da Lei de Diretrizes e Bases da Educação (LDB, Lei n. 9.394/96), consolidada a partir do reconhecimento do governo perante esta modalidade de ensino podendo ser ofertados cursos em EAD nas instituições públicas ou privadas de ensino. Nesse sentido, 
conforme o documento LDB (Brasil, 1996, p. 9), " Art.80. O Poder Público incentivará o desenvolvimento e a veiculação de programas de ensino a distância, em todos os níveis e modalidades de ensino, e de educação continuada.

Partindo deste viés, a Educação a Distância promoveu a democratização tanto na modalidade Básica quanto no nível Superior de Ensino para muitos brasileiros que não tiveram a oportunidade de concluir o processo formal de ensino devido à falta de recursos financeiros e também da falta de universidades nas regiões isoladas no Brasil.

\subsection{O PROCESSO DE ENSINO-APRENDIZAGEM EM EAD}

A Educação a Distância rompe com o paradigma tradicional de ensino presencial em sala de aula, onde o professor é o protagonista central transmissor de conhecimento, redefinindo as novas perspectivas de ensino-aprendizagem em que há interação conjunta de Tecnologia da Informação e Comunicação, professor, tutor, aluno e classe para (re)construir conhecimentos, como aborda no relato/parecer sobre a aprendizagem em EAD conforme Gouveia e Bizzo à Câmara de Educação Básica/CNE (2002, p. 10):

[...] que a aprendizagem em EAD é possível por intermédio dos meios de comunicação, não ocorre sem uma relação estreita entre os vários protagonistas do processo, evidenciando que a participação e a interação entre os alunos e entre alunos, professores e tecnologias em uso são essenciais tanto na educação presencial quanto na educação na distância.

Assim, EAD efetiva-se a partir das TICs por meio de recursos telemáticos, em que o aluno tem acesso às videoaulas, conferências, fórum, bate-papos por meio de uma plataforma virtual disponível pela instituição de ensino. Por conseguinte, o aluno interage com estes recursos tecnológicos e conta também com o auxílio do tutor para orientá-lo e ajudá-lo em suas dúvidas. Neste processo, o professor elabora os materiais de estudo, promovendo as estratégias de ensino, sendo o papel do professor em EAD de propiciar preparação dos conteúdos e atividades, mediando à interação do ensino com o aluno por videoaulas, fórum e bate-papos.

Além disso, atualmente, há os grupos de WhatsApp em que o aluno interage com os colegas de diferentes localidades trocando ideias, experiências e aprendizagem de conteúdos, contando com auxílio também do tutor e da equipe técnica da 
instituição.

Com uso do ambiente virtual, o estudante desenvolve as competências e habilidades argumentativa, dedutiva, interpretativa e a escrita no momento de expressar-se sobre os conteúdos, as leituras, ao relacionar os textos e ideias, segundo afirma Almeida (2010, p. 2):

Participar de um ambiente virtual significa atuar nesse ambiente, expressar pensamentos, tomar decisões, dialogar, trocar informações e experiências e produzir conhecimento. Cada pessoa busca as informações que lhe são mais pertinentes, internaliza-as, apropria-se delas e as transforma em uma nova representação, ao mesmo tempo que transforma-se e volta a agir no grupo transformado e transformando o grupo.

Partindo desse respaldo, o aluno que opta em realizar um curso de ensino a distância, acaba sendo responsável em organizar seu horário de estudo, cumprir as atividades interativas e as produções textuais avaliativas, buscando auxílio do tutor para o esclarecimento de dúvidas quando necessário, como destaca Junge (2019, p. 77):

Por outro lado, ao estudar a distância, você é responsável pelos seus horários, pelo local de seus estudos e pelo esforço que vai colocar no cumprimento das suas tarefas e objetivos. Uma instituição que disponibiliza cursos na modalidade a distância, certamente tem professores e tutores a sua disposição para responder aos questionamentos e auxiliar na compreensão do material. Mas, ao contrário do que acontece em um curso presencial, eles não estarão ativamente cobrando o seu empenho e dedicação ao cumprimento das tarefas.

Embora, o aluno tenha maior autonomia e autodidatismo em gerenciar os seus estudos em EAD, por outro lado, segundo Junge (2019), não há o acompanhamento, a cobrança e exigência do professor em desenvolver as atividades na modalidade presencial de ensino. Dessa forma, requerem do aluno na modalidade EAD maior comprometimento, responsabilidade de realização e conclusão das atividades propostas pelo curso.

\subsection{A REPERCUSSÃO DA PANDEMIA DO COVID-19 NA FORMAÇÃO DOS ES- TUDANTES BRASILEIROS}

O ano de 2020 foi marcado com a notícia do aparecimento de um novo vírus, o coronavírus, aterrorizando a população mundial. Tal vírus surgiu na China primeiramente em Wuhan, na província de Hubei, no mercado público de frutos do mar e de 
animais vivos.

Sendo que no dia trinta de janeiro deste respectivo ano, a Organização Mundial da Saúde (OMS) decretou situação de surto e de emergência pública alertando os demais países sobre o ameaça desta doença. Por ser uma doença de fácil disseminação e transmissão, os países adotaram a medida de prevenção de isolamento social para evitar a transmissão e como forma de prevenção contra o vírus.

O coronavírus se lastrou para os outros países, pois é transmitido por gotículas, ocasionando sintomas de febre alta, tosse, dor de garganta, debilitando o sistema respiratório, podendo evoluir para o quadro clínico de pneumonia e acarretar a morte. Conforme aborda o documento científico de infectologia relatado por Sáfide (2020, p.3) a forma de transmissão do covid-19, ' [...] parece ocorrer principalmente pelo contato com uma pessoa infectada, através de gotículas respiratórias geradas quando a pessoa tosse, espirra, ou por gotículas de saliva ou secreção nasal".

Ainda os cientistas não encontraram um medicamento específico para o tratamento do coronavírus. Assim, as pessoas que apresentam quadro leve da doença são orientados a permanecer em casa em isolamento domiciliar, sendo medicados e acompanhados por atendimento médico em casa.

Segundo dados do documento científico (2020), os grupos de risco de pessoas são os idosos acima de 60 anos e pessoas com co-morbidade, ou seja, pessoas que apresentam problemas cardíacos, pressão alta, diabetes, câncer, asma e outras doenças respiratórias.

Dentre as formas de prevenção desta doença segundo o documento científico de infectologia relatado por Sáfide $(2020$, p. 8) são:

- Lavar as mãos frequentemente com água e sabonete por pelo menos 20 segundos, respeitando os 5 momentos de higienização. Se não houver água e sabonete, usar um desinfetante para as mãos à base de álcool;

- Evitar tocar nos olhos, nariz e boca com as mãos não lavadas;

- Evitar contato próximo com pessoas doentes;

- Ficar em casa quando estiver doente;

- Cobrir boca e nariz ao tossir ou espirrar com um lenço de papel e jogar no lixo;

- Limpar e desinfetar objetos e superfícies tocados com frequência. 
Tendo em vista essas medidas de prevenção acerca do perigo de transmissão do covid-19, o governador do Rio Grande do Sul, Eduardo Leite, baixou o Decreto $n^{\circ} 55.118$ que estabelece a suspensão das aulas nas escolas estaduais a partir do dia vinte três de março ao período até trinta de abril, podendo ser prorrogado por mais tempo devido à necessidade de prevenção de combate contra a doença. Dessa forma, a fim de dar continuidade ao processo de formação dos estudantes gaúchos, o governo em conformidade com o Ministério da Educação adota a Educação a Distância através de plataformas virtuais e também grupos de WhatsApp.

O governo gaúcho está dando suporte pedagógico aos educadores, oferecendo materiais de estudo e cursos de formação continuada sobre o Currículo de Referência do Estado do Rio Grande do Sul.

Nesse sentido, tantos os alunos como os professores estão se adaptando a esta nova modalidade de ensino, sendo um desafio a ser enfrentado na rotina de vida dos estudantes e educadores gaúchos.

\section{METODOLOGIA}

Será adotada, para o desenvolvimento da investigação, a metodologia qualitativa, pois a mesma tem ganhado um olhar especial principalmente na área educacional e conforme Triviños (1987, pg. 116) "o ensino sempre se caracterizou pelo destaque de sua realidade qualitativa".

Esse tipo de pesquisa torna-se compreensível à natureza das relações desse meio, pois em se tratando de educação devem-se levar em consideração as formas de interação, a exemplo desta com delineamento de estudo de caso, visto que dificultaria em uma pesquisa baseada em fontes quantitativa ou exposta a uma criteriosa $e$ metódica experimentação em laboratório, herança do modelo positivista, acometida a ciência.

Triviños (1987) expõe que a abordagem qualitativa em uma pesquisa, exige que o pesquisador tenha um conhecimento aprofundado da realidade que Ihe servirá de contexto no delineamento do estudo, permitindo sobremaneira, certa flexibilidade quanto à formulação e/ou reformulação das hipóteses à medida que se realiza a pesquisa, sem, no entanto, não perder o caráter de uma observação cuidadosa. 
Para maior elucidação dos procedimentos, de acordo com André "os estudos de caso pretendem retratar o idiossincrático e o particular como legítimos em si mesmos" (1998, p. 52).

Corrobora-se, também, com Triviños (1987, p.133) quando conceitua o estudo como "uma categoria de pesquisa cujo objeto é uma unidade que se analisa profundamente".

Este trabalho teve como base pesquisa qualitativa do tipo estudo de caso envolvendo duas professoras que lecionam Didáticas e Fundamentos da Educação no Instituto Estadual de Educação Ponche Verde, da zona urbana, no município de Piratini.

A professora R. tem graduação em Pedagogia pela Universidade Federal de Pelotas e Especialização em Educação pela Universidade do Rio Grande. Ela atua há vinte e três anos como docente do curso Normal nível médio e também Ensino Médio da etapa da Educação Básica.

A professora M. tem graduação em Pedagogia pela Universidade Católica de Pelotas, especialização em Psicopedagogia Institucional pela Universidade da Região da Campanha em Bagé e Educação Inclusiva pela Universidade Leonardo da Vinci e Mestrado em Ensino pelo Instituto Federal Sul- Riograndense de Pelotas campus Visconde da Graça. Ela atua há sete anos como docente no curso Normal nível médio e também Ensino Médio da etapa da Educação Básica.

A pesquisa foi aplicada no período de abril do ano dois mil e vinte através de entrevista estruturada. Assim, a pesquisadora realizou cinco perguntas de forma aberta na qual as docentes poderiam responder com ampla autenticidade e autonomia com relação às indagações. 


\subsection{ANÁLISE DOS DADOS}

1. O que mudou acerca do trabalho docente com relação à modalidade de ensino a Distância?

Professora M: Mudou toda a perspectiva do trabalho docente no qual vinha desenvolvendo, teve que se reinventar na questão de postura e de metodologia, buscando trabalhar com mais mídias e recursos tecnológicos.

Professora R: Mudou praticamente tudo, de repente passamos a trabalhar com tecnologias pouco usuais na nossa ação o que deixa apreensivos e inseguros na prática pedagógica. Trabalhamos quase vinte quatro horas por dia, organizando os materiais e atendendo os alunos.

2. Quantas vezes na semana são enviados os conteúdos e atividades aos alunos?

Professora M: Todos os dias previstos em minhas aulas os conteúdos são enviados, durante quatro vezes na semana, envio atividades de leitura, links para vídeos sobre o conteúdo trabalhado e cobro produção textual.

Professora R: Eu cumpro a carga horária semanal expressa na matriz curricular.

3. Como educadora, qual é o seu ponto de vista com relação ao retorno da aprendizagem ou o feedback dos alunos?

Professora M: Até o momento os alunos têm interagindo muito bem, fazendo esse retorno das atividades, bem como, tirando suas dúvidas.

Professora R: Nas aulas on-line, ela encaminha assuntos e informações que serão retomados após o retorno das aulas presenciais, no entanto, as aulas on-line não têm a mesma qualidade esperada como as aulas presenciais.

4. Se a maioria dos alunos tem acesso às Tecnologias da Comunicação e Informação (TICs)? Quais os recursos mais utilizados?

Professora M.: Sim, todos têm acesso, mas a preocupação é a qualidade de internet que disponibilizam, pois algumas dos dados móveis são poucos, o que dificulta o acesso aos vídeos das aulas.

Professora R.: Sim e que desconhece realidade das demais instituições e que a escola na qual trabalha optou por este recurso por ser mais acessível a todos os alunos.

5. A partir deste cenário atual de pandemia do covid-19, quais são as tuas considerações positivas e negativas sobre o ensino a distância?

Professora M.: Aspectos positivos são em rever valores dos quais não paramos para pensar, exemplo, a importância de estarmos no coletivo. Já o ponto negativo é a aprendizagem real dos alunos, fico me questionando se estão aprendendo, pois nenhuma ferramenta substitui a presença de um professor.

Professora R.: Os aspectos positivos é a capacidade de se reinventar que a escola tem me encantado, além da superação e comprometimento da maioria dos profissionais. Já os aspectos negativos a falta de vínculos com o aluno dificultam a motivação e a aprendizagem.

Após a entrevista com as educadoras, analisou-se que as respostas de ambas são afins com relação aos questionamentos. No primeiro questionamento sobre o que mudou acerca do trabalho docente com relação à modalidade de ensino a Distância, ambas concordaram que houve uma mudança significativa acerca a práxis 
docente, pois tiveram que aderir às novas tecnologias para interagir com os alunos além de reinventar-se como educadoras, buscando atualizar-se com relação ao utilizar vídeos, links e textos interativos em suas propostas de atividades.

Com relação ao segundo questionamento acerca de quantas vezes na semana são enviados os conteúdos e atividades aos alunos, as educadoras responderam que enviam as atividades de acordo com os dias da semana que trabalham, por exemplo, se lecionam duas vezes na semana a disciplina de Didática da Linguagem, elas mandam duas propostas de atividades aos alunos durante a semana via WhatsApp. Nesse sentido, as educadoras devem seguir a matriz curricular da escola.

$\mathrm{Na}$ terceira pergunta, ambas abordaram percepções divergentes com relação ao retorno da aprendizagem ou do feedback dos alunos, a professora $\mathrm{M}$. acredita que a maioria dos alunos estão apresentando um retorno positivo a respeito da aprendizagem, eles solicitam a educadora quando precisam esclarecer dúvidas e apresentam as atividades de acordo com prazo solicitado pela professora.

A professora R. faz uma apreciação comparativa entre as aulas on-line e presenciais, considerando que os alunos não apresentam o mesmo retorno de aprendizagem com relação as aulas presenciais. Salienta ainda que as atividades e informações propostas nas aulas on-line serão retomadas nas aulas presenciais.

Já na terceira pergunta, as educadoras afirmaram que todos os alunos dispõem de acesso as Tecnologias da Informação e da Comunicação, sendo que a instituição de ensino que trabalham optaram pelo aplicativo WhatsApp por ser um recurso acessível a todos os alunos. No entanto, a professora M. destacou que se preocupa com a qualidade da internet, pois alguns alunos têm dificuldade de carregar os vídeos devido à precariedade da oferta da internet.

Com relação à última pergunta sobre as considerações positivas e negativas acerca do ensino a distância, as professoras destacaram como aspecto positivo a capacidade de reinventar a práxis docente, aderindo a novos valores dantes não desempenhados, como por exemplo, propostas de atividades com vídeos e pesquisa de informações em links. Além disso, a professora M. ressalta a importância de pensar no coletivo, numa situação atípica vivenciada pela sociedade brasileira, portanto, o isolamento social, neste momento, é uma forma de prevenção de zelar pela vida dos alunos. Já a professora R. ressalta, ainda, como ponto positivo o comprometimento 
e a superação dos profissionais da educação com a instituição de ensino diante do contexto de coronavírus.

Nas considerações negativas acerca ao ensino a distância, as educadoras ressaltaram a falta de vínculos com os alunos, repercutindo diretamente na aprendizagem dos educandos. Acrescido a isso, a professora R. salienta a falta de motivação dos alunos como aspecto negativo.

\section{CONSIDERAÇÕES FINAIS}

A trajetória de implementação da Educação a Distância no Brasil passou por um percurso de impasses e redescobertas, primeiramente com aulas de datilografia por correspondência, posteriormente, com aulas on-line via rádio a cursos profissionalizantes por intermédio dos Correios e por fim com regulamentação da modalidade de ensino subsidiadas por instituições privadas ou públicas respaldada na Lei de Diretrizes de Bases da Educação (LDB).

A partir da situação de pandemia coronavírus, as escolas públicas estaduais, municipais e privadas passam por significativas mudanças na estrutura de ensino presencial, assim, aderem à modalidade de ensino distância com a finalidade de dar continuidade ao processo formal de ensino aos estudantes brasileiros. Dessa forma, os professores acabam adaptando-se ao sistema de ensino a distância por meio a plataformas digitais ou pelo aplicativo WhatsApp, atualizando-se por cursos de formação sobre recursos tecnológicos e, por conseguinte, redefinindo novas perspectivas de propostas pedagógicas para o ensino-aprendizagem dos alunos via on-line.

\section{REFERÊNCIAS}

ALMEIDA, Maria Elizabeth B. Artigo: Educação à distância no Brasil: diretrizes, políticas, fundamentos e práticas, 2010. Disponível em: < https://scholar.google.com.br/ scholar?hl=pt-BR\&as sdt $=2005 \&$ sciodt $=0 \% 2 C 5 \&$ cites $=30314727316418869 \&$ scips $\mathrm{c}=\& \mathrm{q}=$ Educa $\% \mathrm{C3} \% \mathrm{~A} 7 \% \mathrm{C} 3 \% \mathrm{~A} 3 \mathrm{o}+\% \mathrm{C} 3 \% \mathrm{~A} 0+$ dist $\% \mathrm{C} 3 \% \mathrm{~A} 2 \mathrm{ncia}+\mathrm{no}+\mathrm{Brasil} \% 3 \mathrm{~A}+\mathrm{di}-$ retrizes+pol\%C3\%ADticas $\% 2 \mathrm{C}+$ fundamentos $+\mathrm{e}+\mathrm{pr} \% \mathrm{C} 3 \% \mathrm{~A} 1$ ticas $+\& b \operatorname{bthG}=>$. Acessado em 25/04/2020.

ANDRÉ, M.E.D.A. Etnografia da prática escolar. 2. ed. São Paulo: Papirus, 1998. BALL, S.J. Educational reform: a critical and post-structural approach. Buckingham: Open University Press, 1994. 
BRASIL. Lei $\mathrm{n}^{\circ}$. 9.394, de 20 de dezembro de 1996. Estabelece as diretrizes e bases da educação nacional. Brasília, DF, 1996. Disponível em: < http://legis.senado. leg.br/legislacao/ListaPublicacoes.action?id=102480\&tipoDocument o=LEI\&tipoTexto=PUB >. Brasília: Ministério da Educação, 1996. Acesso em 20/04/2020.

Conselho Nacional de Educação, MEC. Câmara de Educação Básica (2002). Diretrizes Nacionais para a Educação a Distância no âmbito da Educação Básica. Relatores: Gouveia, S F. \& Bizzo, N. M. V. CNE/MEC.

Estado do Rio Grande do Sul. DECRETO N 55.118, DE 16 DE MARÇO DE 2020. (publicado no DOE n. ${ }^{\circ}$ 53, de 17 de março de 2020), disponível em: < https://anajure. org.br/wp-content/uploads/2020/04/rs-decreto-estadual-n-55-118-16-03-2020.pdf>. Acessado em 04/04/ 2020.

JUNGE, Débora de L. V. Produção de materiais autoinstrutivos para a EAD. Indaial: UNIASSELVI, 2019.

Sociedade Brasileira de Pediatria. Documento Científico de Infectologia Novo Covid-19. Marco Aurélio Palazzi Sáfadi (Relator), 2019-2020. Disponível em: <https:// www.sbp.com.br/fileadmin/user_upload/22340d-DocCientifico___Novo_coronavirus. pdf>. Acessado em 05/04/2020.

TRIVIÑOS, Augusto N. S. Introdução à Pesquisa em Ciências Sociais: a Pesquisa Qualitativa em Educação. São Paulo: Atlas, 1987. 


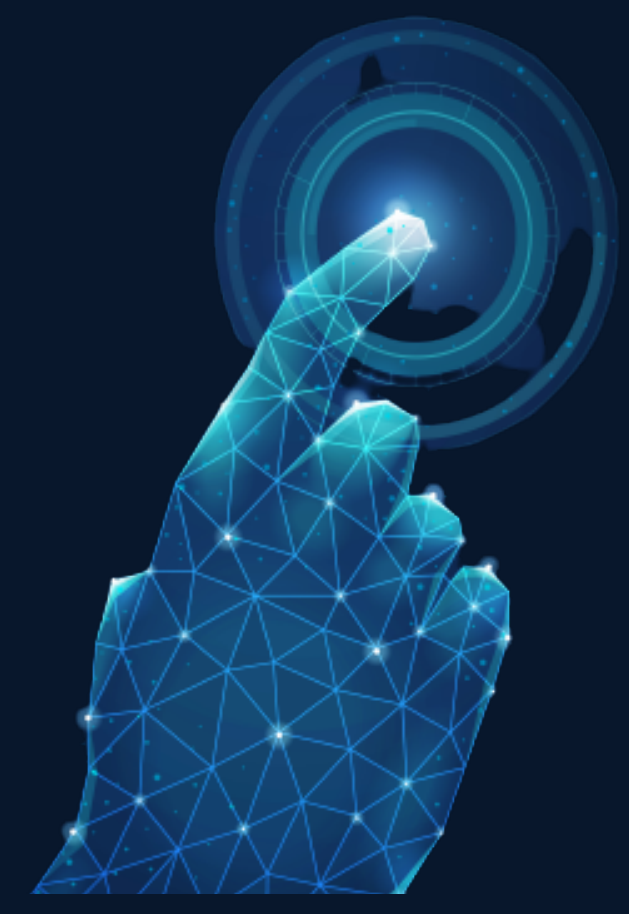

\section{O HIPERTEXTO E AS NOVAS POSSIBILIDADES DE LEITURA}

Luciana Oliveira Atanásio 1

1 Mestra em Linguística- UFPI. Professora IFMA, campus Codó

\section{8}


O processo mais acelerado de Globalização que vem ocorrendo do final do século XX aos dias atuais não modificou apenas as relações econômicas e políticas, interferiu também nas estruturas e relações sociais com a valorização cada vez maior das inovações tecnológicas verificáveis nas novas maneiras de interação e integração entre as pessoas com o advento da tecnologia digital.

Sobre a prática textual, a inserção do computador no processo de comunicação permitiu a criação de uma nova forma de construção textual marcada por características que alteram significativamente a natureza do texto na tela: a interatividade e a hipermodalidade. Nesse novo ambiente, cabe ao leitor escolher seu percurso de leitura entre os diferentes links e construir a coesão e a coerência entre os segmentos textuais acessados.

O advento da informática digital permitiu que a leitura e a escrita enquanto prática social amplie seus significados à medida que ganha novos suportes tecnológicos. Na era da cibercultura o texto se amplia e ganha nova forma, surge o hipertexto. Este, segundo Lévy (2004):

É um conjunto de nós por conexões. Os nós podem ser palavras, páginas, imagens, gráficos, ou parte de gráficos, sequências sonoras, documentos complexos que eles mesmos podem ser hipertextos. Navegar em um hipertexto significa, portanto, desenhar um percurso em uma rede que pode ser tão complicada quanto possível. Porque cada nó pode por sua vez, conter uma rede inteira.» (LÉVY, 2004 p.33)

Isso traz a ideia da leitura hipertextual| ${ }^{1}$ como um campo que remete a diversas possibilidades de leitura. A nova forma de organizar o texto permite ao leitor formas não-lineares de interação, existindo diferenças marcantes em relação à leitura e a hiperleitura. Basta ressaltar que o hipertexto é composto por links, ou seja, verdadeiros nós, que exigem do leitor-navegador fazer escolhas e também "determinar tanto à ordem de acesso aos diferentes segmentos disponibilizados no hipertexto, quanto o eixo coesivo que confere um sentido global ao texto lido" (BRAGA, 2010.p.177). Isso

$1 \quad$ Nesse trabalho, por motivos didáticos, foca-se a leitura hipertextual feita nos meios eletrônicos. Para saber mais sobre a amplitude do hipertexto em textos impressos, consultar: Gomes, Luis Fernando Gomes. Hipertextos multimodais- leitura e escrita na era digital. Jundiaí, Paco Editorial, 2010. Neste trabalho o autor discorre sobre os conceitos de hipertexto em meio impresso e digital. 
faz com que o caminho da leitura se torne menos linear que no texto impresso.

Os diversos conceitos sobre hipertexto traduzem a dimensão da importância e da amplitude dos estudos sobre esse, sendo que tais conceitos tentam abranger a interrelação entre como se configura o hipertexto no ciberespaço e a infinidade de possibilidades de leitura de mundo nas mais diversas perspectivas do conhecimento. Dessa forma é importante se desenvolver uma reflexão teórica sobre e relação texto-leitor considerando-se o contexto atual de acesso ao espaço cibernético como um novo espaço de relacionamento entre as pessoas, pressupondo-se mudanças culturais, preparo tecnológico e, sobretudo um desejo de interagir com o universo imensurável de pessoas, possibilitando o acesso ao conhecimento através de recursos hipertextuais:

Ao analisar os estudos feitos por Lemke (2002), Braga afirma que:

(...) o que difere o texto impresso do hipertexto não é apenas a diferença tecnológica (...) mas sim o fato de, em primeiro lugar, a rede de conexões do hipertexto ativar a nossa expectativa de que haverá links atrelados aos diferentes segmentos textuais e em segundo lugar, a interação entre estes segmentos não ser orientada por uma seqüência padrão pré-estabelecida, que pode ser observada ou não pelo leitor. (BRAGA, 2010.p.179).

É importante ter uma compreensão dos recursos de interatividade que caracterizam todo hipertexto, como nova forma de construção textual. Para isso é necessário considerar-se o contexto tecnológico que propiciou o seu surgimento "O desenvolvimento dos recursos técnicos permitiu que o computador passasse a ser utilizado como uma ferramenta excepcionalmente eficiente para estocar e recuperar diferentes tipos de informação" (BRAGA, 2004.p.146). Para a autora:

A possibilidade de interconexão entre diferentes máquinas viabilizada parcialmente pela criação de linguagens técnicas como html (...) aumentou exponecialmente a fonte de consultas disponível para o usuário. Com o advento da internet, esse conjunto de arquivos (...) passou a ser potencialmente infinito no contexto da rede mundial de computadores (WWW). (BRAGA, 2010.p.178).

Sobre a organização estrutural do hipertexto é importante lembrar que de acordo com teóricos Burbules e Callister (2000) apud Braga (2010), não existe disparidade total em relação à organização de um texto convencional, pelo contrário, através da tela de um computador, o hipertexto amplia todas as estruturas textuais e físicas 
de um texto convencional.

A organização estrutural do hipertexto recupera e expande formas de relações inter e intratextuais já explorados nos textos impressos, principalmente os de natureza acadêmica. Os recursos de escrita, como por exemplo, as notas de rodapé, as referências feitas a outros textos ou as conexões explicitamente indicadas - que convidam o leitor a adiantar ou a voltar atrás na leitura de um texto específico - desempenham uma função próxima daquela a ser preenchida pelos links digitais. (BRAGA, 2010.p.178).

Não se pode esquecer que a interação com o hipertexto demanda a participação ativa do leitor, além das escolhas de caminho, exige a participação do leitor na construção da coesão e coerência geral entre diferentes segmentos textuais acessados pelo leitor, pois: "o texto não sendo mais apresentado como "todo" que tem começo, meio e fim, exigem que o usuário durante sua leitura explore o conjunto de opções disponibilizadas pelos links e construa uma conexão coerente entre elas" (BRAGA,2010.p.181).

Outra peculiaridade do hipertexto é a pluritextualidade, denominada por alguns autores também de multisemiose, nas palavras de Xavier (2010). Num ambiente intersemiótico como o hipertexto, o ato de ler e compreender se viabiliza com muito mais totalidade, pois o usuário é beneficiado pela convergência das interfaces comunicacionais, contribuindo para fazer fluir a compreensão do mesmo, sendo que a pluritextualidade:

É uma novidade fascinante do hipertexto por viabilizar a absorção de diferentes aportes sígnicos numa mesma superfície de leitura, tais como palavras, ícones animados, efeitos sonoros, diagramas e tabelas tridimensionais. A fusão dos diversos recursos das várias linguagens numa só tela de computador acessíveis e utilizáveis simultaneamente em um mesmo ato de leitura provoca um construtivo, embora volumoso impacto perceptual - cognitivo no processamento da leitura. (XAVIER, 2010, p.207).

É claro que nem tudo sobre o hipertexto é considerado positivo. Uma das consequências da modalidade hipertextual de leitura seria, para alguns, o risco provocado pelo excesso de informação. "Essa superabundância do ato de ler redundaria inevitavelmente no afogamento, na asfixia do leitor no oceano da informação". (XAVIER, 2010, p.207). 


\section{A LEITURA HIPERTEXTUAL}

A leitura é um processo intrinsecamente ligado à escrita, faz parte das conquistas da espécie humana em seu processo evolutivo, até porque a plenitude da razão está vinculada ao acúmulo de observações que são passadas através da palavra oral ou escrita.

Pensar a leitura não é pensar apenas o ato de decodificação da palavra escrita. Sabe-se que o processo de ler é bastante complexo, a própria concepção de leitura varia de acordo com a teoria a que se recorre. O indivíduo quando lê precisa necessariamente dar sentido aquilo que leu (em um sentido mais restrito) senão não há objetivos alcançados.

Koch (2006) defende uma concepção de leitura numa perspectiva interacionista em que a relação texto e sujeito é construída pela interação, pois o sentido do texto só existe dentro da mesma. Sendo assim:

A leitura é, pois uma atividade interativa altamente complexa de produção de sentidos, que se realiza evidentemente com base nos elementos lingüísticos presentes na superfície textual e na sua formação de organização, mais requer a mobilização de um vasto conjunto de saberes no interior do evento comunicativo $(\mathrm{KOCH}, 2006, \mathrm{p} .11)$

Orlandi trata a leitura numa perspectiva do discurso o que ajuda a entender o quanto o conceito de leitura é mútuo e complexo. Nesse sentindo, a prática da leitura é um produto no qual é preciso levar em consideração os fatores que constituem as suas condições de produção: "A leitura é o momento crítico da constituição de um texto, pois é o momento privilegiado do processo da interação verbal: aqueles em que os interlocutores, ao se identificarem como os interlocutores, desencadeiam o processo de significação". (ORLANDI, 1983, p.47)

Nessa perspectiva, Kleiman (2000) desenvolveu um estudo sobre a relação texto-leitor ressaltando principalmente os aspectos cognitivos da leitura. Segundo esta: "a compreensão de um texto é um processo que se caracteriza pela utilização de conhecimento prévio: o leitor utiliza na leitura o que ele já sabe: o conhecimento adquirido ao logo de sua vida". (KLEIMAN, 2000, p.13). A leitura é considerada como um processo interativo por isso é necessário à interação de diversos níveis de conhecimento que segundo a autora é: o conhecimento lingüístico, o conhecimento textual, 
o conhecimento de mundo ou o conhecimento enciclopédico. Tais conhecimentos se integram e se interligam dando progressão e significado à leitura a partir de um "esquema" que todo leitor possui:

O esquema é o conhecimento parcial, estruturado que temos na memória sobre assuntos, situações, eventos típicos de nossa cultura(...). O esquema nos permite economia e seletividade na codificação de nossas experiências, isto é, no uso das palavras com as quais tentamos descrever para outro nossas experiências (KLEMAN, 2000, p.23).

Todos esses conhecimentos devem ser ativados durante a leitura para se poder chegar à situação de compreensão, eles são importantes porque fornecem e sugerem caminhos mas, certamente não explicitam tudo o que seria possível explicitar.

No contexto da cibercultura, Levy (2004) traz o significado do mundo marcado pela interatividade, a leitura também é compreendida como um processo interativo, ou seja, condensa ao mesmo tempo diversos níveis do conhecimento. Além disso, com o advento da internet surgiu novos textos com texturas complexas, exigindo um novo perfil de leitor: aquele que deve inserir ao seu conhecimento linguístico, textual e enciclopédico - o conhecimento virtual.

(...) A partir dos diversos suportes eletrônicos e dos novos gêneros textuais que surgem na era da internet, o ato de ler assume novos rumos e os leitores parecem atônitos diante de tantas informações no universo digital (...). O trabalho com esses "novos textos de texturas complexas" exige um leitor, familiarizado com a articulação de diferentes linguagens na composição do texto eletrônico, bem como decodificador capaz de perceber as redes de conexões intra e intertextuais, que sobrepõem na tessitura do hipertexto (SILVA, 2005, p.76-77).

Percebe-se que a leitura através da tela exige um conhecimento prévio tanto da realidade que se rodeia como também das novas linguagens que compõem o hipertexto.

A maneira como o leitor reage diante da leitura, a reader's response, segundo Chartier (2001) também é responsável pela maneira como a leitura se desenvolve no meio virtual, proporcionando uma leitura revolucionária ligada ao cotidiano das pessoas num processo de interiorização de aspectos sociais do indivíduo que se expressa através da interação com o mundo virtual.

Chartier (2001) também aponta três diferenças na leitura em ambiente virtual: A primeira é escrever no texto: consiste em poder modificar o enunciado do texto ou 
apagá-lo "existe a possibilidade de submeter o texto recebido às decisões próprias do leitor para cortar, deslocar, mudar a ordem, introduzir sua própria escrita, etc. Podendo-se escrever no texto ou reescrevê-lo" Chartier (2001, p.145). No hipertexto, devido à maior possibilidade de manuseio do texto, o leitor se apropria deste, apagando ainda mais a ideia de autor e de autoria ${ }^{1}$, fazendo com que o discurso que pertencia a um autor inicial se torne anônimo; ou, dando e trocando a autoria de um texto que inicialmente não pertencia a quem é dado crédito na internet. Isso possibilita, nas palavras de Xavier (2010) "a emancipação do leitor" que pode tornando-se eventualmente também autor ao deixar suas impressões no texto.

Outra diferença do texto impresso para o hipertexto é a possibilidade de simultaneidade entre o que se escreve a simultaneidade da resposta à leitura, Chartier (2001): "E é possível pensar que a produção livresca pudesse seguir o mesmo caminho e que o momento da escrita poderia ser o próprio momento da leitura, sem mediações nem mutimediadores" (CHARTIER, 2001, p.146). Tem-se como exemplo o espaço destinado aos comentários nos sites.

Quando prevalecia somente o texto impresso as críticas vinham através de revistas, jornais, compêndios ou livros sobre o tema - isso ocorria geralmente se o autor tivesse alguma relevância no meio que atuava. No espaço virtual isso acontece de forma muito rápida, pois com os blogs, por exemplo, não se precisa ser famoso para provocar "estardalhaço" ou ter seu texto veiculado em vários sites simultaneamente, basta conseguir (o que não é tão fácil como pode se pensar inicialmente) superar a gama de textos ali postados para que a notoriedade seja estabelecida.

A terceira e última grande transformação da leitura na internet é a possibilidade de construção de uma biblioteca universal com os clássicos, cânones e demais textos que puderem ser transcritos para o hipertexto na internet havendo a tendência da universalização do acesso dos textos em geral: "[...] se cada um dos textos escritos ou impressos do patrimônio textual é transformado em um texto eletrônico[...]" Chartier (2001, p.146). A leitura hipertextual instaura a estrutura da des(ordem), quando favorece a leitura não linear GOMES (2010), pois o leitor irá se focar somente naquilo

$1 \quad$ Numa visão voltada para a autoria e emancipação do leitor no hipetexto ler o artigo de Xavier: Leitura, texto e hipertexto, IN: Hipertexto e gêneros digitais: novas formas de construção de sentido, p. 216. Sobre apagamento do autor, autoria, posse e apropriação do discurso, conferir: FOUCAULT, Michel. A ordem do discurso. 7. ed. São Paulo: Loyola, 2001. e FOUCAULT, Michel. O que é um autor. Lisboa: Passagens/Vega, 2002. 
que lhe interessa: "O que parece estar dentro de um consenso geral é que e a leitura de hipertextos é diferente, ao menos em alguns aspectos da leitura de textos impressos, pois requer habilidades e estratégias de leitura específicas em meio digital". (GOMES, 2010, p.103).

Porém o outro lado dessa leitura hipertextual, como já referido anteriormente, é que se o leitor-navegador não estiver com propósitos bem estabelecidos quando ao que está lendo, se perderá na enormidade de links que se encontram no hipertexto, fugindo do foco de sua leitura.

\section{LEITURA DO MUNDO: DO TEXTO AO HIPERTEXTO}

Paulo Freire, um dos maiores estudiosos da educação que o Brasil e o mundo já conheceram, defende a ideia de que se ensina o educando a ler a partir do conhecimento vocabular do próprio educando. Nessa perspectiva o educador afirmou que "a leitura do mundo precede a leitura da palavra daí, que a posterior leitura desta não possa prescindir da continuidade da leitura daquele" (FREIRE, 1987, p.11). Isso quer dizer que não se lê palavras soltas do mundo real (do qual as palavras fazem parte) e sim, e somente, a partir delas é que a realidade tem significado para qualquer leitor.

Ao mesmo tempo em que a vivência do mundo orienta à leitura das palavras, a influência direta da leitura marca a amplitude da consciência de cada leitor em relação ao meio em que vive, ou seja, as singularidades do seu momento histórico. Dessa maneira afirma Freire: "Ler o mundo tomado como um texto universal e ler a palavra em diferentes suportes e contextos, ampliando a capacidade crítica, evitando o status de assujeitado da história, incluindo-se na sociedade do conhecimento" (FREIRE, 1987, p.25).

Numa visão paulofreiriana o indivíduo precisa ser sujeito de suas ações. Ou seja, é preciso tomar atitude para ler, ter consciência da sua importância, querer ampliar seu conhecimento, desejar novas descobertas, ampliar curiosidade e interessar-se na difusão da qual o leitor se apropria:

(...). Além de constituir-se um processo de construção de significados, pressupõem a inserção do texto no contexto e sua produção, o conhecimento do autor, seus referenciais, suas influências, seus valores suas crenças, as marcas do seu tempo. O ato de ler implica a construção de significados de textos veiculados oralmente, por escrito, em meio eletrônico, através de diferentes manifestações culturais com linguagens variadas, com identidade vinculada a 
cada suporte e a cada linguagem (ROSING,2003,p.25).

Isso quer dizer que ler é uma construção de sentidos e seja qual for o tipo de texto é preciso considerar os seus meios de produção e é através dele que se evidencia mais nitidamente as manifestações culturais e a própria identidade de cada criação textual e suas diversas formas de linguagem. "Atitudes, procedimentos, comportamentos de leitura nessa amplitude e nessa profundidade estão atrelados à decisão do leitor. São atos volitivos." (ROSING, 2003, p.25). O que quer dizer, que também as inovações tecnológicas contribuem para ampliar o potencial de interatividade dos sujeitos, sendo que as tecnologias revolucionaram o processo de transmissão e de comunicação de ideias e de sentimentos.

De acordo com Xavier (2010) a perspectiva da leitura de mundo pela palavra atualmente se amplia com a imersão de uma tecnologia de linguagem. Através desta, o espaço de apreensão de sentido não é apenas composto por palavras, na realidade o universo dos sentidos e significados "são compleximamente disponibilizados aos navegantes do oceano digital". (XAVIER 2010, p.208), pelo hipertexto.

Através do hipertexto, ler o mundo, tornou-se virtualmente possível (XAVIER, 2010) por sua natureza imaterial, ele permite ser acessado em qualquer lugar do planeta, a qualquer hora do dia e da noite e por vários leitores simultaneamente ${ }^{1}$. O hipertexto concretiza a possibilidade do seu usuário-leitor ter uma visão geral sobre as principais discussões e mais importantes questões que envolvem o ser humano na conjuntura atual. De acordo com Xavier (2010), o hipertexto possibilita um alargamento dos horizontes de qualquer leitor, onde as próprias condições físicas viabilizam isso. Para ele, o hipertexto concretiza a ideia de Paulo Freire até as últimas consequências:

A leitura do mundo, da realidade que circunscreve o leitor de Paulo Freire passa a ser profundamente alargada pelo hipertexto (...). O hipertexto reúne condições físicas de materializar a proposta paulofreiriana até as ultimas conseqüências. Se para ler / entender a palavra é necessário saber ler antes o mundo, conforme apregoava o educador, o hipertexto vem consolidar esse processo, uma vez que viabiliza multidimensionalmente a compreensão do leitor pela exploração superlativa de informações, muitas delas inacessíveis sem os recursos da hipermídia (XAVIER 2010, p.209).

1 Excetuando-se as possíveis interferências de acesso. Tome-se como exemplo as restrições a sites ou a resultados de buscas e pesquisas em meio virtual, como ocorre em Cuba e na China. 
Com a revolução do texto eletrônico, segundo Chartier (2001, p.07), a uma nova importância dada aos efeitos produzidos no leitor e a construção dos significados pelas diferenças estruturais entre o texto impresso e o virtual. No caso da leitura, a cibercultura tem imposto uma mudança de paradigmas, em que o hipertexto assume papel de destaque no mundo contemporâneo dos computadores, pois está assumindo novas funções exigindo um dinamismo maior tanto por parte dos autores como dos leitores.

Diante dessa mudança de paradigmas as relações interativas entre leitores e autores modificam-se, ajustando-se as necessidades do mundo contemporâneo. $\mathrm{Na}$ era do hipertexto, as práticas de leitura e escrita começam a sofrer mudanças significativas, alterando o comportamento dos leitores, agora chamados de navegadores, como também o perfil dos autores que desenvolvem uma autoria múltipla, compartilhada, por meio da participação ativa dos receptores (SILVA, 2005, p.73).

Dentro desse novo contexto da cibercultura o perfil do leitor deve ser de crítico e ativo, ou seja, capaz de analisar a realidade social a partir do caráter dinâmico da leitura, em que autor - texto - leitor - mundo são elementos estreitamente ligados. No universo atrativo das telas dos computadores, as visitas teoricamente ilimitadas aos sites, blogs e aos e-mails ganham destaque através do atrativo visual proporcionado pelo hipertexto.

A internet, dentro da tecnologia da linguagem, é vista como um novo espaço de interação humana, onde as configurações textuais passam por reformulações mediante a interação virtual que se utiliza de novos gêneros eletrônicos. É inquestionável que as novas possibilidades de comunicação trazem diferentes padrões de relacionamento que se caracteriza por uma nova forma de escrever e de compor textos. Temos como exemplo os chats, um meio de interação no ciberespaço que tem proporcionado uma linguagem diferente das disposições tradicionais da norma culta da língua que acaba entranhando-se no que é escrito e lido, tornando-se pertinente considerar as peculiaridades entre as manifestações verbais que incluem características dessa linguagem da era tecnológica.

Nada mais inovador que a leitura interativa proporcionada pelo mundo do ciberespaço. Nada mais interessante do que as possibilidades de leitura proporcionada pelo acesso ao hipertexto. Nada mais desafiante do que aliar o conhecimento socialmente enraigado as novas formas de ler e conhecer. 
Não existe, portanto, esconderijos para o leitor, as hiper leituras estão apostos como novas maneiras de sugestão para o conhecimento do mundo real, onde os espaços tornam-se menores para aqueles que não se dispõem para o novo. Por isso, as inovações tecnológicas, o acesso à internet e a leitura hipertextual são desafios que precisam ser considerados por aqueles que não querem fazerem e se tornarem parte das novas possibilidades de leitura proporcionas pelo hipertexto.

\section{REFERENCIAS}

BRAGA, Denise Bértoli. A comunicação interativa em ambiente hipermídia: as vantagens da hipermodalidade para o aprendizado no meio digital. IN: Hipertexto e gêneros digitais: novas formas de construção de sentido. 3 ed. São Paulo: Editora Cortez, 2010.

FREIRE, Paulo. A importância do Ato de ler. São Paulo: Editora Cortez, 1987.

GOMES, Luiz Fernando. Hipertextos multimodais: leitura e escrita na era digital. Jundiaí, Paco Editorial, 2010.

KLEIMAN, Angela. O conhecimento prévio na leitura. IN: Texto e Leitor: Aspectos cognitivos da leitura. Campinas: Pontes. $7^{\text {a }}$ edição. 2000.

$\mathrm{KOCH}$, Ingedore Villaça; ELIAS, Vanda Maria. Ler e Compreender os sentidos do texto. São Paulo: Contexto, 2006.

LÉVY, Pierre. As tecnologias da Inteligência - O futuro do pensamento na era da informática. São Paulo. Editora 34, 2004

ORLANDI, Eni Pulcinelli. A produção da leitura e suas condições. IN: Leitura: Teoria e Prática. $n$

- 1, ano 2. Porto Alegre: ABL/ Mercado Aberto, Abril de 1983.

ROGER, Chartier. AAventura do Livro. Do leitor ao Navegador. São Paulo: UNESP. 2001.

RÖSING, Tânia M.K.A [des] construção da construção. IN: Práticas Leitoras para uma cibercivilização IV: Vivencias interdisciplinares e multimidiais de leitura. Passo Fundo: UPF, 2003. 
SILVA, Ivanda Maria Martins. Leitura literária e novas tecnologias: do texto ao hipertexto, do leitor ao navegador. IN: Literatura em sala de aula: teoria literária à prática escolar. Recife:Programa de Pós - Graduação, UFPE,2005

XAVIER, Antonio Carlos: Leitura, texto e hipertexto. IN: Hipertexto e gêneros digitais: novas formas de construção de sentido. 3 ed. São Paulo: Editora Cortez, 2010 


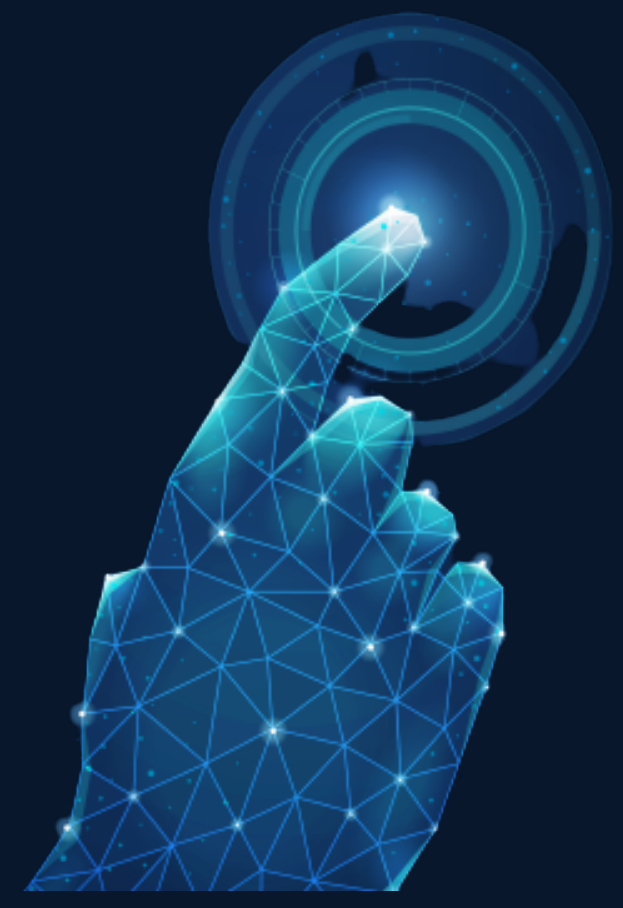

\section{O PROJETO "LITERATURA NA REDE EM TEMPOS DE COVID-19” DA SECRETARIA MUNICIPAL DE EDUCAÇÃO DE FRANCA-SP, O ENSINO REMOTO NA EDUCAÇÃO}

Ana Clara Paris Kemp ${ }^{1}$

Angélica Vieira de Souza-Lopes ${ }^{2}$

1 Graduanda em Relações Internacionais, Bolsista Observatório de Desigualdades de Franca ODF - UNESP Franca. Email: anacpkemp@gmail.com

2 Pós-doutoranda em Geografia - UNESP Rio Claro, membra ODF - UNESP Franca. Email: angelicaviso.geo@gmail.com 


\section{INTRODUÇÃO}

O presente trabalho contempla resultados de investigação científica realizada pelo Grupo de Trabalho em Educação, Esporte e Cultura do Observatório de Desigualdades de Franca, vinculado à Universidade Estadual Paulista "Júlio de Mesquita Filho" - UNESP Franca, o objetivo principal deste trabalho é compreender os projetos propostos de ensino remoto pela Secretaria Municipal de Educação de Franca-SP durante a pandemia de COVID-19 no ano de 2020.

As aulas presenciais, na educação municipal de Franca, estão suspensas desde o início de março de 2020, a infraestrutura escolar municipal apresenta 56 unidades escolares, com abrangência de 16.649 alunos matriculados. Com a necessidade do Ensino Remoto Emergencial, a Secretaria Municipal de Educação de Franca realizou o Projeto "Literatura na rede em tempos de COVID-19", por meio do desenvolvimento de um canal no Youtube denominado "Boas Provocações Mediadas Pelas Histórias Infantis", com a utilização das mídias sociais, como o Facebook e o Whatsapp, para realização das orientações pedagógicas.

A pandemia de COVID-19 impôs o uso de tecnologia na educação, contudo essa ferramenta evidenciou, ainda mais, a enorme desigualdade social vivenciada no Brasil. A intensificação do uso de tecnologia não ocorreu de modo democrático, não alcançou a totalidade de alunos em suas diferentes realidades sociais. O Ensino Remoto Emergencial, deve ser encarado como o próprio nome diz como uma situação de emergência, pois é fundamental o direito a educação de modo democrático.

Para a realização deste trabalho foi utilizado pesquisa bibliográfica e de dados sobre o ensino remoto e levantamento dos projetos estabelecidos pela Secretaria Municipal de Educação de Franca no contexto pandêmico.

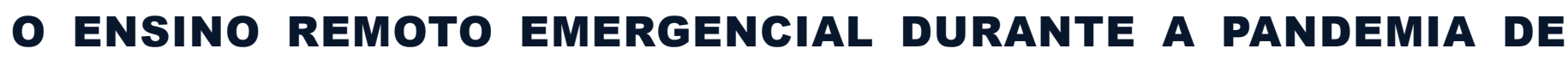 COVID-19}

O novo coronavírus da Síndrome Respiratória Aguda Grave 2 (SARS-Cov-2) provocou uma pandemia com impactos culturais, educacionais, sociais, econômicos e políticos, sendo o primeiro registro de COVID-19 noticiado em Wuhan na China, em dezembro de 2019. A doença COVID-19 foi declarada, pela Organização Mundial 
de Saúde (OMS), como pandemia em 11 de março de 2020 (SCHMIDT et al., 2020).

O ministério da Saúde, de acordo com Portaria n¹88 de 3 de fevereiro de 2020, declarou Emergência em Saúde Pública de Importância Nacional, com classificação de risco em nível 3, por causa do espalhamento do novo coronavírus, de acordo com a Declaração de Emergência em Saúde Pública de Importância Internacional divulgada pela OMS em 30 de janeiro de 2020. Mesmo sem a confirmação de caso de COVID-19 em território brasileiro, essa Portaria foi declarada para que o país pudesse se preparar para enfrentar a pandemia de COVID-19 (BRASIL, 2020a).

O primeiro caso confirmado de contaminação por COVID-19, no Brasil, ocorreu no município de São Paulo no dia 26 de fevereiro de 2020 (LIMA, 2020). No município de Franca, a primeira notificação de caso positivo de COVID-19, ocorreu em 27 de março de 2020, porém esse paciente residia no estado de Minas Gerais, a primeira confirmação de contaminação pelo novo coronavírus em um residente de Franca, aconteceu em 31 de março de 2020 (FRANCA, 2020a).

As aulas presenciais foram suspensas no estado de São Paulo, por meio do Decreto ${ }^{\circ} 64.862$, de 13 de março de 2020 (SÃO PAULO, 2020). No município de Franca, foi determinada situação de emergência por meio do Decreto $n^{\circ} 11.018$, de 19 de março de 2020, com suspensão das aulas presenciais (FRANCA, 2020b).

Por meio do Decreto Legislativo $n^{\circ}$ 6, de 20 de março de 2020, estabeleceu a ocorrência de estado de calamidade pública no país (BRASIL, 2020b). As normas educacionais, referentes ao período de estado de calamidade pública vivenciado no Brasil, foram estabelecidas pela Lei $n^{\circ}$ 14.040, de 18 de agosto de 2020. De acordo com "Art. $1^{\circ}$ Esta Lei estabelece normas educacionais a serem adotadas, em caráter excepcional, durante o estado de calamidade pública" (BRASIL, 2020c).

Conforme o Art. $1^{\circ}$, as normas educacionais estabelecidas são de caráter temporário e relacionam-se ao contexto da pandemia de COVID-19, da necessidade da promoção do isolamento e distanciamento social, garantindo a manutenção da suspensão das aulas presenciais e adoção do ensino remoto.

Em Parágrafo Único, "O Conselho Nacional de Educação (CNE) editará diretrizes nacionais com vistas à implementação do disposto nesta Lei” (BRASIL, 2020c), o que demonstra a necessidade de estabelecer diretrizes pelo órgão do CNE em consonância com o Ministério da Educação (MEC). No Art. $2^{\circ}$, direcionado aos es- 
tabelecimentos de ensino de educação básica, com dispensa "na educação infantil, da obrigatoriedade de observância do mínimo de dias de trabalho educacional e do cumprimento da carga horária mínima anual" (BRASIL, 2020c), sem obrigatoriedade de mínimo de carga horária, enquanto que para o ensino fundamental e médio estabelece a dispensa "da obrigatoriedade de observância do mínimo de dias de efetivo trabalho escolar" (BRASIL, 2020c), porém é exigido o cumprimento da carga horária mínima anual estabelecida pela Lei de Diretrizes e Bases da Educação (LDB) - Lei n. ${ }^{\circ}$ 9.394, de 20 de dezembro de 1996.

As atividades pedagógicas não presenciais deverão ser desenvolvidas para a educação infantil e ensino fundamental e médio:

I - na educação infantil, de acordo com os objetivos de aprendizagem e desenvolvimento dessa etapa da educação básica e com as orientações pediátricas pertinentes quanto ao uso de tecnologias da informação e comunicação;

II - no ensino fundamental e no ensino médio, vinculadas aos conteúdos curriculares de cada etapa e modalidade, inclusive por meio do uso de tecnologias da informação e comunicação, cujo cômputo, para efeitos de integralização da carga horária mínima anual, obedecerá a critérios objetivos estabelecidos pelo CNE (LEI N¹4.040, Artigo $2^{\circ}$, Inciso $4^{\circ}, 2020$ ).

Conforme o Artigo $2^{\circ}$, Inciso $5^{\circ}$ da Lei $\mathrm{N}^{\circ} 14.040 / 2020$, os sistemas de ensino deveram assegurar $\mathrm{o}$ acesso aos meios tecnológicos tanto para os alunos como para os professores, caso utilizem atividades pedagógicas não presenciais para o cumprimento da carga horária anual.

Como se trata do período em que o país está em estado de calamidade pública, quando as aulas retornarem ao modo presencial, serão invalidadas as dispensas propostas pela Lei $n^{\circ} 14.040$, de 18 de agosto de 2020 para a educação infantil, o ensino fundamental e médio e reestabelecerá os dias letivos e a carga mínima anual prevista pela LDB.

Desde março de 2020, as unidades escolares brasileiras passaram a utilizar uma nova modalidade de ensino, já adotada em outros países que tiveram pandemia de COVID-19 a priori, considerada como Ensino Remoto Emergencial- ERE (WILLIAMSON; EYNON; POTTER, 2020).

As atividades no ERE são possibilitadas pelo ambiente virtual, por meio de aulas online, com ferramentas tecnológicas, as aulas ocorrem simultaneamente por meio de conexão com a internet ou são gravadas e disponibilizadas por meio de 
mídias sociais, "a comunicação é predominantemente bidirecional, do tipo um para muitos, no qual o professor protagoniza videoaula ou realiza uma aula expositiva por meio de sistemas de web conferência" (MOREIRA; SCHLEMMER 2020, p. 9).

O ERE é uma modalidade de ensino utilizada no contexto de pandemia por instituições de ensino públicas e privadas, de ensino infantil ao ensino superior, devido a suspensão das aulas presenciais, de acordo com Behar (2020), entende-se ERE devido:

O termo "remoto" significa distante no espaço e se refere a um distanciamento geográfico. O ensino é considerado remoto porque os professores e alunos estão impedidos por decreto de frequentarem instituições educacionais para evitar a disseminação do vírus. É emergencial porque do dia para noite o planejamento pedagógico para o ano letivo de 2020 teve que ser engavetado (BEHAR, 2020, s.p.).

O planejamento anual letivo do ano de 2020 foi preparado, inicialmente, para as aulas presenciais, mas devido à pandemia de COVID-19, esses projetos tiveram que ser alterados para o ERE, "os docentes precisaram por força da urgência, em um curto espaço de tempo, reaprender/refazer sua forma de acesso aos estudantes, encaminhar atividades e acompanhar de modo mais individual a trajetória de cada um" (CASTAMAN; RODRIGUES, 2020, p. 09). Os professores não estavam capacitados para a utilização de novas ferramentas pedagógicas, como o ambiente virtual de ensino, como mídias e softwares.

Acostumados à sala de aula presencial, os docentes tiveram que deixar seu universo familiar e se reinventar, pois a grande maioria não estava preparada e nem capacitada para isso. Podemos, portanto, dizer que o Ensino Remoto Emergencial (ERE) é uma modalidade de ensino que pressupõe o distanciamento geográfico de professores e alunos e foi adotada de forma temporária nos diferentes níveis de ensino por instituições educacionais do mundo inteiro para que as atividades escolares não sejam interrompidas (BEHAR, 2020, s.f.).

Para Costa (2020), com a modalidade de ERE ocorreu um aumento das responsabilidades dos professores, como formular conteúdos para serem trabalhados no ambiente virtual, propor avaliações, o formato das aulas expositivas e a manutenção da participação dos alunos durante as aulas online. As videoaulas são apenas uma parte das atividades do ERE, "nesse tipo de atividade, o professor tem que participar ativamente do conteúdo, interagindo ao vivo com seus alunos e organizando tarefas para serem realizadas e postadas ao longo da semana na plataforma selecionada 
pela instituição" (BEHAR, 2020, s.f).

Conforme Avelino e Mendes (2020), a falta de ferramentas tecnológicas e de acesso à internet para os alunos assistirem as aulas remotas é vivenciada no Brasil, um país com elevada desigualdade social.

[...] nem todas as crianças têm acesso a internet e as atividades propostas pelos educadores não chegam a elas. Além do mais, o ambiente de casa nem sempre é propício, repletos de violência doméstica, alimentação inadequada, iluminação precária, falta de orientação dos educadores para as atividades, entre outros problemas recorrentes no âmbito familiar que prejudicam a conclusão dessas atividades (AVELINO; MENDES, 2020, p.60).

O que evidencia que o Artigo $2^{\circ}$, Inciso $5^{\circ}$ da Lei $N^{\circ} 14.040 / 2020$, que garante que os sistemas de ensino forneçam esses instrumentos de acesso as aulas online, não se coloca em prática, evidenciando a relação de poder e saber na hierarquia de conhecimento e "oportunizando inclusive a evasão e o aumento da desigualdade, assim como o desconforto de ter que assumir o processo de ensino e aprendizagem como condição de autonomia, de empoderamento e de autodeterminação" (CASTAMAN; RODRIGUES, 2020, p. 03).

Para Gusso (2020, s.f) “É importante pontuar que quando se fala em acesso, há um grande abismo entre ter equipamentos, ter serviço de internet e ter condições de acompanhar as atividades propostas pelas escolas e professores". Segundo o autor, durante a pandemia de COVID-19 escancarou-se a desigualdade social brasileira, tanto em relação à ausência de recursos tecnológicos nas escolas, como nas casas dos estudantes, são muitas causas que diferenciam as condições de ensino favorável para os alunos, como local adequado e calmo para o estudo.

Mesmo que consiga acompanhar as atividades remotas, um estudante cuja família tem que lidar com problemas financeiros por conta da pandemia, parentes doentes ou o risco eminente de contaminação, caso familiares estejam trabalhando durante o período de quarentena, pode ter seu rendimento escolar comprometido (GUSSO, 2020, s.f.).

Conforme Freitas (2020), com a nova modalidade de ensino, que sobrecarrega os profissionais de ensino, devido alteração no planejamento anual, os alunos por causa da dificuldade com o ensino remoto, mas também altera o dia a dia dos pais dos alunos, "a sobrecarga diz respeito às condições dos pais em atuarem de forma didática e pedagógica em relação às atribuições que comumente são não somente 
de docentes e escolas, mas de órgãos públicos governamentais" (FREITAS, 2020, s.f.).

\section{RESULTADOS E DISCUSSÃO}

Com a suspensão das aulas presenciais no município de Franca, a Secretaria Municipal de Educação efetivou novas medidas para que as atividades educativas da rede municipal pudessem ser realizadas em casa. Sendo a primeira proposta, a distribuição, no início do mês de abril de 2020, de materiais pedagógicos contendo atividades que podem ser realizadas em casa com o objetivo de garantir os direitos de aprendizagem dos alunos. Segundo a Prefeitura municipal as mais diversas estratégias foram utilizadas para divulgar a distribuição das apostilas visando atingir o maior número de pais e responsáveis, entre elas estão grupos no Facebook e WhatsApp, carros de som e telefonemas.

À vista disso, vale ressaltar que a primeira atividade realizada pela Secretaria Municipal de Educação foi o Projeto Literatura na Rede em Tempo de COVID-19, com a criação de um canal na plataforma Youtube intitulado "SME - Leitura aqui de casa". O canal foi criado no dia 26 de março de 2020 e até o dia 02 de março de 2021 conta com 23.840 visualizações, 683 inscrições e 157 vídeos postados que contam com a participação de cerca de 30 professores. As postagens neste canal ocorreram com maior frequência de março a junho de 2020 e começaram a ficar mais espaçadas desde julho de 2020, em 2021 ainda não foi postado nenhum vídeo. Outro canal relacionado a ciência foi criado também pelo Espaço de Difusão Científica em 27 de maio de 2020, contudo este teve menos difusão apesar dos 94 vídeos postados possui apenas 8.803 visualizações e 391 inscritos, até o dia 02 de março de 2021.

Em relação ao canal "SME - Leitura aqui de casa", o primeiro vídeo do canal foi gravado pelo então Secretário da Educação Edgar Ajax, neste vídeo o Secretário pronunciou a seguinte mensagem: "A Secretaria de Educação pensando em mediar boas práticas nesse período em que todos estão em casa, organizou mais uma proposta lúdica, pedagógica e literária, boas provocações mediadas pelas histórias infantis, venha e embarque conosco no faz de conta, não tão distante e vamos saborear diferentes e atrativas histórias contadas de maneira mágica e pedagógica, senta 
que lá vem história".

A contação de histórias é atividade própria de incentivo à imaginação e o trânsito entre o fictício e o real. Ao preparar uma história para ser contada, tomamos a experiência do narrador e de cada personagem como nossa e ampliamos nossa experiência vivencial por meio da narrativa do autor. Os fatos, as cenas e os contextos são do plano do imaginário, mas os sentimentos e as emoções transcendem a ficção e se materializam na vida real. (RODRIGUES, 2005, p. 4).

Deste modo, se infere que este canal reflete a importância que a Secretaria deu para a continuação das atividades pedagógicas em casa, pois a literatura infantil é de extrema importância para a formação do caráter social e intelectual de uma criança. Até o momento foram postados vídeos em cinco categorias: histórias literárias, faça você mesmo, leitura pelo professor, indicações de leituras para professores e indicações literárias. A categoria "faça você mesmo" é a menor categoria com apenas dois vídeos, a categoria "leitura pelo professor" conta com trinta e dois vídeos, já "indicações de leituras para professores" possui cinco vídeos, na categoria "indicações literárias" foram postados quinze vídeos, a maior categoria de vídeos do canal é a "histórias literárias" com 103 vídeos.

[...] a literatura infantil vem sendo criada, sempre atenta ao nível do leitor a que se destina [...] e consciente de que uma das mais fecundas fontes para a formação dos imaturos é a imaginação - espaço ideal da literatura. É pelo imaginário que o eu pode conquistar o verdadeiro conhecimento de si mesmo e do mundo em que the cumpre viver (COELHO, 2000, p. 141).

Faz-se importante ressaltar a relevância deste canal em tempos de pandemia e distanciamento social, as crianças privadas de sair de casa e de terem um convívio social tão importante para o seu desenvolvimento, deste modo, encontra uma forma de propiciar o seu desenvolvimento de forma ainda efetiva. A audição de livros, assim como realizadas na maioria dos vídeos e em quase todas as categorias, propicia uma função tripla: afetiva, cognitiva e linguística. O "desenvolvimento linguístico influencia o desenvolvimento das capacidades de leitura e da escrita, que por sua vez interagem com a linguagem determinando um tanto maior desenvolvimento linguístico como o da leitura e da escrita" (VILAS-BOAS, 2002, p.81).

A utilização de histórias infantis no processo de ensino aprendizagem promove o ato de aprender divertido, o educando aprende enquanto se diverte, a aprendizagem acontece com um momento lúdico, de imaginação e de faz de 
conta. A tecnologia de informação e comunicação está presente no cotidiano das pessoas, utilizá-la na junção do lado artístico das crianças com a literatura promove a criatividade dos educandos e dos professores (SOUZA-LOPES; KEMP, 2020, p. 728).

Considera-se importante ressaltar o papel do educador nessas ações realizadas durante a pandemia do COVID-19, que se encontrava em regime de teletrabaIho estabelecido pela Medida Provisória (MP) 927, em 22 de março de 2020 (REF), porém esta Medida perdeu seu prazo de vigência no dia 19 de julho de 2020. Com a MP a implementação do teletrabalho foi facilitada, "agora, para que o teletrabalho seja adotado, o empregador deve ter a anuência do empregado conjuntamente com o termo aditivo contemplando a alteração do regime presencial para o teletrabalho (artigo 75, CLT)" (MARTINS, 2020).

Drummond (2020, p. 110) define teletrabalho como "os serviços são prestados em outro local, que não a empresa, podendo ser no domicílio do empregado ou não, e com forte utilização de recursos tecnológicos que permitam a realização das tarefas contratualmente assumidas". Esse regime de trabalho trouxe uma série de desafios aos professores, estes não se encontravam preparados para o ensino remoto, sendo assim, fez-se necessária a submissão a uma "reinvenção docente" que tinha como objetivo "a manutenção de uma educação remota que se faça ativa, presente e minimamente acessível, sem considerar entretanto, as lacunas das condições trabalhistas, estruturais e até mesmo formativas, destes profissionais da educação" (PEREIRA; SANTOS; MANENTI, 2020, p. 29).

Na metade do ano letivo de 2020 , mais precisamente em $1^{\circ}$ de junho, o estado de calamidade no município foi mantido por meio da Resolução $n^{\circ} 12$ da Secretaria Municipal de Educação (FRANCA, 2020c). Esta resolução, assim como todas as medidas tomadas pela Secretaria Municipal de Educação acompanharam as diretrizes do Conselho Nacional de Educação (CNE) e do Ministério da Educação, que por meio do Parecer CNE/CP n5/2020 (CNE, 2020) e Portaria MEC n 343 (BRASIL, 2020d) estabeleceram as condições para o ensino remoto necessário perante a pandemia.

Para o ano letivo de 2021 o MEC com a portaria $n^{\circ} 1.096$, de $1^{\circ}$ de dezembro de 2020 (BRASIL, 2020e) previa o retorno às aulas presenciais a partir de 01 de março 
de 2021, nessa mesma portaria o Ministério da Educação recomenda a observância dos protocolos de segurança para o combate a COVID-19.

No ano letivo de 2021 ao todo são 17,3 mil alunos matriculados na rede municipal de ensino de Franca, distribuídos no Ensino Fundamental (12,5 mil estudantes), no Ensino Infantil (4,5 mil estudantes) e no Ensino de Jovens e Adultos (pouco mais de 400 estudantes).

À vista disso, e também a questão que um dos protocolos de segurança é o distanciamento social que objetiva reduzir as interações sociais para evitar a eventual transmissão do agente patológico em questão, a Secretaria Municipal de Franca lançou em 11 de janeiro de 2021, que se encerrou no final do mês, um questionário com a temática do retorno às aulas presenciais. O questionário realizado pela Secretaria visava obter a opinião dos alunos, pais, responsáveis e professores, cabe lembrar que a rede municipal de ensino atende alunos das séries do fundamental, infantil e EJA. Segundo a atual Secretária de Educação Márcia Gatti:

Esse trabalho visa preparar a logística para o retorno gradual das aulas presenciais de forma segura, seguindo os protocolos sanitários, além de conhecer a quantidade de alunos que irão optar pelo ensino presencial ou remoto, bem como a quantidade de profissionais que estarão retornando as atividades presenciais ou desejarem permanecer em teletrabalho. No questionário, os pais devem responder também sobre o histórico de saúde dos filhos, se tem comorbidades ou tenham alguma limitação que requeira cuidados especiais (FRANCA, 2021).

O resultado do questionário não foi divulgado na integra, porém, as ações da Secretaria Municipal e as notícias postadas no site da Prefeitura levam a crer que a maioria optou por um retorno às aulas presenciais. No dia 08 de fevereiro, em uma segunda-feira, as atividades nas unidades municipais foram retomadas virtualmente, visando um retorno presencial em data oportuna, segundo Márcia Gatti, o ensino deverá continuar online, pois as instalações físicas das escolas necessitam passar por adequações e vistorias, além disso, faz-se necessário aguardar a chegada de equipamentos de proteção e insumos. 
O sistema educacional mundial foi abalado com a Pandemia de COVID-19, no Brasil a desigualdade de acesso aos recursos tecnológicos evidenciou o quanto o acesso ao ensino ocorre de modo incompatível entre as diferentes classes sociais. As aulas presenciais foram suspensas para garantir o isolamento social, principal método de prevenção ao contágio do novo coronavírus, por meio de decretos e leis das diversas esferas, municipais, estaduais e federal, as unidades escolares foram obrigadas a manterem-se fechadas.

Novas tecnologias foram utilizadas para o ensino pela Secretaria Municipal de Educação de Franca, respeitando a necessidade de implantação do Ensino Remoto Emergencial, mas não houve tempo de preparação para os professores e propostas e possibilidades de adaptação para os alunos. Por meio do Projeto Literatura na Rede em Tempo de COVID-19, os alunos tiveram a oportunidade de conhecer histórias e personagens, através da contação de histórias realizada pelo corpo docente municipal, porém a abrangência dessa atividade não pode ser mesurada. Ao pensar na desigualdade social que assola o nosso país, o Ensino Remoto Emergencial acaba por evidenciar ainda mais a diferença de acesso aos meios tecnológicos e a internet.

\section{REFERÊNCIAS}

AVELINO, W. F.; MENDES, J. G. A realidade da educação brasileira a partir do COVID-19. Boletim da Conjuntura (Boca). Ano II, v.2, n.5, Boa Vista, 2020. p. 56-62.

BEHAR, P.A. O Ensino Remoto Emergencial e a Educação a Distância. 2020. Disponível em: https://www.ufrgs.br/coronavirus/base/artigo-o-ensino-remoto-emergencial-e-a-educacao-a-distancia/. Acesso em: 17 out. 2020.

BRASIL, Ministério da Saúde. Portaria N¹88, de 03 de fevereiro de 2020. Declara Emergência em Saúde Pública de importância Nacional (ESPIN) em decorrência da Infecção Humana pelo novo Coronavírus (2019-nCoV). 2020a. Disponível em: https://www.in.gov.br/web/dou/-/portaria-n-188-de-3-de-fevereiro-de-2020-241408388. Acesso em: 20 de outubro de 2020.

BRASIL. Decreto Legislativo $n^{\circ}$ 6, de 20 de março de 2020. Reconhece, para os fins do art. 65 da Lei Complementar $n^{\circ} 101$, de 4 de maio de 2000, a ocorrência do estado de calamidade pública, nos termos da solicitação do Presidente da Repú- 
blica encaminhada por meio da Mensagem $n^{\circ} 93$, de 18 de março de 2020. 2020b. Disponível em: https://legislacao.presidencia.gov.br/atos/?tipo=DLG\&numero=6\&ano=2020\&ato=b1fAzZU5EMZpWT794. Acesso em: 20 de outubro de 2020.

BRASIL. Lei №14.040, de 18 de agosto de 2020. Estabelece normas educacionais excepcionais a serem adotadas durante o estado de calamidade pública reconhecido pelo Decreto Legislativo ${ }^{\circ} 6$, de 20 de março de 2020; e altera a Lei $n^{\circ} 11.947$, de 16 de junho de 2009. 2020c. Acesso em: 25 de fevereiro de 2021.

BRASIL. Ministério da Educação. Portaria $n^{\circ}$ 343, de 17 de março de 2020. 2020d. Dispõe sobre a substituição das aulas presenciais por aulas em meios digitais enquanto durar a situação de pandemia do Novo Coronavírus - COVID-19. Disponível em: https://www.in.gov.br/en/web/dou/-/portaria-n-343-de-17-de-marco-de-2020-248564376. Acesso em: 01 mar. 2021.

BRASIL, Ministério da Educação. Portaria $n^{\circ}$ 1.096, de $1^{\circ}$ de dezembro de 2020. ispõe sobre o retorno às aulas presenciais, sobre a antecipação de conclusão de cursos e sobre caráter excepcional de utilização de recursos educacionais digitais para integralização da carga horária das atividades pedagógicas dos cursos da educação profissional técnica de nível médio, das instituições do sistema federal de ensino, enquanto durar a situação de pandemia do Novo Coronavírus - Covid-19. 2020e. Disponível em: https://www.in.gov.br/en/web/dou/-/portaria-n-1.096-de-30-de-dezembro-de-2020-297416148. Acesso em: 01 mar. 2021.

BRASIL, Presidente da República. Medida Provisória № 927, de 22 de março de 2020. 2020f. Dispõe sobre as medidas trabalhistas para enfrentamento do estado de calamidade pública reconhecido pelo Decreto Legislativo $n^{\circ} 6$, de 20 de março de 2020, e da emergência de saúde pública de importância internacional decorrente do coronavírus (covid-19), e dá outras providências. Disponível em: http://www. planalto. gov.br/ccivil_03/_ato2019-2022/2020/mpv/mpv927.htm. Acesso em: 01 mar. 2020.

CASTAMAN, A. S.; RODRIGUES, R. A. Educação a Distância na crise COVID - 19: um relato de experiência. Research, Society and Development, v. 9, n. 6, e180963699, p. 1-26, 2020.

COELHO, N. N. Literatura infantil: teoria analise didática. 6. ed. São Paulo. Moderna, 2000.

CONSELHO NACIONAL DE EDUCAÇÃO. CNE/CP n 5/2020, 28 de abril de 2020. 2020. Disponível em: http://portal.mec.gov.br/index.php?option=com_docman\&view=download\&alias=145011-pcp005-20\&category_slug=marco-2020-pdf\&lte$\mathrm{mid}=30192$. Acesso em: 02 mar. 2021 
COSTA, R. Entrevista - Lições do coronavírus: ensino remoto emergencial não é EAD. Disponível em: https://desafiosdaeducacao.grupoa.com.br/coronavirus-ensino-remoto/. Acesso em 17 out. 2020.

DRUMMOND, G. Teletrabalho: duração do trabalho e impactos do Covid-19. Revista do Tribunal Regional do Trabalho da $1^{a}$ Região, v. 24, n. 1, p. 109-117, 01 mar. 2021.

FRANCA. Boletim Epidemiológico Coronavírus Franca. 2020a. Disponível em: https://www.franca.sp.gov.br/index.php?option=com_phocadownload\&view=category\&id=1855\&ltemid=1875. Acesso em: 15 out. 2020.

FRANCA (Cidade). Decreto No 11.018, de 19 de março de 2020. 2020b. Declara situação de emergência no Município de Franca e define outras medidas para o enfrentamento da pandemia decorrente do Novo Coronavírus - COVID-19. Disponível em: https://www.franca.sp.gov.br/arquivos/diario-oficial/documentos/1481-Extra-19032020.pdf. Acesso em: 27 nov. 2020.

FRANCA (Cidade). Secretaria Municipal de Educação. Resolução SME N. ${ }^{\circ} 012$ de $1^{\circ}$ de junho de 2020. Dispõe sobre a manutenção do estado de calamidade em Franca, e conforme outras providências de combate e prevenção do COVID-19 e as medidas de flexibilização das atividades econômicas. 2020c. Disponível em: https://www. franca.sp.gov.br/noticias/educacao/instituicoes-de-ensino-ficam-suspensas-de-funcionamento-presencial-ate-dia-30. Acesso em: 02 mar. 2021.

FRANCA, Prefeitura Municipal de. Educação prorroga pesquisa de volta às aulas. 21 jan. 2021. Disponível em: https://www.franca.sp.gov.br/noticias/educacao/educacao-prorroga-pesquisa-de-volta-as-aulas. Acesso em: 02 mar. 2021.

FREITAS, L.C. Pais defendem seus filhos. Blog Avaliação Educacional. 04/04/2020. Disponível em: https://avaliacaoeducacional.com/2020/04/04/pais-defendam-seus-fiIhos/. Acesso em: 17 out.2020.

GUSSO, H. Ensino Remoto Emergencial: não é só sobre acesso e equipamentos. In: FLORES, N. Entrevista. Abril de 2020. Disponível em: https://www.blogs.unicamp. br/covid-19/ensino-remoto-emergencial-nao-e-so-sobre-acesso-e-equipamentos/. Acesso em 17 out. 2020.

LIMA, D. L. F. COVID - 19 no Estado do Ceará: Comportamentos e crenças na chegada da pandemia. Ciência Saúde Coletiva Preprints, p. 1575-1586, 2020. o fim da MP 927. Consultório Jurídico, 2020. Disponível em: https://www.conjur.com. 
br/2020-ago-21/gustavo-martins-quais-consequencia-fim-mp-927\#: :text=A $\% 20$ Medida\%20Provis\%C3\%B3ria\%20n\%C2\%BA\%20927,pandemia\%20causada\%20 pelo\%20novo\%20coronav\%C3\%ADrus. Acesso em: 01 mar. 2021.

MOREIRA, J. A.; SCHLEMMER, E. Por um novo conceito e paradigma de educação digital onlife. Revista UFG, v. 20, p. 1-35, 2020.

SÃO PAULO (Estado). Decreto N64.862, 13 de março de 2020. Disponível em: https:// www.al.sp.gov.br/repositorio/legislacao/decreto/2020/decreto-64862-13.03.2020. html\#: :text=Disp\%C3\%B5e\%20sobre\%20a\%20ado\%C3\%A7\%C3\%A30\%2C\%20 no,recomenda\%C3\%A7\%C3\%B5es\%20no\%20setor\%20privado\%20estadual.2020. Acesso em 20 de outubro de 2020.

PEREIRA, Hortência Pessoa; SANTOS, Fábio Viana; MANENTI, Mariana Aguiar. Saúde mental de docentes em tempos de pandemia: os impactos das atividades remotas. Boletim de Conjuntura (BOCA), Boa Vista, v. 3, n. 9, p. 26-32, out. 2020. ISSN 2675-1488. Disponível em: https://revista.ufrr.br/boca/article/view/Pereiraetal/3074. Acesso em: 12 out. 2020

RODRIGUES, E. B. T. Cultura, arte e contação de histórias. Goiânia: Gwaya, 2005. SCHMIDT, B. et al. Impactos na Saúde Mental e Intervenções Psicológicas Diante da Pandemia do Novo Coronavírus (COVID - 19). SciELO Preprints, p. 1-26, 2020.

SOUZA-LOPES, Angélica Vieira de; KEMP, Ana Clara Paris. O projeto "Boas provocações mediadas pelas histórias infantis": Secretaria Municipal de Educação de Franca-SP. In: XXI Encontro de Pesquisadores: Desafios em Desenvolvimento Regional, 2020, Franca. Anais... Franca: Uni-FACEF, 2020. p. 721-729.

VILAS-BOAS, M. A. Leituras de histórias: o contributo da dimensão sócio - afectiva. In: VIANA, F. L. et al. (org) Leitura literatura infantil ilustração - investigação e prática docente. Portugal, Universidade do Minho, 2002.

WILLIAMSON, B.; EYNON, R.; POTTER, J. Pandemic politics, pedagogies and practices: digital technologies and distance education during the coronavirus emergency. Learning, Media and Technology, Vol. 45, n. 2, p. 107-114, 2020. 


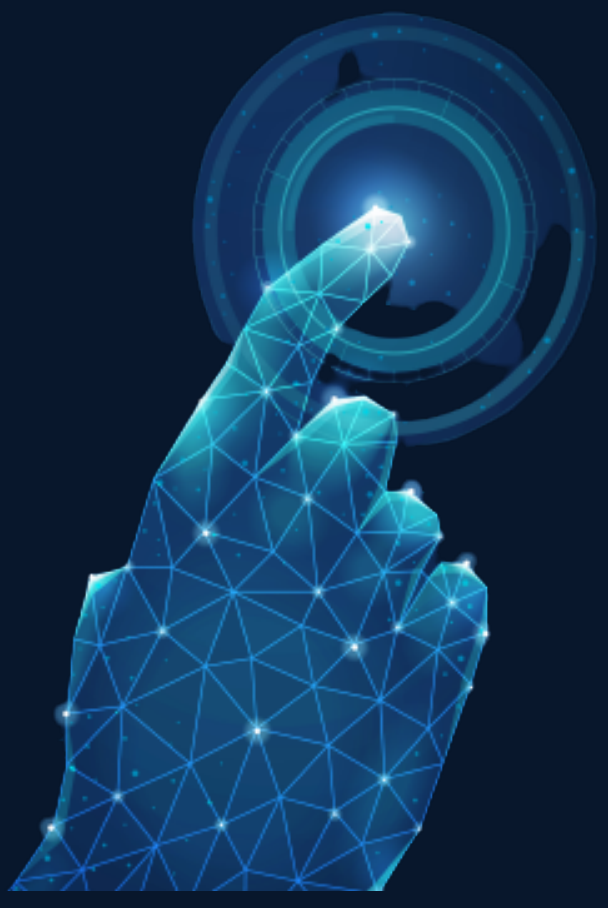

\section{A PRODUÇÃO DE VÍDEO COMO FERRAMENTA TECNOLÓGICA AVALIATIVA DA DISCIPLINA DE PATOLOGIA DO CURSO DE FISIOTERAPIA DE UMA IES PRIVADA EM SÃO LUÍS: RELATO DE EXPERIÊNCIA}

Saint-Clair Asafe Araujo Neves ${ }^{1}$ 
Resumo: O presente artigo faz um relato de experiência sobre a produção de vídeo como ferramenta tecnológica avaliativa da disciplina de patologia do curso de fisioterapia de determinada IES em São Luís entre março e junho de 2020. Para tanto, a pesquisa foi de abordagem qualitativa envolvendo pesquisa bibliográfica e análise documental das metodologias aplicadas no Ensino Remoto baseadas no uso do vídeo como função expressiva dos alunos. Compreende-se tal ferramenta como complementar ao processo de ensino-aprendizagem da linguagem audiovisual e como exercício intelectual e de cidadania necessária em sociedades que fazem o uso intensivo dos meios de comunicação, a fim de que sejam utilizados crítica e criativamente (CARNEIRO, 1997, p. 10). Dessa forma, tecemos reflexões acerca do papel do fisioterapeuta no tratamento oncológico, através da produção de vídeo, apresentando conceitos, dados epidemiológicos, sintomas, tratamentos. Promovendo um maior desenvolvimento da formação acadêmica e profissional, no que tange a comunicação e criatividade, além do estreitamento da relação entre professores e universitários, de modo remoto. Como forma de referenciar as pesquisas buscamos como aporte teórico: autor Moran (1995), Carneiro (1997), dentre outros autores. Como resultado constatou-se que a produção de vídeo entre os discentes de fisioterapia possibilitou uma pratica inovadora de avaliação, permitindo uma participação ativa dos estudantes garantindo sua característica exploradora em tempos de ensino remoto em decorrência da Covid -19 .

Palavras-chave: Vídeo; Ensino remoto; Fisioterapia.

Abstract: This article presents an experience report on video production as a technological assessment tool for the pathology discipline of the physiotherapy course of a specific IES in São Luís between March and June 2020. For this purpose, the research was of a qualitative approach involving bibliographical research and document analysis of methodologies applied in Remote Education based on the use of video as an expressive function of students. Such a tool is understood as complementary to the teaching-learning process of audiovisual language and as an intellectual exercise and necessary citizenship in society that make intensive use of the means of communication, in order to be used critically and creatively (CARNEIRO, 1997, p. 10). Thus, we reflect on the role of the physiotherapist in cancer treatment, through the production of video, presenting concepts, epidemiological data, symptoms, treatments. Promoting a greater development of academic and professional training, with regard to communication and creativity, in addition to the narrowing of the relationship between teachers and university students, remotely. As a way of referencing the research, we sought as a theoretical contribution: author Moran (1995), Carneiro (1997), among 
other authors. As a result, it was found that video production among physiotherapy students enabled an innovative evaluation practice, allowing students to participate actively, guaranteeing their exploratory characteristics in times of remote teaching because of Covid -19 .

Keywords: Video; Remote teaching; Physiotherapy.

\section{INTRODUÇÃO}

O processo educacional vem passando por diversas transformações, entre elas podemos citar a inserção das tecnologias digitais na educação. Considerando tal fato, neste artigo empreendemos esforços para refletir acerca da produção de vídeo como ferramenta tecnológica avaliativa complementar no processo de ensino-aprendizagem. Nesse sentido, propusemos como objetivo geral analisar a produção de vídeo como ferramenta avaliativa no processo de ensino-aprendizagem da disciplina de Patologia do curso de Fisioterapia de uma IES privada de São Luís - MA.

Já como objetivos específicos propomo-nos a: Analisar a contribuição propiciada pela ferramenta da produção de vídeo como complementar no processo de ensino-aprendizagem, bem como relatar a experiência da produção de vídeo como instrumento de avaliação da aprendizagem na disciplina de Patologia do curso de fisioterapia de uma IES privada em São Luís - MA.

Para tanto, a pesquisa foi de abordagem qualitativa envolvendo pesquisa bibliográfica e análise dos aplicativos utilizados na metodologia do Ensino Remoto, baseadas no uso do vídeo como função expressiva dos alunos, contabilizando como registro de trabalho avaliativo. Quanto à pesquisa qualitativa, Godoy (1995, p. 21) considera que: "a abordagem qualitativa, enquanto exercício de pesquisa, não se apresenta como uma proposta rigidamente estruturada, ela permite que a imaginação e a criatividade levem os investigadores a propor trabalhos que explorem novos enfoques".

Nesse sentido, defendemos que o relato de experiências dos fatos acontecidos e os registros dos aplicativos usados para construção e edição de vídeo é um exercício profícuo com potencial de apresentar contribuições significativas no que diz respeitos ao uso das ferramentais digitais na educação, sendo, pois imprescindíveis 
sua discussão e contextualização no meio acadêmico.

Quanto a técnica de pesquisa utilizada para apreensão da percepção dos estudantes acerca da experiência vivida no processo de construção do vídeo, foi realizada entrevista, virtualmente, aos discentes que cursaram a disciplina de Patologia do curso de Fisioterapia no semestre 2020.1, os quais realizaram a atividade de elaboração de vídeo sobre "O Papel do Fisioterapeuta no tratamento oncológico". Também realizamos entrevista à docente, também de forma virtual, em virtude da inviabilidade de encontros presencial com os sujeitos participantes da pesquisa, haja vista que nos encontramos em contexto de pandemia do Covid-19.

Nesse sentido, diante do cenário desafiador no qual nos encontramos em decorrência da presente conjuntura de pandemia do Covid-19, a metodologia do processo de ensino-aprendizagem teve de se adaptar ao Ensino Remoto. Assim, o uso de novas tecnologias e ferramentas foi incorporado nas abordagens de ensino empreendidas nesse cenário desafiador. Segundo Dolan e Collins (2015) "Estudos revelam que quando o professor fala menos, orienta mais e o aluno participa de forma ativa, a aprendizagem é mais significativa" (apud BACICH; MORAN, 2018, p. 40). A aprendizagem neste caso é feita de forma ativa, através de desenvolvimento de projetos e atividades desafiadoras, para resoluções de problemas de forma interdisciplinar, propiciando tomada de decisões e o trabalho em equipe.

A utilização da metodologia audiovisual permite a dinamização das aulas, colaborando para o envolvimento dos discentes, assim como tornando-o protagonista do processo de aprendizagem e garantindo sua autonomia o que caracteriza o futuro dos sistemas de educação. Segundo Pazzini e Araújo (2013, p. 4), “A aprendizagem significativa por meio dos vídeos é um desafio constante, mas sua prática bem aplicada abre possibilidades para uma maior eficiência da arte de ensinar". Nossa análise, pois, se propõe a refletir acerca da relação entre o ensino e o uso de tecnologias digitais, especificando o uso do vídeo nesse processo. 


\section{A PRODUÇÃo de VÍdEO COMO RECURSO COMPLEMENTAR NO PROCESSO DE ENSINO-APRENDIZAGEM}

Conforme pontuamos anteriormente, a abordagem educacional de ensino-aprendizagem vem passando por diversas transformações estratégicas de ensino que buscam criar espaços de aprendizagem nos quais os alunos possam produzir, pensar e conceituar o que fazem, construir conhecimentos sobre os conteúdos envolvidos nas atividades que realizam, bem como desenvolver habilidades criativas e capacidade crítica. Tais estratégias possibilitam também a reflexão acerca dos problemas enfrentados em sociedade e sobre as práticas que realizam, colaborando para o aprendizado e a interação com colegas e professores, com intuito de explorar atitudes e valores pessoais.

Por meio desta perspectiva, a tecnologia vem facilitando o processo de aprendizagem. Para tanto, ela deve ser utilizada de forma que possibilite alcançar objetivos pedagógicos levando em consideração os aspectos sociais. Portanto, a implantação da tecnologia na educação não se dá de forma tão simples, sendo um desafio para os docentes, haja vista que para muitos pode haver o receio em utilizar as ferramentas digitais, bem como a dificuldade quanto a adaptação as novas ferramentas tecnológicas educacionais. Segundo Modelski, Giraffa e Casartelli (2019 p. 3-4):

A evolução da tecnologia permite-nos perceber a mudança de meros receptores da informação para autores, e, com isso, pensar alternativas na formação docente torna-se desafiador, pois estamos imersos nessa realidade que, muitas vezes, não nos permite visualizar alternativas. Estamos acostumados a olhar do locus em que fomos formados, a partir das concepções enraizadas por essa formação e por umas práxis associada a um contexto não digital.

Dessa forma, para a utilização das ferramentas tecnológicas nas práxis educacionais é necessário que se tenha uma preocupação com o desenvolvimento de um planejamento pedagógico que aborde conteúdos, objetivos, metodologias e datas de forma intencional. A elaboração desse plano deve ser voltada para utilização de recursos digitais educacionais que incrementem e dinamizem os processos pedagógicos. Nesse sentido, é imprescindível que o profissional esteja em constante processo de formação continuada, o qual lhe permitirá que desenvolva habilidades e aprimore sua capacidade técnica de uso de estratégicas tecnológicas didáticas.

No que diz respeito ao uso de tecnologias digitais na educação, mais especificamente o vídeo, podemos conceitua-lo como uma ferramenta de ensino estratégica 
que possibilita várias maneiras de utilização, as quais serão escolhidas conforme o objetivo do educador.

Moran (1995) apresenta algumas situações de uso de vídeos em aula, das quais destacamos: vídeo como sensibilização, para introduzir um novo assunto, despertar a curiosidade e motivar os alunos; vídeo como ilustração, como forma de apresentar cenários desconhecidos aos alunos; vídeo como simulação, para mostrar, por meio de simulação, processos químicos, por exemplo; vídeo como conteúdo de ensino, para informar sobre conteúdo específicos; e, vídeo como produção, para registro do trabalho desenvolvido, intervenção ou expressão.

O vídeo é uma forma criativa e inovadora de facilitação de acesso ao conteúdo, tendo custo razoavelmente barato para a sua produção e utilização, sem contar que permite grande alcance de alunos através de plataformas digitais. Exemplo disso é o YouTube que conta com cerca de milhares de produção de vídeo-aulas e trabalhos educacionais. Sendo mais especifico, hoje contamos com plataformas digitais de vídeos totalmente voltada para educação como é o exemplo do Descomplica.

Isto posto, cumpre assinalar que se faz necessário também que as escolas incentivem o uso do vídeo como função expressiva dos alunos, complementando o processo ensino-aprendizagem da linguagem audiovisual e como exercício intelectual e de cidadania, o qual é necessário nos contextos sociais contemporâneos que fazem o uso intensivo dos meios de comunicação, a fim de que sejam utilizados crítica e criativamente (CARNEIRO, 1997, p. 10). Levando em consideração essa perspectiva, fazer uso de tal estratégia tem o potencial de permitir o encorajamento, a aprendizagem ativa, motivar e despertar o interesse, desenvolver a comunicação e estimular a capacidade de iniciativa de trabalho em grupo.

\section{A PRODUÇÃo dE VÍdEO COMO INSTRUMENTO DE AVALIAÇÃO DA APRENDIZAGEM: Relato de experiência}

No exercício de construção desta análise, apresentamos neste item o relato de experiência em relação a utilização do vídeo como produção e registro de trabalho avaliativo na disciplina de Patologia do curso de Fisioterapia em uma IES em São Luís - MA. Para tanto, discorremos acerca das etapas da produção do vídeo, bem como destacamos a percepção dos discentes e docente quanto a realização desta atividade. 


\subsection{Etapas da produção do vídeo}

Quanto a produção do vídeo houve várias etapas, sendo que a primeira etapa foi a delimitação do assunto a ser abordado no vídeo, o qual foi definido pela professora Dra. Adriana Soeiro F. S. Junqueira Ayres. O assunto proposto foi oncologia. Assim, foi orientado que cada grupo fizesse a pesquisa bibliográfica dos assuntos encontrados na literatura. Após esse momento os alunos tiveram que reunir-se de forma remota pela plataforma Google Meet trazendo ideias para a discussão do título do vídeo juntamente com o planejamento e desenvolvimento do mesmo.

Desta forma, nós alunos do $4^{\circ}$ período de fisioterapia escolhemos como título para o vídeo: "O Papel do Fisioterapeuta no tratamento oncológico". Tal exercício possibilitou sermos protagonistas, produtores e construtores de conhecimento.

Na segunda etapa, ocorrida também de forma remota, os produtores do vídeo tiveram que realizar a pesquisa e leituras individualmente a respeito da Oncologia e o papel do fisioterapeuta no tratamento. Após esse momento foi socializado em grupo como funcionaria a dinâmica da produção. A decisão tomada foi que o vídeo seria em formato de um quadro de saúde de telejornal. O quadro recebeu o nome de Saúde em foco, como mostra na figura 1.

Figura 1 - Produção do Vídeo

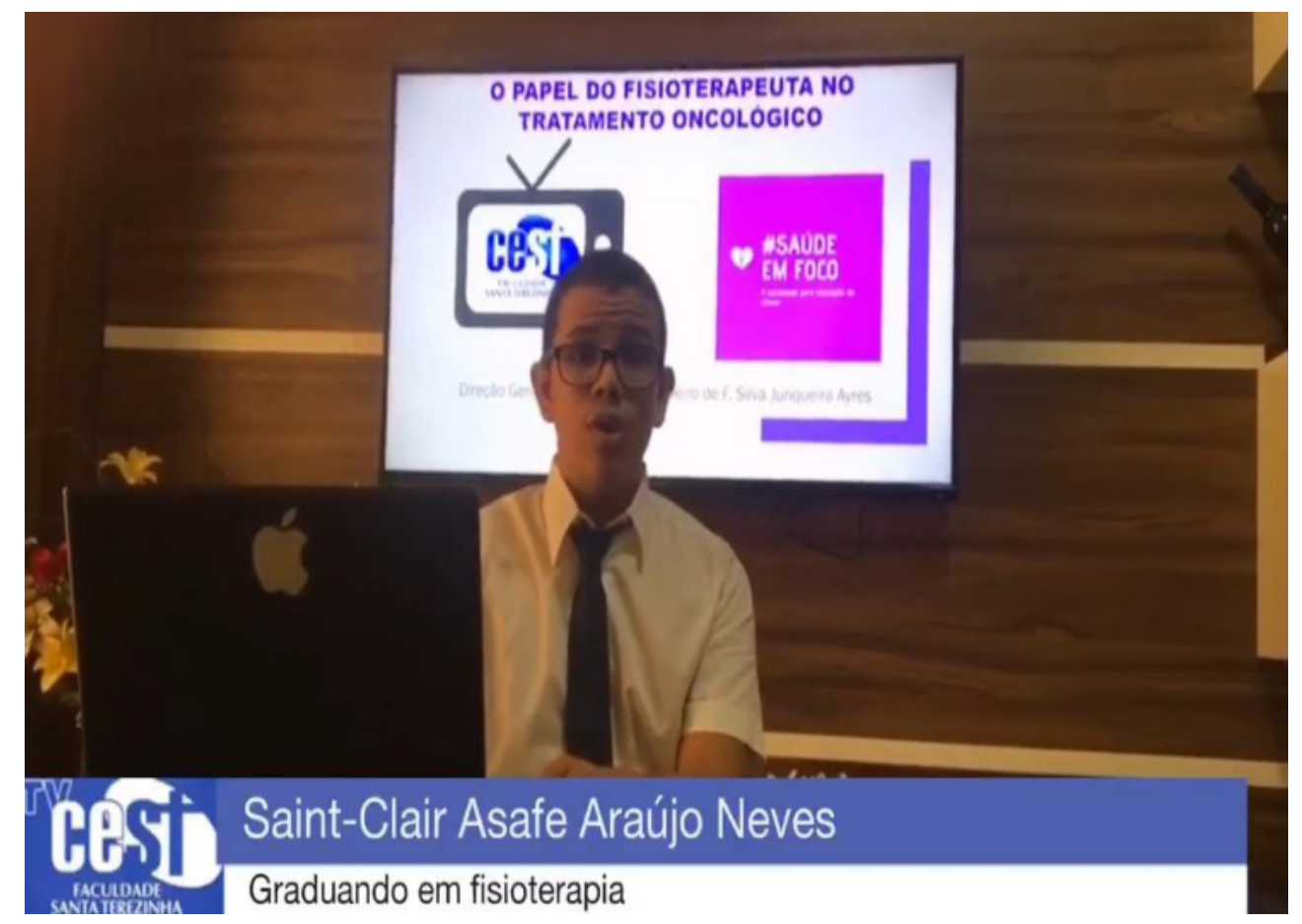

Fonte: Arquivo pessoal.

Cada integrante ficou responsável por realizar a sua gravação. Após encerra- 
das as gravações dos vídeos iniciamos a terceira etapa.

$\mathrm{Na}$ terceira etapa, tivemos a oportunidade de expandirmos o aprendizado no que diz respeito a inovações tecnológicas para edição de vídeo e imagem. Utilizamos alguns aplicativos para construção de artes gráficas e edição de imagem, como por exemplo, o Canva. Já para edição do vídeo foram utilizados os aplicativos Inshot e Imovie.

Foi utilizado os aplicativos Google Classroom para entrega da produção do vídeo como atividade de avaliação e o Google Meet para a apresentação dos vídeos para toda a turma assistir juntamente com o professor. $\mathrm{Na}$ oportunidade, tecemos reflexões acerca do papel do fisioterapeuta no tratamento oncológico, apresentando conceitos, dados epidemiológicos, sintomas e tratamentos.

Tal exercício promoveu um maior desenvolvimento da formação acadêmica e profissional no que tange a comunicação e criatividade, além do estreitamento da relação entre professores e universitários, de modo remoto. Nesse sentido, a discente Mylenna Furtado Barros Silva relatou que:

Gravar um vídeo para a disciplina de patologia foi uma experiência que eu particularmente amei. Pois eu gosto bastante desses modelos de trabalhos mais didáticos, com eles consigo absorver melhor o assunto e desta forma tenho a capacidade de transmitir o que eu sei para quem assiste.

A referida discente tratou em sua apresentação acerca do conceito de neoplasia e dos seus tipos, as benignas e as malignas, e usou de recursos de edição de vídeo para realizar tal ilustração e explicação, conforme demonstra a figura 2.

Figura 2 - Discente apresentando os tipos de neoplasias.

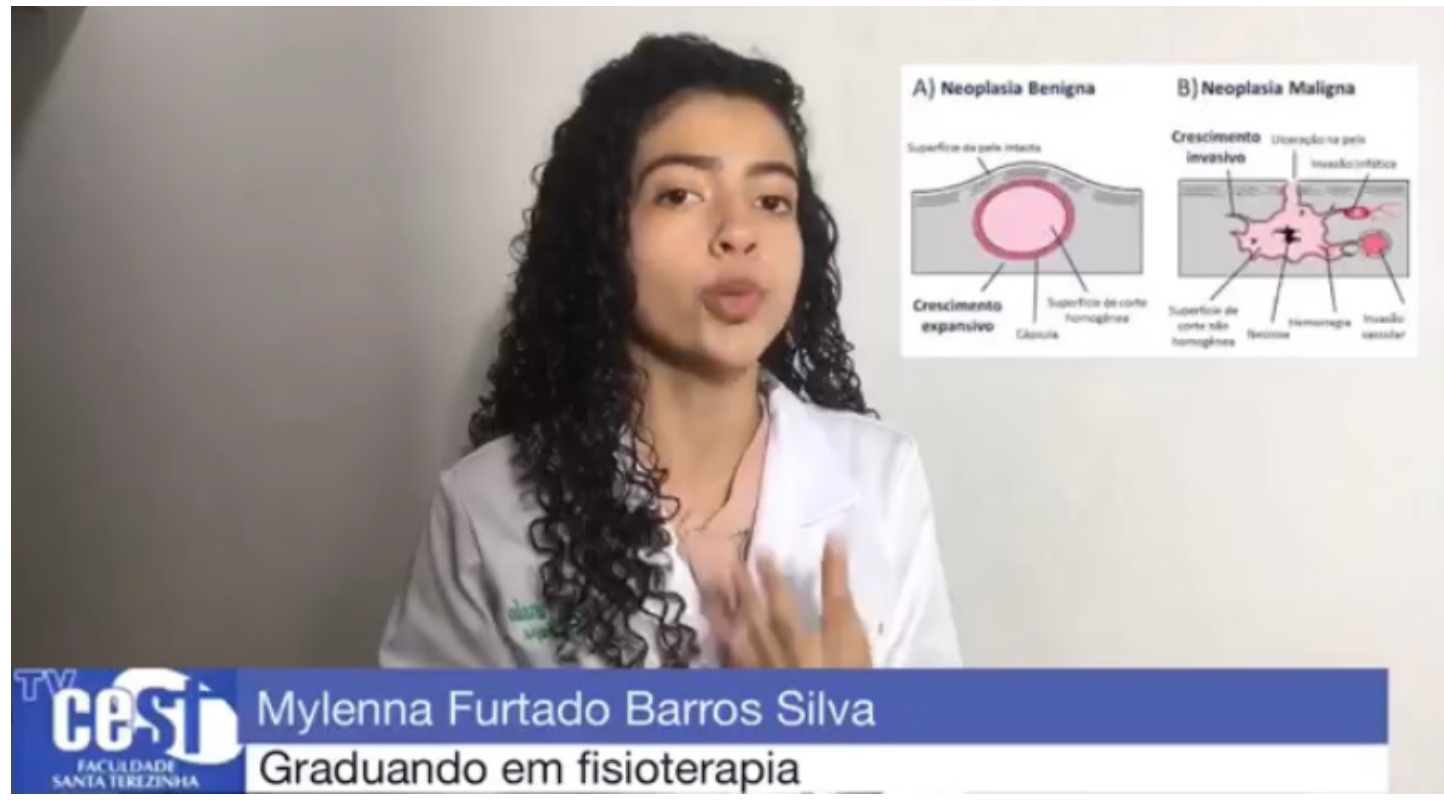

Fonte: Arquivo pessoal. 
Pazzini e Araújo (2013, p. 5) argumentam que "o vídeo ajuda muito a professores e alunos em seu processo de aprendizagem, pois os temas escolhidos são trabaIhados em sala de aula e os estudantes envolvidos de forma criativa e eficaz". Com a realização desta análise, pudemos constatar que a produção de vídeo por parte do discente tem o potencial de torna-lo mais autônomo ainda no processo de absorção dos conteúdos trabalhados, bem como propicia sua melhor compreensão. Levando em consideração tal perspectiva, destacamos o relato da discente Stênnya Rebeca de Sousa Silva, ao falar acerca de sua percepção em relação a produção do vídeo para a disciplina:

Iniciar a gravar vídeos foi sem dúvida um desafio, pois requer domínio do assunto exposto e uma boa oratória, porém, foi e tem sido uma experiência nova e agradável que me desafiou e me fez perceber que consigo passar o conhecimento adiante. Acredito que a comunicação é muito importante no meio acadêmico, principalmente na área da saúde, e esse tipo de trabalho realizado faz com que isso seja desenvolvido.

A discente Stênnya Rebeca abordou os dados estatísticos epidemiológicos do câncer no Brasil e no Mundo, como podemos ver na figura 3.

Figura 3 - Apresentação dos dados estatísticos e epidemiológico do câncer.

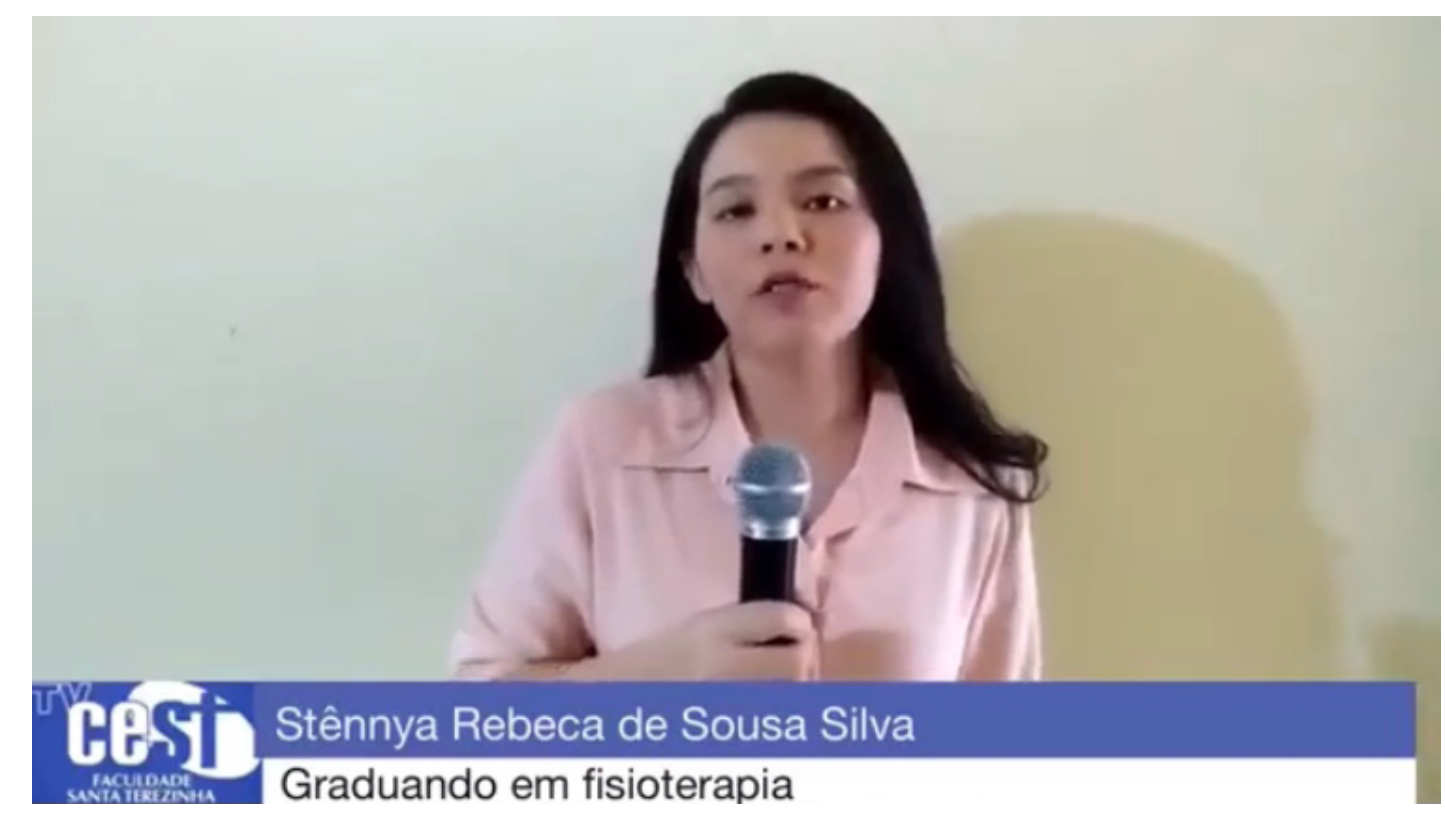

Fonte: Arquivo pessoal.

Já o discente Higor dos Santos Soares, ao falar acerca da sua percepção em relação a construção do vídeo para a disciplina de patologia, destacou que: 
Participar da elaboração do vídeo sobre oncologia, para a avaliação de patologia não foi tão simples, porém bastante interessante. A proposta desafiou a sermos além de meros estudantes, permitiu sermos transmissores de conhecimento, mesmo que a maioria dos alunos não tivesse tanta prática e habilidades em edição de vídeo ou expor o conteúdo de forma criativa.

Para finalizar o vídeo, o aluno Higor Soares discorreu sobre o papel do fisioterapeuta no tratamento oncológico abordando os principais objetivos do tratamento e as técnicas utilizadas, como apresenta a figura 3.

Figura 4 - Parte do vídeo que aborda o papel do fisioterapeuta no tratamento oncológico.

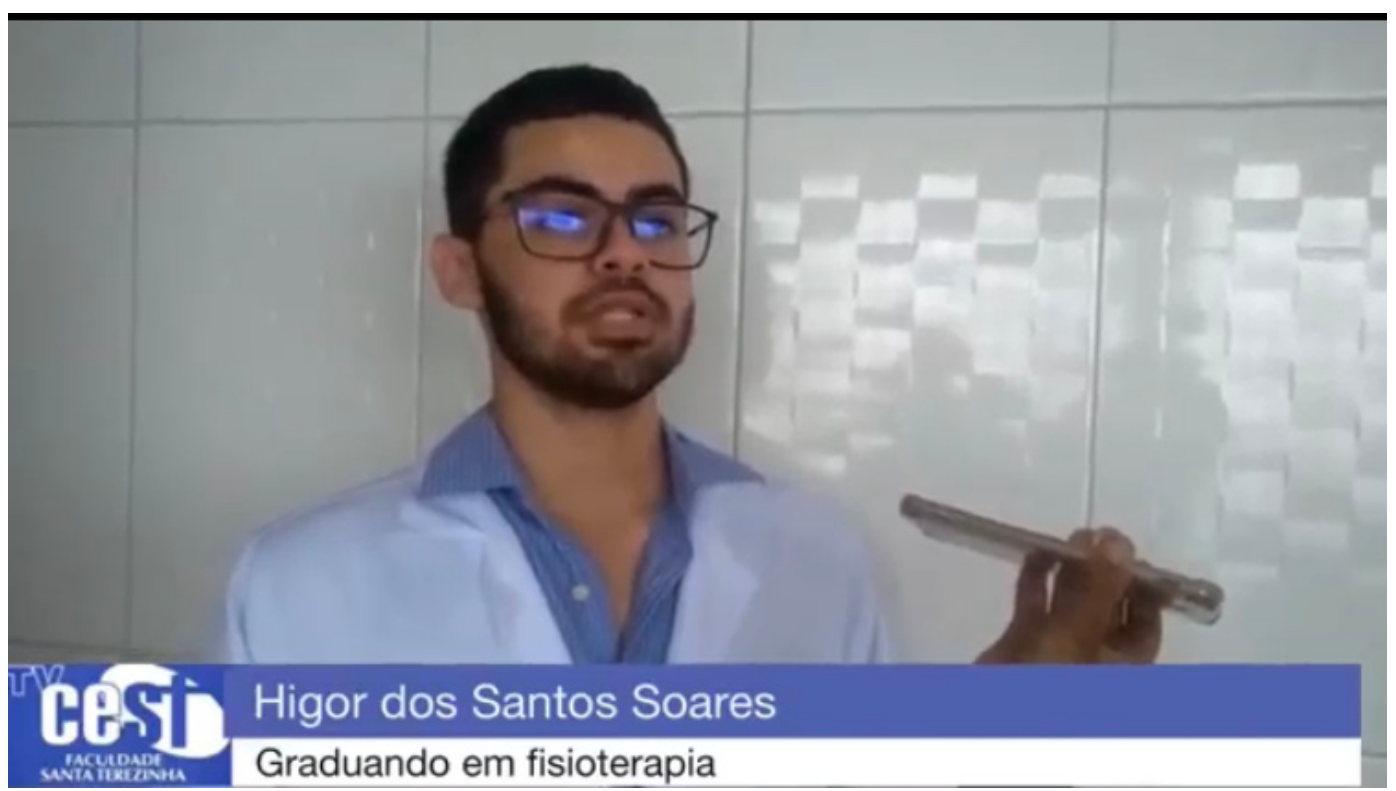

Fonte: Arquivo pessoal.

Cumpre pontuar que, em nossa vivência, o ensino remoto não afetou o vínculo aluno-professor, pelo contrário, pôde promover um maior estreitamento através da virtualização das relações através dos trabalhos desenvolvidos na forma de ensino hibrido. Lévy (1999, p. 158), discorre acerca desse tipo de metodologia pedagógica nos seguintes termos:

Mas o essencial se encontra em um novo estilo de pedagogia, que favorece ao mesmo tempo as aprendizagens personalizadas e a aprendizagem coletiva em rede. Nesse contexto, o professor é incentivado a tornar-se um animador da inteligência coletiva de seus grupos de alunos em vez de um fornecedor direto de conhecimentos.

Acerca das etapas da realização da atividade proposta, foi utilizada também a plataforma Google Classroom para encaminhamento dos documentos institucionais 
com as instruções e respectivas diretrizes utilizadas para o desenvolvimento.

Assim, os critérios de avaliação utilizados foram: Adequação e atendimento ao conteúdo proposto; forma de transmissão da síntese do conteúdo solicitado, observando-se aspectos como eloquência, segurança, domínio do conteúdo, criatividade e originalidade; atendimento das determinações de poketvideo. As determinações quanto ao formato foram: Título de até 10 palavras; tempo mínimo de 4 minutos e máximo de 8 minutos; qualidade do vídeo de mp4 ou superior. As definições quanto ao conteúdo foram as seguintes: Deve trazer definições básicas sobre os assuntos abordados no vídeo; o vídeo pode ser produzido em roteiros, ilustrações, animações, encenação, reportagens críticas, documentários, noticiários.

Foram pontuadas, ainda, algumas observações indispensáveis: a) o aparecimento do aluno no vídeo; b) necessidade de enaltecer as referências sem poluir o conteúdo visual; c) atendimento ao prazo de entrega da postagem do vídeo; d) identificação da autoria e a presença do logotipo da instituição de ensino no vídeo.

O desenvolvimento de trabalhos didáticos como este são profícuas possibilidades de aplicação de novas metodologias de ensino, as quais podem ser aplicadas de forma oportuna e enriquecedora em contextos como o atual, isto é, de medidas de combate a pandemia do Covid-19. Nesse sentido, a docente Adriana Sousa Rego relatou a sua experiência e sua percepção quanto a elaboração do vídeo, destacando:

Acredito que foi um desafio e um enfretamento ao medo, questões de aprovação, questões de valorização. Mas, acima de tudo um passo inovador, uma adaptação ao novo e uma abertura para inúmeras possibilidades de recomeço. Os vídeos elaborados foram de imensa qualidade pois despertaram expectativas e visões ampliadas do processo ensino-aprendizagem.

\section{CONCLUSÃO}

A produção de vídeos de curta duração, feitos pelos estudantes de fisioterapia do $4^{\circ}$, foi proposta como estratégia alternativa para a atividade avaliativa da disciplina de patologia. Essa construção entre os discentes de fisioterapia possibilitou uma prática inovadora de avaliação, a qual permitiu uma participação ativa dos estudantes e garantiu sua característica exploradora em tempos de ensino remoto em decorrência da Pandemia do Covid-19.

Tal produção contribuiu, ainda, para o aprimoramento do saber-fazer da fisio- 
terapia no que diz respeito a um dos seus aspectos de trabalho, o ensinar-aprender, tornando enriquecedora tal formação acadêmica em diversos aspectos, como: trabaIho em equipe, capacidade de sistematização, síntese e transmissão de conteúdo, exercício da oralidade, criatividade, originalidade, dentre outros.

O desenvolvimento da atividade propiciou também o exercício do saber se portar na frente de uma câmera em diversas situações possíveis, como: palestras, reportagens a uma emissora, produção de material audiovisual educativo, divulgação do exercício profissional, participação ativa nos espaços de formação continuada, dentre outros nos quais pode se inserir durante ou após a graduação.

\section{REFERÊNCIAS}

BACICH, L.; MORAN, J. Metodologias ativas para uma educação inovadora: uma abordagem teórico-prática. Porto Alegre: Penso, 2018. E-PUB.

CARNEIRO, V. O educativo como entretenimento na TV cultura. Um estudo de caso. Tese de doutorado, USP, 1997.

Godoy, A. S. Pesquisa qualitativa: Tipos fundamentais. Revista de Administração de Empresas. São Paulo, v. 35, n.3, p, 20-29. Mai./Jun. 1995.

LÉVY, P. Cibercultura, Trad. Carlos Irineu da Costa, $1^{\text {a }}$ edição, $1^{\text {a }}$ Reimpressão, São Paulo: Editora 34, 1999.

MODELSKI, D.; GIRAFFA, L. M M.; CASARTELLA. O. Tecnologias digitais, formação docente e práticas pedagógicas. Educ. Pesqui., São Paulo, v. 45, 2019

MORÁN, J. O vídeo na sala de aula. Comunicação \& Educação, n. 2, p. 27-35, 30 abr. 1995.

PAZZINI, D. N. A; ARAÚJO, F. V. O uso do vídeo como ferramenta de apoio ao ensino-aprendizagem. Disponível em: <https://repositorio.ufsm.br/bitstream/handle/1/729/Pazzini_Darlin_Nalu_Avila.pdf?sequence=1>. Acesso em: 02 set. 2020. 


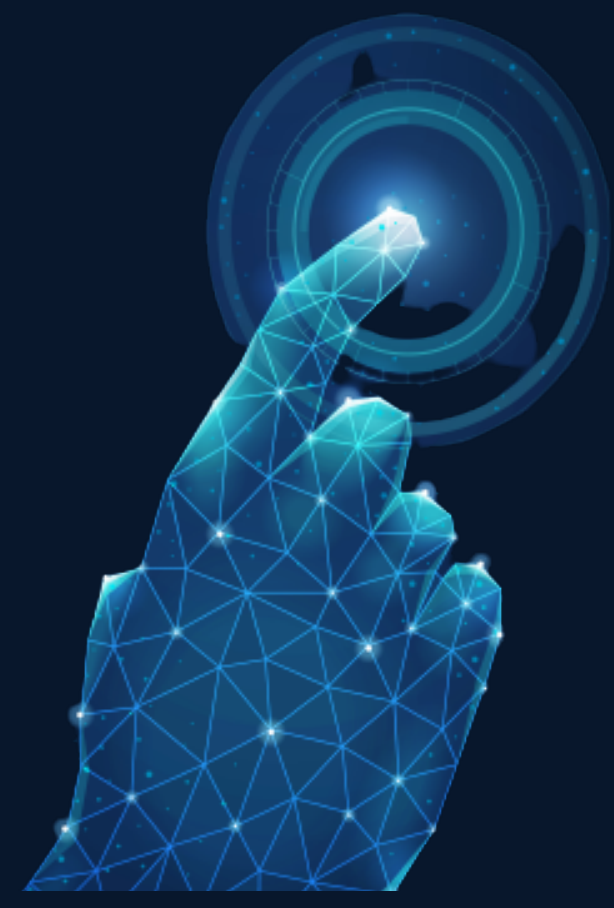

\section{O USO DA TECNOLOGIA EM TEMPO DE PANDEMIA: A COMUNICAÇÃO DOS ALUNOS DE INCLUSÃO COM OS PROFESSORES DE ATENDIMENTO EDUCACIONAL ESPECIALIZADO}

Vanessa Aparecida Palermo Campos ${ }^{1}$

1 Mestranda em Educação, pela UNESP/Marilia SP, Licenciada em Letras/Libras e Pedagogia. Atualmente é Tradutor Intérprete de Libras da Faculdade Estácio de Sá de Ourinhos SP. Email: va_palermo@hotmail.com. 


\section{INTRODUÇÃO}

Ao longo dos últimos anos, vivenciamos importantes avanços legislativos no que diz respeito aos direitos das pessoas com deficiência, sobretudo o direito a educação. A Educação Inclusiva assegura que os alunos frequentem classes comuns com colegas não deficientes da mesma faixa etária. Mas e quando o cenário atual não é o que esperamos? Vem uma pandemia, as escolas se fecham, tendo-se a impressão de que o mundo parou. E a vida tem essa habilidade de mostrar que o impensável e o improvável acontecem e que nossos horizontes de ação podem ser limitados.

Ano de 2020, na qual os professores tiveram sua profissão ressignificada, com a Covid-19, uma doença causada pelo novo Coronavírus, que dentre efeitos, pode causar morte por insuficiência respiratória, sua origem foi na China em 2019, fez com que ocorresse uma pandemia com milhares de mortes no mundo. Nessa situação, no Brasil, as escolas deixaram de funcionar presencialmente as aulas, assim, cada instituição se programou de forma remotamente para atender os alunos. Professores efetuavam e elaboravam os materiais pedagógicos para postagem em plataformas digitais educacionais e para os alunos que por acaso não tenham acesso à internet ou plataforma, também disponibilização desse material de forma impressa.

Frente a essa realidade, o objetivo deste trabalho é identificar como está ocorrendo o processo de inclusão dos alunos com deficiência com as aulas remotas frente ao cenário atual de pandemia.

Para tanto, revisou-se a literatura que trata do tema em questão, visando ampliar conceitos sobre inclusão e o professor especialista do Atendimento Educacional Especializado (AEE), utilizando, também, de uma pesquisa qualitativa feita por meio de questionários com professores da área.

A aplicação de questionários para a coleta de dados e desenvolvimento da pesquisa, parte do princípio da exploração inicial da investigação, levantando dados importantes para a sequência do trabalho e delimitação do espaço e sujeitos pesquisados.

Foram convidados a participarem do estudo, 8 professoras, que atuam no AEE em escolas da Rede Municipal de Ensino de uma cidade do interior de São Paulo. 
Todas do sexo feminino, com idades entre 32 a 67 anos.

Para a coleta de dados, foi aplicado um questionário eletrônico, elaborado pela ferramenta Google Docs. O envio foi realizado por meio de mensagem e-mails. Sobre o questionário, organizamos perguntas referentes a identificação e perfil das participantes, como nome, idade, formação acadêmica, tempo de atuação como professora de educação inclusiva, e qual deficiência é atendida. Os nomes dos participantes foram referidos pela letra $\mathrm{P}$, de professor, seguido de um número de referência pela ordem dos questionários respondidos, para que suas identidades não fossem reveladas.

Com relação aos demais enunciados, as questões foram as seguintes:

1- De acordo com o decreto $n^{\circ} 40.539$ de 19 de março de 2020, você concorda com a medida em ter aulas remotas?

2- Em questão das aulas remotas, a escola fez algum vídeo ou tutorial para orientá-lo na implantação do novo modelo de trabalho?

3- O ambiente ou canal que você está trabalhando, contém vídeo/imagem?

4- O aluno que você atende, participa das aulas online?

5- O aluno tem condições de participar das aulas/interações sozinhos sem ajuda de um familiar?

6- Você tem a colaboração/apoio do familiar?

7- Quantas horas por semana você consegue uma interação/aula com o aluno?

8- Qual a maior dificuldade que você teve/tem durante as aulas?

9- Em relação a deficiência do seu aluno, porque a aula remota dificultaria a aprendizagem dele?

Os resultados dos questionários serão apresentados na sessão de resultados e discussão.

\section{INCLUSÃO DE CRIANÇAS COM DEFICIÊNCIAS NA REDE ESCOLAR}

Sabemos que a inclusão educacional é uma realidade presente cada vez mais nas instituições de ensino. No entanto, para que ela seja de fato eficaz, há necessidade de as propostas da Educação Inclusiva acompanharem com um olhar diferenciado as singularidades humanas (MANTOAN, 2006), possibilitando uma escola como direito de todos os cidadãos, sem que haja distinção entre indivíduos, num processo 
de educação para a equidade e a qualidade. Algo já ressaltado na Constituição Federal de 1988.

A educação, direito de todos e dever do Estado e da família, será promovida e incentivada com a colaboração da sociedade. Visando o pleno desenvolvimento da pessoa, seu preparo para o exercício da cidadania e sua qualificação para o trabalho. (BRASIL,1988)

Ao se afirmar que a educação é direito de todos, faz-se necessário compreender que a educação está baseada na aceitação das diferenças e na valorização do indivíduo, independente dos fatores físicos e psíquicos que os impedem de levar uma vida tida como "normal", mesmo porque o conceito de normalidade consiste numa construção histórica e cultural mutável conforme a época em que se insere (FOUCAULT, 1996).

Nesse sentido, a Educação Inclusiva, além de quebra do conceito de normalidade, tem como princípio a participação e integração de todas as pessoas, sem exceção e preconceito (CONCEIÇÃO, 2017). Portanto, torna-se papel da escola incluir alunos com deficiência física, deficiência intelectual, superdotados, entre outros, ou seja, todas as minorias que são sujeitos de discriminação por qualquer outro motivo. Torna-se imprescindível, assim, para promover a inclusão, que as instituições de ensino conscientizem e preparem os profissionais e os alunos para que acolham e incentivem sobre o assunto (FERNANDES, 2013).

Tal fato é consonante com uma filosofia da inclusão prescrita por legislações, como a Declaração de Salamanca (1994). A filosofia da inclusão proclamada pelo referido documento propõe uma educação de qualidade a todos, aceitando as diferenças individuais como atributo e não como obstáculo, valorizando a diversidade para o enriquecimento das pessoas (UNESCO, 1994).

A Educação Inclusiva em se tratando de fator nacional ganhou força e uma maior notoriedade a partir da Constituição Federal de 1988 (BRASIL, 1988) e da Lei de Diretrizes e Bases da Educação Nacional em 1996 - LDB 9394/96 (BRASIL, 1996). Ambas ofereceram um maior respaldo as pessoas com deficiências, destacando e promovendo transformações no sistema educacional quanto financiamento, currículo, gestão, avaliação, organização pedagógica, materiais didáticos e presença de instrumentos de comunicação na escola para o atendimento a esse grupo de alunos (BRASIL, 1988; 1996). 
Essas discussões legais são reflexos dos desafios da sociedade contemporânea da tentativa de superação das relações de desigualdade, tema principalmente abordado em discussões sobre diversidade humana e ao pluralismo cultural (SACRISTAN; GOMEZ, 2009). Sendo assim, um dos desafios posto pela contemporaneidade às políticas educacionais é o de garantir o direito humano universal, social à educação (BRASIL, 1997).

Ambrosetti (1999) esclarece que trabalhar com a diversidade é uma atividade complexa, não é, portanto, ignorar as diferenças ou impedir o exercício da individualidade, pois a diversidade abrange um vasto e árduo trabalho. Ao contrário do que se pensa trabalhar com a diversidade, requer envolver o favorecimento continuo de diálogo. Neste sentido, constitui imperativo "dar espaço para a expressão de cada um e para a participação de todos na construção de um coletivo apoiado no conhecimento mútuo, na cooperação e também na solidariedade" (AMBROSETTI, 1999, p. 92).

As lutas enfrentadas pela aceitação da diversidade no âmbito escolar são grandes, no entanto, é fundamental conscientizar as crianças desde cedo a aceitar as diferenças individuais. Segundo Conceição e Moraes (2017) somente desta forma contaremos com adultos que problematizam o preconceito de todas as espécies, possibilitando a construção da escola como um espaço real para ensinar as crianças o respeito para com o próximo. Nesse sentido, os professores devem trabalhar com a questão da diversidade e inclusão discutindo com seus alunos o que nos torna iguais e merecedores de respeito.

Rendo e Vega (2000) ressaltam a importância da escola nessa atuação social. Para eles, a instituição de ensino ocupa espaço importante no processo de educação e socialização das novas gerações, na produção de mecanismos de luta pela aceitação a diversidade e inclusão escolar. Tal visão não procura dogmatizar o ensino, mas gerar uma "sociedade pluralista, democrática e socializante" (RENDO; VEGA, 2000, p. 21).

Nesse sentido, segundo Mantoan (2006, p. 25),

Inclusão é o privilégio de conviver com as diferenças, ou seja, é a nossa capacidade de entender e reconhecer o outro e, assim, ter o privilégio de conviver e compartilhar com pessoas diferentes de nós. A educação inclusiva acolhe todas as pessoas, sem exceção. [...] Ainda citando a educadora: Costumo dizer que estar junto é se aglomerar no cinema, no ônibus e até na sala de aula com pessoas que não conhecemos. Já inclusão é estar com, é 
Porém, essa batalha não é só da escola. Não basta garantir a inclusão apenas na sala de aula, a Carta para o Terceiro Milênio (BRASIL, 1999) deixa claro que em todos os setores a necessidade de inclusão é eminente, precisando quebrar as amarras da discriminação, do preconceito e da homogeneidade das pessoas. Tal documento percebe que todos os sujeitos com deficiência ou não, devem viver como seres capazes e ativos em uma sociedade.

Entretanto, a inclusão educacional acaba por assustar os diferentes profissionais, principalmente os professores. Os mesmos se sentem receosos ao receber em sua sala uma criança com deficiência. Conforme Fumegalli (2012), os professores devem se preparar para essa nova realidade e se adequar a clientela de alunos que irão receber e assim proporcionar aos mesmos às mesmas oportunidades educacionais que são oferecidas as outras crianças, e preparar para que o ambiente favoreça a aprendizagem dessa criança, desta forma é necessário compreender o papel do professor frente à inclusão.

\section{PAPEl dos professores frente À INCLUsão Com Aulas REMOTAS EM TEMPO DE PANDEMIA}

A inclusão como já destacado está conquistando cada vez mais espaço nas instituições de ensino. Desta forma é fundamental compreender o papel dos professores frente a esse processo, visto que estes são os principais agentes de transformação da realidade vivenciada nas escolas pelos alunos que serão inclusos, pois a visão que o aluno terá da escola inclusiva de primeiro momento será a visão que o professor o apresentará (MORAES; LUIZ, 2016).

Embora não seja um processo novo, a inclusão ainda não é plenamente aceita por muitos professores, pois muitos profissionais se sentem despreparados para trabalhar com crianças que possuem deficiências integradas nas salas de aula regulares da rede de ensino. (CONCEIÇÃO; MORAES, 2017). Esse cenário se tornou ainda pior devido ao impacto que o estado de emergência global oriundo da pandemia de Covid-19 teve sobre todos, principalmente, na educação.

O estado de calamidade global, em decorrência do coronavírus, trouxe a lume a necessidade de investimento e remodelamento emergencial de sistemas e práticas 
educacionais para o fortalecimento dos direitos sociais, culturais e econômicos e para a redução das desigualdades educacionais historicamente acumuladas (SILVA; SOUZA, 2020).

Nesse sentindo, os sistemas educacionais têm recorrido a plataformas digitais on-line para tentar minimizar o impacto sofrido pela pandemia. Essa solução momentânea, no entanto, levanta alguns questionamentos referentes ao acesso desses alunos às ferramentas como por exemplo: a escola pública terá estrutura para suportar as aulas, atividades e demais trabalhos no espaço virtual? Os alunos possuem os recursos necessários para conseguirem participar dessas atividades? Que atitudes os sistemas educacionais tomaram para reverter o quadro negativo dos alunos que não possuem as ferramentas de acesso como um computador e internet banda larga? Os professores receberão treinamento especifico para a instrumentalização da plataforma? Como ficam os alunos do AEE, que necessitam de um acompanhamento mais próximo com o professor?

González (2007) afirma que se houver preparação e competência do profissional para lidar de forma eficaz na preparação do projeto educativo, de realizar adaptações curriculares e de adequar-se as novas metodologias e tecnologias, o processo de ensino e aprendizagem chegará a todos os alunos com deficiência, sem dificuldades de assimilação e aplicabilidade do mesmo.

Desta forma, entendemos que se todos os aspectos para a inclusão forem devidamente atendidos - estrutura física, metodologias adequadas e as necessidades de cada aluno -, poderemos considerar que a inclusão educacional de fato estará sendo bem aplicada e que a escola estará cumprindo seu papel primordial de atender todos os seus alunos, não fazendo distinção entre os problemas que os mesmos apresentam (MAZZOTTA, 2003).

Torna-se necessário ao professor, atuante no processo educacional, refletir sobre sua formação, seu preparo para atuar nessa nova concepção de escola que está para todos. Do docente espera-se que desempenhe de forma adequada sua prática pedagógica e promova de fato uma educação de qualidade, considerando a heterogeneidade do grupo, visando o bem-estar e valorizando a aprendizagem individual de cada aluno que frequenta este ambiente (FREITAS, 2001), e que, agora, está inserido em um totalmente novo, o virtual. 
Tais reflexões, tornam fundamentais os processos de formação continuada dos docentes, acentuando o aspecto reflexivo e prático de uma tomada de consciência frente a novos desafios educacionais. Desafios esses que no momento aparecem como a inclusão digital, a atualização, adaptação e inclusão de novas práticas pedagógicas e pôr fim a sensibilidade de compreender cada estudante como um ser em desenvolvimento, e que, como tal, possui suas peculiaridades e especificidades.

Como podemos observar, o papel do professor é essencial para a aprendizagem dos alunos, no entanto, é fundamental que o professor possa se capacitar para trabalhar com seu público de maneira efetiva, visto que assim, a educação será de maior qualidade e os professores estarão aptos para exercer seu papel com competência.

\section{RESULTADOS E DISCUSSÃO}

Ao considerarmos nosso objetivo de identificar como está ocorrendo o processo de inclusão dos alunos com deficiência com as aulas remotas frente ao cenário atual de pandemia, tivemos a participação de 8 professoras, com média de 32 a 67 anos na pesquisa. Em relação a formação, todas professoras possui a graduação em Pedagogia, e as especializações em Educação Especial e Tradutor Intérprete de Libras. O tempo de experiência de trabalho na docência nessa etapa de educação declarado pelas docentes oscilou entre o mínimo de 2 anos e no máximo 9 anos. Atualmente os alunos com deficiência atendidos por essas professoras de AEE são: Deficiência Intelectual, Deficiência Auditiva e Surdez, Autismo e Síndrome de Down.

Iniciamos o questionário com uma pergunta que apontava o Decreto 40.539/2020 sobre à medida que entrou em vigor a retomada das aulas remotas, $87 \%$ responderam que concordam com as aulas remotas, e 12,5\% afirmaram que não concordam. Em face a essa afirmação, as professoras foram questionadas: "Em relação as aulas remotas, a escola produziu algum material ou tutorial para orientá-lo na implantação no novo modelo de trabalho? ". As respostas indicaram que $87,5 \%$ responderam que sim, e 12,5\% que não recebeu nenhuma orientação.

É fundamental que a escola de subsídios para que a inclusão aconteça e atenda os alunos com qualidade, pautada em elementos legais, como LDB 9394/96 (BRASIL,1996) e Constituição Federal de 1988 (BRASIL, 1988). 
Entretanto, conforme Alves (2009) relata, para uma educação inclusiva mais efetiva,

O importante não é só capacitar o professor, mas também toda equipe de funcionários desta escola, já que o indivíduo não estará apenas dentro de sala de aula. [...] Alguém tem por obrigação treinar estes profissionais. Não adiante cobrar sem dar subsídios suficientes para uma boa adaptação deste indivíduo na escola. Esta preparação, com todos os profissionais serve para promover o progresso no sentido do estabelecimento de escolas inclusivas. (ALVES, 2009, p.45,46).

Posto isto, o que se espera é que o corpo docente estejam preparados e qualificados para o trabalho da inclusão educacional. Somente, assim, pode ser "abandonada definitivamente as barreiras seletistas de aprendizagem" (SILVA, 2009, p.12) e que o meio social se adapte ao aluno incluído ao invés de buscar-se que o estudante se adapte à sociedade.

Nesse mesmo sentido, questionamos se o ambiente virtual disponibilizado possuía recursos de multimídia adequados para a necessidade do trabalho, $62,5 \%$ das professoras alegaram que sim, e outras $37,5 \%$ que não.

A inserção de metodologias diferenciadas nas aulas são fundamentais para a aprendizagem e isso não se relaciona somente as práticas para alunos de inclusão, isso é necessário para todos os alunos, pois o conhecimento flui com mais naturalidade quando os alunos se interessam e se sentem mais motivados durante as aulas. Tal elemento corrobora com o promulgado pela LDB 9394/96 (BRASIL, 1996), em seu artigo 59, em que propaga que a Educação Inclusiva precisa elaborar "currículos, métodos, técnicas, recursos educativos e organização específicos, para atender às suas necessidades" (BRASIL, 1996).

Perguntamos sobre a participação dos alunos de inclusão nessas aulas remotas, $62,5 \%$ responderam que sim, participam, e $37,5 \%$ que os alunos não participam.

Ao comentar sobre as dificuldades dos alunos em lidar com as aulas remotas, perguntamos: " O aluno atendido por você tem condições de participar das aulas/ interações sozinho e/ou sem o acompanhamento de um familiar ou responsável? ", a maioria com $87,5 \%$ demonstrou que o aluno não tem condições, e apenas $12,5 \%$ que sim, o aluno tem condições sozinhas. Em continuação nesse seguimento, foi abordado sobre a colaboração da família na realização das atividades e trabalhos propostos, $75 \%$ relataram que tem o apoio da família, outros $25 \%$ disseram que não, isso 
vindo dificultar o trabalho do professor em realizar as atividades propostas em sala de aula. Se o aluno não tem condições sozinhas e não tem a ajuda familiar, como o professor conseguiria passar algum conteúdo ou ter alguma aprendizagem com esse aluno, uma vez que, sem a participação da família, o trabalho efetivo torna-se impraticável (MANTOAN et al, 2010).

Atribui-se aos pais a responsabilidade pela formação da autoestima da pessoa com deficiência vinculando-se, portanto, a sua função quanto a formação emocional. Consequentemente os pais contribuem para a superação dos efeitos negativos da deficiência, favorecendo assim, a própria aceitação de sua condição (ROSS, 1998, p. 241)

A família necessita transmitir à criança força, superação, fortalecendo sua autoestima, deixando aquele estigma de "coitadinha", fazendo com que a mesma veja que possui capacidade.

Ao questionar quantas horas por semana em média os professores conseguem uma interação/aula com o aluno, percebemos que a maioria com $75 \%$ consegue apenas de 1 a 2 horas/semanais, outros 12,5 de 3 a 4 horas/semanais, e $12 \% 5$ nenhum.

Ao comentar sobre as dificuldades em que possui durante a realização do atendimento escolar remoto, os comentários das participantes da pesquisa giram em torno dos seguintes argumentos:

Preciso das ativades impressas para meu aluno (P1)

Meu aluno não possui computador nem internet em casa (P2)

Por ser surdos, necessito de um boa qualidade de conexão de ambas partes, porém não é o que acontece. A tela fica travando a todo momento, com isso o aluno perde partes da interpretação, vindo a dificultar a comunicação entre o aluno surdo e o intérprete. Quando a conexão cai, o aluno fica sem o atendimento, sendo difícil o professor retornar o assunto para o aluno novamente (P3)

Falta de aparelhos eletrônicos, como computador ou celular (P4)

Interação com a Plataforma de Aprendizagem de forma pedagógica (P5)

As interverções pessoais (P6)

Se concentrar nas atividades (P7)

$\mathrm{Na}$ adptação das atividades (P8)

Gonzáles (2007) afirma que se houver preparação e competência do profissional para lidar de forma eficaz na preparação do projeto educativo, de realizar adapta- 
ções curriculares e de adequar nova metodologia, o processo de ensino e de aprendizagem chegará a todos os alunos com deficiência sem dificuldade de assimilação e aplicabilidade do mesmo. Porém estamos falando de uma época em pandemia, na qual o cenário atual é árduo. Desta forma, entendemos que se todos os aspectos para a inclusão forem devidamente atendidos - estrutura física, metodologias adequadas e as necessidades de cada aluno, poderemos considerar que a inclusão educacional de fato está sendo bem aplicada e que a escola está cumprindo seu papel primordial, que é de atender todos os alunos sem fazer distinção entre as dificuldades que os mesmos apresentam (MAZZOTTA, 2003).

Ao indagar se as aulas remotas vêm dificultando a aprendizagem do aluno, as professoras respondem:

Sim, pois ele necessita de um atendimento com mais contato físico (P1)

Sim, não possui autonomia para o estudo e a família não tem condiçãoes de ajudá-lo (P2)

Sim, pois presencialmente fica mais fácil da comunicação acontecer sem interrompimento. Percebo que na forma remota o aluno surdo fica mais disperso, não aparentando ter muito interesse pelo conteúdo estudado (P3)

Sim. Meu aluno necessita de rotina, no momento está complicado as regras da pandemia. Pois o mesmo necessita de intervenção constante nas atividades. Para amenizar o momento, o mesmo vem realizando as atividades propostas com auxílio de material concreto (P4)

Sim, o aluno necessita da prática educacional e do contato com o ambiente e com o professor para que desenvolva na sua integralidade (P5)

Sim, falta o contato direto (P6)

Sim, a interação professora/aluna (P7)

Sim, pois não tem como estar junto dando atenção e apoio necessário nas atividades (P8)

Sem dúvida, não podemos deixar de falar sobre essa questão de interação professor/aluno, é nela que a formação do cidadão se realiza, estabilizando a missão maior da educação. Sabemos que a situação de isolamento social é estressante para todos, inclusive para os alunos que têm alguma limitação. A inclusão questiona não somente as políticas e a organização da educação especial e da educação regular, mas também o próprio conceito de integração (MAZZOTA, 1996).

Sendo assim, podemos observar que existe uma certa dificuldade em lidar com 
o atendimento dos alunos da AEE durante as aulas remotas devido a situação de emergência que nos encontramos. Entretanto, se faz necessário neste momento, a colaboração, união e dedicação de todos os familiares e/ou responsáveis para que estes alunos portadores de necessidades especiais sejam assistidos da maneira mais eficaz possível. E é notável que, seja por parte da família ou dos sistemas de ensino, todos estão se empenhando para que as barreiras, tão densas, sejam superadas.

\section{CONCLUSÃo}

Sabemos que ainda não temos estudos consistentes sobre esse período de isolamento social, causado pelo Coronavírus, as questões concernentes às relações interpessoais no ambiente escolar vêm sendo aos poucos comtempladas em pesquisas. Assim, destacamos que muitos são os desafios interpostos ao sistema ou rede públicas de ensino na implantação da política de inclusão escolar no Brasil, a qual assegura a matrícula do aluno com deficiência em sala de aula comum. Nessa esteira, está estabelecido, desde a Constituição Federal de 1988, como fator de equidade, que a esse alunado seja garantido AEE, e com o cenário atual, motivou a realização dessa pesquisa junto dessas professoras especialistas, atuantes em escolas públicas.

Desta forma, percebemos, é essencial que a escola, os alunos e os professores se adaptem a essa realidade, acolhendo bem esses alunos, preparando materiais adequados a aprendizagem e se aperfeiçoando para que a inclusão seja de fato significativa e promovedora de conhecimento e desenvolvimento para a vida do aluno incluso e não seja meramente mais uma forma de exclusão.

Outro aspecto importante é a parceria da família com o professor de AEE, para que as atividades propostas sejam devidamente colocadas à criança de acordo com suas possibilidades no intuito de que saiba realizá-las sentindo-se inclusa, uma vez que esse caráter da inclusão.

Percebemos percepção das professoras especialistas sobre as aulas remotas em tempo de pandemia para alunos de inclusão ainda é falha. As professoras apresentaram a falta de recursos e materiais pedagógicos adequados ao trabalho e apoio da família. É importante que se tenha mais estudos sobre a temática, considerando 
a importância de compreender questões relacionadas com o pedagógico antes, durante e pós-pandemia.

Mesmo assim, acreditamos que a escola regular deve buscar receber e atender com qualidade todos os alunos, independente das características que possam apresentar. Ela é o espaço educacional que deve ser usufruído por todos. Os alunos não devem ser deixados de "fora da escola" e mais do que isso, não devem mais ser segregados em espaços escolares diferenciados ou mesmo excluídos dentro da classe comum ou remotamente. O princípio fundamental desta política é de que o sistema regular deve atender a diversidade do alunado, isto é, todos os que se encontram excluídos, frequentadores da escola, mesmo que virtualmente.

\section{REFERÊNCIAS}

AMBROSETTI, Neusa Banhara. O "eu" e o "nós": trabalhando com a diversidade em sala de aula. In: ANDRÉ, Marli (org). Pedagogia das diferenças na sala de Aula. Campinas: Papirus, 1999. p. 81-105.

BRASIL. Carta para o Terceiro Milênio, 1999. Disponível em: http://portal.mec.gov.br/ seesp/arquivos/pdf/carta_milenio.pdf. Acesso em: 15/08/2020.

BRASIL. Constituição Federal. Artigo 205, 1988. Disponível em: http://www2.camara.leg.br/legin/fed/consti/1988/constituicao-1988-5-outubro-1988-322142-publicacaooriginal-1-pl.html. Acesso em: 23/08/2020.

BRASIL. Declaração dos Direitos de Todos 1990. Disponível em: http://www.ohchr. org/EN/UDHR/Documents/UDHR_Translations/por.pdf. Acesso em: 21/07/2020.

BRASIL. Parâmetros Curricular Nacional (PCN's). Disponível em: http://portal.mec. gov.br/seb/arquivos/pdf/livro01.pdf. Acesso em: 12/07/2020.

BRASIL. Conselho Nacional de Educação. Parecer $n^{\circ}$ 017/2001. Disponível em: http://portal.mec.gov.br/cne/arquivos/pdf/CEB017_2001.pdf. Acesso em: 23/08/2020.

CONCEIÇÃO OLIVEIRA, Érica Fernanda; DE MORAES, João Carlos Pereira. O processo de inclusão de alunos com deficiência no interior de São Paulo: entre professores de Educação Física e polivalentes. Boletim Técnico do Senac, v. 43, n. 2, 2017.

DENARI, F. Um (novo) olhar sobre a formação do professor de educação especial: da segregação à inclusão. Inclusão e educação: doze olhares sobre a Educação Inclusiva. São Paulo: Summus, p. 35-63, 2006. 
FERNANDES, P. Políticas de educação especial em Portugal: uma análise a partir de um quadro de referência europeu. Acta Scientiarum, Maringá, v. 35, n. 2, p. 201-211, July-Dec, 2013.

GONZÁLES, E. Necessidades educacionais específicas: intervenção psicoeducacional. Porto Alegre: Artmed, 2007.

FOUCAULT, Michel. Ordem do discurso (A). Edições Loyola, 1996.

FUMEGALLI, Rita de Cássia de Ávila. Inclusão escolar: O desafio de uma educação para todos? ljuí, RS. 2012

LDB - Lei de Diretrizes e Bases da Educação Nacional, Lei n 9.394, de 1996.

MITTLER, Peter. Educação Inclusiva: contextos sociais: Porto Alegre: Artmed, 2003 MANTOAN, M. Caminhos pedagógicos da inclusão. Brasília: Dina livro. 2006.

MANTOAN, Maria Teresa Eglér et al. A educação especial na perspectiva da inclusão escolar: a escola comum inclusiva. Brasília: Ministério da Educação, v. 1, 2010.

MAZZOTTA, Marcos José. Identidade dos alunos com necessidades educacionais especiais no contexto da política educacional brasileira. Movimento - revista de educação, n.07, 2003.

NÓVOA, A. Formação de professores e trabalho pedagógico. Lisboa: Educa, 1997.

OLIVEIRA, F.M. G. S. As salas de recurso como apoio pedagógico especializado à educação escolar do deficiente mental. 2004. Dissertação (Mestrado em Educação ) - Programa de Pós Graduação em Educação - UFMS.

ROSS, P. R. Pressupostos da integração: Integração frente à realidade educacional. Anais do III Congresso Ibero-Americano de Educação Especial, volume 3. Foz do Iguaçu - PR: Qualidade, 1998.

SACRISTÁN, Gimeno; GÓMEZ, AI Pérez. Compreender e transformar o ensino-4. Artmed Editora, 2009.

SILVA, Denise dos Santos Vasconcelos; SOUSA, Francisco Cavalcante de. DIREITO À EDUCAÇÃO IGUALITÁRIA E(M) TEMPOS DE PANDEMIA: desafios, possibilidades e perspectivas no brasil. Revista Jurídica Luso-Brasileira, Lisboa, v. 4, n. 6, p. 961-979, 04 ago. 2020. Disponível em: https://www.cidp.pt/revistas/ rjlb/2020/4/2020_04_0961_0979.pdf. Acesso em: 13 set. 2020. 


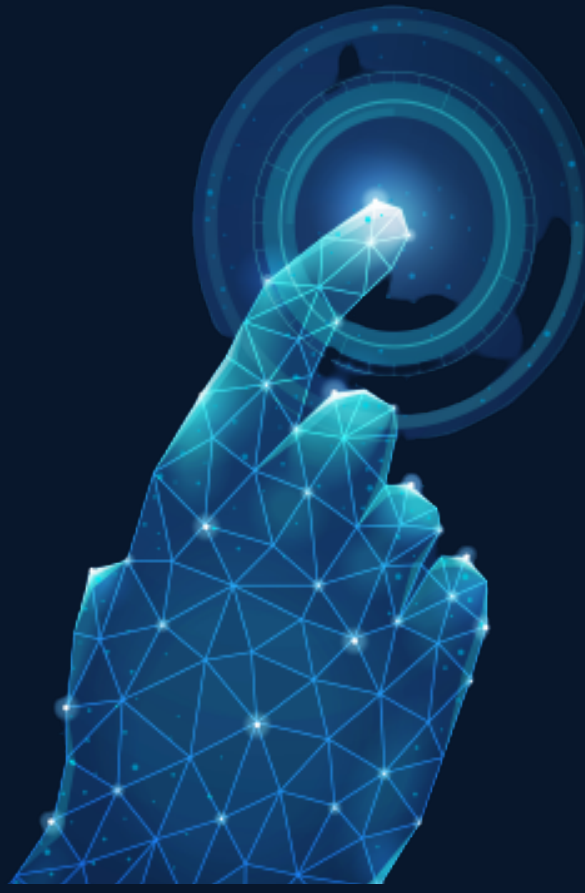

\section{O ENSINO REMOTO MEDIATIZADO POR TECNOLOGIAS: INTERAÇÃO LITERATURA INFANTIL, O BRINCAR E A CRIANÇA PRÉ-ESCOLAR}

Marlei Mitura ${ }^{1}$

Nájela Tavares Ujiie ${ }^{2}$

1 Pedagoga. Especialista em Educação Infantil, Educação Inclusiva e Gestão Escolar. Professora da Rede Pública Municipal de Cruz Machado-PR, e-mail marleimitura81@gmail.com.

2 Doutora em Ensino de Ciência e Tecnologia. Docente do Colegiado de Pedagogia e do Programa de Pós-Graduação em Ensino: Formação Docente Interdisciplinar (PPIFOR), da Universidade Estadual do Paraná, Campus de Paranavaí. Líder do Grupo de Estudo e Pesquisa em Educação: teoria e prática (GEPE) e do Grupo de Estudos e Pesquisa Práxis Educativa Infantil (GEPPEI), e-mail najelaujile@yahoo.com.br. 


\section{INTRODUÇÃO}

A Pandemia do Covid-19 desencadeada no ano de 2020 no cenário mundial impulsionou mudanças na vida cotidiana e a demanda de reinvenção dos processos educativos em todos os níveis de ensino. Nesse cenário fomos direcionados e absorvidos pelo ensino remoto emergencial.

Moreira e Schlemmer (2020) definem o ensino remoto como processo de transposição da realidade presencial a realidade digital, com metodologias, conteúdos e práticas pedagógicas típicas do universo educativo presencial, mas implicados pela urgência de ressignificar as ações educativas e formativas, a fim de promover uma educação de qualidade, designada como educação OnLife, dimensionamento com o qual coadunamos, pontuando que a vida e a educação esta e esta sendo: presencial e digital ao mesmo tempo, offline e online, contradição e movimento, dialética e dialógica, composta de processos imbricados. A educação OnLife compreende que offline e online, presencial e virtual são o híbrido da nova realidade da vida e da educação.

O ensino híbrido que vinha buscando espaço na seara educacional desde o início do século XXI, de acordo com Bacich, Tanzi Neto e Trevisani (2015), no cenário pandêmico invade a educação e a escola para ficar, mas com um delineamento próprio ao novo contexto da vida, que vem sendo ressignificada.

De acordo com Almeida (2020, p. 32): "No ensino híbrido há uma mistura literal, tanto de metodologias quanto de ações dos diversos atores envolvidos". Assim, para planejar nossas ações educativas adequada em cada nível de ensino precisamos compreender o momento e a teorização (inovação) que pode oferecer sustentáculo a práxis pedagógica.

Frente ao exposto, neste capítulo buscaremos realizar um relato de experiência reflexivo e analítico da práxis pedagógica delineada em uma turma de crianças préescolares, situada em uma cidade de pequeno porte do interior do Estado do Paraná.

Dando tessitura ao que explanaremos evidenciaremos as bases legais e a fundamentação teórica que sustentou nossa ação educacional, na sequência detalharemos a prática educativa viabilizada pela parceria família-escola, que foi tangenciada pela interação literatura infantil, o brincar e a criança em sua singularidade humana e existencial. Por fim, pontuaremos as aprendizagens construídas pela interação professor-família-aluno-conhecimento-tecnologias. 


\section{EDUCAÇÃO INFANTIL: A LITERATURA, O BRINCAR E A CRIANÇA}

A educação infantil de acordo com as Diretrizes Curriculares Nacionais da Educação Infantil (DCNEI - BRASIL, 2010) é definida como primeira etapa da educação básica, oferecida em creches e pré-escolas, às quais se caracterizam como espaços institucionais educacionais públicos ou privados que educam e cuidam de crianças de 0 a 5 anos de idade no período diurno, em jornada integral ou parcial, regulados e supervisionados por órgão competente do sistema de ensino.

Nessa seara de bases normativas e legais a educação infantil tem ancoragem em princípios éticos, políticos e estéticos, eixo norteador pautado em interações e brincadeiras que venham garantir os seis direitos de aprendizagens, à saber: conviver, brincar, participar, explorar, expressar e conhecer. Outrossim, com a aprovação da Base Nacional Comum Curricular (BNCC - BRASIL, 2018) a educação da infância reverbera ação pedagógica interdisciplinar em seus cinco campos de experiência: o eu, o outro e nós; corpo, gestos e movimentos; traços, sons, cores e imagens; escuta, fala, pensamento e imaginação; e, espaços, tempos, quantidades, relações e transformações.

Vemos, pois, que a ação educativa e pedagógica endereçada a criança da educação infantil contempla encantamento, interação, múltiplas linguagens, proatividade, dentre outros tantos elementos.

De acordo com Ujiie e Pinheiro (2017) a literatura infantil tem por característica a recriação do real numa esfera imaginativa lúdica, o que não significa imitação, mas sim uma transposição que apresenta elos, remetendo a uma determinada realidade, proporcionando ao leitor novos sentidos na sua percepção de mundo.

Segundo Coelho (2000, p. 27): "A Literatura Infantil é, antes de tudo, literatura; ou melhor, é arte: fenômeno de criatividade que representa o mundo, o homem, a vida, através da palavra". A autora complementa afirmando que tanto a literatura infantil quanto a literatura destinada ao público adulto têm a mesma essência, apenas as diferenças estão na natureza do leitor.

O contato e a apreciação de textos literários na época da infância são considerados essenciais para a formação de leitores. Sendo assim, torna-se indiscutível o papel humanizador da literatura na vida do educando e na prática da leitura literária na escola e/ou na família. O letramento literário abre a criança a um universo de possibilidades e aprendizagens (SANTOS e MORAES, 2013). 
O brincar é linguagem peculiar à criança da primeira infância. Igualmente a BNCC (BRASIL, 2018) ao considerar a criança em sua essência e integralidade pondera que a interação e a brincadeira é o ponto chave das propostas pedagógicas para a educação infantil.

Ujiie (2014, p. 90) pondera o brincar como laboratório do pensamento infantil, espaço-tempo da criança, âmbito constituído por uma linguagem simbólica singular. "[...] O brincar funciona como cenário no qual a criança se constitui como sujeito que atua e cria a partir de seu potencial de desenvolvimento e cultura, elaborando seu próprio conhecimento".

Nessa conjuntura a criança é tida por nós como potente, sujeito de direitos, ativa, inventiva, capaz de aprender e produzir cultura, por meio da interação que lhe é peculiar. A criança é determinante e determinada está aberta a múltiplos estímulos, significações e aprendizagens.

Assim, observamos que o contexto de vida e educação se interpenetram e sofrem influência mútua a todo tempo. A Pandemia do Covid-19 acaba por forjar um novo modelo educativo, com base na Educação OnLife, ancorada numa nova realidade que é o ensino híbrido (online/offline), o qual se articula ao paradigma da complexidade a muito emergente no cenário educacional e social, que evidencia um ecossistema educativo/social presente na figura apresentada a seguir como forma de exemplificação.

Figura 1 - Ecossistema Educativo/Social OnLife

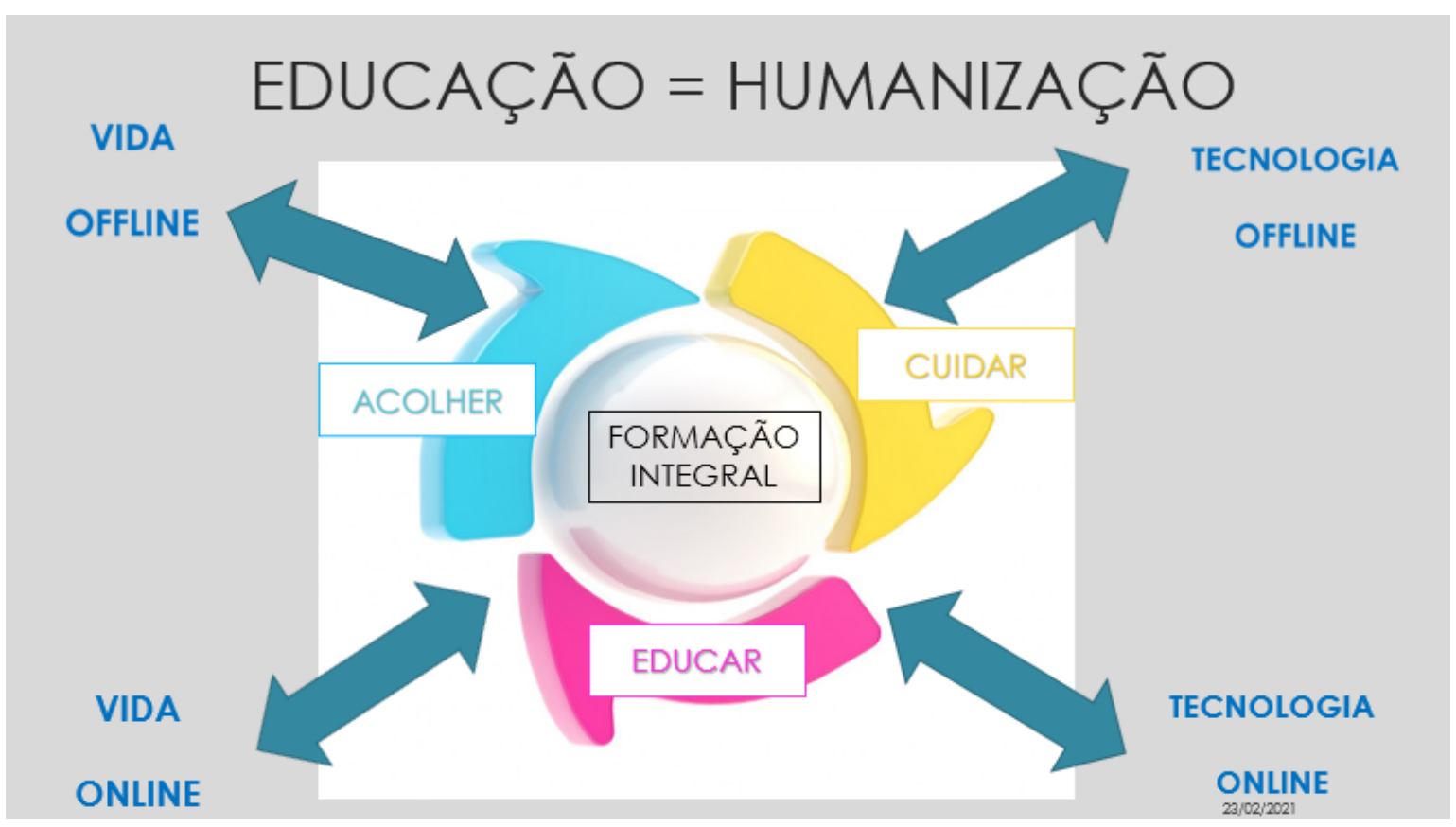

Fonte: Curso de Formação de Professores da Educação Infantil, Ujiie (2021). 
Vida, educação e tecnologia tem interrelação mútua e constante no processo da formação integral do sujeito, que no cenário pandêmico precisa ser acolhido, cuidado e educado, para se formar em plenitude permeado de ações e interações conectivas entre online/offline o híbrido da nova realidade mundo.

Considerando as bases legais e teóricas explicitadas é que buscamos delinear nossa práxis educativa e o trilhar do processo ensino-aprendizagem em uma turma de pré-escolares, o qual detalharemos na seção subsequente.

\section{INTERAÇÃO LITERATURA INFANTIL, O BRINCAR E A CRIANÇA PRÉ- ESCOLAR: RESULTADOS E DISCUSSÃO}

No período pandêmico e de isolamento social foi necessário adaptar nossas práticas educativas para manter a interação com as crianças da educação infantil. Propusemos as famílias uma parceria efetiva, para que estimulassem as crianças nas vivências do cotidiano, proporcionando conhecimento e autoconhecimento pelas interações e brincadeiras, com interlocuções semanais e envio de propostas educativas, junto à turma de pré-escolar (infantil IV), composta por onze crianças de quatro a cinco anos.

No decorrer das interações remotas percebemos que a cada semana íamos nos distanciando, muitos não lembravam o nome dos colegas e da professora, o que vinha sendo construído começou a desconstruir-se. Assim, buscamos uma experiência que fortalecesse o vínculo da turma, de forma online, com ancoragem na literatura infantil e na brincadeira como fonte de aprendizagem, significação, produção de sentido e significado.

Nesse bojo, ao planejar a ação pedagógica consideramos as dez competências gerais da BNCC (BRASIL, 2018): 1. conhecimento, 2. pensamento científico, crítico e criativo, 3. repertório cultural, 4. comunicação, 5. cultura digital, 6. trabalho e projeto de vida, 7. argumentação, 8. autoconhecimento e autocuidado, 9. empatia e cooperação, e, 10. responsabilidade e cidadania. Primamos por estabelecer uma parceria profícua com a família pautada numa relação de interdependência e coparticipação regida por afetividade e diálogo.

Neste contexto com respaldo em Almeida (2020) orientamos as famílias a se enxergarem como parte do ecossistema educativo atual, que se materializa e se con- 
solida pela interação entre professor-família-aluno-conhecimento-tecnologias.

Assim, buscamos esclarecer os papéis pontuando que os familiares/responsáveis são tutores que participam efetivamente em casa, da condução educativa e efetivação das atividades, registram em fotografia, áudio ou vídeo, coletam observáveis do processo ensino-aprendizagem, que serão encaminhados para análise e avaliação dos professores.

Nós professores continuamos comprometidos com a curadoria do processo ensino-aprendizagem, responsável pelo planejamento, intencionalidade educativa, roteiro e encaminhamento didático-pedagógico, documentação pedagógica reflexiva, avaliação da aprendizagem da criança e do processo educativo.

Para consolidar a ação educativa iniciamos o roteiro de aprendizagem orientando as famílias a assistir com as crianças, na página do You Tube "Varal de histórias" a contação da história de Isabella Carpaneda e Angiolina Bragança: "Quer brincar de pique-esconde?"

Na sequência conversamos por áudio com as crianças sobre a brincadeira, se eles conheciam, se já haviam brincado e se gostariam de brincar. Uma criança relatou que não tinha nenhum amigo para brincar, então propusemos para as crianças convidar as pessoas da família que estavam em casa e brincar de pique-esconde dentro de casa, a atividade foi realizada por $90 \%$ da turma, com retorno de observáveis (fotografias, áudios e vídeos).

As crianças gostaram da brincadeira em família, propusemos que lembrassem a experiência relatassem e fizessem o registro pictórico, em um desenho que poderia ser colorido. Foram criativos os desenhos, a maioria das crianças não possuíam traços definidos e as famílias escreveram ao lado do desenho o que a criança queria representar, algumas crianças com mais desenvoltura para vídeos explicaram por vídeo o desenho a turma. A figura 2 possibilita a visualização dos momentos narrados acima. 
Figura 2 - O Brincar de Pique-Esconde e o Registro Pictórico

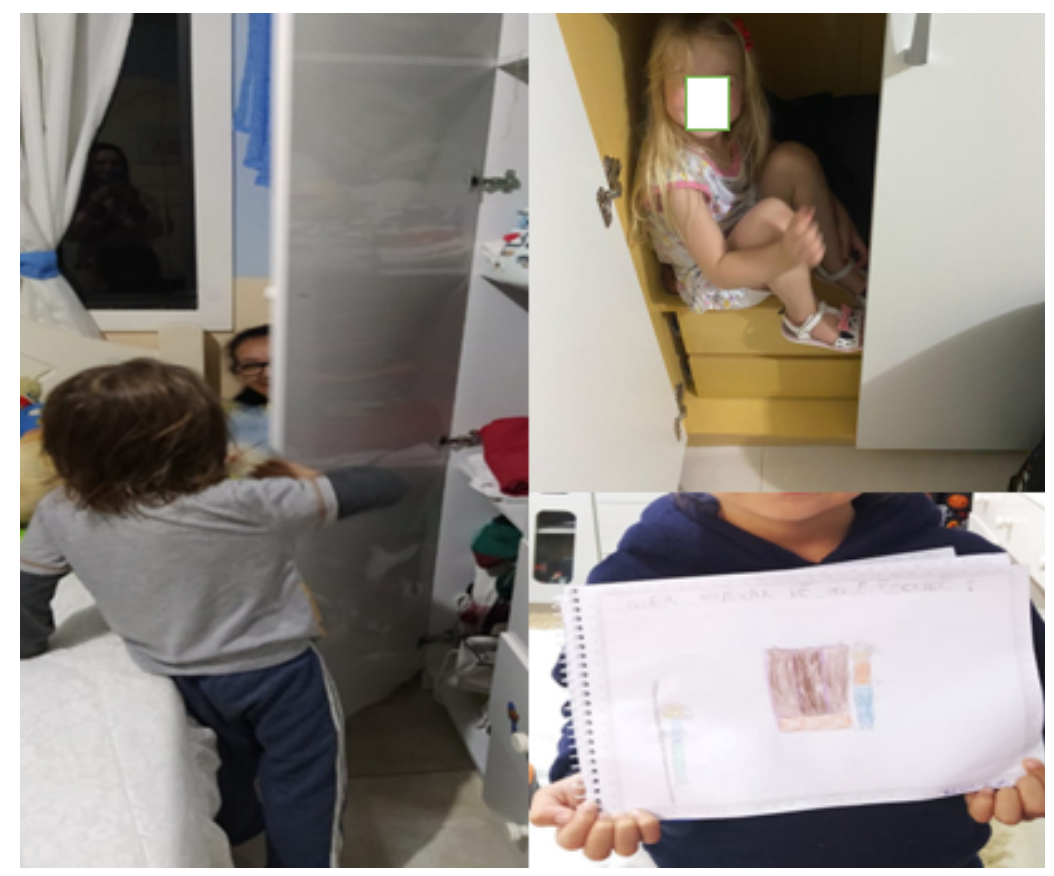

Fonte: Acervo das autoras, 2020.

Observamos que o encantamento da história e da brincadeira em um contexto significativo, auxiliou a criança a representá-lo e construir noções básicas de orientação espacial dentro, embaixo, atrás, desenhando-se dentro do guarda-roupa, embaixo da mesa, atrás do sofá. Cada família realizou a atividade no seu tempo, compartilhando as conclusões no grupo do WhatsApp da turma no decorrer da semana.

$\mathrm{Na}$ continuidade, solicitamos que as crianças assistissem novamente a contação da história e na sequência orientamos para a criança escolher um bicho ou uma página da história que mais gostou e com ajuda da família reconstruir essa parte da história. Por áudio explicamos para trocar o nome do bicho pelo seu nome e a parte do corpo do bicho por uma parte do seu corpo, mantendo palavras que rimam na história. Pedimos as famílias que brincassem com as rimas da história para a criança entender e depois de explorar as rimas a criança ia montando as frases e o adulto escrevendo. Explicamos as famílias à importância deste momento de escrita onde o adulto é o escriba e estimula a criança a perceber que o que se fala pode ser escrito.

Mediante esta ação foi produzido um texto coletivo da turma, o qual foi estruturado no formato livro e distribuído às crianças, o qual possibilitou a retomada dos nomes e a produção da identidade coletiva da turma de pré-escolares do infantil IV, com os nomes das crianças e da professora. Na ocasião confeccionaram com o ma- 
terial encaminhado fantoches a partir de copos descartáveis, que tiveram afixados as fotografias de todos os membros da turma, possibilitando a teatralização da história e o brincar de faz-de-conta com o grupo sala modulado. A ação perdurou por cerca de cinco semanas com produção de significados fecundos as crianças, suas famílias e também a seara educativa os quais temos anseio de disseminar para inspirar outras práticas. A figura 3 evidencia os momentos vivenciados.

Figura 3 - Momentos Vivenciados na Ação Educativa em Ensino Remoto

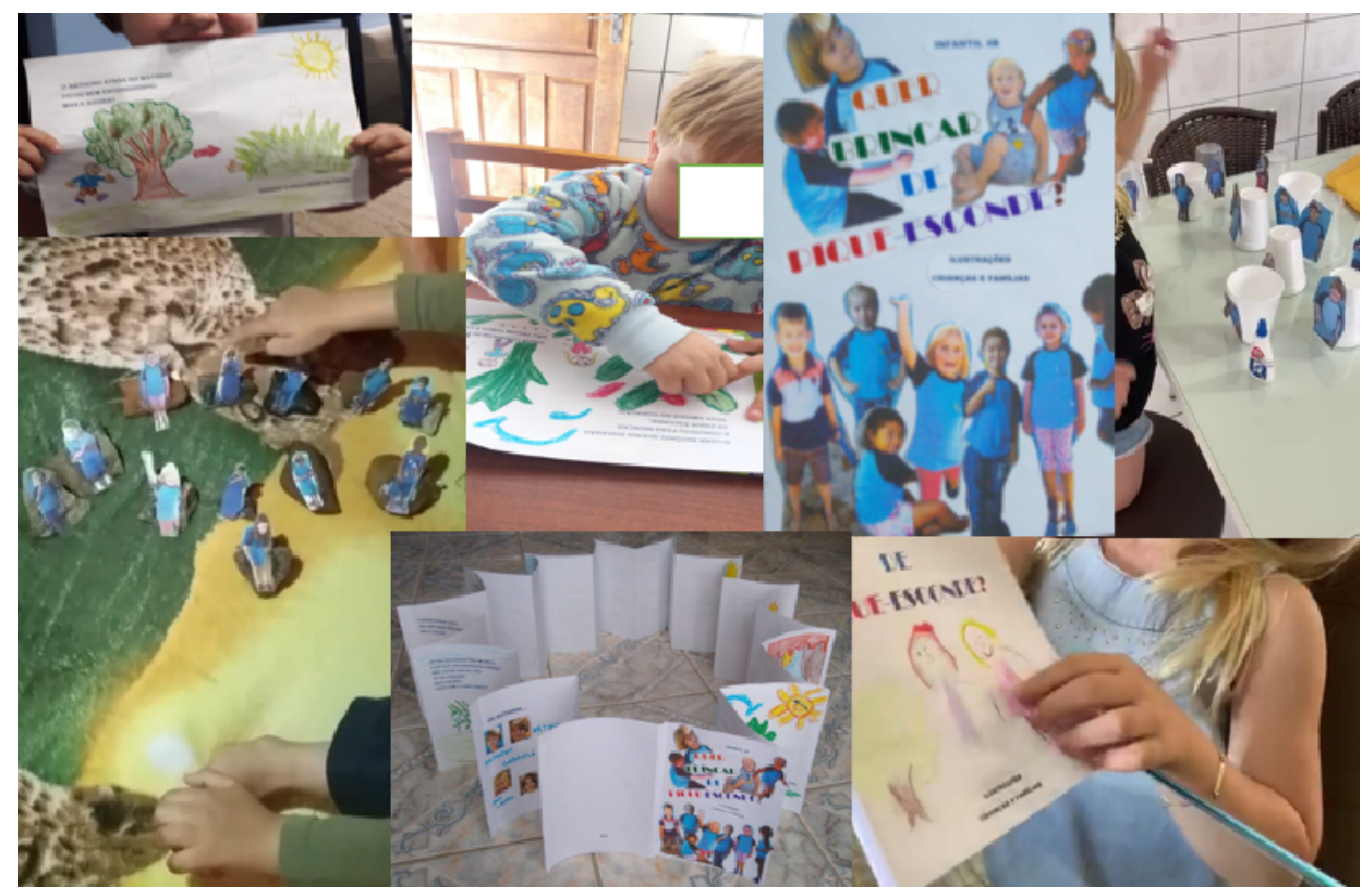

Fonte: Acervo das autoras, 2020.

A experiência educativa desenvolvida com a articulação da literatura infantil e do brincar possibilitou momentos de aprendizagem vinculado ao lúdico e ao prazer. Criança gosta de histórias e a educação infantil é espaço oportuno para apresentar o universo literário, realizar imersão, vivencia significativa neste âmbito e também produzir adaptações de textos literários como a realizada por este coletivo que apresentamos no quadro 1 a seguir transcrita, que foi oportunizada pela ação interativa e parceira entre professor-família-aluno-conhecimento-tecnologias. 


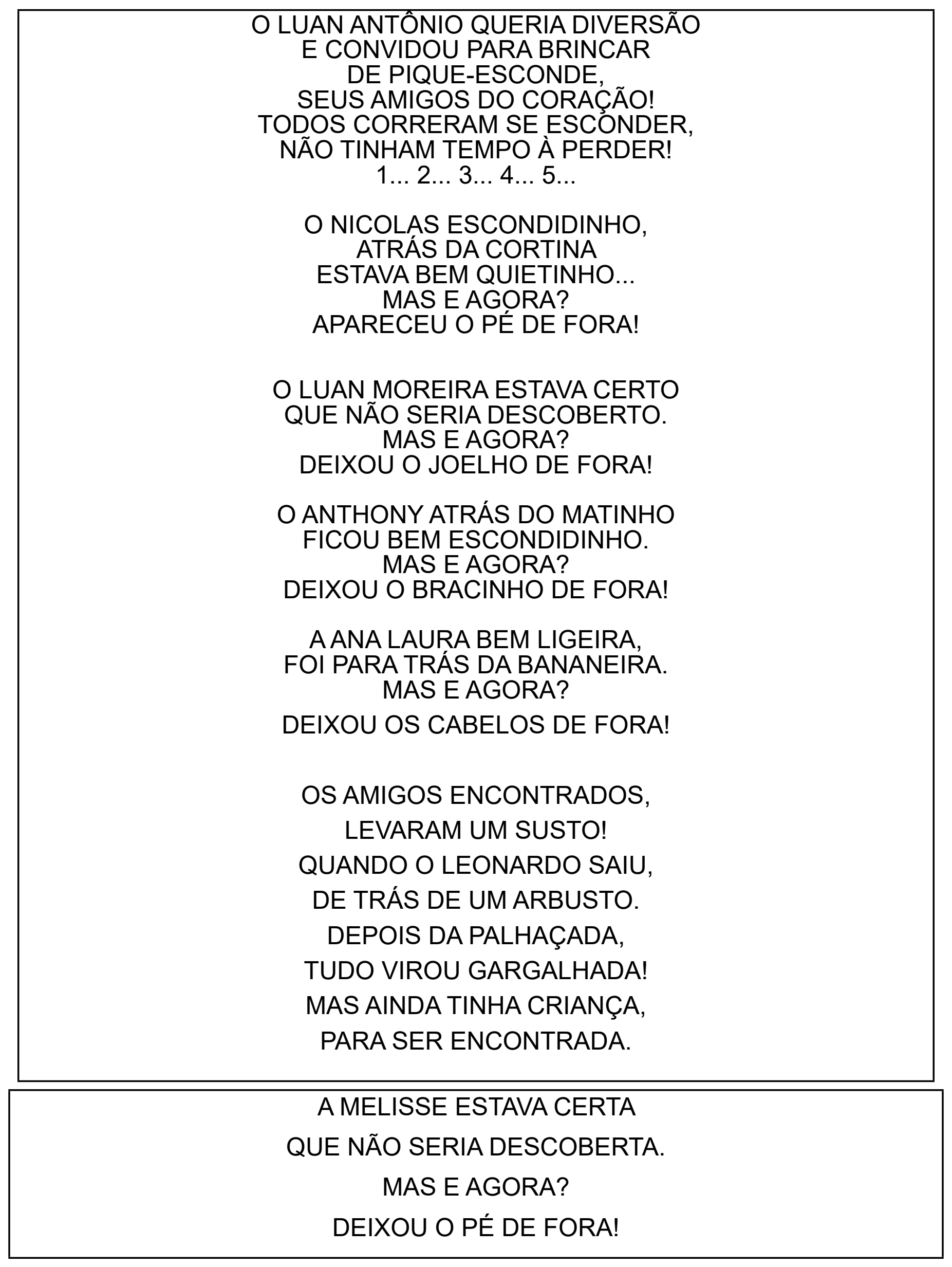


O THALYSON ENCOLHIDINHO,

ATRÁS DOS GALHOS FICOU

QUIETINHO.

MAS E AGORA?

DEIXOU A CABEÇA DE FORA!

A GABRIELA ENTROU NUMA TOCA

E SE ESCONDEU BEM DIREITINHO.

MAS E AGORA?

DEIXOU O DEDINHO DE FORA!

A ESTER ESTAVA CERTA

QUE NÃO SERIA DESCOBERTA.

MAS E AGORA?

DEIXOU A PERNA DE FORA!

SÓ FALTAVA ENCONTRAR UM AMIGO,

O ARTHUR, QUE PRESSENTIA O PERIGO

BEM LIGEIRO SAIU DE TRÁS

DE UM COQUEIRO.

MAS E AGORA?

FICOU COM O CORPO TODO DE FORA!

TODOS GOSTARAM DE BRINCAR,

FELIZES SENTARAM

PARA DESCANSAR

E OUVIR UMA HISTÓRIA!

Fonte: Produção Coletiva - Infantil IV, crianças e famílias 2020.

A participação das famílias no desenvolver das atividades e devolutivas no grupo do WhatsApp da turma por vídeos e fotos foi fundamental, assim foi possível observar durante as atividades, a participação ativa das crianças em sugestões e trocas de ideias que contribuíram para o desenvolvimento e aprendizagem.

A construção do livro e dos fantoches ajudou a reestabelecer o vínculo da turma, fortaleceu o sentimento de pertencimento ao grupo de pré-escolares do infantil IV. Ao realizar as atividades remotas as crianças desenvolveram-se plenamente de forma concreta e prazerosa com a coparticipação das famílias, que tiveram envolvimento e se sentiram engajadas no trabalho de formação integral da criança, constituindo um ecossistema educativo/social com resultado exitoso para as crianças-alunos e para docente estrategista desta ação educacional. 


\section{CONSIDERAÇÕES FINAIS}

Ao concluir este relato o propósito é clarificar o que é educação OnLife e ensino híbrido como eles tomam parte do cenário educacional pandêmico de ensino remoto, e de que forma podem contribuir para repensar o planejamento da rotina e dos roteiros de aprendizagem desde a educação infantil.

Igualmente referendamos a importância da parceria família-escola para superar desafios e dar materialidade ao processo ensino-aprendizagem, com respeito, engajamento, partilha, afeto, diálogo, disposição e coparticipação.

Enfim, documentamos o percurso e narramos ao longo deste capítulo para dar a ele possibilidade de existir e coexistir em outras realidades, que o tomem como inspiração para ação educativa.

\section{REFERÊNCIAS}

ALMEIDA, Geraldo Peçanha de. Ensino Híbrido: rotas para implantação na educação infantil e no ensino fundamental. Curitiba-PR: Pró Infantil, 2020.

BACICH, Lilian, TANZI NETO, Adolfo, TREVISANI, Fernando de Mello. Ensino Híbrido: personalização e tecnologia da educação. Porto Alegre-RS: Penso, 2015.

BRASIL. Ministério da Educação. Diretrizes Curriculares Nacionais para a Educação Infantil. Secretaria de Educação Básica. Brasília-DF: MEC, SEB, 2010.

BRASIL. Base Nacional Comum Curricular. Brasília-DF:SEB, 2018.

CARPANEDA, Isabella; BRAGANÇA,Angiolina. Quer brincar de pique-esconde? São Paulo: FTD, 2006. Disponível em: https://www.youtube.com/watch?v=VRfxt6kHx1c

COELHO, Noely Novaes. Literatura infantil: teoria, análise, didática. São Paulo: Moderna, 2000.

MOREIRA, José António; SCHLEMMER, Eliane. Por um novo conceito e paradigma de educação digital onlife. In: Revista UFG. 2020, V.20, 63438. Disponível em: https:// www.revistas.ufg.br/revistaufg/article/view/63438/36079

SANTOS, Fábio Cardoso dos; MORAES, Fabiano. Alfabetizar letrando com a literatura infantil. São Paulo: Cortez, 2013. (Coleção biblioteca básica de alfabetização e letramento). 
UJIIE, Nájela Tavares. O lúdico como direito e manifestação cultural da infância: apontamentos e interlocuções. In: PELOSO, Franciele Clara Peloso; SILVA, Sandra Salete de Camargo. Infância e inclusão: cenas da experiência humana. Curitiba: Íthala, 2014, p. 81-110.

UJIIE, Nájela Tavares. PINHEIRO, Nilcéia Ap. Maciel. Prática pedagógica interdisciplinar: articulação entre enfoque CTS e a literatura infantil. In: UJIIE, Nájela Tavares; PIETROBON, Sandra Regina. Práxis educativa e infância: intersecções para a formação integral da criança. Curitiba-PR: CRV, 2017, p. 145-158. 


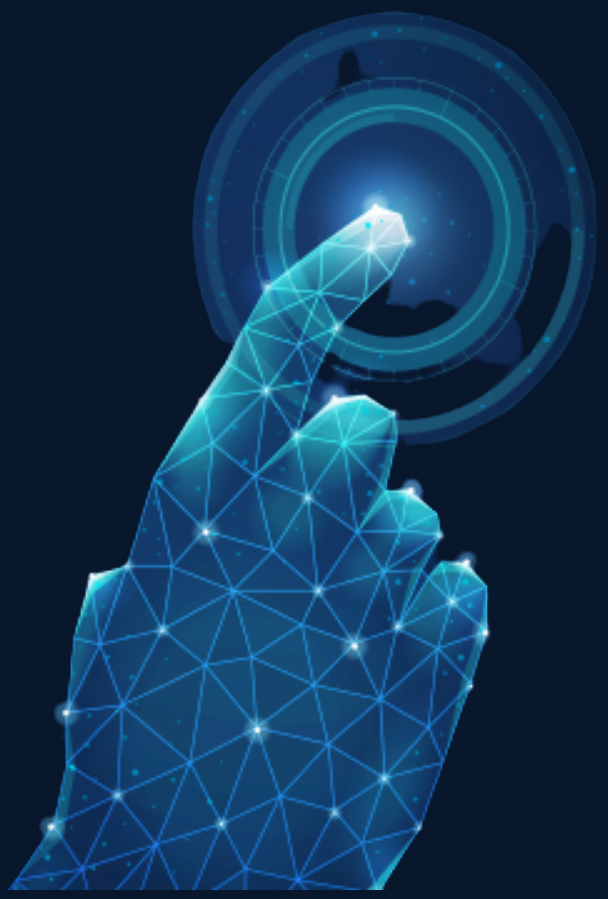

\section{O PROCESSO DE INCLUSÃO DIGITAL EM UMA ESCOLA PÚBLICA ESTADUAL DE SÃO JOÃO DA SERRA - PI}

Letícia Maria da Silva ${ }^{1}$

1 - leticiasjs2020@hotmail.com. Orientador: Elayne Cristina Rocha Dias - elaynedias2017@ outlook.com 


\section{INTRODUÇÃO}

Na sociedade contemporânea ao qual estamos vivenciando, presenciamos as inovações tecnológicas ocorrendo a todo tempo. Com isso, notamos as diversas mudanças que o mundo vem percorrendo, tanto na economia, quanto na sociedade.

Com o decorrer dos avanços tecnológicos, notamos que as escolas vêm com o intuito de modernizar a metodologia tradicional usada pelos professores, pois os mesmos presenciam o uso das tecnologias dentro e fora da sala de aula pelos alunos. As tecnologias são facilitadoras para abrangência da informação, mas infelizmente nem todos usufruem desses meios. Desse modo, com o surgimento e avanços das tecnologias, surgiu-se a necessidade da inclusão digital.

Segundo Silva et al. (2005), inclusão digital representa a coexistência complexa de conceitos, cujo ponto central é a educação para a informação. Teixeira (2010) chama a atenção para que o processo de inclusão não se torne apenas a inclusão do indivíduo como consumidor.

Com isso, a escola torna-se uma das principais facilitadoras para a inclusão digital. Incluir é usufruir o que se tem direito, fazer parte do que lhe é apresentado e poder agir de forma democrática. A inclusão digital corresponde a um meio para que todos possam ter acesso às tecnologias da informação, mas o incluído digitalmente não é somente aquele que faz uso dessa tecnologia para os seus meios privados, mas também usufrui dessas tecnologias para sua carreira profissional, uso como meios de comunicação, formas de obter aprendizado entre outras.

Segundo Dorneles (2012), é preciso que os professores sejam formados adequadamente, para implementarem o uso das Tecnologias de Informação e Comunicação (TICs) no processo de ensino-aprendizagem.

Sendo assim, torna-se necessário a formação continuada dos professores. Eles não estão familiarizados com as tecnologias da informação dentro da sala de aula, com isso as tecnologias se tornam um desafio enorme no ambiente ensino. Com a dificuldade permanente dos professores quanto ao uso das tecnologias da informação, torna-se impossível de ser inserida a inclusão digital no contexto escolar, pois os mesmos não serão capazes de auxiliar os alunos no uso dessas tecnologias. 
A relevância do tema a ser explorado diz respeito à inclusão digital: Possibilidades e desafios em uma escola de ensino médio. Portanto, esse trabalho é de grande importância acadêmica, educacional e social, visando à qualidade na educação.

A escola é o principal agente na vida dos alunos, faz parte do papel escolar formar cidadãos democráticos e capazes de utilizar os meios tecnológicos para ampliar os seus conhecimentos e garantir o uso das tecnologias para o meio profissional.

A escola pública localizada no município de São João da Serra-PI tem passado por diversas dificuldades com as tecnologias, assim implicando de forma negativa na inclusão digital. Diante das dificuldades existentes, a escola busca alguma possibilidade para que haja inclusão digital dentro da instituição.

Mediante disso, levantou-se o seguinte problema: Quais as possibilidades e os desafios na inclusão digital em uma escola de ensino médio no município de São João da Serra-PI? Em busca de alcançar respostas sobre essa problemática, temos como objetivo geral: Analisar os desafios e as possibilidades em relação à inclusão digital em uma escola do Ensino Médio de São João da Serra- PI.

Os específicos consistem em: Identificar as tecnologias de informação existentes dentro do contexto escolar e Definir a eficiência e a eficácia das tecnologias da informação para a inclusão digital dos educadores e educandos na escola de ensino médio no município de São João da Serra-PI. Assim, esses objetivos são norteadores para o desenvolvimento da presente pesquisa.

O presente trabalho justifica-se pela emergência da inclusão digital nas instituições de ensino. As tecnologias estão avançando cada vez mais. Assim, fazendo com que elas fiquem mais presentes ainda nas salas de aula. Dessa forma, torna-se notório a ampla dimensão que as tecnologias estão tomando no âmbito escolar.

As motivações para a presente pesquisa partiram-se ao ver as dificuldades da inclusão digital no ensino médio, essas observações foram feitas com o decorrer dos estágios praticados ao longo da graduação. Além disso, o fato de ter estudado na instituição ao qual a pesquisa está sendo feita, torna-se um dos motivos para a escolha do tema, pois já obtenho um breve conhecimento das dificuldades e das possibilidades que a escola tem para que a inclusão digital aconteça. 
computadores na educação, em lugar de reduzir, pode expandir a capacidade crítica e criativa de nossos meninos e meninas. Dependendo de quem o usa, a favor de que e de quem e para quê. O homem concreto deve se instrumentar com o recurso da ciência e da tecnologia para melhor lutar pela causa de sua humanização e de sua libertação. (FREIRE, 2001, p. 98)

Assim, como Freire (2001), justifica-se que as tecnologias podem abrir possibilidades, horizontes e tornar-se um sujeito mais crítico dentro da sociedade. Sendo assim, a inclusão digital deve existir dentro do âmbito de ensino-aprendizado, mas que seja igual para todos os envolvidos no contexto escolar.

Destaca-se como metodologia uma abordagem qualitativa, realizada por métodos bibliográficos, a partir das leituras de Freire (2001), Silva Filho (2003), Teixeira (2010), dentre outros, com aplicação de questionários com professores do $3^{\circ}$ ano do ensino médio, diretores e pedagogos desta instituição.

Dessa maneira, espera-se uma contribuição em relação ao tema apontado, para que as discussões sobre inclusão digital sejam mais aprofundadas e saiam da teoria para a prática.

Muitas instituições passam por dificuldades de inserção tecnológica devido à falta de manutenção dos recursos. Portanto, o tema é de suma importância para a promoção da igualdade tecnológica e sua rapidez dentro das instituições.

Enfim, esse trabalho divide-se em: (I) Introdução, constando tema, problemática, objetivos, justificativa e metodologia; (II) Referencial Teórico, intitulado "O Processo de Inclusão Digital no Contexto Educacional"; (III) Metodologia; (IV) Resultados e Discussões; (V) Conclusões e Referências.

\section{O PROCESSO DE INCLUSÃo DIGITAL NO CONTEXTO EDUCACIONAL}

O processo de inclusão digital vem a cada dia contribuindo para modificações na vida dos sujeitos em nossa sociedade. Desta maneira, esse trabalho procura evidenciar aspectos relacionados às dificuldades surgidas no processo de inserção digital no contexto escolar, em particular, no ensino médio de São João da Serra- PI. A próxima seção, abordará sobre o conceito de inclusão digital e as dificuldades e possibilidades enfrentadas pelas instituições na implementação nesse processo. 


\subsection{O conceito de inclusão digital, as dificuldades e possibilidades em sua implementação na instituição de ensino}

Uma das grandes dificuldades percorridas pelos participantes das diversas instituições de ensino corresponde à implementação da tecnologia. A escola busca inovar a forma de ensino-aprendizagem através das tecnologias de informação e comunicação (TIC), como promoção de metodologias diversificadas (Carneiro, 2015).

Neste sentido, faz-se necessário a implementação de recursos tecnológicos na promoção do processo de ensino- aprendizagem dos estudantes, destacando as dificuldades e vantagens nesse procedimento. Outro ponto corresponde à compreensão do conceito de inclusão digital.

Segundo Pacheco (2011), a educação digital no cotidiano escolar, reflete sobre a prática pedagógica dos docentes da instituição, como ferramenta essencial para a transformação e aquisição de saberes. Assim, a formação continuada dos profissionais pedagógicos é um desafio a ser enfrentado.

Inclusão digital é a denominação dada, aos esforços de fazer com que a sociedade possa obter os conhecimentos necessários para utilizar com um mínimo de proficiência os recursos da tecnologia de informação e da comunicação existentes e dispor de acesso regular a esses recursos. (XAVIER, 2005, p. 2)

Ainda sobre as dificuldades no processo da inclusão digital, o artigo de Lima et e al (2015) relata que muitas escolas não possuem os recursos adequados e outras instituições possuem recursos, mas não apresentam profissionais capacitados para a utilização deles.

Neste sentido as referências destacadas nesta seção, apresentam pontos em comuns tais como: conceitos de inclusão digital, que equivale a uma extensão natural para o contexto digital, estabelecendo como objetivo a acessibilidade para o maior número de sujeitos.

Enquanto muitos autores focam nas dificuldades do processo de inclusão, o trabalho de Pacheco (2011), reflete sobre a importância de uma formação continuada para os docentes, mas em que muitos lugares essa capacitação não acontece por inúmeros fatores, como por exemplo a falta de recursos financeiros por parte das secretarias de educação.

Assim, percebe-se que essas referências trazem impactos na sociedade, no sentido de provocar auxílio, ampliação e construção de novos saberes dentro do co- 
tidiano escolar e social.

Além desses autores, procurou-se fazer um levantamento bibliográfico na plataforma do Google Acadêmico, com o intuito de aprofundarmos a temática. Estabeleceu-se como descritor "Inclusão Digital na Escola".

\section{METODOLOGIA}

Para melhor compreensão da metodologia optou-se pela divisão em tópicos.

\subsection{Tipo de pesquisa}

A presente pesquisa caracteriza-se com abordagem qualitativa e do tipo bibliográfica. Busca-se compreender os desafios e as possibilidades na inclusão digital em uma escola de ensino médio localizada no município de São João da Serra-PI. A pesquisa qualitativa é um método de investigação, esse tipo de pesquisa tem como foco principal entender o comportamento do consumidor. Desse modo, essa pesquisa não apresenta resultados em números exatos. Baptista e Cunha (2007, p. 173) fazem a seguinte definição sobre esse tipo de pesquisa:

A pesquisa qualitativa focaliza a sua atenção nas causas das reações dos usuários, da informação e na relação do problema informacional, ela tende a aplicar um enfoque mais holístico do que o método quantitativo. Além disso, ela dá mais atenção aos aspectos subjetivos de experiência e do comportamento humano.

A pesquisa bibliográfica é uma revisão da literatura, ou seja, esse tipo de pesquisa tem como objetivo fazer uma junção, ou reunião, do que se tem falado sobre determinado tema. Boccato (2006, p. 266) faz o seguinte esclarecimento:

A pesquisa bibliográfica busca a resolução de um problema (hipótese) por meio de referenciais teóricos publicados, analisando e discutindo as várias contribuições científicas. Esse tipo de pesquisa trará subsídios para o conhecimento sobre o que foi pesquisado, como e sob que enfoque e/ou perspectivas foi tratado o assunto apresentado na literatura científica. Para tanto, é de suma importância que o pesquisador realize um planejamento sistemático do processo de pesquisa, compreendendo desde a definição temática, passando pela construção lógica do trabalho até a decisão da sua forma de comunicação e divulgação.

A próxima seção irá retratar sobre a caracterização dos sujeitos e amostra dessa pesquisa. 


\subsection{Sujeitos da pesquisa e amostra}

Os sujeitos de pesquisa são de suma importância para o tema desse presente trabalho, pois com a participação dos sujeitos, tem-se a oportunidade para que haja um melhor esclarecimento através de questionamentos sobre as dificuldades e as possibilidades da inclusão digital na presente escola.

Com o intuito de obter respostas sobre alguns questionamentos, foram escoIhidos alguns participantes da instituição para responder os questionários. O público alvo para fazer parte dos questionamentos a respeito do tema foram: dois (02) professores do $3^{\circ}$ ano do ensino médio, uma Diretora e uma Coordenadora Pedagógica.

\subsection{Instrumento de pesquisa}

O instrumento é de imensa importância para a coleta de dados durante uma pesquisa. Através dele podem-se obter informações que demonstram a realidade ao qual a escola está vivenciando em meio a essa era digital que estamos passando. Desse modo, organizou-se um questionário do tipo aberto. O mesmo foi feito com a intensão de obter informações relacionadas ao problema de pesquisa proposto: Quais as possibilidades e os desafios na inclusão digital em uma escola de ensino médio no município de São João da Serra-PI?

Para cada sujeito da pesquisa temos os seguintes questionamentos:

\section{Professores da sala de aula regular (aplicação com dois docentes do $3^{\circ}$} ano do ensino médio)

Qual sua formação inicial e o seu tempo de experiência profissional?; O que você entende por inclusão digital?; Como ocorre o processo de inclusão digital na escola?; Qual a possibilidade da inclusão digital ocorrer nesta escola?; Quais os desafios no processo de inclusão digital nesta escola? Dentre outras.

\section{Diretora}

Qual sua formação inicial e seu tempo de experiência profissional?; O que você entende por inclusão digital?; Como ocorre o processo de inclusão digital na escola?; Quais as possibilidades e vantagens quando se há inclusão digital?; Quais os desa- 
fios no processo de inclusão digital nesta escola?; Existe laboratório de informática? Se sim como funciona e se não o que necessita para inclusão do mesmo no ambiente escolar?; Qual a possibilidade da inclusão digital ocorrer na escola?

\section{Coordenadora Pedagógica}

Qual sua formação inicial e seu tempo de experiência profissional?; O que você entende por inclusão digital?; Como ocorre o processo de inclusão digital na escola? Quais as possibilidades e vantagens quando se há inclusão digital?; Quais os desafios no processo de inclusão digital nesta escola?; Qual a possibilidade da inclusão digital ocorrer nesta escola?

A aplicação dos questionários proporcionou a busca por melhores resultados em relação a essa problemática. Para a análise dos dados, consideramos as categorias: dificuldades e possibilidades de inclusão digital, encontradas durante as respostas dos sujeitos desta pesquisa.

A seguir temos um esquema para melhor compreensão da metodologia:

Pesquisa bibliográfica

Campo empírico da

pesquisa:

01 escola estadual do

município de São João da

Serra-PI

Participantes:

02 Professores; 01

Coordenadora; 01 Diretora
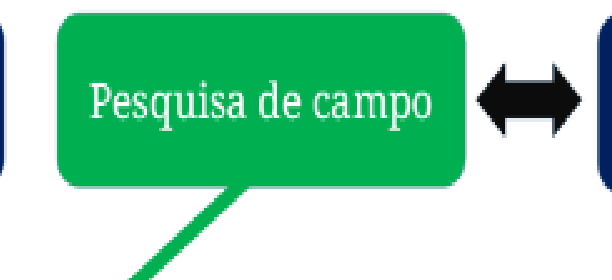

Abordagem qualitativa

Fonte: arquivo da autora, (2020) 


\section{RESULTADOS E DISCUSSÕES}

O presente estudo contempla a pesquisa qualitativa e bibliográfica, para a busca de aprofundamento dos dados, aplicaram-se questionários com os seguintes sujeitos: professores; diretor e pedagoga.

A escola possui oito (08) salas de aula, uma sala de vídeo, uma biblioteca, um laboratório de informática, um pátio coberto, dois (02) banheiros com quatro (4) divisões cada um, dois (02) banheiros para professores, uma quadra esportiva, uma cantina, uma sala dos professores, uma sala da coordenação e uma diretoria. Ao todo a escola conta com

42 funcionários. As figuras 01 e 02 demonstram o espaço físico da instituição pesquisada.

\section{Figura 01: Escola pesquisada}

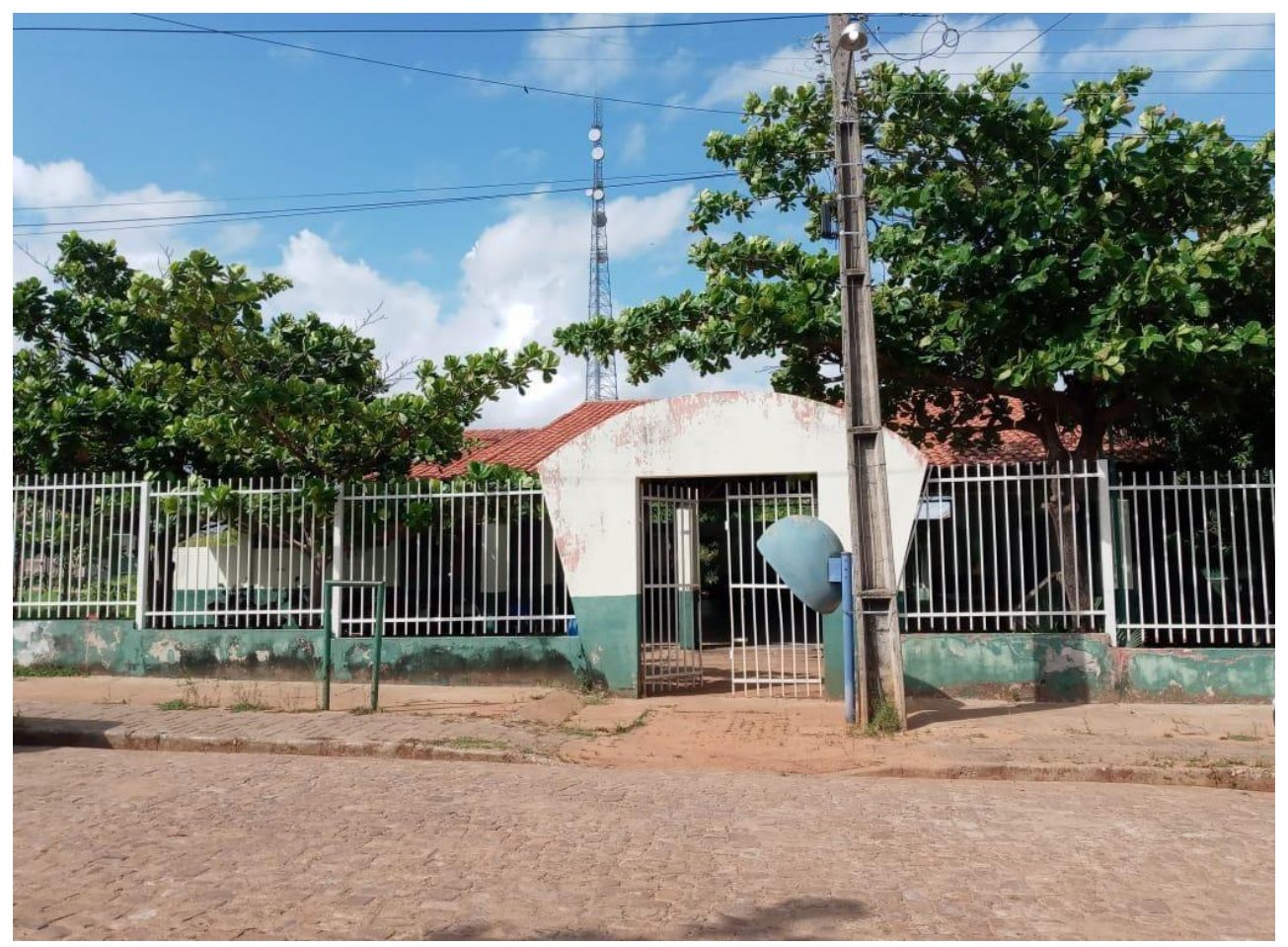

Fonte: arquivo da autora, (2020)

A figura 01 retrata especificamente da parte de entrada da instituição, enquanto a 02 refere-se ao interior do laboratório de informática. 


\section{Figura 02: Parte interna do laboratório de informática}

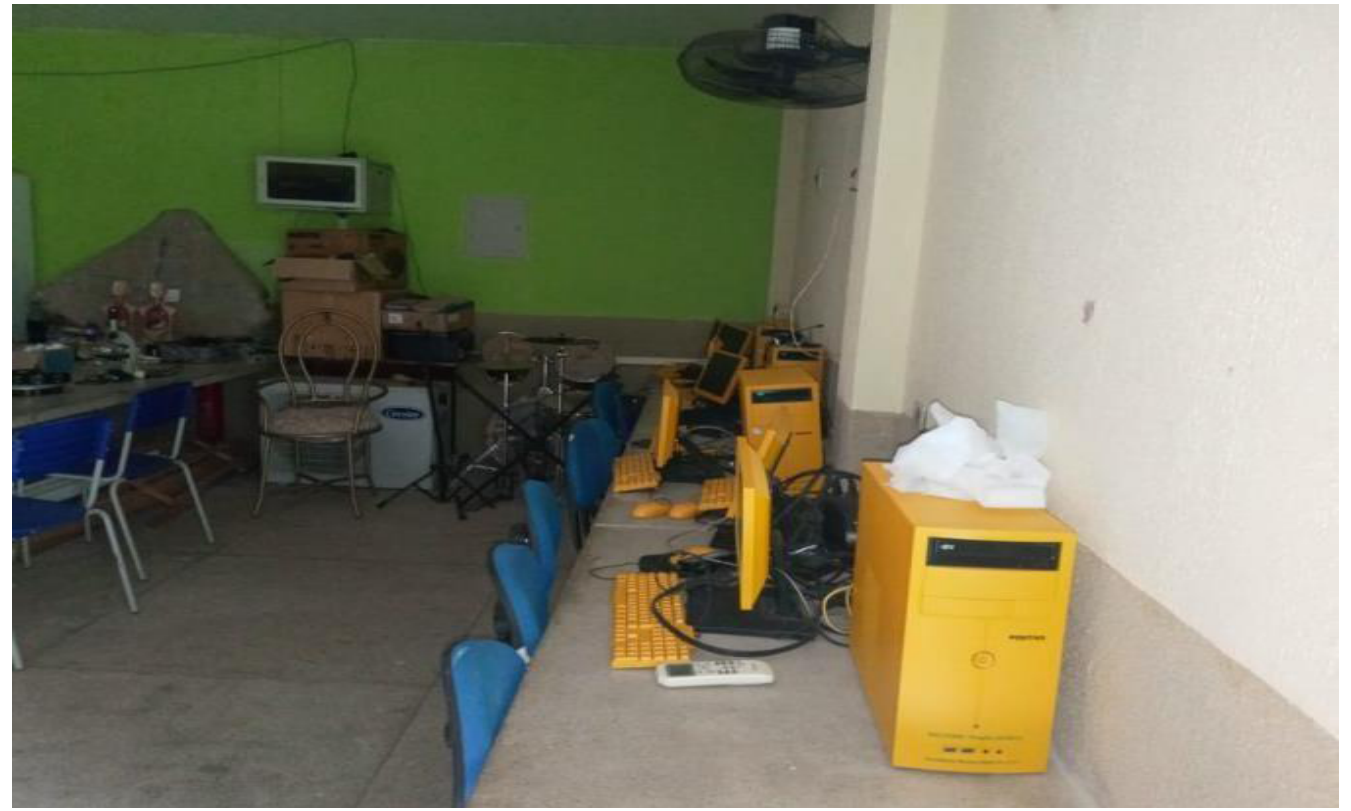

Fonte: arquivo da autora, (2020)

Além das imagens da estrutura física da instituição de ensino, realizou-se a aplicação de questionários com: coordenadora pedagógica, ao qual se perguntou sobre sua formação; como ocorre o processo de inclusão digital, as possibilidades e vantagens desse processo, dentre outras. Sobre como ocorre o processo de inclusão digital na escola temos:

Sobre sua formação inicial e o seu tempo de experiência profissional, temos:

Minha formação inicial é licenciatura em Educação Física pela UESPI e anos depois cursei a Licenciatura em Pedagogia. Tenho 20 anos de experiência profissional. (Coordenadora Pedagógica)

Sobre como ocorre o processo de inclusão digital na escola temos:

Por meio do uso das metodologias ativas e digitais, nas quais os professores planejam atividades que provoquem o agir ativo do aluno e uso frequente das ferramentas tecnológicas que dispõe para realizar o que é proposto. (Coordenadora Pedagógica)

Segundo Borges (2008) a inclusão digital ocorre quando o indivíduo utiliza a informática como um meio de acesso à educação, ao trabalho, às relações sociais, à comunicação e ao exercício de sua cidadania. Portanto, incluir o indivíduo digital e socialmente requer ações que Ihe ofereçam condições de autonomia e habilidade cognitiva para compreender e atuar na sociedade informacional. 
Compreende-se que para ocorrer inclusão digital, os alunos devem ter autonomia sobre as ferramentas tecnológicas e estarem em total interação sobre os recursos thes oferecidos. Os alunos teriam maior autonomia e interação com as ferramentas tecnológicas nesta escola se o laboratório de informática e seus recursos tecnológicos estivessem adequados para o uso e a escola tivesse um profissional para exercer seu trabalho.

Sobre as possibilidades e vantagens quando se há inclusão digital, a resposta consiste em:

O ensino remoto é uma possibilidade de inclusão digital, visto que os alunos estão sem ir à escola (física). Dessa forma, essa nova forma de receber as orientações dos professores por meio de recursos digitais, possibilita maior contato com dispositivos tecnológicos. Quanto às vantagens podemos elencar que a inclusão digital promove o ganho de competências e habilidades que o mundo de trabalho requer de trabalhadores (que dominem as tecnologias e sejam capazes de se adaptar às novas exigências que surgiram).

Porto (2006) citado por Nascimento (2016), dentre as muitas contribuições dos recursos tecnológicos para a educação, ela destaca que o potencial educativo de alguns de seus elementos que pertencem ao processo da inclusão digital na escola está à rapidez, recepção individualizada, interatividade e participação, hipertextualidade, realidade virtual e digitalização/ideologiall e ainda acrescenta afirmando que a escola e os meios tecnológicos de comunicação e informação caminham em paralelo.

Acredita-se que a inclusão digital oferece diversas possibilidades e vantagens para os incluídos, melhorias na perspectiva de emprego e novos meios de comunicação é uma das possibilidades e vantagens existentes.

Em relação aos desafios no processo de inclusão digital nesta escola:

O principal desafio a ser vencido quanto à inclusão digital é o acesso a uma internet de qualidade e a dispositivos modernos como computadores e celulares tanto por professor quanto por alunos. As dificuldades e resistências que pessoas que não fazem parte da geração nativos da tecnologia possuem em acessar o conhecimento e enxergar as possibilidades de crescimento que isso representa. O professor que não recebeu formação em letramento digital e que apresenta resistência ao uso das tic 's em seus planejamentos e metodologias também se apresenta como um desafio a ser superado para a plenitude da inclusão digital.

Silva (2014) citado por Nascimento (2016) é preciso, contudo, perceber a inserção dos recursos das tecnologias da informação e da comunicação na escola 
para além da inclusão digital, mediante a apropriação destes recursos enquanto instrumentos que estendem a capacidade humana de armazenar, resgatar, explorar e divulgar a informação. Neste contexto, a escola é desafiada a observar, reconhecer, apropriar-se e contribuir para com a consolidação de uma nova cultura de aprendizagem.

Assim, torna-se nítido que a internet, falta de manutenção, falta de um profissional de informática, são alguns dos desafios no processo de inclusão digital na escola.

Questionou-se sobre a possibilidade da inclusão digital ocorrer nesta escola,

A possibilidade existe e está ocorrendo. A formação continuada acontece no sentido de conscientizar o professor sobre a importância e necessidade de vivemos em sociedade que o processo de inclusão seja democrático, ou seja, que todos possam usufruir dos benefícios das ferramentas digitais para aquisição de conhecimento.

Xavier (2005) A inclusão digital deve estar presente também na escola, que no desempenho do seu papel não pode ficar alheia a esta evolução. Faz-se necessário a inserção de políticas e ações que promovam uma educação digital, inserindo o uso do computador no cotidiano pedagógico da escola. A educação é um processo e a inclusão digital é elemento essencial desse processo.

Existe certa possibilidade de ocorrer à inclusão digital, porém, isso necessitaria de manutenção nas ferramentas pedagógicas, internet de qualidade, formação continuada dos professores e de um profissional de informática.

Para os docentes (02), buscaram-se respostas quanto à formação inicial; a compreensão sobre inclusão digital; as possibilidades desse processo etc.

Sobre sua formação inicial e o seu tempo de experiência profissional, temos:

Professora, formada em Letras português pela Universidade Estadual do Piauí. Tenho 11(onze) anos de experiência no referido cargo. (Professor 1)

Licenciatura plena em História, 20 anos de tempo de serviço. (Professor 2)

Sobre a compreensão de inclusão digital:

É o processo de democratização do acesso às tecnologias da informação de modo a permitir a inserção de todos, na sociedade da informação e comunicação digital. (Professor 01)

$O$ acesso à internet, assim como aos novos meios de acesso às informações.

(Professor 2) 
Xavier (2005) Inclusão digital é a denominação dada, aos esforços de fazer com que a sociedade possa obter os conhecimentos necessários para utilizar com um mínimo de proficiência os recursos da tecnologia de informação e da comunicação existentes e dispor de acesso regular a esses recursos. É gerar igualdade de oportunidades na sociedade da informação.

A inclusão digital é exatamente o acesso às tecnologias e suas ferramentas digitais para todos os cidadãos. Dessa forma, seu maior objetivo é a democratização das tecnologias.

Sobre a possibilidade da inclusão digital ocorrer nesta escola, temos:

Há uma grande possibilidade, pois, os recursos tecnológicos são usados com bastante frequência. (Professor 01)

De certa forma está ocorrendo muito lentamente, seria mais rápida se nossos governantes realmente se importassem com a educação! (Professor 02)

Xavier (2005) refere-se que a inclusão digital não se trata apenas do ensino de informática nas escolas e sim, do ensino pela informática, com o intuito de buscar construir a cidadania e a participação social na perspectiva de uma sociedade mais justa e democrática. Assim, sem exclusões, o conhecimento tecnológico disseminado para a maior parcela da população, poderá proporcionar vida mais digna com novas oportunidades.

Acredita-se que a inclusão digital esteja ocorrendo, porém, é notório para todos que a inclusão digital ocorreria de forma mais satisfatória se as ferramentas tecnológicas existentes dentro do laboratório de informática estivessem totalmente aptas para uso.

Questionou-se aos docentes sobre os desafios no processo de inclusão digital nesta escola, temos:

Um dos maiores desafios é a falta de uma internet de qualidade. Pois, muitas vezes para se utilizar um determinado equipamento precisamos da mesma. Outro desafio é a falta de muitos outros equipamentos tecnológicos que a escola ainda não dispõe. (Professor 1)

Os desafios são mais financeiros, tanto para reforma, como para compra de equipamentos tecnológicos e também para formação de professores. (Professor 2) 
Xavier (2005) O ingresso da humanidade na era da informação é um fato, mas ainda, para uma pequena parte da população. As novas tecnologias vieram para ficar e se esse conhecimento não for compartilhado pela sociedade, corre-se o risco de ratificar o abismo que a separa, tornando os excluídos cada vez mais excluídos. Situação que só será diferente se forem aplicadas ações eficazes para promover sua inclusão digital.

É nítido que a falta de internet de qualidade nessa escola é de extrema dificuldade, assim como a falta de manutenção nas ferramentas tecnológicas do laboratório.

Para a diretora, buscaram-se respostas quanto a sua formação inicial, sobre o processo de inclusão, dentre outras.

Sobre sua formação inicial e o seu tempo de experiência profissional, temos:

A minha formação inicial é licenciatura em Letras Portuguesa. O tempo de experiência profissional são 33 anos. (Diretora)

Sobre o processo de inclusão:

Na escola que trabalho a inclusão digital já aconteceu, pois utilizamos-a no processo de ensino aprendizagem dos alunos, na formação digital dos professores e, ainda é mediada com a própria inclusão social. Os colaboradores da escola utilizam as diversas ferramentas para aquisição da inclusão digital, como: computadores, rede de internet, sistemas integrados de notas, frequências e comunicação com os pais dos alunos por meio de mensagens. Os alunos da escola são inclusos digitalmente por meios de atividades que buscam o acesso da informação por meios de pesquisas, sites, projetos digitais redes de computadores e redes sociais, agregando de forma consciente o seu uso a construção do seu próprio aprendizado. (Diretora)

Tajra (1998) citado por Nascimento (2016) garante que a Informática é uma grande aliada na Educação desde que seja bem utilizada, apresentando muitas contribuições para o processo de ensino e aprendizagem, pois com a sua utilização adequada é possível desenvolver as mais variadas habilidades. Além disso, não se tem mais dúvida, quanto à importância do papel do professor no uso das tecnologias digitais.

Infelizmente, o processo de inclusão digital nesta escola ocorre de forma lenta, o uso de internet e ferramentas tecnologias são mais utilizados pelos professores, visto que a escola não possui ferramentas tecnológicas com manutenção e muito menos internet para que todos os envolvidos possam usar.

Em relação às possibilidades e vantagens quando se há inclusão digital, a di- 
retora informa que:

As possibilidades da inclusão digital vão desde maximização do tempo, simplificação de atividades e principalmente a potencialidade de comunicação; e formulação de diversas formas que facilitem o acesso e o manejo das tecnologias. (Diretora)

Kenski (2006) citado por Nascimento (2016), as novas tecnologias de informação e comunicação, caracterizadas como midiáticas, são, portanto, mais do que simples suportes. Elas interferem em nosso modo de pensar, sentir, agir, de nos relacionarmos socialmente e adquirirmos conhecimentos. Criam uma nova cultura e um novo modelo de sociedade.

A inclusão digital pode mudar a vida de uma pessoa, tanto na parte profissional e social, quanto no modo de pensar e agir.

Sobre os desafios no processo de inclusão digital na escola campo, temos a informação pela diretora:

Quanto aos desafios da implementação da inclusão digital na escola foram: formação continuada dos colaboradores para entendimento dos benefícios da inclusão digital e sua aplicabilidade; ferramentas para o seu desenvolvimento não são $100 \%$ funcionantes havendo necessidade de manutenção cotidianamente; implementação do uso da inclusão digital (tecnologias e internet) de forma consciente nos alunos. (Diretora)

Xavier (2005) A exclusão socioeconômica desencadeia a exclusão digital ao mesmo tempo em que a exclusão digital aprofunda a exclusão socioeconômica. A inclusão digital deveria ser fruto de uma política com destinação orçamentária a fim de que ações promovam a inclusão e equiparação de oportunidades a todos os cidadãos. Neste contexto, é preciso levar em conta indivíduos com baixa escolaridade, baixa renda e com limitações físicas.

Sobre a existência de um laboratório e o seu funcionamento, temos:

Sim. O funcionamento neste momento está parado devido a pandemia, mas antes os alunos têm disponíveis computadores para realizarem suas atividades, e realizam projetos que visam a informação, comunicação e uso de rede sociais para aquisição de conhecimento. (Diretora)

Segundo Bovo (2002) citado por Nascimento (2016), hoje, vive-se num mundo dominado pela informação e por processos que ocorrem de maneira muito rápida e imperceptível. Portanto, em vez de memorizar informação, os estudantes devem ser ensinados a buscá-la e usá-la. Essas mudanças podem ser introduzidas com a pre- 
sença do computador, que deve propiciar as condições aos estudantes exercitarem a capacidade de procurar e selecionar informação, resolver problemas e aprender independentemente.

O laboratório dessa devida escola permanece sem uso, isso corresponde à falta de manutenção e a falta de um profissional adequado para auxiliar os alunos quanto ao uso das ferramentas tecnológicas existentes nesse laboratório.

Ainda sobre a possibilidade da inclusão digital ocorrer na escola, tem-se a informação que:

A inclusão digital já ocorre na escola, de forma ainda incipiente, mas com resultados satisfatórios. (Diretora)

Xavier (2005) refere-se que a inclusão digital deve estar integrada aos conteúdos curriculares. Cada unidade de ensino deve construir o seu projeto político-pedagógico tomando como norte os processos para a Inclusão Digital, atendendo às necessidades da localidade na qual está inserida. Deve-se questionar sobre implicações ideológicas e suas repercussões no processo de ensino e aprendizagem. As principais recomendações neste sentido implicam na modificação do ambiente educativo, de modo que se torne adequado ao uso das tecnologias.

A possibilidade da ocorrência da inclusão digital nesta escola está sendo de forma lenta, devido à falta de manutenção nas ferramentas tecnológicas existentes e a um profissional da área de informática.

\section{CONCLUSÃo}

O presente trabalho teve como objetivo analisar os desafios e as possibilidades em relação à inclusão digital em uma escola do Ensino Médio de São João da Serra- PI. Sabe-se que a inclusão digital é de suma importância na era digital ao qual estamos vivenciando, o que nos faz perceber a sua importância na área educacional. Notamos que a inclusão digital pode mudar vidas, fazendo com que haja transformações no oferecimento de serviços e informações de valor cultural, econômico e social.

A partir dos resultados obtidos corroborou-se que é existente a possibilidade de ocorrer à inclusão digital na escola de ensino médio de São João da Serra-PI, de certa forma'a inclusão digital ocorre, porém de forma lenta, devido aos desafios com relação à internet, falta de manutenção em equipamentos tecnológicos do laboratório 
de informática e também a não formação continuada dos professores. Esses resultados nos fazem compreender o quanto o tema deste trabalho torna-se importante para que possamos compreender o percurso completo do processo de inclusão digital no ensino médio de São João da Serra-PI.

As tecnologias existentes no laboratório ao qual faz parte desse contexto escolar estão sem manutenção, fazendo com que a inclusão digital não avance. Vale salientar que as tecnologias em funcionamento são mais utilizadas pelos professores do que pelos próprios alunos, visto que alguns professores possuem seu próprio computador. Além disso, observamos que não é muito satisfatória a eficiência e a eficácia das tecnologias da informação para a inclusão digital dos docentes e educandos na escola, devido muitas tecnologias não estarem em uso.

\section{REFERÊNCIAS}

BAPTISTA, S. G.; CUNHA, M. B. da. Estudos de usuários: visão global dos métodos de coletas de dados. Perspectivas em ciência da informação, Belo Horizonte, v. 12, n. 2, p. 168-184, maio/ago. 2007.

BOCCATO, V. R. C. Metodologia da pesquisa bibliográfica na área odontológica e o artigo científico como forma de comunicação. Rev. Odontol. Univ. Cidade São Paulo, São Paulo, v. 18, n. 3, p. 265-274, 2006.

BORGES, M. d. (2008). Inserção da informática no ambiente escolar: inclusão digital e laboratórios de informática numa rede municipal de ensino. Anais do XXVIII congresso SBC , 147.

BOVO, Vanilda Galvão. Monografia: O uso do computador na Educação de Jovens e Adultos. Curitiba: 2002. A Revista Partes, ISSN 1678-8419, SP.

CARNEIRO, Nilcéia Saldanha. Inclusão digital no ensino médio: análise da implementação da tecnologia na escola estadual deputado João Evaristo curvo da cidade de Jauru-MT. Dissertação de Mestrado. Belo Horizonte - MG, 2015.

DORNELES, D. M. A formação do professor para o uso das TICs em sala de aula: uma discussão a partir do projeto piloto UCA no Acre. Texto Livre, Belo Horizonte, v. 5, n. 2, 2012.

FREIRE, P. A pedagogia dos sonhos possíveis. São Paulo: UNESP, 2001 
KENSKI, V. M. Tecnologias e ensino presencial e a distância. 4. ed. São Paulo: Papirus. 2006.

LIMA, Rafaela. SILVA, André Pedro. SOUSA, Ingrid Braz. OLIVEIRA, Daniele. FARIAS, Cecir. Inclusão Digital para jovens do ensino médio de uma escola estadual do cariri paraibano. Anais do III Congresso Nacional de Educação - CONEDU. Cariri, Paraíba: 2015.

NASCIMENTO, Manoel Gomes. Inclusão digital no processo de ensino e aprendizagem em escola pública. Boa Vista - RR Fevereiro de 2016

PACHECO, Marcia Arantes Buiatti. Educação digital: uma perspectiva de inclusão no cotidiano da escola. Dissertação de Mestrado. Uberlândia, 2011.

PORTO, Tania Maria Esperon. As tecnologias de comunicação e informação na escola: relações possíveis... relações construídas. Revista Brasileira de Educação, abr/ 2006.

SILVA FILHO, A. M. Os três pilares da inclusão digital. 2003. Disponível em: <www.comunicacao.pro.br/setepontos/2/trespilares.htm>. Acesso em: 07 jul. 2015.

SILVA, H. et al. Inclusão digital e educação para a competência informacional: uma questão de ética e cidadania. Ci. Inf., Brasília, v. 34, n. 1, p.28-36, jan./abr. 2005.

SILVA, Renildo Franco da. Novas tecnologias e educação: a evolução do processo de ensino e aprendizagem na sociedade contemporânea. Revista Educação e Linguagem, ano 1. n o 1, Jun. p. 23-35 2014

TAJRA, S.F. Informática na Educação: professor na atualidade. São Paulo: Érica, 1998.

TEIXEIRA, Adriano Canabarro. Inclusão Digital: novas perspectivas para a informática educativa. Ijuí: Ed. Unijuí, 2010

XAVIER, Karine. Inclusão digital nas escolas públicas: uma questão social. 2005 


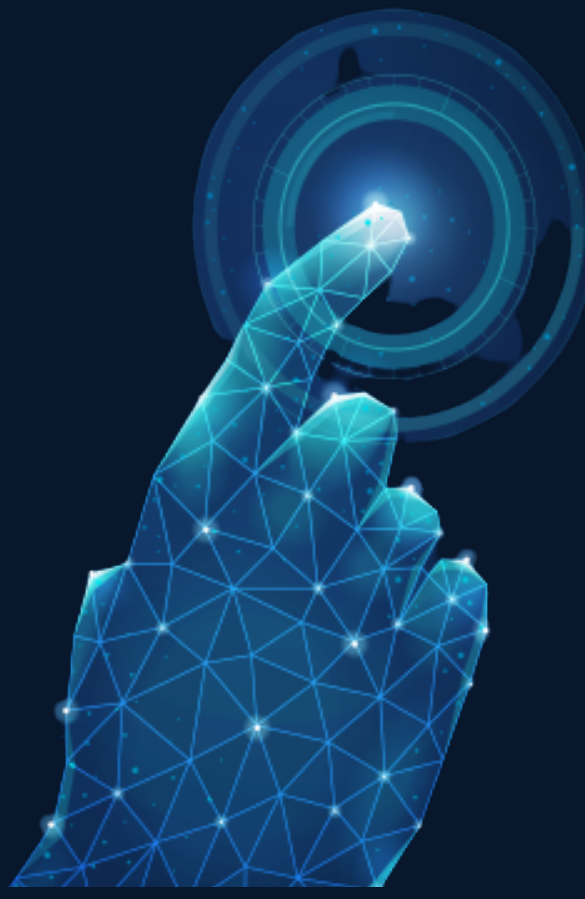

\section{O UNIVERSO EDUCACIONAL E O DIREITO AUTORAL NO BRASIL CONTEMPORÂNEO}

Vanessa Andriani Maria ${ }^{1}$

$1 \quad$ Graduada em Agronomia pela UFSM (1997) e Mestre em Ciência e Tecnologia Agroindustrial pela UFPel (1999),graduada em Direito pela ULBRA (2011), com Pós-Graduação Lato Sensu -Especialização em Advocacia Trabalhista e Advocacia Cível pelo Centro Universitário UNA (2020).Graduanda em Formação Pedagógica em Geografia (UNIASSELVI). Integra a Comissão de Gênero e o grupo de estudos em Violência Doméstica da OAB Subseção Santa Maria - RS. E-mail: vanessamariaadvs@gmail.com 


\section{INTRODUÇÃo}

A proteção ao Direito Autoral está prevista no artigo $5^{\circ}$ da Constituição nos incisos XXVII, XVIII e XIX, entretanto, é importante lembrar que os incisos XXII e XIII, do artigo $5^{\circ}$, tratam de forma geral do direito à propriedade, logo, o Direito Autoral também deve respeitar a função social da propriedade, conforme reitera o artigo 170 da Constituição.

O uso de obras protegidas deve sempre observar os preceitos constitucionais atribuídos a quem detém os Direitos Autorais, bem como os conferidos à sociedade; buscando o equilíbrio entre os autores e a sociedade, ressalvando as limitações ao Direito Autoral. Tais limitações através de um rol taxativo descrito no artigo 46 mencionam em que casos as obras podem ser utilizadas sem autorização do detentor de Direitos Autorais.

Salienta-se que o Direito Autoral protege as obras decorrentes do intelecto humano, ou seja, protege as obras literárias, científicas e artísticas, assim como os programas de computador.

O trabalho usa como referência a superação do juízo do Direito Autoral como direito absoluto e incontestável, defendendo uma ponderação deste com outros valores e preceitos. É importante observar o interesse do autor ao considerar o Direito Autoral, assim como o interesse público, que representa tanto o interesse de quem usa a concepção, como o de toda a coletividade. Deste modo, podem-se nortear as limitações deste direito, já que o crescimento do consumo das diversas obras intelectuais pela internet é uma realidade implacável sem volta, diante do desenvolvimento da tecnologia, permitindo que estas sejam acessadas em diferentes suportes e em qualquer lugar. Os direitos de acesso, muitas vezes, entram em conflito com o Direito do Autor, devido às restrições que estes conferem ao uso das criações intelectuais em benefício do criador da obra.

Neste sentido, o intuito desta pesquisa é identificar de que maneira o autor pode fazer uso desta proteção, de forma a manter o equilíbrio entre os seus direitos e os direitos de acesso da sociedade em geral; evitando potenciais conflitos quanto à exploração da obra. São apresentados parâmetros para a identificação dessa 
violação caracterizando assim, o abuso em face ao Direito Autoral, e de forma mais específica, as limitações legais do Direito Autoral quanto à reprodução para uso privado de pequenos trechos sem fins lucrativos, à luz da atual legislação pátria.

Para uma avaliação mais particular do Direito Autoral fizemos uma análise mais aprofundada, através da doutrina presente em livros e apreciação de questões relacionadas à aplicação desses interesses juridicamente protegidos.

Nesse aspecto, a imposição de limites aos direitos do autor exige certa ponderação entre os interesses de titulares e usuários, os quais devem visar o bemestar geral e, sobretudo estar fundamentados em lei, mantendo-se as liberdades fundamentais constitucionalmente garantidas tanto a autores quanto a usuários. O regime jurídico deve contribuir para o acesso ao conhecimento e à informação, principalmente em se tratando de educação, considerada direito fundamental e bem essencial a todos.

Este é o caso, em questão, da limitação prevista pelo inciso II do art. 46 da Lei 9.610 de 1998, referente ao limite máximo de páginas que podem ser xerocopiadas de exemplares com fins estudantis e acadêmicos, limitando a cópia de conteúdo de livros a pequenos trechos, embora não vise lucro por quem assim o faz ou mesmo real prejuízo comercial ao autor da obra.

\section{FUNDAMENTOS DO DIREITO AUTORAL E SUA EVOLUÇÃO HISTÓRICA}

Com a Constituição da República de 1891, os direitos de autor ganharam, pela primeira vez no Brasil, patamar constitucional. $\mathrm{\S} 26$, do art. 72 , garantia aos autores de obras literárias e artísticas em geral "o direito exclusivo de reproduzi-las, pela imprensa ou por qualquer outro processo mecânico", estendendo esse direito aos herdeiros "pelo tempo que a lei determinar". (SOUZA, 2006, p. 157)

No Brasil, os Direitos Autorais são regulados, principalmente, pela Lei 9.610 de 1998, a qual substituiu a lei 5.988, de 1973. Esta legislação objetiva a proteção dos bens intelectuais de caráter literário, científico ou artístico, uma vez que, da análise do conteúdo do Direito de Autor, temos a coexistência de dois direitos autônomos: - os de cunho moral, relacionados à proteção da personalidade do criador da obra 
e outros de cunho patrimonial, relacionados aos direitos de utilização econômica da obra. (BITTAR, 2001, p. 50)

Promulgada no Brasil pelo Decreto 75.699/75, a Convenção de Berna, uma das convenções internacionais que versa sobre os Direitos Autorais, determina, em seu artigo 2, quais são as obras suscetíveis de proteção, entretanto essa não é uma lista restritiva, podendo a tutela legal ser ampliada a diversas obras não listadas.

A Carta de 1988, concedeu um privilégio incomum para os direitos de autor ao prevê-los expressamente no rol de direitos e garantias fundamentais. Igual condição se verifica na Constituição dos Estados Unidos da América, na qual os direitos de propriedade intelectual precedem, em tempo e dignidade, os princípios que regem os direitos fundamentais. Regra de supremacia federal, os direitos dos autores e titulares sobre suas obras artísticas e literárias são objeto frequente de discussões jurídicas profundas, razão pela qual os constitucionalistas têm dedicado atenção e cuidado na elaboração do equilíbrio das normas e à justeza de sua aplicação. (BARBOSA, 2001 apud BITTAR, 2001. p.10)

\section{ASPECTOS RELEVANTES ACERCA DOS FUNDAMENTOS CONSTITUCIONAIS E LEGAIS VIGENTES}

A Constituição Federal de 1988 dedica especial atenção ao artigo $5^{\circ}$, onde são consagrados preceitos civis fundamentais, como por exemplo, a propriedade privada e sua função social. O Direito Autoral foi tutelado, uma vez que a Constituição Federal assevera no seu artigo $5^{\circ}$, inciso XXVII, que "aos autores pertence o direito exclusivo de utilização, publicação ou reprodução de suas obras, transmissível aos herdeiros pelo tempo que a lei fixar".

O artigo 215 prevê que compete ao Estado garantir a todos "o pleno exercício dos direitos culturais e acesso às fontes da cultura nacional, e apoiará e incentivará a valorização e a difusão das manifestações culturais” e também o artigo 216 cita que "constitui patrimônio cultural brasileiro os bens de natureza material e imaterial, tomados individualmente ou em conjunto".

No Direito brasileiro hodierno, os Direitos Autorais são tutelados: cumulada, sucessiva ou independentemente em âmbito penal, civil e administrativo. A tripla

\section{3}


proteção recebida conforma-se à respectiva natureza de tais direitos e, na prática, à resposta do ordenamento à violação ocorrida está sujeita ao mecanismo acionado pelo lesado que pode, dependendo do caso, desdobrar-se por um, dois ou pelos três ramos citados. Isso porque, haja vista a independência das tutelas que prevalece em nosso sistema jurídico, é assegurada ao autor a mais ampla proteção aos seus direitos, proporcionando-Ihe a garantia, à defesa e/ou à reparação devida e adequada perante as ameaças ou lesões sofridas. (BITTAR,2005, pp.131 - 132)

Os Direitos Autorais encontram amparo constitucional, através de prerrogativas de ordem moral e patrimonial, as quais permitem a proteção da personalidade do autor em relação a sua obra, assim como o domínio da exploração comercial desta por qualquer meio ou processo conhecido. (OLARTE COLLAZOS e ROJAS CHAVARRO, 2010)

A Lei $n^{\circ}$ 9.610, de 19 de fevereiro de 1998, ou Lei de Direitos Autorais, atualmente regula o Direito Autoral brasileiro, bem como os que lhes são conexos.

O autor será sempre uma pessoa física, enquanto que o titular do Direito Autoral poderá ser pessoa física ou jurídica. Segundo os ensinamentos de Abrão:

O sujeito de Direito Autoral, criador de uma obra estética é sempre uma pessoa física, não importando sua condição pessoal, social, política ou jurídica, ou sua crença espiritual. O titular do direito deverá ser uma pessoa física ou jurídica, que adquiriu essa condição por transferência contratual ou decorrência natural (morte do autor). Autor como pessoa jurídica originária, é qualidade adquirida por presunção legal, caso da obra coletiva. ( ABRÃO, 2002, p. 148)

Os direitos patrimoniais, ao contrário dos direitos morais, referem-se à utilização da obra, que necessariamente não precisa ser econômica. O princípio básico, parte da ideia de propriedade e da utilização decorrente da vontade do criador. Para ele, "a sua vontade determina o que acontece com a obra, quem e como a utilizará", pois "qualquer utilização depende de sua autorização". (HAMMES, 2002)

Como os direitos de autor já se encontram reconhecidos pela Constituição Federal cabe aplicá-los de forma mais eficaz possível aos direitos dos titulares e dos usuários, atendendo ao mandado de cumprimento de sua função social, relacionada a todo e qualquer direito de propriedade. 


\section{SOBRE A PIRATARIA E COMPARTILHAMENTO DE ARQUIVOS}

É grande o volume de arquivos compartilhados diariamente na Internet, sendo que aumenta a cada dia, o que estimula uma transformação na forma de produzir e distribuir conteúdo midiático. Diante disso, a indústria de conteúdo busca manter sua liderança por meio de mudanças na legislação; propondo alterações na regulamentação de acesso à informação. Trata-se de uma tarefa quase impossível nos dias atuais, pois com a velocidade nos avanços tecnológicos de comunicação e a quantidade imensa de arquivos que são trocados entre os usuários da Internet e programas de compartilhamento; a fiscalização pela sociedade e pelo Estado é inviabilizada, uma vez que o compartilhamento, seja ele de forma consciente e deliberada ou não, é prática comum nos dias atuais. (CESAR, 2013, p.107)

Podemos encontrar no ordenamento jurídico pátrio um conceito legal para o que é pirataria. De acordo com o artigo $1^{\circ}$, §único, do Decreto $n^{\circ} 5.244$, de 14 de Outubro de 2004, que dispõe sobre a composição e funcionamento do Conselho Nacional de Combate à Pirataria e Delitos contra a Propriedade Intelectual, entendese por pirataria, para os fins deste Decreto, a violação aos Direitos Autorais de que tratam as Leis $n^{\circ} 9.609$ e 9.610, ambas de 19 de fevereiro de 1998. (BRASIL, 2004)

No que concerne ao combate à pirataria, houve evolução para tratar do tema. Foi criado pelo Ministério da Justiça o Conselho Nacional de Combate à Pirataria (CNCP) desde 2004 para tratar assuntos relacionados à questão.

O objeto material do delito é o original ou a cópia da obra intelectual. O original, evidentemente, é a obra inicial, enquanto a cópia é uma reprodução, feita por qualquer meio. Para fins de tipificação, independe se o sujeito ativo se valeu de uma ou de outra. (NUCCl, 2007, p. 744)

Inexiste uma estrutura centralizada que concentre o compartilhamento de arquivos, facilitando assim, a dispersão rápida de conteúdo protegido por Direitos Autorais e democratização no acesso a qualquer conteúdo digital: tanto filmes como músicas e livros.

Desafios surgem e surgirão desde a radiodifusão até a internet, a serem abordados pelo Poder Judiciário acerca da temática "pirataria". Fato é que mesmo que as gravadoras e as sociedades jurídicas passassem por uma reestruturação, 
para que conseguissem enfrentar um problema dessa dimensão e pudessem criar alternativas para resolvê-lo ou tentar minimizar seus impactos negativos, não existe modo de exercer uma vistoria sobre cada um dos computadores, dentre os muitos usuários conectados pelas mais diversas localidades do mundo. Com certeza, afrontaria até mesmo o direito à privacidade e intimidade de cada um deles, o que não é compatível com um Estado Democrático de Direito.

A permanente e acelerada inovação e a popularização de novas tecnologias permitem hoje, a qualquer pessoa, a realização de cópias de altíssima qualidade a um custo extremamente baixo. A partir daí, caracteriza-se a mobilidade e a portabilidade da informação, com impactos evidentes nos hábitos da sociedade e, de forma particular, nos de consumo. A informação, que é transmitida ininterruptamente, precisa ser exibida e, portanto, copiada, por diversas vezes. Na rede mundial de computadores, um dos principais meios hoje utilizados para a transmissão de informação, para que uma pessoa acesse a qualquer página, a informação deve ser recebida, copiada (ainda que temporariamente), decodificada e exibida em seu computador. Tais possibilidades devem ser encaradas como uma ameaça a direitos de artistas e autores, ou podem representar uma nova oportunidade de negócios para a indústria da cultura e do entretenimento? (GUERRINI, 2008)

O escopo deste estudo não é criticar os Direitos Autorais, tão necessários para proteger os autores e para instigar a criação. Todavia, é de extrema relevância ventilar como essa proteção é conduzido atualmente e de que modo poderia ser feita, não restringindo o acesso ao conhecimento, à cultura e à informação por todos.

\section{LIMITAÇÕES DO DIREITO AUTORAL: BREVES CONSIDERAÇÕES}

No Direito Autoral, a função social está atrelada à busca pelo equilíbrio entre a proteção dada ao autor e ao acesso ao conhecimento, que a sociedade possui.

Segundo BITTAR (1992, p. 26),

[...] os Direitos Autorais - a exemplo de outros direitos privados - vêm sendo constitucionalizados em vários países, compondo o elenco dos denominados 'direitos fundamentais da pessoa' ou 'liberdades públicas', em razão da evolução alcançada no plano da preservação, ante ao Estado, de direitos inatos do homem. 
José Afonso da Silva menciona que: "A função social da propriedade não se confunde com os sistemas de limitação da propriedade. Estes dizem respeito ao exercício do direito ao proprietário; aquela, à estrutura do direito mesmo, à propriedade. "(SILVA, 2005)

Os limites do Direito Autoral são como permissões legais para o uso de obras de terceiros, protegidas por Direitos Autorais, independentemente de autorização dos detentores de tais direitos.

O artigo 46 da Lei de Direitos Autorais diz:

Não constitui ofensa aos Direitos Autorais:

I - a reprodução:

a) na imprensa diária ou periódica, de notícia ou de artigo informativo, publicado em diários ou periódicos, com a menção do nome do autor, se assinados, e da publicação de onde foram transcritos;

b) em diários ou periódicos, de discursos pronunciados em reuniões públicas de qualquer natureza;

c) de retratos, ou de outra forma de representação da imagem, feitos sob encomenda, quando realizada pelo proprietário do objeto encomendado, não havendo a oposição da pessoa neles representada ou de seus herdeiros;

d) de obras literárias, artísticas ou científicas, para uso exclusivo de deficientes visuais, sempre que a reprodução, sem fins comerciais, seja feita mediante o sistema Braille ou outro procedimento em qualquer suporte para esses destinatários;

II - a reprodução, em um só exemplar de pequenos trechos, para uso privado do copista, desde que feita por este, sem intuito de lucro;

III - a citação em livros, jornais, revistas ou qualquer outro meio de comunicação, de passagens de qualquer obra, para fins de estudo, crítica ou polêmica, na medida justificada para o fim a atingir, indicando-se o nome do autor e a origem da obra;

IV - o apanhado de lições em estabelecimentos de ensino por aqueles a quem elas se dirigem, vedada sua publicação, integral ou parcial, sem autorização prévia e expressa de quem as ministrou;

V - a utilização de obras literárias, artísticas ou científicas, fonogramas e transmissão de rádio e televisão em estabelecimentos comerciais, exclusivamente para demonstração à clientela, desde que esses estabelecimentos comercializem os suportes ou equipamentos que permitam a sua utilização;

VI - a representação teatral e a execução musical, quando realizadas no recesso familiar ou, para fins exclusivamente didáticos, nos estabelecimentos de ensino, não havendo em qualquer caso intuito de lucro;

VII - a utilização de obras literárias, artísticas ou científicas para produzir prova judiciária ou administrativa; 
VIII - a reprodução, em quaisquer obras, de pequenos trechos de obras preexistentes, de qualquer natureza, ou de obra integral, quando de artes plásticas, sempre que a reprodução em si não seja o objetivo principal da obra nova e que não prejudique a exploração normal da obra reproduzida nem cause um prejuízo injustificado aos legítimos interesses dos autores.

Ressalta-se que o direito da exclusividade autoral positivado no art. $5^{\circ}, \mathrm{XXVII}$, CRFB não constitui direito absoluto, uma vez que se torna vital a ponderação de valores através da leitura da funcionalização. O art. $5^{\circ}$, XIV e o art. 215 , ambos da CRFB, asseguram indistintamente o acesso à informação, às fontes da cultura e o exercício dos direitos culturais como direitos subjetivos juridicamente protegidos que transcendem a esfera individual dos sujeitos de direito. (SOARES, 2006).

Guilherme Carboni avalia que essas hipóteses de limitação constituem um rol taxativo. São hipóteses que não deixam margem para interpretação. Não foram feitas na base de um princípio geral. Não existe, também, na nossa legislação um inciso que permita uma livre reprodução em casos envolvendo educação, pesquisa, ciência e qualquer coisa semelhante, da mesma forma, como não existe um artigo que diga que o impacto econômico da reprodução deva ser levado em consideração. (CARBONI, 2008, p.24)

Algumas questões a respeito da cópia privada merecem maior destaque por este parecer um dos incisos mais polêmicos da lei de Direitos Autorais.

No Brasil, não temos a permissão da cópia privada, tínhamos na nossa lei anterior, a qual nos possibilitava fazer uma cópia integral de um único exemplar, sem intuito de lucro. Com a lei de 1998, e a possibilidade de se fazer cópias apenas de "pequenos trechos" levanta-se toda uma discussão, de qual seria a extensão de "pequenos trechos".

Há algumas tentativas de quantificar, inclusive projetos de lei trabalhando nessa linha da quantificação do "pequeno trecho". Há outras tentativas de interpretar isso de forma bastante restrita, como por exemplo, quando a lei fala que a cópia teria de ser feita pelo copista (uma interpretação bastante restritiva, no sentido de que só o copista é que poderia fazer essa cópia). Ou seja, num país como o Brasil, onde a cópia normalmente é feita por empresas, pequenas empresas, localizadas nas universidades, de xerox, isso não seria permitido, isso violaria, não estaria de acordo com esse inciso da lei de Direitos Autorais. (Idem, ibidem, p.25) 


\section{CONTRIBUIÇÕES PARA UM DIREITO AUTORAL CONTEMPORÂNEO}

A Lei de Direitos Autorais brasileira (Lei n. 9.610/98) estabelece limitações e exceções nos artigos 46, 47 e 48, e em geral com texto bastante restritivo, somente a letra da lei é considerada.

Os Direitos Autorais compreendem, por sua natureza e finalidade, um conjunto unificado de prerrogativas, cuja intenção fundamental é resguardar o autor e permitirIhe, de um lado, a defesa da paternidade e da integridade de sua obra e, de outro, a fruição dos proventos econômicos resultantes de sua utilização, balizados nos mecanismos de tutela dos direitos individuais. Diante da importância social dos criadores e de suas obras, improvável a afirmativa de que os direitos de autor não são dignos de merecimento da tutela penal. São, assim, merecedores da guarida penal ante a seriedade das lesões aos direitos de autor e as consequências nocivas para o livre desenvolvimento da comunidade. (NASCIMENTO, 2014, p.147)

No tocante à tutela penal dos Direitos Autorais de caráter moral, faz-se necessário um redesenho da norma para que preveja pormenorizadamente as condutas consideradas de maior gravidade, graduando-lhes as penas de acordo com a sua reprovabilidade, em vista da lesão ao bem jurídico. De outro lado, as condutas que possam ser tuteladas por outros ramos do Direito devem ser excluídas da norma penal, descriminalizando-as. (Ibidem, 2014, p.128)

Quanto à excessiva criminalização dos delitos patrimoniais, Salvador Netto propõe uma evolução das normas na esfera judicial, alinhando os discursos no sentido de aplacar as respostas punitivas e reduzir as hipóteses de tipificação:

As restrições dos conteúdos típicos podem ser feitas tanto em âmbito legislativo, na alteração do texto legal, quanto judicial, por meio de ferramentas de interpretação que restrinjam a criminalização somente àqueles casos de efetivos e significativos prejuízos patrimoniais. Cuida-se, dessa forma, da almejada consagração de um sistema penal mínimo no campo patrimonial, utilizando-se, para tanto, de reformas legislativas, adoção de princípios restritivos de interpretação, sanções penais não pecuniárias, sanções não penais, composições entre vítimas e autores, além de instrumentos processuais. (SALVADOR NETTO, 2013, p. 262)

É possível afirmar que a legislação brasileira de Direitos Autorais não promove o uso justo das obras intelectuais, havendo fortes restrições e lacunas que impactam diretamente no acesso ao conhecimento. São diversos os exemplos de situações nas 
quais o acesso ao conhecimento é negado sob alegação de que se estão protegendo Direitos Autorais, a começar pelos altos preços de livros e pela interpretação restritiva que se tenta impor no Brasil com relação ao artigo 46, VIII, da Lei de Direitos Autorais, vedando-se a fotocópia ao máximo. Os mesmos problemas são encontrados no que diz respeito ao preço para acesso a programas de computadores: dificulta-se a inclusão digital e estimula-se a ilegalidade, não só por conta dos altos custos como também pela ainda baixa difusão de programas alternativos gratuitos. (GUERRINI, 2008)

Com efeito, percebe-se que a concessão de um direito exclusivo pelo Estado ao autor resulta imprescindível para restrição das forças livres da concorrência, pois, caso deixado à liberdade do mercado, a criação intelectual seria imediatamente dissipada pela liberdade de cópia. As forças livres do mercado permitiriam a absorção imediata das inovações e das criações por seus agentes mais hábeis. De outra parte, como qualquer outro direito, o de exploração da obra intelectual está submetido a limitações legais, especialmente para atender determinadas necessidades sociais. Apesar disso, é dever estatal preservar um oportuno equilíbrio a fim de se resguardar os legítimos interesses do autor, estimular a produção de novos bens culturais e, consequentemente, incentivar os investimentos industriais e comerciais dos diversos setores envolvidos nessa relação jurídica. (NASCIMENTO, 2014. p. 131)

Diante da análise feita até aqui, fica evidente, o impacto do Direito Autoral sobre práticas educacionais diárias é essencial para as práticas educacionais que determinados usos permitidos estejam expressos na lei, para afastar dúvidas no campo da educação.

Os Direitos Autorais necessariamente devem promover os direitos humanos, nunca representar o impedimento destes. Necessitamos de leis novas e adequadas a nossa realidade, por isso é fundamental refletirmos que caminhos pretendemos seguir. Logo, é indispensável avaliarmos o uso ponderado da tecnologia como forma de disseminação do conhecimento, e não de sua restrição indevida. 
Conclui-se, que a legislação autoral em vigor no Brasil tem a função de proteger os direitos de autor, sendo que o fato de se encontrar obras disponíveis para pesquisa pública em meio eletrônico não sugere que estas são públicas ou de domínio público, porquanto são de titularidade do autor ou de terceiro legitimado.

Com o intuito de não desmerecer o autor, fazer uso de suas palavras é permitido, desde que as fontes sejam devidamente referenciadas. Logo, a citação de trechos e passagens de obras de vários autores com a finalidade de fundamentar a arguição do trabalho, compará-lo, não constitui violação de Direitos Autorais, desde que haja a devida referência dos autores e suas obras empregadas.

Salienta-se que a reprodução de pequeno trecho tem restrição quanto ao tamanho e não deve se tornar o escopo principal de uma nova obra, entretanto nada impede que esteja empregado em tal obra para fins de estudo, embasamento ou citação.

Diversas informações encontram-se dispostas nos mais variados meios de comunicação, principalmente no meio eletrônico. É de extrema relevância saber utilizá-las de forma apropriada, na execução de um trabalho de qualidade.

\section{REFERÊNCIAS}

ABRÃO, Eliane Yachouh. Direitos de Autor e Direitos Conexos. São Paulo: Editora do Brasil, 2002, p. 148.

BITTAR, Carlos Alberto. Direito de autor. 2. ed. Rio de Janeiro : Forense Universitária, 1994. $168 \mathrm{p}$.

1992. $216 p$.

Contornos atuais do direito do autor. São Paulo: Revista dos Tribunais,

BRASIL Constituição de 16 de julho de 1934. Constituição Da República Dos Estados Unidos Do Brasil. Disponível em: <http://www.planalto.gov.br/ccivil_03/ constituicao/constituicao34.htm> Acesso em: 16 de fevereiro de 2021.

Constituição de 18 de setembro de 1946. Constituição dos Estados Unidos do Brasil. Disponível em: <http://www.planalto.gov.br/ccivil_03/Constituicao/ Constituicao46.htm> Acesso em: 16 de fevereiro de 2021. 
Constituição de 24 de janeiro de 1967. Constituição Da República Federativa Do Brasil. Disponível em: <http://www.planalto.gov.br/ccivil_03/constituicao/ constituicao67.htm> Acesso em 17 de fevereiro de 2021.

Emenda Constitucional $\mathrm{n}^{\circ} 1$ de 17.10.1969. Emenda Constitucional $\mathrm{N}^{\circ}$ 1, De 17 De Outubro De 1969. Disponível em: http://www.planalto.gov.br/ccivil_03/ Constituicao/Emendas/Emc_anterior1988/emc01-69.htm Acesso em 16 de fevereiro de 2021.

Decreto $N^{\circ} 5.244$ De 14 De Outubro De 2004. Disponível em: <http://www.planalto.gov.br/ccivil_03/_Ato2004-2006/2004/Decreto/D5244. htm\#: :text=Disp\%C3\%B5e\%20sobre\%20a\%20composi\%C3\%A7\%C3\%A30\%20 e,Intelectual\%2C\%20e\%20d\%C3\%A1\%20outras\%20provid\%C3\%AAncias> Acesso em 15 de fevereiro de 2021.

CARBONI, Guilherme. Aspectos Gerais da Teoria da Função Social do Direito de Autor. Disponível em <https://gcarbonicombr.files.wordpress.com/2016/08/aspectosgerais-da-teoria-da-func3a7c3a3o-social-do-direito-de-autor.pdf > Acesso em 26 de maio de 2020.

CARBONI, Guilherme. Limitações e exceções da lei. In: Fórum Nacional de Direito Autoral. Seminário Direitos Autorais e Acesso à Cultura (2008: São Paulo, SP). Anais do Seminário Direitos Autorais e Acesso à Cultura [recurso eletrônico], 27 e 28 de agosto de 2008. Brasília: Ministério da Cultura, Coordenação Geral de Direito Autoral, 2008. p.24-25.

CESAR, Daniel Jorge Teixeira. A cultura da cópia: estudo sobre o compartilhamento de arquivos e a prática da pirataria virtual. 2013. 107 f. Dissertação (Mestrado em Sociologia) - Universidade de Brasília, Brasília, 2013.

GUERRINI, Estela Waksberg. Direitos Autorais e os Direitos dos Consumidores. In: Fórum Nacional de Direito Autoral. Seminário Direitos Autorais e Acesso à Cultura (2008: São Paulo, SP). Anais do Seminário Direitos Autorais e Acesso à Cultura [recurso eletrônico], 27 e 28 de agosto de 2008. Brasília: Ministério da Cultura, Coordenação Geral de Direito Autoral, 2008.

HAMMES, Bruno Jorge. O Direito da Propriedade Intelectual. 3.ed. São Leopoldo: Unisinos, 2002. http://www.nbb.com.br/pub/propriedade13.pdf>. Acesso em 15 de fevereiro de 2021.

NASCIMENTO, Elisa Gattás Fernandes do. A tutela penal dos Direitos Autorais. São Paulo, 2014. Fls. 147. Dissertação de mestrado - Universidade de São Paulo, Faculdade de Direito, Programa de Pós Graduação em Direito, 2014. 
NIGRI, Deborah Fisch. Direito Autoral e a Convergência de Mídias - Cadernos de Direito da Internet. vol. II. Rio de Janeiro: Editora Lumen Juris, 2006.

NUCCl, Guilherme de Souza. Código Penal Comentado. 6. ed. São Paulo: RT, 2007.p. 744

OLARTE COLLAZOS, Jorge Mario; ROJAS CHAVARRO, Miguel Angelo. La protección del derecho de autor y los derechos conexos en el ámbito penal. Dirección Nacional de Derecho de Autor, Ministerio del Interior y de Justicia. Colômbia, 2010. Disponível em: <http://www.derechodeautor.gov.co/documents/10181/11769/> acesso em: 15 de fevereiro de 2021. 10.48209/978-12-994306-2-9 


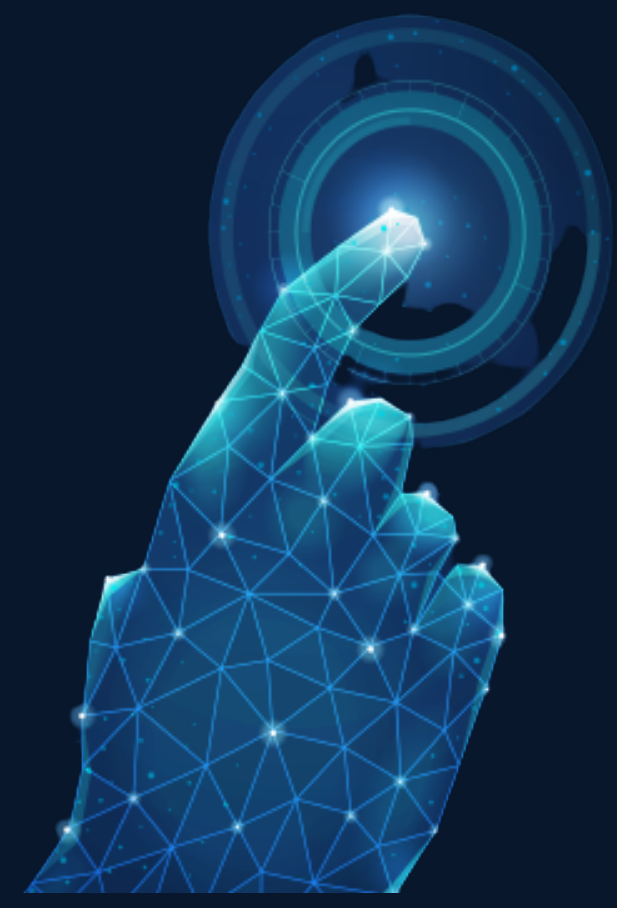

\section{TECNOLOGIAS DA INFORMAÇÃO E COMUNICA- ÇÃO (TICS): ESTRÁTEGIAS PARA A FORMAÇÃO DE PROFESSORES NO ENSINO A DISTÂNCIA}

Roberto da Silva ${ }^{1}$

Poliana dos Santos Silva ${ }^{2}$ Ana Paula dos Santos Silva ${ }^{3}$

1 Lattes:http://lattes.cnpq.br/7196538730934531. Especialização: Pós-graduação em Psicopedagogia-UPE/PE; Coordenação Pedagógica - FAVENI-ES. Psicopedagogia Institucional e Clínica (cursando) - FAVENI-ES E-mail.roberto.secd@gmail.com

2 Lattes: http://lattes.cnpq.br/7960787409799569. Graduada em Licenciatura em Ciências Biológicas - UNOPAR - Garanhuns/PE. Cursando Licenciatura em Pedagogia -UFAPE. Especialização: Pós-graduação em Psicopedagogia Institucional e Clinica (cursando) - FAVENI- ES. E-mail. polianasantos39@hotmail.com

3 Lattes: http://lattes.cnpq.br/5127537320088490. Graduando em Licienciatura em Pedagogia - UNOPAR - Garanhuns/PE. E-mail.anapaullasantosilva2020@gmail.com 
Resumo: O processo de ensino e aprendizagem se revela na prática do professor e dos alunos quando utilizam os recursos tecnológicos disponíveis. O presente trabalho tem como propósito refletir sobre a prática educativa, focando nas Estratégias Tecnológicas digitais em sala de aula, identificando as ferramentas de grande valia na construção das informações durante os processos de ensino e de aprendizado. Trata-se de um estudo explicativo, mostrando a importância das TICs diante da nova era das tecnologias na qual podem ser usadas na modalidade de EAD conhecido como ensino por meio de ferramentas tecnológicas, para aprimorar os estudos onde permite várias maneiras para concretizar os métodos educacionais trazendo soluções eficazes em projetos que envolvam a participação ativa dos discentes. Para tanto a pesquisa foi realizada por meio do estudo de caso de um curso de Graduação à distância. Assim foi possível analisar que, a evolução tecnológica tem acolhido um desempenho eficaz nessa modalidade de ensino, atendendo assim as necessidades daqueles que buscam, e quanto ao ensino, tem garantido a formação dos discentes com qualidade e segurança em seus procedimentos, capacitando profissionais formadores de opiniões que, no exercício de suas atribuições possam demonstrar suas atitudes, aptidões e conhecimento. Sendo assim, cabem ao governo investir na produção de novos softwares, para que os docentes tenham as ferramentas nas mãos, podendo assim colocar em prática as estratégias de ensino-aprendizagem. Por isso que a categoria da EAD vai proceder da fomentação do estudante que deve buscar todas as informações essenciais para sua aprendizagem.

Palavras-chave: Educação a Distância, Práticas Educacionais, Tecnologias de Informação.

\section{INFORMATION AND COMMUNICATION TECHNOLOGIES (TICS): STRATEGIES FOR TRAINING TEACHERS IN DISTANCE EDUCATION}

ABSTRACT: The teaching and learning process is revealed in the practice of the teacher and the students when they use the available technological resources. This work aims to reflect on educational practice, focusing on digital Technological Strategies in the classroom, identifying the tools of great value in the construction of information during the teaching and learning processes. This is an explanatory study, showing the importance of ICTs in the face of the new era of technologies in which they can be used in the distance learning modality known as teaching through technological tools, to improve studies where it allows several ways to materialize educational methods bringing effective solutions in projects that involve the active participation of students. For this purpose, the research was carried out through the case study of an undergra- 
duate distance course. Thus, it was possible to analyze that technological evolution has received an effective performance in this type of teaching, thus meeting the needs of those who seek, and as for teaching, it has guaranteed the training of students with quality and safety in their procedures, training professionals who train opinions that, in the exercise of their duties, can demonstrate their attitudes, skills and knowledge. Thus, it is up to the government to invest in the production of new software, so that teachers have the tools in their hands, thus being able to put teaching-learning strategies into practice. That is why the EAD category will proceed from fostering students who must seek all the essential information for their learning.

Keywords: Distance Education, Educational Practices, Technologies of information.

\section{INTRODUÇÃO}

Nos dias atuais, para que haja aprendizagem deve haver dinamismo, portanto a adaptação não é apenas dos alunos, mas também dos professores, as aulas modernizadas, não necessitam apenas do uso tecnológicos, é necessário que a equipe escolar se adapte aos novos equipamentos.

É preciso reconhecer que a tecnologia da informação e comunicação trouxeram novos questionamentos e criaram novas formas dos sujeitos lidarem com o mundo, trazendo a problemática de como formar sujeitos preparados e capazes de lidarem com tais exigências de maneira crítica, ética e autônoma.

O objetivo é fazer os educadores refletirem sobre como podem usar a tecnologia no dia a dia para ensinar melhor a tecnologia esta presente em tudo e com ela temos muito que aprender.

O presente trabalho tem como propósito refletir sobre a prática educativa, focando nas Estratégias Tecnológicas digitais em sala de aula, identificando as ferramentas de grande valia na construção das informações durante os processos de ensino e de aprendizado.

Assim o papel do professor é de fundamental importância na mediação do educando com os meios de comunicação e informação, amparando-os pessoas a terem o pensamento autônomo, crítico, trazendo consciência do mundo a sua volta, abrangendo a realidade e atuando sobre ela.

Muitas crianças de 6 (SEIS) à 8 (OITO) anos já tem o domínio do uso das tecnologias, igual ou melhor de uma pessoa já adulta, e para os professores mostrarem 
que tem domínio no uso das tecnologias, é necessário que os educadores sejam motivadores da instituição de ensino e que os mesmos se atualizem e inovem seus laboratórios, modernizem os equipamentos necessários e dê condições para que os mesmos possam trabalhar de forma dinâmica e inovadora; também é necessário um treinamento para que estes profissionais possam exercer suas funções adequadamente.

A escola e o professor são as bases do desenvolvimento social, cultural e intelectual, pois o papel do professor é oferecer aos seus alunos a fonte do conhecimento preparando-o para desenvolverem suas qualidades críticas e questionadoras, e não serem somente espectadores ou meros receptores de informações é dever dos professores ensinar á seus alunos, como pensar, questionar e a aprender a ver a nossa realidade, para que possam construir opiniões próprias, para que isto ocorra o professor deve, em primeiro lugar, gostar e acreditar naquilo que faz, ou seja, através de seus atos e ações ele servirá de exemplo para seus alunos; se ele ensina a refletir ele deve também refletir, se ele ensina a respeitar o próximo ele deve respeitar seus educandos e assim por diante.

Deste modo ele está sendo prova viva daquilo que está ensinando, pois o bom educador transmite seus conhecimentos com clareza e entendimento, (explica o conteúdo quantas vezes for preciso) educador é diferente do detentor que apenas repassa o que aprendeu e tenta fazer com que seus alunos decorem e não apreenda os conteúdos aplicados.

O grande desafio para a escola implica em mudanças que desde a concepção de educação de aprendizagem e formação de professores, até a definição de política pública que possam garantir a democratização e apropriação destas ferramentas em umas perspectivas críticas.

Sobretudo é preciso implantar laboratórios de informática nas escolas, assim é necessário que todos os membros do ambiente escolar inclusive os pais tenham seu papel redesenhado. Depois, é preciso levar em conta a construção de conteúdos inovadores, que usem todo o potencial dessas tecnologias na EAD.

Para tanto a educação não pode mais viver sob o modelo antigo, sob o risco de virar virtual e invisível para a sociedade, tendo em vista que às novas tecnologias devem ser exploradas para servir como meios de construção do conhecimento, e não 
somente para a sua difusão. A tecnologia na sala de aula também pode servir como uma grande biblioteca, com os conteúdos de pesquisas e sites de notícias que disponibilizam conteúdo para análise; vários recursos tecnológicos oferecem relatórios de aprendizagem, para mostrar aos estudantes de maneira individual ou coletiva, os pontos das matérias que os discípulos têm maior índice de acertos e em quais os alunos tem ampla dificuldade de aprendizagem.

Diante disto os professores da nova geração tem que estar preparado para não só ficar na inalterabilidade de quadro negro e giz, eles têm que se adequar as novas tecnologias que estão aparecendo no mercado. Para acompanhar o desenvolvimento tecnológico, os computadores, tabletes e smartphones (celulares) necessitam está conectados à internet, os softwares para estudo, jogos eletrônicos de alguma matéria, vídeo aula pelo Youtube.

Vivemos em uma sociedade que sofre mudanças constantemente, os educadores e as escolas de rede públicas e privadas precisam acompanhar essas mudanças, pois através das tecnologias temos as ferramentas que podem ajudar a transmitir uma educação de qualidade.

A geração criada a partir das novas tecnologias precisa de um motivo, ou seja, os jovens da atualidade precisa saber como aquele conteúdo especificamente pode ser útil na sua vida profissional ou até mesmo na vida pessoal.

O uso da tecnologia deve ser utilizado no dia a dia e principalmente no conteúdo curricular das matérias, pois o uso das tecnologias enriquece o ambiente com os colegas e constroem seus conhecimentos.

\section{MATERIAIS E MÉTODOS}

Trata-se de um estudo explicativo, mostrando a importância das TICs diante da nova era das tecnologias na qual podem ser usadas na modalidade de EAD conhecido como ensino por meio de ferramentas tecnológicas, para aprimorar os estudos onde permite várias maneiras para concretizar os métodos educacionais, trazendo soluções eficazes em projetos que envolvam a participação ativa dos discentes. Para tanto a pesquisa foi realizada por meio do estudo de caso de um curso de Graduação à distância.

Este trabalho foi elaborado por educandos do $1^{\circ}$ período do curso de Ciências 
Biológicas da Universidade Norte do Paraná (UNOPAR)-2017-Garanhuns, salientando que é resultado de uma pesquisa realizada pelo grupo, e tem como objetivo expor sobre nosso olhar a utilização da tecnologia para a inclusão de alunos com necessidades especiais. Tratamos de assuntos pouco discutidos e de suma importância para se construir uma sociedade justa e totalmente inclusiva, onde os usos de equipamentos tecnológicos ajudem a deixar os alunos sem necessidades especiais, como também a sua importância dentro da educação inclusiva.

Assim foi possível analisar que, a evolução tecnológica tem acolhido um desempenho eficaz nessa modalidade de ensino, atendendo assim as necessidades daqueles que buscam, e quanto ao ensino, tem garantido a formação dos discentes com qualidade e segurança em seus procedimentos, capacitando profissionais formadores de opiniões que, no exercício de suas atribuições possam demonstrar suas atitudes, aptidões e conhecimento.

\section{DISCUSSÃO}

Não se trata de, apenas, discutir a incorporação das TIC pelas escolas. O resultado do ensino com uso mais intenso, por exemplo, de tecnologia eletrônica tem redundado em sistemas de baixíssima interação, que replicam grosseira e indefinidamente uma matriz de aula como as denominadas, mais recentemente, de tele aulas.

Scheibe (2006) e Zuin (2006, p. 951) já apontaram a "pulverização da autoridade pedagógica”, quando se lança mão de mediação técnica, acompanhada de serviços de apoio a essa mediação, como é o caso dos tutores na educação à distância, principalmente no ensino superior.

Conforme a ideias dos autores a cima, podemos afirmar que os avanços tecnológicos estão cada vez mais destinados a mudar sua maneira de viver, e usá-las para que assim possa ajudar os estudantes aprenderem e um sinal que um futuro promissor é possível para todos e não há limitações. Para tanto as tecnologias são ferramentas, máquinas de conhecimentos que ajudam as pessoas a ficar, mas próximas, através dos meios de comunicações, porém a internet é um meio de comunicação de grande utilidade para as coisas boas, visto que a internet tem o poder de juntar as pessoas, mas distantes, e separar as que estão próximas. O uso da tecnologia deve ser utilizado no dia a dia e principalmente no conteúdo curricular das matérias, pois 
o uso das tecnologias enriquece o ambiente de aprendizagem onde os estudantes interagem com os objetos tecnológicos em sala de aula e constroem seus conhecimentos adquiridos da aprendizagem.

Segundo com os estudos de (Mercado) como se abrange, o professor é um importante elemento nesse novo método de interação da tecnologia com a Educação a Distância. Do mesmo modo, é imprescindível que os professores "saibam incorporar e aproveitar as novas tecnologias no procedimento de aprendizagem exigindo-se assim um novo desenho do processo didático metodológico tradicionalmente usado em nossas escolas" (MERCADO, 1999, p. 14).

Sabemos que a tecnologia na educação deve se integrar na forma multidisciplinar, constituindo-se em mais uma possibilidade que o professor pode contar para a realização do seu trabalho, desenvolvendo atividades que propiciem uma reflexão por parte do aluno e realizando a interação entre as diversas disciplinas e os recursos que a mesma oferece. Sobretudo a tecnologia aproxima os professores do universo dos discentes do século XXI ajudando a prepara-los para a vida presente e futura, cada vez mais mediadas pelos recursos tecnológicos.

Perante o estudo e as pesquisas para a elaboração do presente trabalho, entende-se como a tecnologia e fundamental para todo processo escolar, e para a formação de educadores atualizados para a nova era da tecnologia, como o uso delas se aprimorar a cada dia apreando melhorias para todos em geral.

$\mathrm{Na}$ minha concepção ensinar e aprender estão sendo desafiados como nunca foi antes. Contudo há informações demais, múltiplas fontes, visões diferentes de mundo. É válido ressaltar que educar hoje é mais complexo porque a sociedade também é mais complexa. As tecnologias começam há estar um pouco mais ao alcance do estudante e do professor. Devemos repensar todo o processo, reaprender a ensinar, a estar com os alunos, a orientar atividades, a definir o que vale a pena fazer para aprender, juntos ou separados.

É preciso que nós educadores, continuemos nos apropriando cada vez mais dos conhecimentos para a ampla utilização das ferramentas tecnológicas disponíveis nos dias atuais, criando possibilidades de uso dessas tecnologias que aguce no aluno o interesse pela pesquisa dentro e fora da escola, desenvolvendo no educando, as capacidades de interpretação, síntese e criticidade, uma vez que, a escola é o espaço 
apropriado para ensinar como as pessoas devem se portar diante das tecnologias.

Para tanto a utilização de tecnologias no ambiente escolar e na sala de aula impulsiona a abertura desses espaços ao mundo e ao contexto, permitindo assim, articular as situações globais e locais, sem, abandonar o universo de conhecimentos acumulados ao longo do desenvolvimento da humanidade. Pois tecnologias e conhecimentos se integram para produzir novos conhecimentos que permitam compreender as problemáticas atuais e desenvolver projetos, em busca de alternativas para a transformação do cotidiano e a construção da cidadania.

Assim ao desenvolver projetos em sala de aula, é fundamental levantar problemáticas relacionadas com a realidade do estudante, cujas questões e temáticas em estudo partem do conhecimento que ele traz de seu contexto e buscam construir investigações para construir um conhecimento científico que ajude aos educandos a compreender o mundo e a conviver criticamente na sociedade. Sendo assim, a partir da busca e organização de informações oriundas de distintas fontes e tecnologias, que fomentar em valoriza a articulação entre novas formas de representação de conhecimentos através das mídias e respectivas maneiras de linguagem que mobilizam pensamentos criativos, sentimentos e representações, contribuindo para a comunicação, a interação entre pessoas e objetos de conhecimento, na aprendizagem e o desenvolvimento de produções.

Entretanto é preciso compreender as diferentes estratégias de representação e comunicação propiciadas pelas tecnologias disponíveis na escola, bem como criar dinâmicas que permitam estabelecer o diálogo entre as formas de linguagem das mídias, que são os desafios para a educação atual, que requerem o desenvolvimento de programas de formação continuada de professores.

\section{ALGUMAS FERRAMENTAS QUE ENCONTRAMOS NAS ESCOLAS SÃO:}

$\begin{array}{ll}\checkmark & \text { Data show } \\ \checkmark & \text { Computadores } \\ \checkmark & \text { Televisão } \\ \checkmark & \text { Retroprojetor } \\ \checkmark & \text { Tabletes } \\ \checkmark & \text { Tela de projeção }\end{array}$


$\checkmark$ Caixa de som (áudio)

$\checkmark$ Micro systems

$\checkmark$ Aparelho de DVDs

$\checkmark$ Projetor de multimídia

$\checkmark$ Laboratório

$\checkmark$ Câmera digital

$\checkmark$ Sala de informática

\section{FERRAMENTAS QUE ENCONTRAMOS NAS ESCOLAS}

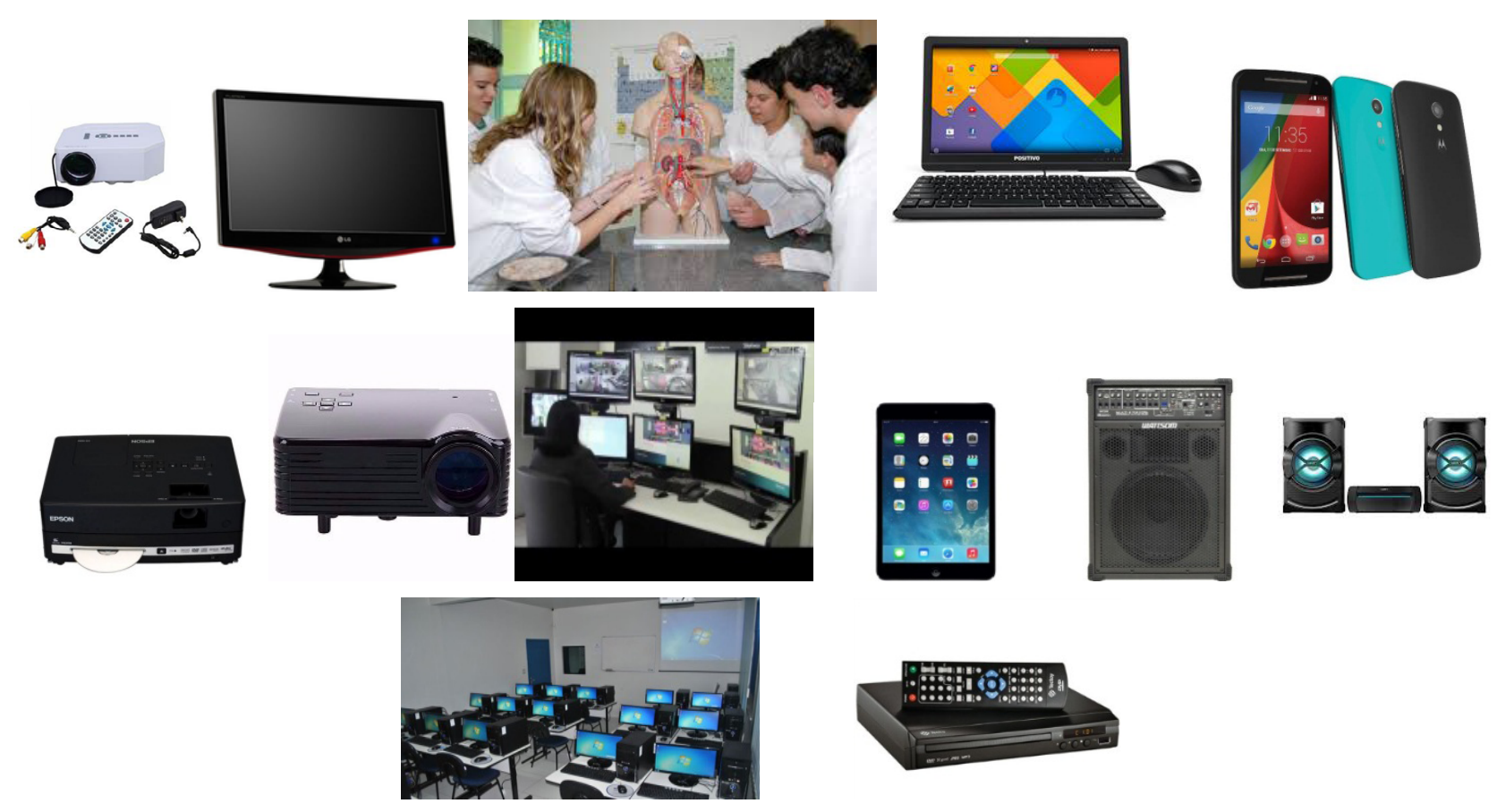

Fonte: Google

É de suma importância saber aplicar de forma prática os conhecimentos adquiridos até aqui para servi de apoio para o professor interagir na sala de aula com seus colegiais, as novas tecnologias devem ser incorporadas à educação, não como um simples recursos didáticos, fruto de um ensino tradicional ou remodelado, mas como um mecanismo estruturador de uma nova educação, com novas teorias e metodologias. Os recursos tecnológicos devem ser utilizados como mais uma ferramenta na construção de conhecimentos.

As gerações mais recentes estão intensamente envolvidas com as tecnologias atuais, porém boa parte do seu dia é para navegarem na internet. As pessoas estão sempre conectadas seja em casa, na escola, na rua ou no trabalho, a tecnologia está 
presente em nosso cotidiano, hoje é praticamente impossível ir a algum lugar e não ver uma pessoa ou outra com um celular em mãos.

Vivemos na era da comunicação (Computadores, tabletes, celulares smartphones, Televisões digitais, rádios, sons, revistas, jornais e softwares, WhatsApp, facebook, twiter, Outlook, Messenger entre outros). Esses são os meios de comunicações que trazem as notícias que acontece no mundo, para que possamos ficar atualizados.

\section{CONCLUSÃo}

Sendo assim, cabem ao governo investir na produção de novos softwares, para que os docentes tenham as ferramentas nas mãos, podendo assim colocar em prática as estratégias de ensino-aprendizagem. Por isso que a categoria da EAD vai proceder da fomentação do estudante que deve buscar todas as informações essenciais para sua aprendizagem.

Argumentando assim a escola deve atualizar, oferecendo aos educandos um processo que esteja de acordo com a atualidade; pois não se pode mais dispor apenas como único recurso o quadro de giz, pois este método já está ultrapassado. Portanto tem-se que inovar, investindo em tecnologia digital. Atualmente podemos contar com vários cursos tecnológicos, com o objetivo de capacitar novos profissionais (um exemplo disso é nos alunos de uma instituição de ensino a distância (EAD) além das aulas remotas e trabalhos homi Office).

Este trabalho obteve, entre outros objetivos, o de analisar os desafios dos docentes e, evidenciar as novas tecnologias como mais um recurso para o processo de ensino aprendizagem. Ressalta-se a importância de esclarecer sobre tecnologia, pois ainda se pensa que tecnologia é apenas o computador, poucos encaram outros meios, mas aqui o que importa não é ter uma nova tecnologia, mas, sim, saber utilizá-la com objetivos definidos. Sabemos que é preocupante a falta de disponibilidade de recurso tecnológico em algumas escolas, na maioria das vezes se tem o quadro que é o recurso mais tradicional, mas a sugestão é que cada vez mais as tecnologias sejam como fomentadoras do trabalho professor/aluno e não como um empecilho desse trabalho. 


\section{REFERÊNCIAS}

Albuquerque Costa, F. Elementos para reflexão sobre a integração dos TIC na educação politica e gestão da educação dos olhares críticos. Rio de Janeiro: DPA. Editora 2002

ALONSO, Katia Morosov. Tecnologias da informação e comunicação e formação de professores: sobre rede e escolas. Educação \& Sociedade, v. 29, n. 104, p. 747768, 2008.

DE ALMEIDA, Maria Elizabeth Bianconcini. Prática e formação de professores na integração de mídias. 2003.

MERCADO, Luis Paulo Leopoldo. Formação continuada de professores e novas tecnologias. Maceió. EDUFAL, 1999.

SCHEIBE, L. Formação de professores: dilemas da formação inicial à distância. Educere et Educare, Cascavel, v. 1, p. 199-212, 2006.

SOFFA, Marilice Mugnaini; TORRES, Patrícia Lupion. O processo ensino-aprendizagem mediado pelas tecnologias da informação e comunicação na formação de professores on-line. In: IX Congresso Nacional de Educação-EDUCERE. PUCRS. 2009.

ZUIN, A.A.S. Educação à distância ou educação distante? O Programa Universidade Aberta do Brasil, o tutor e o professor virtual. Educação \& Sociedade, Campinas, v. 27, n. 96, p. 935-954, out. 2006. 


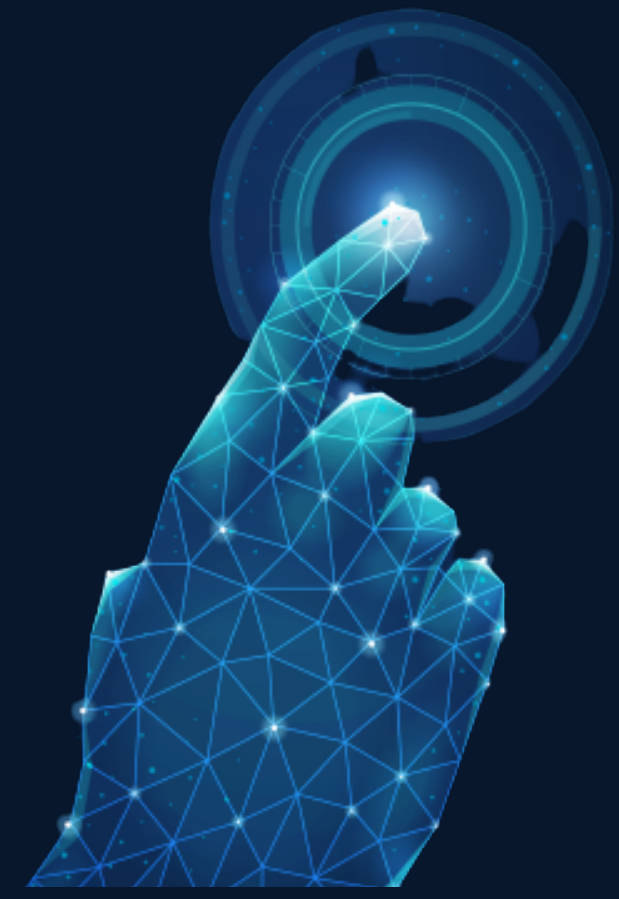

\section{TECNOLOGIAS DIGITAIS NA EDUCAÇÃO: O USO DA INTERNET NA PRÁTICA PEDAGÓGICA DO PROFESSOR}

Richard Fernandes ${ }^{1}$

1 Mestre em Cognição, Tecnologias e Instituições pela Universidade Federal Rural do Semi-Árido (UFERSA). Graduado em Pedagogia-UERN, Comunicação Social (com habilitação em Publicidade e Propaganda) -UERN e Especialista em Psicopedagogia Clínica e Institucional. E-mail: richard201125@live.com 


\section{INTRODUÇÃO}

A internet, como sendo uma tecnologia intangível de redes interligadas no globo, veio a possibilitar ao professor, da era contemporânea, a oportunidade de "beber" em várias fontes de conhecimentos, que antes eram limitadas, principalmente por barreiras físicas. Dessa forma, McLuhan (1974) vem afirmar que os meios de comunicação digital se tornaram a extensão do homem. Ou seja, as tecnologias digitais, como a internet e o computador, passaram a facilitar o processo comunicacional entre os sujeitos no mundo.

Nessa perspectiva, com as mudanças evolucionarias que passaram a ocorrer, no século XXI, no âmbito da educação (principalmente por causa da incorporação das Tecnologias Digitais de Informação e Comunicação - TDICs na sala de aula), as instituições de ensino vêm esforçando-se para reformular o seu Projeto Político Pedagógico - PPP para estarem em sintonia com uma nova abordagem híbrida de ensinar e aprender por meio das TDICs.

De fato, quando o professor faz uso da web, este tem a oportunidade de navegar em um oceano de informações/conhecimentos, que segundo Lévy (1999, p.17), "Os seres humanos é quem navega e alimenta esse universo". Em consonância com o pensamento desse autor contemporâneo, as novas tecnologias da informação chegaram para proporcionar um conhecimento compartilhado, no qual os usuários da web podem ser o próprio agente do seu processo comunicacional.

Nesse contexto, a internet ao proporcionar essa conectividade/interatividade entre os sujeitos no ciberespaço, possibilita ao professor a oportunidade de desenvolver uma prática pedagógica voltada para trabalhar a autonomia intelectual do aluno. Nesse sentido, Mizukami (1986, p. 71) afirma que: "a autonomia intelectual será assegurada pelo desenvolvimento da personalidade e pela aquisição de instrumental lógico-racional. A educação deverá visar que cada aluno chegue a essa autonomia". Assim, entende-se que o desenvolvimento da autonomia intelectual do aluno, de certa forma, está ligado ao incremento de abordagens de ensino-aprendizagem onde o discente possa ser o próprio protagonista do processo de construção de conhecimento. 
Para tanto, a modalidade de ensino a distância trouxe grandes desafios emergentes para o profissional da área da educação, haja vista que boa parte das escolas/universidades públicas do Brasil não têm ainda uma infraestrutura/ambientes apropriados para poderem oferecer aos alunos um ensino mediado pelas TDICs. Dessa forma, o presente artigo busca trazer para o leitor uma discussão teórica sobre a questão das novas tecnologias digitais na prática pedagógica do professor, destacando o uso da internet como uma ferramenta interativa de ensino e aprendizagem na prática pedagógica. Assim, para compreendermos melhor toda à dinamicidade proporcionada pela internet na prática docente, o presente estudo parte de um enfoque metodológico de uma pesquisa bibliográfica, de cunho exploratória, utilizando como fundamentação teórica Lévy (1999), que nos apresenta conceitos chaves para compreender as novas mudanças culturais no ciberespaço; McLuhan (1974), que traz um pensamento evolucionário sobre as tecnologias como meios de extensão do homem, e Valente (1996), que busca abordar à função do computador na prática pedagógica do professor.

\section{A TECNOLOGIA COMO PRODUTO DA EVOLUÇÃO HUMANA}

As tecnologias sempre estiveram interligadas às práticas de sobrevivência do homem. No período clássico da pré-história, o homem primitivo, já lançava mão de tecnologias rudimentares para poder fabricar utensílios, como flechas para caçar aves/animais e instrumentos para auxiliá-lo no cultivo da agricultura. Por mais remotas que sejam essas técnicas, possivelmente foi com elas que a espécie homo sapiens começaram a compreender sua verdadeira dependência biológica em relação à natureza. Além disso, foi a partir do uso destas primeiras tecnologias que o homem começou a fazer cultura e, consequentemente, a transmitir para outras gerações futuras (SIMONDON, 1969).

Nesse contexto, na Idade Média, o conceito epistemológico de tecnologia deixa de lado os resquícios etimológico da era pré-histórica e, por sua vez, passa a ser ligado ao de ciência moderna. Isso garantiu que essa técnica fosse reservada literalmente à classe aristocrática e ao clero, que, a princípio, eram camadas da sociedade quem detinham o acesso/domínio do saber científico.

Dessa forma, diante das transformações que passaram a ocorrer no seio da 
sociedade medieval, principalmente por causa da transferência de boa parte da população do campo para as cidades, as tecnologias se tornaram um grande meio para transformar a cultura do clero e da aristocracia (classes essas consideradas detentoras do saber científico, por muitos séculos).

Nesse sentido, como a igreja era quem detinha à função de educar na Idade Média, o sistema de ensino, basicamente se concentrava em dois modelos - um literário e o outro científico. No literário, além de fazer parte o cunho humanístico, eram ensinados gramática, dialética, literatura e retórica -, sem possuir uma reflexão científica quando se estudava esses campos de conhecimento. Já na parte científica, que estava ligado às ciências da natureza, eram ensinado geometria, astronomia, aritmética (ANDERSON, 1982).

Nessa perspectiva, no final da Idade Média, a tecnologia daria um salto extraordinário para o futuro, com o advento do movimento intelectual renascentista. Esse movimento intelectual, de ideologia filosófica-europeia, tinha como objetivo colocar o homem no centro do processo racional (antropocentrismo), para, assim, poder sobrepor ao pensamento medieval-católico (teocentrismo), que, a princípio, por muitos anos, era quem detinha o saber científico.

Dessa forma, o alemão Johannes Gutemberg ao criar a então revolucionada máquina de impressão de livros e jornais passaria a contribuir, de certo modo, para democratizar o saber científico para diferentes classes sociais. A partir desse advento histórico, o conhecimento científico passou a ser propagado através de livros impressos para um grande público no mundo, contrariando, assim, os preceitos dogmáticos do clero, que, por muitos anos, ocultava do leitor grandes obras científicas de autores, como: Aristóteles e Confúcio.

Historicamente, a sociedade contemporânea revolucionou as tecnologias quando trouxe à tona o desenvolvimento das primeiras máquinas inteligentes - computadores. A princípio, os primeiros computadores foram fabricados com intenções de auxiliar os cientistas em cálculos matemáticos no período da Segunda Guerra Mundial. Contudo, após esse advento histórico, os cientistas passaram a ter em mente outros objetivos para o uso dessa máquina conectada à internet.

Inicialmente, quando a internet foi posta para a sociedade civil grande parte da população não tinha interesse por essa tecnologia, uma vez que era um ambiente 
virtual usado apenas para trocas de textos, arquivos e mensagens. Entretanto, o engenheiro Inglês Tim Berners-Lee ao desenvolver em meados de1992 a World Wide Web, a internet ganhava uma nova roupagem atrativa, que possibilitaria a descentralização dessa tecnologia para à sociedade contemporânea (BERTONCELLO, 1999).

Diante desse quadro expansionista das tecnológicas no globo, a sociedade contemporânea embarca em um "navio" para desbravar um oceano de hipertextos jamais navegado antes pelo homo sapiens. Ratificando esse pensamento, Lévy (1999) vem afirmar que esse oceano não é composto de águas, mas, sim, pelo um universo de informações.

\section{O USO DA INTERNET NA PRÁTICA PEDAGÓGICA DO PROFESSOR}

A internet por ser uma ferramenta educacional que permite o professor navegar em um oceano de informações/conhecimentos, torna-se no século XXI uma inovadora opção para as escolas construir práticas pedagógicas mais atrativas para o aluno desenvolver o seu próprio processo de ensino-aprendizagem. Além disso, a internet quando é incorporada pelo professor em sala de aula, passa a ser um instrumento didático-pedagógico que possibilita a esse profissional trabalhar a Zona de Desenvolvimento Proximal (ZDP), que para Vygotsky (1984) é um processo cooperativo de aprendizagem que se dá entre o professor e o aluno.

Diante disso, ao incorporar a internet em sua prática pedagógica, o professor tem a chance de romper com o modelo de ensino tradicional, que há séculos vem fazendo parte do currículo escolar das instituições públicas e privadas do país. Ademais, o uso dessa ferramenta de ensino em sala de aula torna-se algo essencial para o professor poder trabalhar com os alunos habilidades e competências requeridas pela vida em comunidade ou pelo mercado de trabalho.

Nesse sentido, Valente (1996) ressalta que a sociedade do conhecimento exige um homem crítico, criativo, com capacidade de pensar, de aprender a aprender, trabalhar em grupo e de conhecer o seu potencial intelectual. Esse ser-no-mundo deverá ter consigo uma visão geral sobre os diferentes problemas que afligem a humanidade contemporânea, como às problemáticas sociais/políticas e ecológicas, e, além disso, possuir um profundo conhecimento sobre outros domínios específicos que a era digital passou a requerer do sujeito. Em outras palavras, um sujeito atento 
e, ao mesmo tempo, sensível às mudanças da sociedade, com uma visão transdisciplinar e com capacidade constante de aprimoramento e depuração de ideais e ações teóricas e práticas (VALENTE, 1996, p. 5-6.).

Ademais, em consonância com o pensamento desse autor, podemos compreender que as escolas quando incorporam a internet na prática pedagógica do professor, possibilita a estes profissionais desenvolver um ambiente de ensino-aprendizagem mais dinâmico e atrativo para que os alunos possam construir conhecimento a partir da resolução de problemas.

Nesse contexto, buscando incorporar essas transformações para o campo educacional, o Ministério da Educação (MEC) acrescentou mais um novo artigo na Lei das Diretrizes e Bases da Educação Nacional (LDB), que traz no seu artigo (art. 80, $\S 40$.), a importância de incorporar à internet como ferramenta de ensino no ambiente educacional das escolas. Em consonância com essas ações inovadoras, o Plano Nacional da Educação (PNE), traz definido na meta sete, especificamente, políticas públicas para triplicar o acesso à internet aos alunos da educação pública, prazo esse definido para ser alcançado até $2024 .{ }^{1}$ De fato, a inserção da internet no ambiente das escolas possibilita mudanças de paradigma na prática pedagógica, tendo em vista que essa ferramenta educacional proporciona uma aprendizagem coletiva entre professor e aluno (Lévy (1999).

Dessa forma, podemos afirmar que a internet é hoje uma ferramenta de ensino-aprendizagem de suma importância para o aluno desenvolver a sua própria autonomia intelectual. Para entendermos melhor como o aluno pode desenvolver a sua própria autonomia intelectual com o uso da internet, Deleuze (1999) afirma que o aluno é um ser que constrói seu próprio método de aprendizagem percorrendo por si só o caminho de ensinar e aprender na resolução de problemas.

Aprender é o nome que convém aos atos subjetivos operados em face da objetividade do problema (Ideia), ao passo que saber designa apenas a generalidade do conceito ou a calma posse de uma regra das soluções (...) Aprender é penetrar no universal das relações que constituem a ideia e nas singularidades que lhes correspondem. (...) Aprender a nadar é conjugar pontos relevantes de nosso corpo com os pontos singulares da ideia objetiva para formar um campo problemático. Esta conjugação determina para nós um limiar de consciência ao nível do qual nossos atos reais se ajustam as nossas percepções das correlações reais do objeto, fornecendo, então, uma solução do problema (DELEUZE, 1998, p. 96.).

1 Disponível em: <http://www.todospelaeducação.org.br/ > Acesso em 15 de jun. de 2020. 
Assim, contribuindo com esse discurso, dados recentes publicado pelo Comitê Gestor de Internet no Brasil (CGI.br), demostra que 48\% dos alunos disseram que começaram a manusear essa tecnologia sem o auxílio de nenhum instrutor. ${ }^{1}$ De fato, são números que confirma a importância do professor inserir essa tecnologia na sala de aula, levando em conta sempre os conhecimentos prévios que os alunos já trazem consigo de casa. A princípio, esses conhecimentos prévios dos alunos irão contribuir, de certa forma, para o professor elaborar atividades teórico-práticas mais atrativas na sala de aula para que estes possam desenvolver suas habilidades e competências.

À primeira vista, quando o aluno tem a oportunidade de usar a internet como instrumento de ensino-aprendizagem, às barreiras que possa existir na realização de pesquisas se transformam em verdadeiros caminhos que pode levá-lo a explorar diferentes fontes de conhecimentos, que existem no ciberespaço. Entretanto, é uma prática pedagógica que requer um olhar crítico por parte do professor, uma vez que nesse oceano de informações/conhecimentos existem uma gama de hipertextos/janelas que podem tirar o foco do aluno para outras dimensões, deixando de lado o objetivo final proposto pelo professor, que é, de fato, o desenvolvimento de uma aprendizagem significativa.

Diante disso, Mcluhan (1974, p.13), ressalta que "nós estamos entrando na nova era da educação, que passa a ser programada no sentido da descoberta, mais do que no sentido da instrução". Portanto, as tecnologias digitais, como a internet, é hoje uma nova fonte de extensão de conhecimento norteadora, que, a princípio, precisa de professores capacitados e comprometidos com seu fazer pedagógico, para que, assim, o aluno possa fazer uso dessa tecnologia corretamente na sala de aula ou na sua própria casa. Entretanto, quando o professor não tem essa preocupação, as TDICs podem se tornar meros artefatos à serviço de diversões/brincadeiras para os alunos.

Em linhas gerais, o uso das tecnologias digitais, na prática pedagógica do professor, rompe totalmente o velho paradigma de ensino tradicional. Isso porque o modelo de ensino vertical/hierárquico/dogmático, presente, na maioria das vezes, no currículo escolar tradicional, passa a dá lugar a um estilo de ensino-aprendizagem

1 Disponível em: http://www.cgi.br/ > Acesso em 08 de jun. de 2020. 
horizontal/cooperador/colaborador entre professor-aluno. Nesse ambiente de relações dialógicas, de construção de conhecimento - que é a internet - é possível compreender que, não existe mais um único detentor de conhecimento, haja vista que o professor e o aluno podem construir sabres em conjuntos.

Dessa forma, Pérez Gómez (2015, p. 21) salienta que:

\begin{abstract}
A internet, portanto, não é só um depósito inesgotável de informações e uma base mais ou menos ordenada ou caótica base de dados, conceitos e teorias, uma biblioteca excelente e viva ao alcance de todos e todas, mas, sobretudo, é um espaço para a interpretação e a ação, um poderoso meio de comunicação, uma plataforma de intercambio para o encontro, a colaboração em projetos conjuntos, a criação de novas comunidades virtuais, a interação entre iguais próximos ou distantes, o projeto compartilhado e a organização de mobilizações globais, bem como para a expressão individual e coletiva dos próprios talentos, sentimentos, desejos e projetos.
\end{abstract}

Em consonância com o discurso desse autor, entende-se que a internet é uma tecnologia digital que oferece um ambiente virtual recheado de múltiplas funções para o sujeito explorar como achar mais adequado. Ademais, ao navegar nesse oceano de informações, o sujeito quebra barreias físicas, para se conectar com diferentes comunidades equidistantes no mundo.

Sendo assim, as instituições quando incorporam no currículo escolar as novas tecnologias digitais, como a internet, o professor passa a ensinar-aprender juntamente com os alunos. Essa forma interativa/dialógica de ensinar-aprender, além de contribuir no fortalecimento de laços fortes entre professor-aluno, possibilita explorar uma nova dimensão educacional fora do ambiente físico da instituição escolar.

Para tanto, como a revolução tecnológica foi bastante tardia nos países subdesenvolvidos, especificamente, como no Brasil, a integralização do uso da internet no currículo escolar ainda é uma realidade que vem ocorrendo de forma gradativa, principalmente por causa de fatores estruturantes, como poucos investimentos em políticas públicas para fornecer equipamentos de qualidade para as instituições públicas de ensino, e, na maioria das vezes, a falta de qualificação técnica dos professores para manusear essa ferramenta educacional. Para ratificar esse pensamento, dados expostos no Portal Todos pela Educação demostra que 48\% das escolas brasileiras não têm computadores nas instituições escolares. Em relação ao uso dessa tecno- 
logia pelos professores, $67,7 \%$ disseram que utilizam computadores nas escolas e, consequentemente, $20,2 \%$ dizem que não usam computadores na sua prática pedagógica de ensino. ${ }^{1}$

Por sua vez, entende-se que a evolução tecnológica apesar de algo positivo para a área da educação, contudo, é perceptível que as instituições escolares não estão preparadas para vivenciar uma nova realidade educacional de ensinar e aprender por meio do uso das TDICs. Essa realidade é vista na prática quando se têm desafios/problemáticas no âmbito da educação para serem transpassadas pelo poder público das três esferas de governo - Federal, Estadual e Municipal.

\section{CONSIDERAÇÕES FINAIS}

Diante das grandes transformações tecnológicas e culturais que passaram a ocorrer no seio da sociedade contemporânea, a área da educação passou a buscar emigrar suas práticas pedagógicas para o ciberespaço com o objetivo de atender/ adequar as novas formas de ensinar e aprender requeridas pelos nativos digitais (alunos) no século XXI. Dessa forma, para Lévy (1999), nesse novo contexto educacional, onde as tecnologias da informação facilitam a convergência de saberes interdisciplinares, o professor deixa de ser o centro do processo de ensino-aprendizagem, e passa a construir uma prática pedagógica mediada em sintonia com os conhecimentos prévios do aluno.

Nesse contexto, a internet ao ser inserida no espaço formal da educação, proporciona ao professor várias chances de poder trabalhar um modelo de ensino interdisciplinar para os alunos. Ou seja, uma prática educativa onde diferentes disciplinas do currículo escolar podem ser trabalhadas em conjuntas por esse profissional da educação. Além disso, o professor de uma disciplina específica quando exerce sua prática pedagógica por meio da internet, os alunos têm a possibilidade de assimilarem conhecimentos que não foram trabalhados por outros professores em sala de aula, ou até mesmo, aprenderem aqueles conteúdos que não foram incorporados na grade curricular da disciplina, mas que podem ser estudados e, consequentemente, ajudá-los no desenvolvimento do seu processo de ensino-aprendizagem.

1 Todos pela educação. Disponível em: http://www.todospelaeducação.org.br/> Acesso em 10 nov. de 2019. 
Diante disso, tornou-se evidente, por meio dessa pesquisa, que existe a necessidade de se investir na formação continuada dos professores (em relação ao conhecimento e manuseio das novas tecnologias da informação), para que estes possam, assim, incorporar as TDICs na sua prática pedagógica, tanto no ambiente das universidades como no espaço das escolas de ensino básico. Por outro lado, também, constatou-se a necessidade de se investir em mais políticas públicas para equipar o ambiente das escolas públicas com computadores com acesso à internet de qualidade.

Assim sendo, espera-se que desse ensaio possam surgir mais debates sobre a importância de se introduzir as novas tecnologias na prática pedagógica do professor no século XXI.

\section{REFERÊNCIAS}

ANDERSON, Perry. Passagens da antiguidade ao feudalismo. Porto, Afrontamento, 1982.

BERTONCELLO, L. T. Importância de um planejamento estratégico no comércio eletrônico. Porto Alegre: Sebrae, 1999.

DELEUZE, Gilles. Diferença e repetição. Tradução Luiz Orlandi, Roberto Machado. 2. ed. Rio de Janeiro: Graal, 1998.

HEIDEGGER, M. Ser e tempo. 15ª . ed. Trad. Márcia de Sá Cavalcanti. Petrópolis: Vozes, 2005.

LÉVY, P. Cibercultura. Trad. Carlos Irineu da Costa. São Paulo: Editora 34, 1999.

LÉVY, Pierre. As tecnologias da inteligência: o futuro do pensamento na era da informática. Rio de Janeiro: $34^{a}$ ed. 1993. (Coleção TRANS).

MCLUHAN, Marshall. Os meios de comunicação como extensão do homem. São Paulo: Editora Cultrix LTDA, 1974.

MIZUKAMI, M. G. N. Ensino: as abordagens do processo. São Paulo: EPU, 1986.

PÉREZ GÓMEZ, Ángel I. Educação na era digital: a escola educativa. Porto Alegre: Penso, 2015. 
PERRENOUD, Philippe. As competências para ensinar no século XXI: a formação dos professores e o desvio da avaliação. Porto Alegre: Artmed, 2007.

SIMONDON, G., (1969). Du mode d'existence des objets techniques. Paris: Aubier-Montaigne.

VALENTE, Armando. Informática na educação: conformar ou transformar a escola. Florianópolis: CED/UFSC, 1996. (Texto apresentado no VIII ENDIPE).

VYGOTSKY, L. S. (1984) A formação social da mente. São Paulo: Martins Fontes 


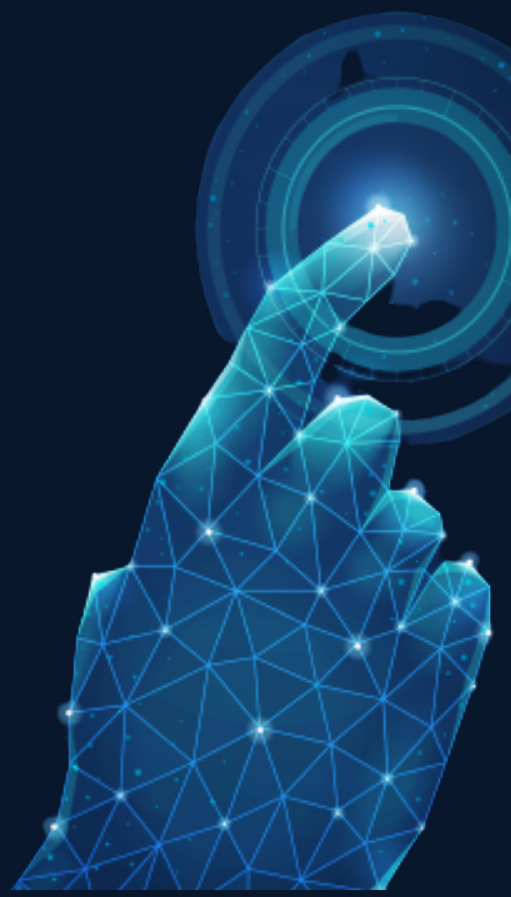

\section{O CELULAR COMO FERRAMENTA NO ENSINO DE LEITURA}

Aline Aparecida Teodoro ${ }^{1}$ Eliane dos Santos Macedo Oliveira ${ }^{2}$

1 Graduada em Licenciatura em Letras e suas respectivas literaturas pela UNICENTRO/Paraná.

2 Mestra em Educação pela UNIOESTE/Paraná. 


\section{CONSIDERAÇÕES INICIAIS}

Ensinar e desenvolver as habilidades de leitura dos diversos gêneros e tipos textuais na sociedade da informação rápida e instantânea é um desafio aos professores de Língua Portuguesa, pois tanto os gêneros quanto as tecnologias modificam-se muito rapidamente e exigem a mobilização de muitos conhecimentos de mundo, linguísticos e tecnológicos, os multiletramentos, assim, pensando em aliar leitura e tecnologia, este artigo visa aprofundar-se nas potencialidades e desafios da utilização do celular em práticas de ensino e incentivo à leitura, principalmente nas séries finais do ensino básico.

Entendemos que abordar a leitura é extremamente importante, pois indicadores de avaliações externas como a Prova Brasil ${ }^{1}$ revelam que o nível de leitura e interpretação textual dos alunos nos anos finais do ensino fundamental está insatisfatório e é cada vez mais evidente o desinteresse que um percentual significativo destes alunos apresenta em relação à leitura e seus processos.

Ao considerar que a escola é o espaço formal de socialização dos conhecimentos científicos e para muitos alunos ela será o principal e, muitas vezes, único espaço de acesso a estes conhecimentos, é importante que o ensino e incentivo da leitura sejam realizados com o auxílio de metodologias e ferramentas que contemplem a diversidade de gêneros e tipos textuais que compõem a língua materna.

Neste sentido, o objetivo geral deste estudo é compreender e apresentar as potencialidades do aparelho celular para o desenvolvimento de atividades de leitura em sala de aula. Esse objetivo geral desdobra-se nos seguintes objetivos específicos: (i) Investigar a importância da tecnologia para o ensino de língua portuguesa, mais especificamente o uso do celular para o incentivo e desenvolvimento das habilidades de leitura; (ii) Verificar as possibilidades de utilização do celular como ferramenta para o ensino de leitura; (iii) Apresentar uma proposta alternativa de leitura com a utilização do celular, tendo em vista alunos do Ensino Médio.

Inicialmente realizamos uma pesquisa explanatória em que fizemos um levantamento de estudos (artigos, teses e dissertações) no banco de dados da CAPES,

1 A Prova Brasil, criada em 2005, pelo Ministério da Educação e Cultura, avalia estudantes de escolas públicas de $5^{\circ} \mathrm{s}$ e $9^{\circ} \mathrm{S}$ anos do Ensino Fundamental e $3^{\circ} \mathrm{s}$ anos do Ensino Médio, nas disciplinas de Língua Portuguesa e Matemática, com foco na leitura e resolução de problemas, respectivamente. Disponível em: http://portal.mec.gov.br/prova-brasil Acesso em: 01 jun. 2020. 
no catálogo de teses e dissertações e no portal de periódicos, tendo como palavra-chave de busca "uso do celular". Esse levantamento revelou os seguintes trabalhos:

\section{DESENVOLVIMENTO}

\section{Estado de arte}

\begin{tabular}{|c|c|c|c|}
\hline Autor & $\begin{array}{l}\text { Modalidade } \\
\text { (Artigol } \\
\text { Dissertaçãol } \\
\text { Tese) }\end{array}$ & Título & Breve descrição \\
\hline $\begin{array}{c}\text { Debora Katiene } \\
\text { Praxedes Costa } \\
\text { Morais }\end{array}$ & Dissertação & $\begin{array}{l}\text { Multiletramentos na escola: o uso } \\
\text { do celular e do whatsapp nas } \\
\text { aulas de produção textual em } \\
\text { Língua Portuguesa (2015) }\end{array}$ & $\begin{array}{c}\text { O objetivo da pesquisa foi analisar } \\
\text { o uso do aplicativo whatsapp na } \\
\text { construção de saberes, através de } \\
\text { prática de letramento no espaço } \\
\text { digital e na produção textual dos } \\
\text { alunos. }\end{array}$ \\
\hline $\begin{array}{c}\text { Luiza Carla } \\
\text { da Silva Soares }\end{array}$ & Artigo & $\begin{array}{l}\text { Desafios ao uso do Smartphone } \\
\text { como ferramenta pedagógica } \\
(2016)\end{array}$ & $\begin{array}{l}\text { O objetivo desta pesquisa foi fazer } \\
\text { reflexões sobre o uso de celulares } \\
\text { no âmbito escolar como } \\
\text { instrumento facilitador no } \\
\text { processo de ensino } \\
\text { aprendizagem. }\end{array}$ \\
\hline $\begin{array}{c}\text { Dinah de Angelis } \\
\text { Santos Vieira }\end{array}$ & Dissertação & $\begin{array}{c}\text { Por um ambiente novo de ensino } \\
\text { e aprendizagem da ortografia para } \\
\text { a "geração polegar" } \\
(2016)\end{array}$ & $\begin{array}{l}\text { O objetivo da pesquisa foi } \\
\text { desenvolver um ambiente virtual } \\
\text { de ensino e aprendizagem com o } \\
\text { uso do celular, a fim de conhecer, } \\
\text { aprimorar a ortografia e as } \\
\text { habilidades de escrita dos alunos. }\end{array}$ \\
\hline $\begin{array}{l}\text { Fernando } \\
\text { Roberto Lima } \\
\text { dos Santos }\end{array}$ & Dissertação & $\begin{array}{c}\text { Narrativas Digitais, Paródias, } \\
\text { Colagem e Remix: explorando o } \\
\text { uso do celular em aulas de Língua } \\
\text { Portuguesa (2017) }\end{array}$ & $\begin{array}{c}\text { O objetivo da pesquisa foi } \\
\text { investigar o uso do celular como } \\
\text { instrumento de ensino e } \\
\text { aprendizagem de língua } \\
\text { portuguesa, bem como, as } \\
\text { dificuldades referentes ao uso } \\
\text { deste método. }\end{array}$ \\
\hline $\begin{array}{c}\text { Josefa dos San- } \\
\text { tos } \\
\text { Silva }\end{array}$ & Dissertação & $\begin{array}{l}\text { A Tecnologia Móvel na } \\
\text { Aprendizagem Colaborativa em } \\
\text { uma Comunidade de Prática: para } \\
\text { uma Escola de seu Tempo (2017) }\end{array}$ & $\begin{array}{c}\text { O objetivo desta pesquisa foi } \\
\text { analisar as crenças dos alunos } \\
\text { em relação as TIC e suas } \\
\text { contribuições para a } \\
\text { aprendizagem. }\end{array}$ \\
\hline $\begin{array}{c}\text { Luciana Lopes } \\
\text { Benvindo }\end{array}$ & Dissertação & $\begin{array}{l}\text { O uso de ferramentas tecnológi- } \\
\text { cas em aulas de Língua } \\
\text { Portuguesa: cultura maker, } \\
\text { gamificação e multiletramentos } \\
\text { (2019) }\end{array}$ & $\begin{array}{l}\text { O objetivo desta pesquisa foi } \\
\text { verificar o uso das tecnologias e } \\
\text { cultura maker no ensino de } \\
\text { Língua Portuguesa. }\end{array}$ \\
\hline $\begin{array}{l}\text { Giselda dos } \\
\text { Santos Costa }\end{array}$ & Tese & $\begin{array}{c}\text { MOBILE LEARNING: Explorando } \\
\text { potencialidades com o uso do } \\
\text { celular no ensino - aprendizagem } \\
\text { de língua inglesa como língua } \\
\text { estrangeira com alunos da escola } \\
\text { pública (2013) }\end{array}$ & $\begin{array}{l}\text { O objetivo desta pesquisa foi } \\
\text { analisar as potencialidades do } \\
\text { uso do celular em aulas de língua } \\
\text { inglesa, através do aplicativo de } \\
\text { mensagem instantâneo Whatsapp } \\
\text { para o melhoramento de } \\
\text { habilidades de leitura e escrita } \\
\text { (dificuldade na ortografia). }\end{array}$ \\
\hline
\end{tabular}


O levantamento revelou a escassez de trabalhos sobre o assunto, como pode ser verificado no quadro acima e, além dos registrados, encontramos outros quatro (4), que não foram referenciados por não terem sua divulgação autorizada. A carência de trabalhos justifica a importância de se tratar deste tema que, no contexto em que as escolas se encontram e as dificuldades que enfrentam na atualidade, nos põem ainda mais nesta realidade.

O uso do celular como instrumento pedagógico já é uma realidade em nossas escolas, com o ensino remoto adotado devido à pandemia causada pela COVID-19. Porém, o modo abrupto como foi inserido nas atividades escolares exige o desenvolvimento de metodologias e estratégias para que não seja apenas um instrumento para receber e enviar atividades.

Costa (2013), muito antes das aulas remotas, ao explorar as potencialidades do celular nas aulas de língua inglesa, defende que essa ferramenta tecnológica seja usada na afirmação e melhoramento das habilidades de leitura e escrita dos alunos, através de novas alternativas metodológicas que busquem diminuir ou sanar suas dificuldades. A autora propõe em seu estudo, a utilização do celular e do aplicativo de mensagens instantâneas, WhatsApp, para sanar as dificuldades existentes no campo da ortografia. Através das análises, Costa (2013) chegou à conclusão de que com o celular e o aplicativo de mensagens instantâneas, o ensino-aprendizagem da ortografia, pode alcançar resultados bastante positivos. Porém, a autora não descartar os desafios que essa proposta traz, principalmente quando se pensa no ensino tradicional.

\begin{abstract}
Por outro lado, não se pode deixar de considerar que a inserção do celular em sala de aula e da interface WhatsApp, com o objetivo de melhorar aprendizagem ortográfica dos alunos, é um desafio constituído de barreiras impostas pela tradição educacional. É um trabalho que exige ousadia do professor, e também determinação (COSTA, 2013, p.116-117).
\end{abstract}

Morais (2015) abordou o uso do aplicativo de mensagens instantâneas WhatsApp para a construção de saberes no espaço escolar, em práticas de letramento no espaço digital, verificando as contribuições pedagógicas dos multiletramentos, para a produção textual em aulas de Língua Portuguesa. A pesquisa concluiu que ainda são privilegiadas práticas de letramento tradicional nas escolas, mas que o cresci- 
mento do uso de ambientes digitais pelos indivíduos que foram, são ou serão alunos é inquestionável, sendo assim é preciso que haja novas práticas nas instituições de ensino, com o uso de ferramentas tecnológicas (celular), a fim de favorecer os multiletramentos.

Não se pode mais negar que as tecnologias fazem parte da vida social dos discentes, e que o celular é um instrumento que o acompanha e permite a interação com seus pares, por isso pode/deve ser parte integrante das atividades desenvolvidas em sala de aula. Daí a importância de pesquisas que abordem novas práticas pedagógicas que utilizem as TCls na produção de conhecimento relacionados ao espaço escolar. Conforme Morais (2015, p.100),

Divulgar é necessário para que os envolvidos na educação percebam que a realização dessas práticas de letramentos sociais contribui para o desenvolvimento da autonomia, da responsabilidade coletiva, da criticidade, além do reconhecimento da diversidade cultural do alunado.

Os alunos da contemporaneidade são parte de um mundo no qual a tecnologia possibilita transformações e soluções de grande parte das demandas do cotidiano com apenas alguns cliques no aparelho celular, esses são os nativos do mundo digital. Como não pensar nesta geração dentro das salas de aula, em diversos níveis de formação escolar? Em nossos dias atuais é quase que impossível pensar na educação sem a incorporação das novas tecnologias dentro das escolas, com suas particularidades e especificidades.

Mesmo que a maioria dos alunos da atualidade estejam conectados, a escola continuava, em sua maioria, resistente ao uso das TICs em sala de aula, pois a maioria das instituições segue o modelo tradicional de ensino, em que o professor é o detentor e responsável por passar o conhecimento aos alunos; e a ênfase deste modelo de educação é a memorização de conteúdos, muitas vezes isolados do contexto de vida dos discentes. Ainda que consideremos o contexto social atual, percebemos mesmo com a introdução inesperada das tecnologias para a continuidade das aulas no modelo de ensino remoto, a inaptidão de professores e alunos no desenvolvimento das atividades, exatamente porque essa inserção vai de encontro ao modelo tradicional. Muitos (professores e alunos) não sabem o que ou como fazer. 
Soares (2016) em sua pesquisa denominada "Desafios ao uso do Smartphone como ferramenta Pedagógica", traz uma reflexão sobre o uso dos Smartphones (celulares) no meio escolar como ferramenta facilitadora no processo de ensino/aprendizagem, ressaltando que o uso deste aparelho tem promovido mudanças no ambiente escolar, uma vez que a facilidade de acesso a informações contidas no ciberespaço e as criações coletivas de saberes, podem ser consideradas uma revolução no processo de aprendizagem.

A pesquisa da autora teve como público alvo os docentes que, através de um questionário, puderam se expressar quanto ao uso deste instrumento tecnológico como ferramenta pedagógica e seus desafios. Através da análise das respostas dadas pelos professores, a pesquisadora concluiu que os desafios estão na concepção de estratégias para que os alunos não se dispersem durante o uso desta ferramenta, podendo assim construir o processo de aquisição de conhecimento de forma prazerosa e eficaz.

Segundo Santos (2017), “As contribuições pedagógicas no uso das TICs, o que inclui o celular, em relação à construção de narrativas digitais, colagem e remix, nos multiletramentos", são positivamente viáveis no âmbito escolar para o ensino aprendizagem em aulas de Língua Portuguesa. Contudo, a autora recomenda cautela quanto à hiper valorização das tecnologias, devido a situações de não universalização no uso deste equipamento por motivos socioeconômicos, o que interferiria no decorrer do processo de aplicação das atividades propostas. Exatamente como temos testemunhado atualmente, não pela hiper valorização, mas pela necessidade que se impôs.

Então, analisando todos esses esforços em debater o assunto que aqui vem sendo tratado, não podemos deixar de ouvir a parte mais importante destes debates, os estudantes. Silva (2017), em sua dissertação, aborda as crenças dos discentes em relação ao uso das tecnologias móveis (celular) no processo de aprendizagem escolar e o papel que o professor tem neste processo, sendo o celular um elemento que direciona, motiva e integra, nesta comunidade de prática; com o intuito de tornar esse aprendizado mais atrativo e produtivo.

A autora explica que o estímulo é parte essencial para que os educandos possam construir suas próprias histórias, formarem suas "identidades", tomarem cons- 
ciência de que enquanto indivíduos são seres interativos e, portanto, o convívio contribui para que ressignifiquem e sejam ressignificados e se reconheçam como parte integradora do mundo, ou seja, conhecer e dominar as tecnologias pode colaborar para a construção desta identidade social do indivíduo; levando em conta que quando esse faz um acesso à rede virtual, deixa um pouco de seu conhecimento, que é agregado a outros inúmeros "conhecimentos" criando, assim, a inteligência coletiva; que é a característica marcante da atualidade.

Silva (2017), concluiu sua pesquisa afirmando que a construção de contos coletivos em aulas de Língua Portuguesa, com o uso dos aplicativos WhatsApp ou Google Docs., tornou-se o ponto de encontro entre escola, tecnologia e aprendizagem; e os discentes que não acreditavam no uso do aparelho celular como instrumentos de aprendizagem puderam reavaliar suas crenças.

Benvindo (2019), abordou o uso das ferramentas tecnológicas nas aulas de Língua Portuguesa, na cidade de São Paulo, a partir do conceito de cultura maker, gamificação e multiletramentos, verificando e refletindo sobre como utilizar aparatos tecnológicos para a construção do conhecimento em sala de aula. Segundo a autora, o uso da gamificação consiste em usar recursos de jogos em outros contextos, aqui no caso o uso na educação; para que os alunos, através desta prática, possam atingir o objetivo de aquisição de conhecimento. Quanto ao uso da cultura maker no campo da educação, a autora explica que consiste em usar o ambiente da sala de aula para que através da colaboração e transmissão de informação entre os alunos, possa ser gerado o conhecimento, usando a tecnologia como ponte para que isso aconteça de forma eficaz como, por exemplo, no incentivo de hábitos de leitura e interpretação de textos. No que diz respeito aos multiletramentos, a autora explica que, com o uso do celular, houve um maior incentivo à leitura de diferentes tipos de textos, contribuindo não apenas para a leitura em si, mas também no incentivo de atividades interativas que aprimoram suas capacidades comunicativas, sua escrita e o manuseio da tecnologia.

Todas as pesquisas mostram diferentes formas de utilização do aparelho celular em sala de aula, revelando as potencialidades deste aparelho como ferramenta para o ensino, principalmente para o ensino da língua portuguesa. Atualmente, refletir sobre o uso desta tecnologia é de suma importância, pois está incluída no ensino 
e faz parte do dia a dia da aprendizagem dos alunos.

Neste trabalho destacamos a necessidade de que os alunos compreendam o contexto do mundo globalizado e tecnológico em que estão inseridos, pois é de fundamental importância para que possam desenvolver funcionalidades que os auxiliem no uso consciente e produtivo das ferramentas tecnológicas. Para isso, o professor é peça vital para estabelecer a ponte entre os conhecimentos teóricos, práticos, tecnológicos e o aluno no processo de construção dos conhecimentos.

\section{Leitura, ensino e tecnologia}

Ensinar a ler e escrever em vários níveis de ensino, bem como, promover o incentivo e o hábito da leitura de diversificados gêneros textuais é um desafio na era da informação instantânea, visto que conceitos e práticas são criados e discutidos como propostas para formar leitores críticos capazes de interagir com a diversidade de textos e suas múltiplas linguagens.

Utilizar a linguagem é, enfim, interagir a partir do intercâmbio de textos. Vem daí, a necessidade de propiciar aos alunos condições para o desenvolvimento de competências, habilidades e estratégias linguístico-textual discursivas para a produção, compreensão e interpretação de textos orais e escritos, oportunizando o desenvolvimento do senso crítico, ético e estético (CREUS, 2007, p. 106).

Os processos de ensino e a utilização de novas tecnologias apontadas por diversas pesquisas como instrumentos metodológicos são tidas como recursos capazes de motivar os alunos pelo conhecimento de ensino de maneira mais próxima da linguagem por ele vivenciada.

As novas máquinas digitais de agora talvez sejam mais radicais que essas do século XIX e início do século XX porque não intervêm apenas em um campo parcial da atividade humana, como aconteceu nas artes plásticas e na literatura modernista e moderna, mas fazem redefinições radicais da totalidade do espaço-tempo do planeta, do corpo, do sujeito, das formas de sensibilidade, da política etc., fundamentais na invenção de novas formas de escrita e leitura (HANSEN, 2013, p. 21).

Desde o começo da história humana, o indivíduo busca transformar e recriar sua realidade, por meio do trabalho e das tecnologias que possam auxiliá-lo no processo de apropriação da natureza e suas vivencias sociais. A este propósito Vásquez (1968, p. 247) afirma que: 
O homem é o ser que tem de estar inventando ou criando constantemente novas soluções. Uma vez encontrada uma solução, Ihe basta repetir ou imitar o que ficou resolvido; em primeiro lugar, porque ele mesmo cria novas necessidades que invalidam as soluções encontradas e, em segundo lugar, porque a própria vida com suas novas exigências, se encarrega de invalidá-las (VÁSQUEZ, 1968, p. 247).

Toda e qualquer ferramenta criada ou modificada por uma pessoa para facilitar o trabalho por ele desenvolvido é uma tecnologia; no decorrer da história o homem aprendeu a desenvolver e controlar o fogo, inventou a roda e a fundição de metais, que são novas tecnologias que possibilitaram sua sobrevivência na terra.

A tecnologia muda à forma de aprender e ensinar, e pode ser usada a fim de aproximá-la do universo do aluno, preparando-o para a vida presente e futura, tendo em vista que cada vez mais nossas vidas têm a presença dos recursos tecnológicos.

À educação relega-se, pois, a necessidade de vincular suas práticas associadas ao uso das TICs (Tecnologias de Informação e Comunicação), a fim de desvincular-se de metodologias tradicionais de ensino, empoderando o professor como o mediador, o provocador da aprendizagem e da sua utilização. Lévy (1999, p.158) aponta que "neste contexto, o professor é incentivado a tornar-se um animador da inteligência coletiva de seus grupos de alunos em vez de fornecedor direto de conhecimentos".

Outros recursos são apontados em variados estudos como promotores de aprendizagens mais amplas, tais como os web e sites propostos nos estudos de Grotto (2004), para quem:

A inserção de ambientes virtuais de aprendizagem na prática pedagógica não foge a regra geral. Para intervir, os professores, assim como outros agentes educacionais, precisam dispor de conhecimentos e habilidades específicas. Necessitam, dentre outras coisas, conhecer os diferentes ambientes disponíveis na Web, para que possam contribuir na prática, de forma que atendam aos objetivos educacionais (GROTTO, 2004, p. 119-120).

Muitos são os recursos e possibilidades de utilização das TICs no ensino de língua portuguesa e para o incentivo da leitura, porém, ainda nos deparamos com indicadores como Prova Brasil, Pisa (Programa Internacional de Avaliação de Alunos) e Prova Paraná que apontam nível básico de leitura e, muitas vezes, abaixo do básico para os alunos avaliados.

Os estudos apresentados evidenciam que é inegável a inserção das novas tecnologias aos métodos educacionais e pontuam as posturas a serem adotadas, 
apresentam práticas e recursos demonstrados como eficientes ao propósito de incentivo à leitura. Entretanto, não pontuam especificamente os desafios relegados aos educadores, a percepção destes em relação a tantas mudanças e o processo de formação insuficiente e, muitas vezes, inexistente, além de pontuar a formação sobre a perspectiva do aprender a aprender, o que torna necessários estudos que ampliem tais enfoques a fim de verificar a prática concreta e os entraves que inviabilizam a utilização de recursos como os apresentados a favor do processo de ensino e aprendizagem, pois conforme aponta Alvez-Mazzoti (2003, p.4):

[...] Tardif considera que um dos maiores problemas da pesquisa em ciências da educação consiste em abordar o estudo do ensino de um ponto de vista normativo, o que significa dizer que os pesquisadores se interessam muito mais pelo que os professores deveriam ser, fazer e saber, do que pelo que eles são, fazem e sabem realmente (ALVEZ-MAZZOTI, 2003, p.4).

Assim, é preciso ampliar o enfoque de estudos a partir de uma análise crítica sobre os condicionantes históricos e sociais que impendem um ensino fomentado pelo saber científico a partir do uso das TICs no ensino da língua materna.

E, por fim, traremos a lume a teoria dos multiletramentos, abordada por Roxane Rojo e Eduardo Moura. Os multiletramentos discutem "o uso de novas tecnologias de comunicação e de informação [...], mas caracteriza-se como um trabalho que parte das culturas de referência do alunado (popular, local, de massa)" (ROJO; MOURA, 2012, p. 8), e também “de gêneros, mídias e linguagens por eles conhecidos" (ROJO; MOURA, 2012, p. 8).

De acordo com Rojo (2012), o termo multiletramentos foi criado por um grupo de professores e pesquisadores na década de 90 nos Estados Unidos, denominado Grupo Nova Londres, sendo que o prefixo "multi" diz respeito à multiculturalidade das sociedades, ou seja, a multiplicidade da cultura das nações; também à multimodalidade dos textos contidos nela. De acordo com a autora, as novas formas de comunicação e interação do mundo globalizado e interconectado, e os seus novos meios de comunicação vêm afetando o uso da linguagem e até formando uma nova compreensão sobre ela.

Segundo proposta dos multiletramentos, as diversidades culturais precisam ser tratadas e representadas dentro do âmbito escolar, com propostas de novos letramentos, de caráter multimodal ou multissemiótico. Roxane Rojo (2012) defende a 
"descolecionalização" dos acervos das escolas, e a introdução de novos e outros gêneros de discurso, novas tecnologias, mídias, línguas, variedades e linguagens.

São as mudanças na linguagem no século XXI, com o uso das tecnologias digitais, que trabalham com toda e qualquer linguagem, o uso da mídia digital faz a integração das linguagens, sejam elas estáticas (fotografia e pintura) ou em movimento (cinema e vídeos), áudios, músicas, entre outras. Essas são as novas possibilidades, os multiletramentos que tornam os textos multisemióticos, textos que estão por toda parte, ao alcance de nossas mãos e exigem um indivíduo que não seja apenas letrado, mas que seja ativo, crítico, conhecedor dos vários outros tipos de linguagem.

A leitura de um texto multimodal requer um leitor ativo, que seja capaz de articular linguagem verbal e não verbal, fazer relações e questionamentos que o ajude a construir sentido, esse tipo de texto traz ao processo de leitura dinamismo e possibilidades de leitura mais coerente com o mundo atual. A introdução das TICs vem para renovar a dinâmica do uso do lápis, giz, caneta, lousa e papel, como ferramentas usadas dentro das salas de aula e introduzir novas ferramentas como o áudio, vídeo, tratamento da imagem, edição e diagramação, essas são as novas práticas de ensino.

E para que essas novas abordagens aconteçam é necessárias novas estéticas no âmbito escolar, esse caminho já começou a ser trilhado, porém de forma lenta e receosa por parte da comunidade escolar, no que diz respeito ao uso das TICs em sala de aula. A utilização do celular, por exemplo, que é uma ferramenta tecnológica cheia de possibilidades, não é vista com bons olhos dentro das instituições, por ser um instrumento que pode agregar conhecimento, mas ao mesmo tempo dispersar o alunado se não bem planejado e conduzido em seu uso.

Nos multiletramentos, o leitor, que na concepção anterior era apenas um consumidor dos produtos culturais, neste novo formato de mídia digital passa a ser um leitor dinâmico e crítico, já que os textos deste formato têm por característica serem interativos, ou seja, permite que esse leitor interaja com muitos outros interlocutores que pode ser outro leitor, ferramentas do texto entre outras, formando a inteligência coletiva e uma construção de sentido muito mais ampla e enriquecedora.

A Base Nacional Comum Curricular (BNCC) (2018), que é um documento ligado aos direitos de aprendizagem no ensino brasileiro, aborda que para o desenvol- 
vimento dos alunos, é necessário que algumas competências da interação comunicativa sejam trabalhadas, como ter conhecimento e saber utilizar conhecimentos de linguagem verbal, verbo visual, tecnológica, digital e multimodal, artística; para que o aluno seja capaz de construir sentidos. Com isso, a escola colabora com a formação de cidadãos críticos, reflexivos, expressivos e aptos a convivência social.

Segundo esse documento, o objetivo principal do trabalho com a Língua Portuguesa é o desenvolvimento da escuta, a fim de se construir sentidos coerentes para textos orais e escritos, mas a leitura não se resume a decodificação de símbolos, ela é a compreensão do texto lido e, para isso, é necessário acessar conhecimentos prévios e outros recursos. O eixo leitura, segundo a BNCC, tem como foco o desenvolvimento destas habilidades de compreensão e interpretação de textos verbais e não verbais, identificação de gêneros textuais que correspondem as competências específicas da Língua Portuguesa no Ensino Fundamental.

Neste mesmo documento, há a reflexão da importância da tecnologia no desenvolvimento educacional dos estudantes, destacando que ela vem ganhando cada vez mais espaço e está ao nosso alcance com informações a todo instante, e que é fundamental que acompanhemos e utilizemos essa ferramenta. Pensando em todo este contexto que foi tratado aqui, propomos uma sequência didática que pode contribuir para o uso do celular como ferramenta pedagógica facilitadora no processo ensino/aprendizagem.

\section{CONSIDERAÇÕES FINAIS}

Este trabalho mostra que as práticas de letramento tradicionais nas escolas ainda são privilegiadas, mas o crescimento do uso de ambientes digitais pelos indivíduos é inquestionável, sendo assim é necessário o uso de novas práticas no âmbito escolar, algumas iniciativas já foram tomadas, mas é necessário que se ampliem por toda a rede de educação.

Pudemos refletir sobre a importância do uso do aparelho celular como ferramenta tecnológica facilitadora no processo de aquisição de conhecimento, sendo que o celular possibilita uma prática de letramento criativa, inovadora, dinâmica e estimulante para os alunos. No uso desta tecnologia como ferramenta para o ensino de práticas de leitura, também pudemos destacar sua eficácia apontando uma proposta 
de atividade de leitura que, além de desenvolver habilidades referentes a leitura e a oralidade, contribui para a construção colaborativa e inteligência coletiva.

Esperamos contribuir de maneira significativa para que novas práticas com o uso desta tecnologia possa ser usada em aulas de Língua Portuguesa, a fim de que os indivíduos envolvidos neste processo escolar possa ser capaz de ler e interpretar textos de vários gêneros textuais, usando seu desenvolvimento cognitivo, seu conhecimento sobre a língua, as ferramentas tecnológicas como aliadas neste processos.

\section{REFERÊNCIAS}

ALVES-MAZOTTI, Alda Judith. Impactos da pesquisa educacional sobre as práticas escolares. In: ZAGO, Nadir; CARVALHO, Marília Pinto de; VILELA, Rita Amélia (Orgs.). Itinerários de pesquisa: perspectivas qualitativas em Sociologia da Educação. Rio de Janeiro: DP\&A, 2003.

BENVINDO, Luciana Lopes. O uso de ferramentas tecnológicas em aulas de língua portuguesa: cultura maker, gamificação e multiletramentos. Assis, 2019. Disponível em: https://repositorio.unesp.br/handle/11449/182068 Acesso em: 12 ago. 2020.

COSTA, Dinah de Ângelis Santos Vieira. Por um ambiente novo de ensino e aprendizagem da ortografia para a "geração polegar". Monte Claros-MG, 2016. Disponível em: http://webcache.googleusercontent.com/search?q=cache:W6I8tG4lyLMJ:www.posgraduacao.unimontes.br/uploads/sites/14/2018/11/Disserta\%25C3\%25A7\%25C3\%25A3o-Dinah-de-Angelis.pdf+\&cd=1\&hl=pt-BR\&ct=clnk\&gl=br Acesso em: 27 jul. 2020.

COSTA, Giselda dos Santos. MOBILE LEARNING: Explorando potencialidades com o uso do celular no ensino-aprendizagem de língua inglesa como língua estrangeira com alunos da escola pública. Recife: UFPE, 2013.

CREUS, Susana de Quinteiros. Estudos sobre o texto/discurso. In: AGUIAR, Vera Teixeira; PEREIRA, Vera Wannmacher. (org.). Pesquisa em letras. Porto Alegre: EDIPUCRS, 2007.

GROTTO, Eliane Maria B. Práticas docentes com o uso de ambientes baseados em web sites: uma possibilidade de ensino. Dissertação de Mestrado/UFSM. Orientação Eduardo Adolfo Terrazzan. Santa Maria, 2004.

HANSEN, João Adolfo. O que é um livro? São Paulo: SESCSP, 2013. 
LÉVY, Pierre. Cibercultura. São Paulo: Editora 34, 1999.

MORAIS, Debora Katiene Praxedes Costa. Multiletramentos na escola: o uso do celular e do whatsapp nas aulas de produção textual em língua portuguesa. Mossoró-RN, 2015. Disponível em: http://www.uern.br/controledepaginas/profletras-mossoro-dissertacoes/arquivos/3621da\%E2\%80\%B0bora_praxedes_costa_morais.pdf Acesso em: 28 jul. 2020.

ROJO. Roxane Helena R. MOURA. Eduardo. Multiletramentos na escola. São Paulo: Parábola Editorial, 2012.

ROJO, Roxane. Pedagogia dos multiletramentos: diversidade cultural e linguagens na escola. In: ROJO. Roxane Helena R. MOURA. Eduardo. Multiletramentos na escola. São Paulo: Parábola Editorial, 2012.

SANTOS, Fernando Roberto Lima. Narrativas Digitais, Paródias, Colagem e Remix: explorando o uso do celular em aulas de Língua Portuguesa. Maceió-AL, 2017. Disponível em: http://www.repositorio.ufal.br/handle/riufal/1856 Acesso em: 28 jul. 2020.

SILVA, Josefa dos Santos. A tecnologia móvel na aprendizagem colaborativa em uma comunidade de prática: para uma escola de seu tempo. Araguaína, 2017. Disponível em: http://repositorio.uft.edu.br/handle/11612/925 Acesso em: 12 ago. 2020.

SOARES, Luiza. C. S. Dispositivos móveis na educação: Desafios ao uso do smartphone como ferramenta pedagógica. Encontro Internacional de Formação de Professores (ENFOPE), v. 9, p. 1-12, 2016.

VASQUEZ, Adolfo Sánchez. Filosofia da Práxis. Rio de Janeiro: Paz e Terra, 1968. 


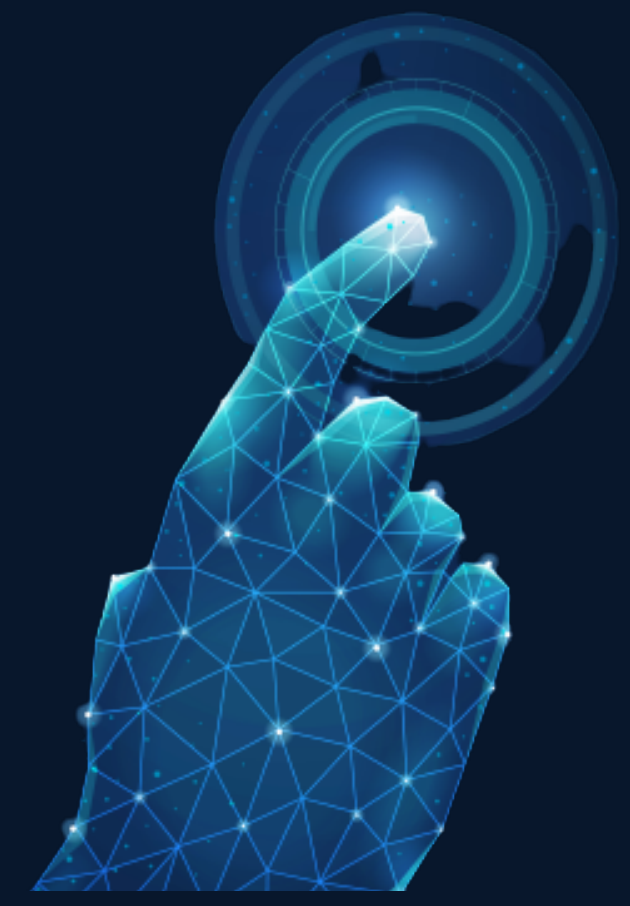

\section{CINEMA EM SALA DE AULA E OS POTENCIAIS DE APRENDIZAGEM}

Nice Rejane da Silva Oliveira ${ }^{1}$

Rodrigo José Rodrigues Maciel $^{2}$

1 Mestra em Ensino de História pela Universidade Federal do Tocantins - Secretaria de Educação do Maranhão, Imperatriz, MA. E-mail: nice.rejane@cegaitz.org

2 Graduando em Licenciatura em História - Universidade Estadual da Região Tocantina do Maranhão, Imperatriz, MA. E-mail: rodrigojrmaciel@gmail.com 


\section{INTRODUÇÃO}

A pesquisa tem como objetivo ajudar a difundir o uso do cinema em sala de aula, focando na noção de como essa ferramenta é capaz de desenvolver várias capacidades do indivíduo, como por exemplo, perceber a realidade ao seu redor através de um olhar mais crítico. O objetivo desse estudo e pesquisa na área cinematográfica, busca uma contribuição na quebra de paradigma do cinema, que muitas vezes é encarado apenas como um conteúdo expositivo para preencher horários vagos. Como embasamento teórico, foi utilizado uma pesquisa analítica partindo de uma revisão bibliográfica composta por referências nacionais nesse campo como Rogério de Almeida (2014; 2017) e Marcos Napolitano (2003).

O estudo do aporte teórico apontou para a relação histórica entre o cinema e a educação. Uma concepção que foi expandida pelo movimento da Escola Nova e a extensão de documentos históricos pelas primeiras gerações da Escola dos Annales. É notável que levar o novo cinematógrafo para dentro do ambiente escolar abriu portas para um novo jeito de ensinar, cujo tanto o professor quanto os alunos caminhariam lado a lado, construindo um novo conhecimento. Ademais, quebrar o rigor das aulas expositivas baseadas no livro didático e torna-las mais atrativas para os alunos é uma das características desse tipo de didática.

Um dos pontos importantes para a aplicação de qualquer trabalho é a metodologia. Neste quesito, para esse estudo foi feito um apanhado de indicações metodológicas para o uso do cinema em sala de aula, Jairo Carvalho do Nascimento (2008), Elí Henn Fabris (2008) e Marcos Napolitano (2003) deram as principais contribuições na montagem do texto. Esse tópico tem como objetivo ilustrar, com passos simples, alguns caminhos metodológicos e atividades para que aja o melhor aproveitamento possível da obra escolhida pelo professor. É importante deixa claro que não há uma única maneira de utilizar o cinema e as indicações deixadas aqui não são absolutas e imutáveis, tendo em vista que podem ser adaptadas para as múltiplas realidades dentro da sala de aula.

Este artigo também faz algumas pontuações sobre as barreiras que dificultam a total difusão dessa pratica pedagógica, buscando refletir como contorná-las. Relações como quebra de paradigma, o acesso aos equipamentos tecnológicos e o pou- 
co tempo das aulas na área das ciências humanas são algumas questões levantadas no texto.

Todo esse conjunto de informações procura desenvolver o uso do cinema em sala de aula, expandindo o conhecimento e utilizando seu potencial da melhor forma. Em um mundo cujas novas tecnologias são produzidas constantemente, cabe ao professor se atualizar e desenvolver sempre uma nova didática, buscando a atenção do aluno.

\section{RELAÇÃO ENTRE CINEMA E EDUCAÇÃO}

No final do século XX, a Europa passou, pelas palavras Albagli (2014), um alargamento de mecanismos de apropriação privada da produção intelectual e cultural, gerando esse desenvolvimento do campo industrial, colocando em foco as relações entre ciência e poder. A consolidação do capitalismo e a nova necessidade de produzir foram as engrenagens que movimentaram o século marcado pela consolidação de novos ideais intelectuais, políticos, econômicos e culturais em todo o mundo.

Fruto da industrialização do Ocidente, o cinematógrafo dos irmãos franceses Louis e Auguste Lumière criou uma nova forma de se contar uma história. Uma arte que uniu música, teatro e fotografia em um ritmo visualmente inovador, provocando as mais diversas emoções enquanto atraía para uma diversidade de novas sensações. Eduardo Morettin (2009) diz que o maravilhamento causado pela nitidez e realismo das imagens conseguiu atrair o público em um ritmo crescente, os convidando para novas experiências corpóreas, se tornando o exemplo definitivo do conceito aristotélico de catarse.

Outro ponto a ser levado em consideração é o fato do impacto que aas Grandes Guerras do século XX tiveram, fazendo com que a pedagogia buscasse formas de preservar a natureza boa das crianças. Essa revolução, conhecida como Revolução da Escola Nova, começou a buscar novas práticas pedagógicas que priorizassem liberdade e espontaneidade dos discentes. A prática educacional que nasceu dessa proposta começou a conciliar a arte como um todo no currículo escolar. Dentre elas o cinema, sendo tratado como uma arte que se mostrou capaz de atrair indivíduos de vários ciclos sociais. Dessa maneira, esse movimento artístico começou a ser direcionado a fazer uma ligação com a educação. 
Ao dialogar sobre o uso do cinema na educação, Jairo Nascimento (2008) afirma:

Ensinar a partir do cinema significa, enfim, provocar o olhar do sujeito, estimular seus sentidos com a imagem em movimento; despertar o seu olhar crítico, na perspectiva de que ele possa perceber que aquilo que vê é uma representação de uma dada realidade social, construída ideologicamente por alguém que detém uma determinada visão de mundo. (NASCIMENTO, 2008, pg. 22)

Fabris (2008, pg. 120) discorre que os filmes são produções de imagem e som, que aliados as técnicas e conceitos desenvolveram uma linguagem única, desse modo, cria um sistema de significações. Essas histórias interagem de modo avassalador com o inconsciente humano, dando luz aos sonhos, realizando uma experiência de catarse. Durante um tempo médio de uma hora e meia, o espectador emerge em um universo ficcional e o passa a entender como uma realidade próxima. Embora viva no tempo presente, a mente de quem assiste é convidada a andar por passado e futuro, através das imagens apresentadas, embarcando em uma espécie de viagem que o aproxima de povos, línguas e costumes desconhecidos, enriquecendo sua própria história.

O cinema traz consigo valores culturais do universo social em que ele é produzido ou também da esfera que ele pretende representar. Sendo representado como arte, ela concede uma experiência aos estudantes a entenderem conceitos através de um novo ponto de vista. Rogério de Almeida (2017, pg.14), aborda em seu texto a relação metodológica que vai além de um simples uso recreativo. Para o autor, existem sete formas de perceber como o cinema funciona no indivíduo: cognitivo, filosófico, estético, mítico, existencial, antropológico e poético. Essas formas não se separam, elas interagem em um sistema de complementaridade buscando um objetivo em comum: o conhecimento.

O mesmo autor usa os estudos sobre o rizoma (múltiplas raízes de uma planta) de Deleuze e Guattari (1995, pg.36) como metáfora ao apontar que o conhecimento é um sistema aberto, no qual existem diversos caminhos para chegar até ele (ALMEIDA, 2017, pg.3). A escola funciona como um ambiente que oferece uma convivência social aos discentes, onde juntos, constroem habilidades sociais que serão úteis pelo resto sua vida.

Por outro lado, Rosália Duarte (2002, pg.17) aborda em Cinema e Educação, 
o uso de obras cinematográficas nesse processo de socialização ao convidar os espectadores a participar, de forma passiva, de um novo universo de ideias. Se bem trabalhado, o filme vai ajudar o aluno a entender o universo social em que está inserido, na qual essa representação fílmica vai funcionar como uma espécie de espelho, refletindo as práticas sociais do ano em que foi produzida.

Marcos Napolitano (2003, pg.7), referência nos estudos da inserção do cinema na sala de aula, dialoga sobre o uso dos filmes ficcionais como instrumento pedagógico. Nesse caso, o filme deixaria sua função de entretenimento para se tornar um mediador entre o objeto trabalhado pelo professor e a turma. A ideia de usar os filmes hollywoodianos, que são geralmente voltados para o mercado, para passar uma mensagem também é defendida por Leonardo Carmo (2003, pg.86). O autor disserta que um filme "serve para desalienação dos sentidos", ou seja, modifica a visão de mundo do espectador para que ele deixe a condição passiva e aja de forma crítica.

A ideia do uso da cinegrafia em sala de aula também é defendida por Ismail Xavier (2008, pg. 15), que em seu texto, explica que seu uso provoca uma reflexão pessoal no aluno, que começa a fazer comparações entre o mundo apresentado pelo filme e o mundo em que vive. Essa prática, como um todo, condiciona o discente a se tornar, aos poucos, um formador de ideias críticas no campo da realidade coletiva. $O$ lado artístico da linguagem cinematográfica, como uma prática de lazer, vai trabalhar o seu lado sensível e criativo, proporcionando uma maior desenvoltura em relação as ciências humanas. Fabris (2008, pg. 8) diz que isso é um processo infinito chamado de "interpelação" que ajuda o sujeito a se desenvolver e criar significados para suas ações.

Rogério de Almeida (2014, pg. 13) afirma que existem três vetores a qual o cinema atua: com tela, espelho e janela. A "tela" engloba a linguagem usada, sua simbologia como arte, seu discurso e a narrativa do filme. O "espelho" seria a metáfora empregada no filme e como ela é identificada pelo espectador. E a "janela" é, pelas ideias do autor, como um recorte do mundo através de um ponto de vista. Dentro do campo educacional, a linguagem cinematográfica vai procurar o aluno tentando trazê-lo para dentro desses três vetores, na intenção de tirá-lo do campo de agentes passivos do ensino, proposta essa alinhada aos interesses da Escola Nova.

Ao dialogar com as ideias de Epstein (1921), Aumont coloca que o cinema é

\section{4}


um instrumento inteligente por si só, não pensando de outras formas, mas também pensando de maneira original. Essa ideia vai de encontro com a interpelação de Fabris (2008), mostrando que cada indivíduo vai interpretar o filme de maneira única, usando sua própria filosofia e imaginação para entender as metáforas apresentadas.

É importante citar que este recurso não visa substituir o livro didático ou qualquer outro tipo de material impresso. O cinema é mais um instrumento que pode estar incluso dentro do planejamento do professor, com toda a riqueza de possibilidades que ele pode oferecer. Nas palavras de Jairo Nascimento, o cinema é: um facilitador do processo ensino aprendizagem. (NASCIMENTO, 2008, pg. 12)

Ao relacionar o filme com o ensino de história, o uso do cinema na escola quebra o rigor do ensino tradicional, se tornando um veículo propagador de ideias. O uso das imagens fílmicas em sala de aula ajudam a construir um conhecimento histórico quando aliado ao livro didático. Tudo o que é dito em sala de aula pelo professor toma vida temporariamente, conquistando o interesse do estudante. Ao adentrar no contexto brasileiro, há diversos filmes que interpretam eventos nacionais, o que pode provocar maior imersão do aluno, que passa a se sentir representado na tela. (NASCIMENTO, 2008, pg. 6)

Quando o professor aborda com sua turma um filme histórico, ou cujo o assunto remete ao seu interesse didático, o filme ganha um efeito de "realidade", que deve ser trabalhado por ambas as partes para um aproveitamento maior deste instrumento. Nesse processo, professor e aluno devem se unir à procura do mesmo interesse, com o mestre guiando sem revelar o caminho. Com esse trabalho, a turma pode, pelas palavras de Cristiane Nova (1996, pg. 220): "ler as infinitas possibilidades de leituras de realidades".

Ao se questionar sobre os motivos de usar o cinema em sala de aula, Mirna Fonseca (2016), diz que: "O trabalho com cinema na escola não pode ser visto como redentor de todos os problemas por que passa a escola básica brasileira. Mas os projetos já conhecidos, os relatos de professores que experimentaram levar o cinema para a sala de aula são muito inspiradores e relevantes para um contato com a sétima arte" (FONSECA, 2016, pg. 48). Ou seja, mesmo que não resolva os problemas em sala de aula, a autora se coloca esperançosa sobre este recurso metodológico. 
Para que um trabalho seja aplicado da forma mais proveitosa possível, é necessário que se tenha uma metodologia. O método, aplicado de maneira correta, pode levar a uma experiência singular no aproveitamento do objeto escolhido. Existe um grande número de artigos e publicações que tentam estabelecer uma metodologia para o uso do cinema em sala de aula, principalmente quando se situa no ensino de história. A proposta desta seção é apenas analisar o que já foi publicado nesse campo de pesquisa, sem apontar uma única forma de propor essa atividade.

Marcos Napolitano (2003), ícone nas pesquisas de cinegrafia, tem sua pesquisa em Como usar o cinema em sala de aula como referência no campo brasileiro. O autor tem como objetivo abrir a discussão com professores, tanto àqueles que querem iniciar o uso do cinema em sala de aula, quanto àqueles que querem usar a cinegrafia mais do que "ilustração de aulas e conteúdo" (pg. 7). Sua obra é composta por estratégias que ajudam o profissional não especialista a utilizar o cinema da forma mais proveitosa, fazendo ponderações e considerando que o cinema é um instrumento de comunicação de massa e uma parte importante da indústria de lazer (pg. 14).

A metodologia oferecida pelo autor tem como norte: a seleção de filmes e atividades baseadas no conteúdo da cinegrafia de acordo com o objeto trabalhado pelo professor. O próprio autor afirma que prefere "discutir o cinema ficcional, cujo conteúdo e cuja utilização em sala de aula têm sido menos discutidos do ponto de vista didático-pedagógico" (p.30). O seu livro também contém uma bibliografia e um glossário com termos próprios do universo cinematográfico. Ele também conta com uma lista com mais de cem filmes comentados pelo próprio autor com sugestões metodológicas, entre elas: atividades, pontos para debate e projetos direcionados para serem realizados em sala, norteando a ação do professor, que é fundamental no papel de mediador.

Elí Henn Fabris (2008) em Cinema e Educação: Um caminho metodológico, traça um caminho metodológico dando algumas indicações de como prosseguir com o instrumento cinematográfico, se alinhando com os apontamentos levantados por

\section{6}


Marcos Napolitano. Primeiro ponto é Filmografia para Analise, cuja a película seria selecionada a partir da problematização de um objeto. Após isso o professor assistiria ao filme várias vezes, fazendo pesquisas em revistas, livros e sites especializados na internet, buscando sempre comentários, sinopses, críticas sobre o filme escolhido. Outro ponto importante levantando pela autora é a Filmografia complementar, que seriam outros filmes que fazem relação com o objeto da aula. (FABRIS, 2008, pg. 127)

A autora também indica entregar a ficha técnica para os alunos antes do filme, contendo sinopse, elenco e características da produção do filme para ajudar a turma a compreender outros elementos cinematográficos. Outra informação importante junto a ficha é a tabela de linguagem cinematográfica, um recurso indispensável para quem não está habituado ao estudo do cinema. Mesmo que a intenção da aula não seja transforma o aluno em um especialista em cinema, é importante que eles conheçam conceitos básicos como ângulo, planos, fotografia, etc.

Fabris (2008) alerta que o professor deve ter uma visão ampla de sua turma antes de fazer a seleção de películas. Como já foi dito, a processo de interpelação é único para cada indivíduo. Ao citar Ellsworth (2001), a autora coloca: "como o cinema, vão escolher um alvo para suas histórias; mesmo assim, o endereçamento não tem garantia de acertar o ponto previsto. Os significados pretendidos pelos produtores escapam, atingem outros alvos ou até mesmo produzem outros sentidos, alcançando outros endereços". Ou seja, mesmo que o diretor e os produtores tentem emitir uma mensagem ao um público específico, pode ocorrer que isso não aconteça.

Fabris (2008) ainda propõe uma ficha de critérios de seleção dos filmes, levando em consideração: relevância (se os filmes foram premiados nacional ou internacionalmente, se haviam relação ou não com a literatura brasileira); disponibilidade do filme (se o filme pode ser facilmente comprado ou acessado pelas plataformas de stremming); problematização em relação ao objeto trabalhado.

O uso do cinema em sala de aula é, geralmente, ligado ao ensino da disciplina de história. Em relação a isso, Jairo Carvalho do Nascimento, propôs uma análise de metodologia focada em filmes históricos que, ou reproduzem um acontecimento histórico, com a interpretação do diretor, ou filmes de biografia. Em relação a isso, o 
autor escreve:

Em ambos os casos, o cineasta não reproduz objetivamente a realidade; reconstrói-a, de acordo com seus interesses individuais ou dos produtores. Ele produz uma forma de evidência baseada na interpretação histórica e, respaldada pela linguagem e pelos efeitos cinematográficos, constrói um "efeito de realidade" ou "ilusão de realidade", uma "autenticidade" que deve ser "desmistificada" como outra fonte qualquer. (NASCIMENTO, 2008, pg. 12)

Mirna Fonseca (2016) faz uma ponderação em relação ao uso de cinema apontado por Jairo Nascimento. Para a autora, também é necessário olhar para o filme na dimensão cultural-artística, ou seja, usá-lo por completo, não só como para explanar o objeto da aula.

Jairo Nascimento também faz algumas pontuações sobre o cuidado técnico-operacional durante a produção do plano de aula. Ele indica que o professor tome precaução na disponibilidade dos equipamentos eletrônicos, que devem estar em condições de serem usados. Nesse ponto, o professor deve ter em mente se vai exibir o filme completo ou apenas fragmentos, metodologia indicada em relação ao curto tempo das aulas. Outro ponto a ser levado em consideração é sobre a abordagem do autor. Ele indica que o professor não deve sair da sala durante o filme para evitar a dispersão da atenção da turma e ajudar a entender a importância da atividade que está sendo praticada. Logo ele também recomenda deixar que a película corra sem interrupções, mas que deve voltar para alguma cena, caso o aluno peça para revê-la. É importante que isso não ocorra de forma indiscriminada, atrapalhando o andamento do filme. (NASCIMENTO, 2008, pg.14)

Os caminhos metodológicos apontados nessa seção não têm propósito em formar um pesquisador, apenas indicar um dos caminhos para o aproveitamento do cinema em sala de aula. O professor deve ter apenas a noção de alguns elementos chave da linguagem cinematográfica, para que ele possa ressaltar algumas partes do filme que conversam com o objeto da aula. Nada no cinema é feito por acaso, mesmo que pareça em primeira análise. Destrinchar essas camadas do aparente e transformar em conhecimento junto com a turma é um dos elementos deste instrumento.

Outro ponto ressaltado por Jairo Nascimento é a articulação do filme com outras fontes. Nesse mesmo trabalho ele faz uma comparação com uma canção da banda Legião Urbana e o filme Nascido para matar, de Stanley Kubrick. Ele coloca

\section{8}


esses dois instrumentos artísticos lado a lado e dialoga sobre pontos de convergência e divergência em ambos.

\section{DESAFIOS PARA O USO DO CINEMA NA ESCOLA}

Mesmo que a cinegrafia, como já foi citada, seja um instrumento artístico e pedagógico com um grande potencial didático, ainda há algumas barreiras a serem enfrentadas para que aja seu aproveitamento total. Esta seção do texto irá listar algumas dessas barreiras, procurando refletir sobre alguns desses problemas.

Vitória Fonseca (2016) em Filmes no ensino de História na visão dos livros didáticos: "use com moderação" faz alguns levantamentos em relação à questão da participação dos livros didáticos para auxiliar o professor no uso do cinema. Após analisar sete coleções de livros didáticos voltados para o ensino de História nos anos finais do Ensino Fundamental, a autora notou que em várias orientações ao professor continham palavras que se remetessem a "cuidado" e "preocupação". Isso se refere ao bom planejamento da aula, que apesar de todas as possibilidades, é preciso estar atento para os limites do recurso (2016, pg. 63).

Antes de propor o uso do cinema de forma efetiva em sala de aula, o professor tem, como primeira barreira, desconstruir a imagem expositiva que esta ferramenta tem no ambiente escolar. Ter em mente que o cinema está lá para ajudar na construção de um novo conhecimento ao invés de ser um mero conteúdo para "matar o tempo" ou para ilustrar uma situação presente no livro didático. Ambas as partes da sala de aula devem entender o motivo e pontos positivos da ferramenta, contribuindo para o andar da aula.

O rigor da aula tradicional, baseada na aula ilustrativa com o dever de ensinar através da informação é o primeiro paradigma a ser quebrado antes da utilização da cinegrafia. O debate cinematográfico vai construir o conhecimento de uma nova forma. Agora, o professor deve colocar os alunos como agentes ativos dessa construção, assim como visava os pilares da Escola Nova. O professor assume o papel de mediador do conhecimento, guiando a turma, sem apontar o resultado final e corrigindo quando preciso.

Outro ponto relacionado ao citado acima, que se mostra um dificultador, é o tempo curto das aulas. O currículo do ensino básico, nos últimos anos, tentou prio- 
rizar o ensino de matemática e português, diminuindo o tempo de aula de matérias das aulas de humanas, que vão, em média, de 40 minutos à uma hora. A maioria dos filmes, principalmente os filmes históricos, tem em média 90 a 120 minutos. Uma estratégia que pode ser usada para contornar esse problema é exibir apenas o trecho relacionado ao objeto de estudo da aula. Essa opção deve ser pensada durante o planejamento da aula.

É comum que o corpo docente tenha certo receio antes de utilizar as imagens como mediadora de conhecimento para seus alunos. Entre as barreiras que se colocam diante a inserção completa deste recurso em sala de aula, é possível destacar duas: acesso aos equipamentos tecnológicos necessários e a qualificação do professor diante a linguagem cinematográfica.

Em relação a despesas, os recursos midiáticos ainda é um desafio a ser enfrentado. Desde o Governo FHC, o Estado distribui um conjunto de equipamentos eletrônicos e verbas que permitem as escolas de ensino básico acompanharem as mudanças da sociedade (NASCIMENTO, 2008, pg. 5). Mirna Fonseca (2016) aponta que no Governo Lula:

Houve grande mudança na atividade cultural do país, que contou com a criação do Ministério da Cultura (MinC) e, por conseguinte, a reativação e promoção de atividades voltadas às várias áreas da cultura. O cinema/audiovisual foi contemplado com editais de fomento a festivais, mostras e projetos de criação, o que chegou às escolas por meio de acervos fílmicos ou programas que incluíam a criação de vídeos, filmes e animações, e até pela exibição de filmes produzidos nas escolas em festivais de cinema. (FONSECA, 2016, pg. 38)

Junto com a tecnologia midiática, o professor deve estar adaptado a elas, conseguindo usar este recurso de forma hábil. Na internet estão disponibilizados alguns roteiros contendo as etapas que podem ajudar na manipulação da tecnologia. Além de fornecer o equipamento eletrônico, a escola também deve oferecer um lugar adequado para o seguimento da aula.

A capacitação do professor em relação ao cinema deve ser levada em consideração. Ao decidir em seu planejamento que haverá o uso da cinegrafia como instrumento para desenvolvimento do senso crítico e reflexivo, o profissional deve estar equipado com alguns conhecimentos em relação à linguagem cinematográfica. Como já foi mencionado, Fabris (2008) indica o uso de uma tabela que contém uma

\section{0}


breve explicação sobre alguns conceitos únicos do cinema. Ambas as partes da sala de aula devem ter uma pequena noção do corpo técnico do filme.

Antes de iniciar um trabalho com o cinema, o professor deve se perguntar como e porque fazer isso. Tomando como base as ideias trazidas por Bergala (2008) e Ranciére (2013). Ademais, Mirna Fonseca afirma que é importante:

Deixar os alunos experimentarem, arriscar-se junto com eles na descoberta desse mundo que se revela na escola é dar a si mesmo a oportunidade de emancipar-se, emancipando o outro [...] para um trabalho honesto com cinema na escola, o professor precisa enxergar-se ignorante e emancipar-se para, assim, emancipar seus alunos, saindo assim da sua zona de conforto. Ele precisa confiar no aluno, na sua capacidade, no seu potencial, nas suas vontades e nas suas escolhas. (FONSECA, 2016, pg. 40)

A própria autora convida o professor e o aluno a se lançarem juntos em uma jornada de conhecimento e autoconhecimento a qual ela chama de "comunhão da ignorância". Ao utilizar o cinema, ambos se colocam na mesma posição de seres emancipados que constroem um conhecimento juntos.

\section{CONSIDERAÇÕES FINAIS}

Usando como base os argumentos expostos acima e a literatura especializada, vemos que aplicação do cinema em sala de aula, não deve ser só constantemente desenvolvida, visando os desafios apontados no último tópico, mas também difundida, quebrando as barreiras da "aula tradicional" e da visão ilustrativa do cinema. Usar o cinema e tentar aproveitar em seu maior potencial tem grandes benefícios ao desenvolvimento dos alunos, entre eles: despertar do senso crítico; participar como um agente ativo na educação; desenvolvimento do espírito criativo e sensível; maior imersão e dinamismo nas aulas.

A inserção deste recurso deve estar apoiada em uma metodologia adaptada a realidade do profissional e dos estudantes. Também é importante ressaltar que o cinema não é a resposta para todos os problemas da sala de aula, mas sim, um recurso interessante que concede um maior dinamismo, atraindo os alunos com as imagens da sétima arte. A pesquisa indicou que existem diversos caminhos no uso do cinema e que mesmo que existam desafios para sua implementação como o tempo da aulas e a dificuldade no manejo dos equipamentos eletrônicos, os benefícios apontados

\section{1}


falam por si. A infraestrutura e o baixo investimento nesse tipo de atividade recreativa são problemas que devem ser enfrentados, mas a pesquisa e a extensão devem romper as paredes da universidade e alcançar as salas de aula.

\section{REFERÊNCIAS}

ALBAGLI, Sarita. Ciência Aberta em questão. In: SEMINÁRIO INTERNACIONAL CIÊNCIA ABERTA, QUESTÕES ABERTAS, Rio de Janeiro, 2014. Trabalho apresentado...Rio de Janeiro: Liinc; IBICT; OKF; Unirio, 2014.

ALMEIDA, Rogério de. Possibilidades formativas do cinema. Revista Rebeca, São Paulo, v. 6, jul./dez. 2014.

ALMEIDA, Rogério de. Cinema e Educação: Fundamentos e Perspectivas. Educ. rev., Belo Horizonte, v. 33, e153836, 2017.

AUMONT, Jacques et al. A estética do filme. Campinas-SP: Papirus, 2002. . Montage Eisenstein. Paris: Images Modernes, 2005.

CARMO, Leonardo. O cinema do feitiço contra o feiticeiro. Revista Iberoamericana de Educação, Canoas, n. 32, p. 71-94, 2003.

DELEUZE, Gilles; GUATTARI, Félix. Mil platôs. São Paulo: Editora 34, 1995. v. 1.

DUARTE, Rosália. Cinema \& Educação. Belo Horizonte: Autêntica, 2002.

FABRIS, Elí Henn. Cinema e Educação: um caminho metodológico. Educação e Realidade, Porto Alegre, v. 33, n. 1, p. 117-134, jan./jun. 2008.

FONSECA, Mirna Juliana Santos. Cinema na escola pra quê? Revista Educação e Cultura Contemporânea. Rio de Janeiro, vol. 13, n. 3,p.32 -55, 2016.

FONSECA, Vitória Azevedo da. Filmes no ensino de História na visão dos livros didáticos: "use com moderação". Revista Labirinto, Rondônia, vol. 24, ano 26, n. 02, p. 57-70, jan. a jun. 2016.

MORETTIN, Eduardo. Uma história do cinema: movimentos, gêneros e diretores. São Paulo: Secretaria da Educação. In: [S.I: s.n.], 2009. 
NASCIMENTO, Jairo Carvalho do. Cinema e Ensino de História: realidade escolar, propostas e práticas na sala de aula. Revista de História e Estudos Culturais, Abril/Maio/Junho de 2008, vol.5 ano V n.2

NAPOLITANO, Marcos. Como usar o cinema na sala de aula. São Paulo: Contexto, 2003

NOVA, Cristiane. O cinema e o conhecimento da história. Olho da História, Salvador, v. 2, n. 3, p. 220, nov. 1996.

XAVIER, Ismail. O discurso cinematográfico: opacidade e transparência. São Paulo: Paz e Terra, 2005. 


\section{LUCIANA GONÇALVES DE OLIVEIRA MARAIA}

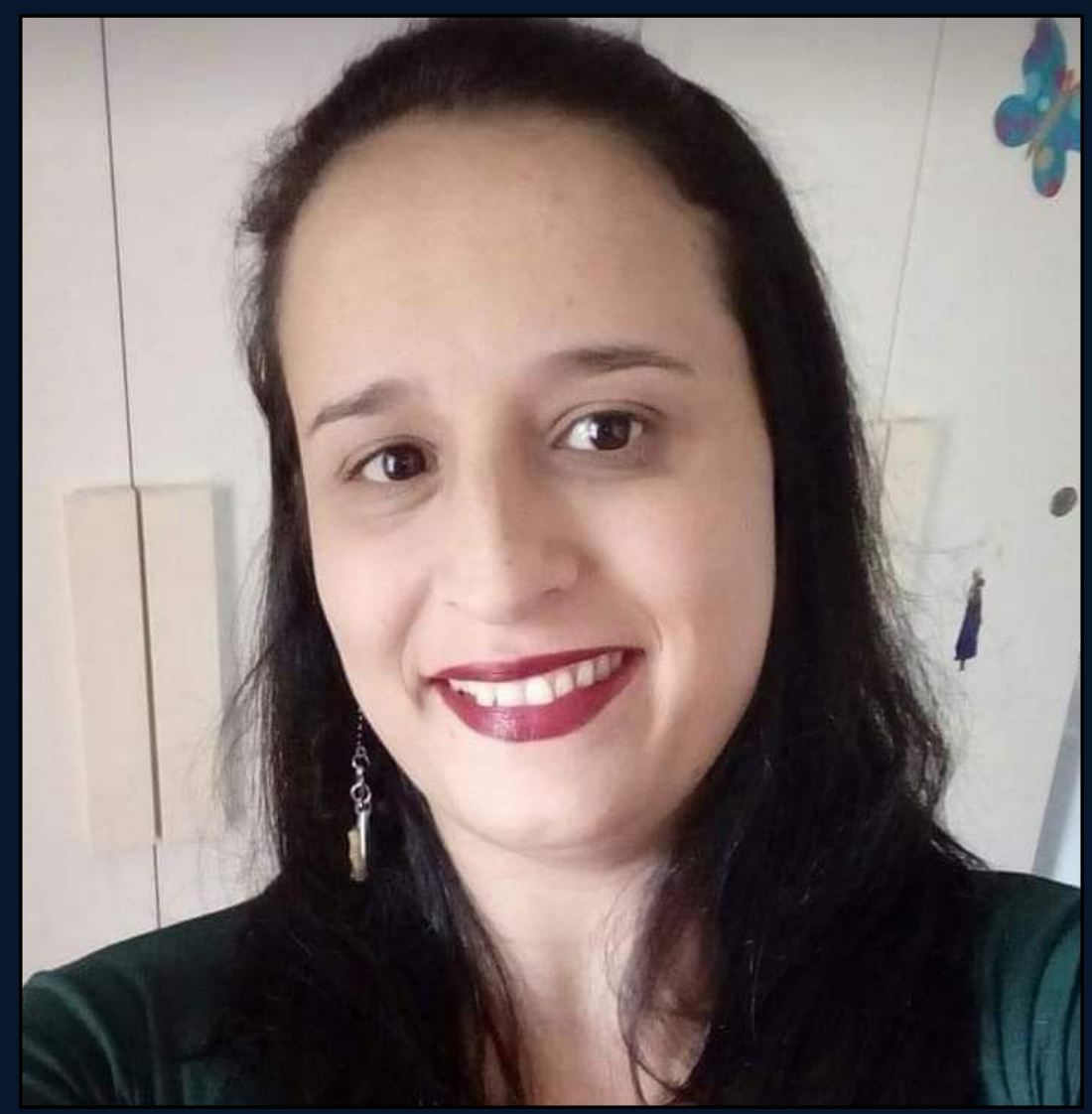

Possui Mestrado Profissional em Ensino e suas Tecnologias pelo Instituto Federal Fluminense. Especialista em Administração e Supervisão Escolar pela Universidade Cândido Mendes. Possui graduação em Pedagogia pela Universidade Federal do Estado do Rio de Janeiro (2013). Membro da equipe gestora do Centro Municipal de Educação Integral de Campos dos Goytacazes. Atualmente é professora efetiva da Prefeitura Municipal de Campos dos Goytacazes, desde 2003. Atuou como professora mediadora para o uso das tecnologias digitais. Tem experiência na área de Educação, com ênfase em Educação/Ensino, atuando principalmente nos seguintes temas: tecnologias digitais, metodologias, alfabetização científica, ensino fundamental, formação docente. 
A⿵⺆一

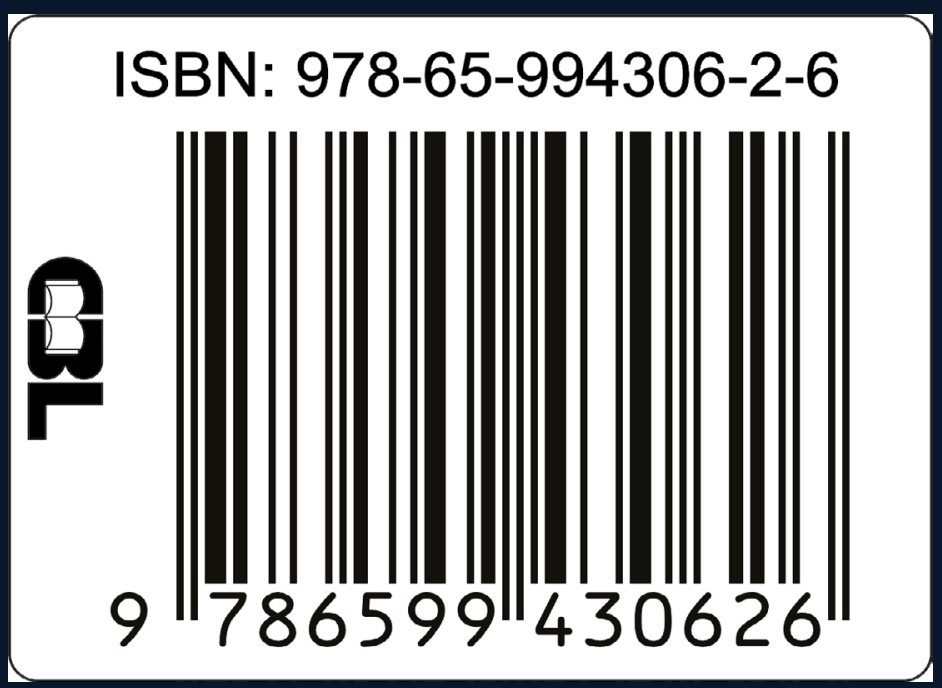

